\title{
Diseño del proceso: Pretratamiento enzimático para extracción de aceites vegetales en un extractor de columna.
}

\section{Florencia Verónica Grasso}

Tesis presentada para el grado de DOCTOR en INGENIERÍA Departamento de Ingeniería Química

$$
\text { Facultad de Ingeniería }
$$
Universidad Nacional de La Plata 
A mis viejos Nené y Rubén, a mi amor Leo y a mis dos soles Guadalupe y Juan. 


\section{AGRADECIMIENTOS}

Quisiera agradecer, en primer lugar, a la directora de tesis Dra. Beatriz Maroto por enseñarme a transitar el camino del esfuerzo individual y del trabajo independiente; a la Dra. Noemí Zaritzky por su valioso aporte en cuanto a la orientación de este estudio; al Dr. Celso Camusso que fue director del proyecto en el marco del cual se desarrolló parte de esta tesis; al Ingeniero Eduardo Amadeo por su ayuda desinteresada; a Genencor-Danisco International Inc. por la provisión de las enzimas empleadas; a Sergio Liste y a Aceitera Bunge S.A. por la provisión de las muestras de laminado y expandido de soja; al Geólogo Julio Fernandéz del ClTeQ de la Universidad Tecnológica Nacional-Facultad Regional Córdoba por su auxilio en las determinaciones de área superficial; a la Ingeniera Patricia Perissé por dedicar parte de su tiempo a enseñarme las técnicas de tintura y corte para micrografías y también gracias por ayudarme a interpretarlas; al Dr. Mauro Valente de la Facultad de Matemáticas, Astronomía y Física de la Universidad Nacional de Córdoba por su apoyo técnico en la programación de MatLab; a Secyt-UNC y CONICET por el financiamiento al proyecto; a la Facultad de Ciencias Agropecuarias de la Universidad Nacional de Córdoba y al CIDCA-CONICET de la Universidad Nacional de La Plata por brindarme el espacio físico y los equipos necesarios para llevar a cabo la parte experimental de este trabajo; a la Facultad de Ciencias Exactas, Físicas y Naturales de la Universidad Nacional de Córdoba por darme la oportunidad de abrazar esta profesión; a Bety, Silvina, Pichi, Mauri y Sil por ayudarme con los ensayos de calidad de los aceites; a todos los que participaron de una u otra manera y especialmente a Pato: amiga, gracias por todo! 


\section{INDICE}

INDICE $\quad$ i a iii

NOMENCLATURA iv a $v$

RESUMEN 1

Hipótesis general 3

Objetivo general 3

Objetivos específicos $\quad 5$

CAPITULO 1: Introducción $\quad 7$

1.1 La Industria Aceitera $\quad 7$

$\begin{array}{ll}1.2 \text { Fuentes de aceites vegetales } & 9\end{array}$

1.2.1 Estructura de las oleaginosas $\quad 10$

$\begin{array}{ll}1.3 \text { Procesos de extracción } & 13\end{array}$

1.3.1 Procesos convencionales 13

$\begin{array}{ll}\text { 1.3.2 Procesos acuosos } & 16\end{array}$

1.3.3 Extracción por solvente versus procesos de

1.3.3.1 Aspectos económicos y ambientales 18

1.3.3.2 Calidad de aceite y proteína 19

1.3.4 Pretratamientos de uso industrial $\quad 20$

1.3.4.1 Molienda 21

1.3.4.2 Acondicionamiento 21

1.3.4.3 Laminado 21

1.3.4.4 Expandido 21

1.3.4.5 Uso de enzimas en procesos de extracción

1.3.4.6 Uso de enzimas en procesos de extracción

1.4 Transferencia de masa en la extracción 32

$\begin{array}{ll}\text { 1.4.1 Transporte difusivo } & 34\end{array}$

1.4.1.1 Determinación de coeficientes de difusión 36

1.4.2 Transporte convectivo 38

1.4.2.1 Transferencia de masa interfacial 43

1.4.2.2 Correlaciones para transferencia de masa 44

1.4.2.3 Determinación del equilibrio 45

1.4.2.4 Balance macroscópico para transferencia de masa 46

CAPITULO 2: Materiales y Metodologías Generales 49

2.1 Materiales $\quad 49$

2.1.1 Laminado de soja $\quad 49$

2.1.2 Expandido de soja $\quad 50$

2.1.3 Enzimas $\quad 50$

2.1.4 Reactor $\quad 54$

2.1.5 Sistema de calefacción y agitación $\quad 54$ 
2.1.6 Reactivos $\quad 54$

2.2 Metodologías $\quad 55$

2.2.1 Almacenamiento de las muestras $\quad 55$

2.2.2 Extracción de aceite con pretratamiento enzimático 55

2.2.3 Determinación del contenido de aceite 58

2.2.4 Caracterización de la calidad del aceite extraído 59

2.2.4.1 Indice de acidez $\quad 59$

2.2.4.2 Indice de iodo 61

2.2.4.3 Indice de saponificación 63

2.2.4.4 Indice de peróxido 64

2.2.5 Determinación de pérdidas de aceite 65

\section{CAPITULO 3: Efecto de las variables de la hidrólisis enzimática sobre el rendimiento en aceite de la extracción con hexano}

$\begin{array}{ll}3.1 \text { Parte Experimental } & 69\end{array}$

3.1.1 Materiales $\quad 69$

3.1.2 Metodologías

3.1.2.1 Selección de mezclas enzimáticas 69

3.1.2.2 Optimización del tratamiento enzimático 70

3.2 Resultados y Discusión 73

3.2.1 Selección de mezclas enzimáticas $\quad 73$

3.2.2 Caracterización de la calidad del aceite extraído 75

3.2.3 Optimización del tratamiento enzimático 76

$\begin{array}{ll}3.3 \text { Conclusiones parciales } & 85\end{array}$

CAPÍTULO 4: Efectos del pretratamiento enzimático sobre la velocidad de extracción de aceite de soja con hexano 88

$\begin{array}{ll}\text { 4.1 Parte Experimental } & 90\end{array}$

4.1.1 Materiales $\quad 90$

4.1.2 Metodologías $\quad 94$

4.1.2.1 Pretratamiento enzimático 94

4.1.2.2 Modelo difusional y determinación de coeficientes de difusión efectiva 94

4.1.2.2.1 Consideraciones y estrategias experimentales 101

4.1.2.3 Efecto de la temperatura 102

4.1.2.4 Procedimiento experimental 103

4.1.2.4.1 Tratamiento enzimático 103

4.1.2.4.2. Determinación de la evolución de la concentración con el tiempo

4.1.2.4.3 Determinación del efecto de la temperatura 104

4.2 Resultados y Discusión

4.2.1 Modelo difusional y determinación de coeficientes 
de difusión efectiva

4.2.2 Efecto de la temperatura 118

4.3 Conclusiones parciales 123

\section{CAPÍTULO 5}

Extracción de aceite de soja en columna de lecho fijo: influencia del material de partida.

5.1 Parte experimental 128

5.1.1 Materiales $\quad 128$

5.1.1.1 Reactor 128

5.1.1.2 Sistema de calefacción y agitación 128

5.1.1.3 Columna de extracción 128

5.1.2 Metodologías 129

5.1.2.1 Procedimiento experimental 129

5.1.2.1.1 Pretratamiento enzimático 129

5.1.2.1.2 Determinación de curvas patrón $\quad 129$

5.1.2.1.3 Cálculo de la porosidad del lecho $\quad 130$

5.1.2.1.4 Determinación de cinética de extracción 130

5.1.2.1.5 Determinación del equilibrio 131

5.1.2.2 Transferencia de masa en el extractor 132

5.1.2.3 Obtención de los parámetros asociados al modelo 137

5.1.2.2.1 Coeficiente de difusividad efectiva en el sólido 137

5.1.2.2.2 Coeficiente de difusividad molecular en el solvente

5.1.2.2.3 Coeficiente de transferencia de masa en el líquido

5.1.2.2.4 Coeficiente de transferencia de masa en el sólido

5.2.1 Determinación de curvas patrón $\quad 144$

5.2.2 Determinación del equilibrio $\quad 145$

5.2.3 Determinación de los parámetros asociados al modelo $\quad 147$

5.2.3.1 Coeficiente de difusividad efectiva en el sólido $\quad 147$

5.2.3.2 Coeficiente de difusividad molecular en el solvente

5.2.3.3 Coeficiente de transferencia de masa en el líquido

5.2.3.4 Coeficiente de transferencia de masa en el sólido 148

5.2.4 Aplicación del modelo de balance macroscópico 149

5.2.4.1 Efecto de Q 154

5.2.4.2 Efecto de la relación $\mathrm{A} / \mathrm{V}_{\mathrm{S}} \quad 154$

5.2.4.3 Efecto de $\mathrm{k}_{\mathrm{L}} \quad 155$

5.2.4.4 Efecto de $\mathrm{k}_{\mathrm{S}} \quad 156$

5.3 Conclusiones parciales 
ANEXOS (Hojas técnicas de las enzimas) 


\section{NOMENCLATURA}

A Area disponible para la transferencia de masa, $\mathrm{m}^{2} \cdot \mathrm{m}^{-3}$

a Area, $\mathrm{m}^{2}$

Aa Factor pre-exponencial de Arrhenius

C Concentración, moles. $\mathrm{L}^{-1}$

D Coeficiente de difusión, $\mathrm{m}^{2} \cdot \mathrm{s}^{-1}$

d Diámetro, $m$

Ea Energía de Activación, $\mathrm{kJ} \mathrm{mol}^{-1}$

exp Función exponencial

GL Grado de libertad

Indice de iodo, $\mathrm{g}$ iodo. $\mathrm{Kg}^{-1}$ de aceite

Coeficiente de transferencia de masa, m.s ${ }^{-1}$

$\mathrm{K} \quad$ Constante de equilibrio de partición, $\mathrm{g}$ aceite fase sólida $/ \mathrm{g}$ aceite fase líquida

$\mathrm{k}_{\mathrm{B}} \quad$ Constante de Bolzman, J. K $\mathrm{K}^{-1}$

I Semiespesor de la lámina, $m$

$\mathrm{L} \quad$ Longitud de la columna, $\mathrm{m}$

M Peso molecular, g. mol ${ }^{-1}$

MC Media de cuadrados

$\mathrm{N} \quad$ Normalidad, equivalentes. $\mathrm{L}^{-1}$

$\mathrm{N}_{\mathrm{A}} \quad$ Flujo másico molar, moles.s ${ }^{-1}$

P Peso,g

q Cantidad de aceite por masa inicial de sólido

Q Caudal volumétrico, $\mathrm{m}^{3} \cdot \mathrm{s}^{-1}$

$\mathrm{R} \quad$ Radio de la molécula, $m$

$r \quad$ Radio de la esfera, $m$

$\mathrm{R}^{2} \quad$ Coeficiente de determinación

$\mathrm{Re} \quad$ Número de Reynolds

SC Suma de cuadrados

Sc Número de Schmidt

Sh Número de Sherwood

$\mathrm{T} \quad$ Temperatura, ${ }^{\circ} \mathrm{C}$

$\mathrm{t} \quad$ Tiempo, $\mathrm{s}$

$\mathrm{V} \quad$ Volumen, $\mathrm{m}^{3}$

v Velocidad superficial, $\mathrm{m} . \mathrm{s}^{-1}$

$x \quad$ Coordenada espacial

$\mathrm{X} \quad$ Fracción de masa

y Coordenada espacial

Y Función objetivo: rendimiento en aceite

z Coordenada espacial

\section{Letras griegas}

$\begin{array}{ll}\varepsilon & \text { Porosidad } \\ \phi & \text { Parámetro de asociación del solvente } \\ \mu & \text { Viscosidad de la fase, } \mathrm{g} \cdot \mathrm{m}^{-1} \cdot \mathrm{s}^{-1} \\ \pi & \text { Constante }\end{array}$




$$
\begin{array}{ll}
\rho & \text { Densidad, } g \cdot \mathrm{m}^{-3} \\
\tau & \text { Tortuosidad }
\end{array}
$$

\section{Subíndices}

$\begin{array}{ll}\mathrm{S} & \text { Sólido } \\ \mathrm{L} & \text { Líquido } \\ \mathrm{o} & \text { Inicial } \\ \mathrm{i} & \text { Interfacial } \\ \mathrm{M} & \text { Muestra } \\ \mathrm{f} & \text { Final } \\ \mathrm{A} & \text { Molar } \\ \mathrm{e} & \text { Partícula } \\ \mathrm{ef} & \text { Efectiva } \\ \wedge & \text { Media } \\ - & \text { Promedio } \\ - & \text { Estimado }\end{array}$




\section{RESUMEN}

El presente trabajo consistió en la exploración y el estudio de un tratamiento enzimático llevado a cabo sobre semillas de soja, previo a la extracción del aceite, con el fin de mejorar el rendimiento en aceite durante la extracción con hexano.

Se emplearon sólidos de soja con distinto grado de preparación. Se seleccionaron las condiciones óptimas de $\mathrm{pH}$, tiempo y temperatura de incubación y combinación de actividades enzimáticas, para maximizar el rendimiento de la extracción en términos de cantidad de aceite. Se evaluó la influencia del tratamiento enzimático sobre el transporte difusivo que ocurre durante la extracción del aceite determinando experimentalmente coeficientes de difusión para cada sólido. Por último, se caracterizó la extracción en una sección de lecho fijo constituido por las semillas tratadas y se estableció un modelo matemático para describir el comportamiento del sistema en estudio durante la extracción con solvente.

El pretratamiento enzimático para alcanzar el máximo rendimiento de aceite se obtuvo por incubación con una mezcla enzimática con actividades enzimáticas celulasa, proteasa neutra, $\alpha$-amilasa, pectinasa, hemicelulasa y glucoamilasa. La calidad del aceite obtenido fue similar a la obtenida para un aceite de soja crudo, sin refinar. La optimización de variables determinó incubación a pH 5,4 y $38 \stackrel{\circ}{\circ} \mathrm{C}$ durante 9,7 h para laminado de soja y a pH 5,8 y $43,5 \stackrel{\circ}{ } \mathrm{C}$ durante $5,8 \mathrm{~h}$ para expandido de soja. Se obtuvieron rendimientos de aceite mayores: $27,59 \%$ y $26,64 \%$ para laminado y expandido hidrolizados, respectivamente. Se estimaron coeficientes de difusión efectiva para cada sólido en el orden de $10^{-11}$ a $10^{-10}$. El modelo de la $2 \mathrm{da}$ ley de Fick fue válido para todas las temperaturas de extracción ensayadas. Se obtuvieron energías de activación más bajas para los sólidos con más pretratamientos. El modelo matemático propuesto de balance macroscópico resultó apropiado. La máxima velocidad de extracción se obtuvo cuando el lecho estaba constituido por expandido pretratado enzimáticamente. Para obtener bajos contenidos residuales de aceite en el material de partida deben emplearse sólidos con coeficientes de difusión elevados, caudales de alimentación de solvente bajos, altas áreas específicas y solventes de extracción con altos coeficientes de transferencia de masa en el líquido. 
En conclusión, la incubación enzimática podría emplearse como pretratamiento antes de la extracción para aumentar el rendimiento en aceite, obtener mayores velocidades de extracción y/o emplear menores cantidades de solvente. 


\section{Hipótesis general}

“Es de amplio conocimiento que las enzimas hidrolíticas, por su efecto catalítico sobre macromoléculas, permiten la degradación de estructuras complejas como las celulares. Si esta degradación se lleva a cabo sobre materiales vegetales, como una semilla de soja, luego de una incubación enzimática que hidrolice no solo uno de los macrocomponentes estructurales, sino varios de ellos simultáneamente, se logra facilitar la liberación de una mayor cantidad de aceite y su consecuente separación de la matriz sólida original. La aplicación directa de este procedimiento puede trasladarse a nivel productivo, ya que una incubación multienzimática del material de partida puede emplearse como pretratamiento industrial previo de las operaciones de extracción convencionales. La mayor liberación de aceite por la acción degradativa de las enzimas produce aumentos en el rendimiento de aceite".

\section{Objetivo general}

El objetivo general es estudiar, a escala laboratorio, la factibilidad técnica de un pretratamiento de incubación enzimática sobre semillas de soja, determinar las condiciones óptimas de esta incubación, establecer la influencia que ejerce esta degradación enzimática sobre los rendimientos y la velocidad de extracción y determinar en qué etapa de la preparación industrial de las semillas podría acoplarse esta nueva operación de pretratamiento. 


\section{Objetivos específicos}

- Seleccionar la mezcla de actividades enzimáticas óptima para lograr el máximo rendimiento en aceite, extraído con solvente, partiendo de los sólidos de soja hidrolizados.

- Establecer la influencia que ejercen las variables operacionales temperatura, $\mathrm{pH}$ y tiempo de incubación enzimática sobre la eficiencia del pretratamiento para encontrar las condiciones óptimas que produzcan el rendimiento máximo en aceite.

Determinar el efecto del pretratamiento enzimático sobre la calidad del aceite obtenido por extracción con solvente.

Modelizar la difusión en estado no estacionario que ocurre como parte del proceso de extracción de aceite a partir de sólidos con distintos grados de pretratamiento.

- Estimar coeficientes de difusión efectiva de aceite en hexano para laminado y expandido de soja con y sin tratamiento enzimático, a distintas temperaturas de extracción.

Medir el efecto del pretratamiento enzimático sobre la velocidad de extracción por estimación de los coeficientes de difusión para todos los sólidos ensayados.

- Determinar la influencia de la temperatura sobre el fenómeno difusivo y proponer la aplicación del modelo de Arrhenius.

Obtener un modelo matemático que describa el sistema de extracción de aceite con hexano en una sección de un lecho fijo, donde se considera que la concentración de aceite en el líquido es muy pequeña. 
- Cuantificar las resistencias interna y externa a la transferencia de masa durante la extracción de aceite de soja con hexano en la sección del lecho fijo.

- Determinar la influencia que el pretratamiento enzimático ejerce sobre la transferencia de masa en el sistema de extracción de la sección de lecho fijo, considerando tanto la resistencia interna como la resistencia externa.

- Explorar la influencia teórica que ejercen cada uno de los parámetros del modelo sobre la velocidad de extracción para el sistema de lecho fijo en estudio.

Concluir, en base a los resultados obtenidos, la posible adaptación de la operación de pretratamiento enzimático a los procesos existentes para la extracción industrial de aceite de soja con hexano. 


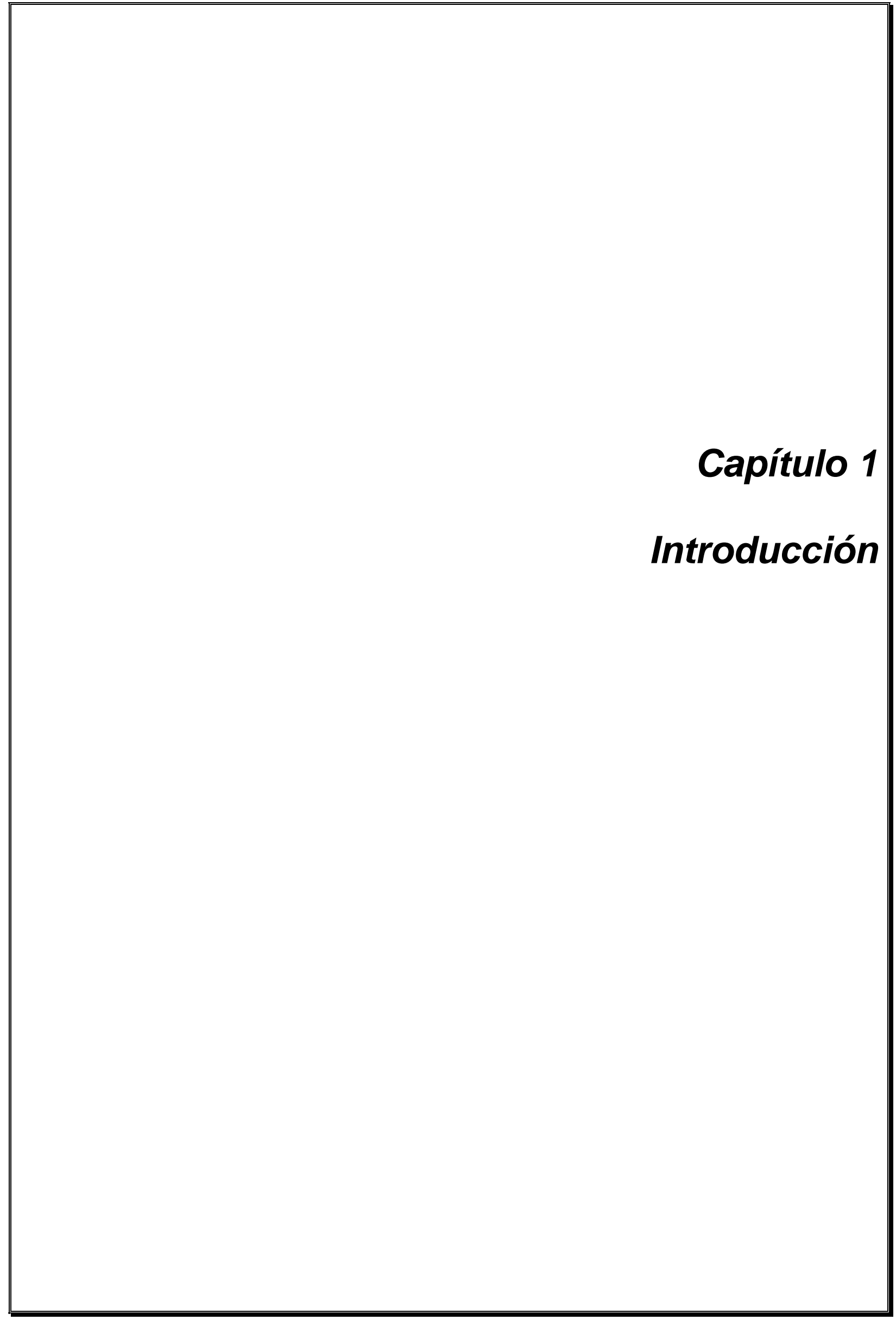




\section{Introducción}

\subsection{La industria aceitera}

Los aceites de semillas constituyen el $70 \%$ de la producción mundial de aceites, siendo el $30 \%$ de esta producción aceite de soja. La reconocida calidad de este aceite y el valor nutritivo de la harina proteica hace de la soja una oleaginosa primaria a nivel mundial.

El complejo industrial oleaginoso es el principal rubro de exportación de la economía de Argentina (SAGyP, 2009). La producción de las principales semillas oleaginosas mostró en los últimos años un incremento ininterrumpido. La industria, por su parte, acompañó este aumento con inversiones destinadas a incrementar la capacidad de molienda.

La soja y el girasol son los dos principales cultivos oleaginosos de Argentina. Si bien el segundo es el de mayor tradición (su producción data de la década de 1920), en los últimos diez años la soja ha protagonizado una gran expansión que se refleja tanto en los volúmenes obtenidos como en las inversiones realizadas por las plantas procesadoras.

El cultivo de la soja se ha convertido en la actividad económica más importante del sector agropecuario de nuestro país: Argentina es el tercer productor mundial de poroto de soja luego de Estados Unidos y Brasil. Medida en volumen, su participación en el mercado supera el $20 \%$. Durante la última década la producción nacional se incrementó en forma sostenida: la superficie implantada con soja creció a un ritmo promedio de $9 \%$ anual. Las principales provincias productoras son Córdoba, Buenos Aires y Santa Fe pero es creciente la implantación de soja en zonas consideradas marginales (SAGYP, 2009).

La molturación de esta semilla durante 2007 sobrepasó los 36,2 millones de toneladas y marcó un récord de molienda. Fue $11 \%$ superior a la de 2006 . Como los rendimientos también fueron mayores, la producción de aceite resultó $13 \%$ mayor que la del año precedente: se obtuvieron 6,96 millones de toneladas. Según las estimaciones, la campaña 2008/09 la producción de soja alcanzó las 50,5 millones 
de toneladas. Nuestro país exportó 14,7 millones de toneladas sin procesar, 37,49 millones de toneladas fueron destinadas al mercado interno y 35,9 millones de toneladas fueron destinadas al crushing. Del mencionado crushing, se produjeron 28,1 millones de toneladas de harina de soja y 6,87 millones de toneladas de aceite crudo (Aceites y Grasas, 2009).

La combinación entre alta producción y bajo consumo doméstico convierten a la Argentina en el mayor exportador mundial de aceite de soja. El sector presenta desde hace varios años un gran dinamismo, con importantes inversiones tendientes a ampliar su capacidad de molturación y almacenamiento y a mejorar las instalaciones portuarias. En 2006 la capacidad de procesamiento de la industria alcanzó las 149.000 toneladas diarias. La industria aceitera local, de avanzada tecnología, registra el mayor crecimiento entre los principales productores del mundo. A nivel nacional, el consumo per cápita de aceite de soja en 2007 alcanzó los $14,7 \mathrm{~kg} / \mathrm{hab} / \mathrm{año}$, valor que constituye un récord para este aceite (SAGYP, 2009). Con respecto a la producción de aceite de la campaña 2008/09, se emplearon 1,15 millones de toneladas en el mercado interno y se exportaron 5,70 millones de toneladas (Aceites y Grasas, 2009).

El complejo sojero, integrado por porotos, aceites y harinas, constituye la principal fuente de divisas para el país (SAGYP, 2009).

El ingreso por exportaciones sólo de aceite crudo de soja representó el 1,94 \% del PBI argentino en el año 2008 (Infobae, 2009).

En los diez últimos años, la producción, industrialización y venta de oleaginosas se desarrolló en un escenario complejo. Sin embargo, las inversiones fueron constantes, lo que permitió incrementar los volúmenes, mantener el liderazgo mundial en las exportaciones y situar esta actividad entre las industrias más desarrolladas del mundo. Se trata de uno de los sectores más competitivos de la economía nacional y su brillante desempeño se vincula tanto con las tecnologías aplicadas en la producción primaria, como en el grado de eficiencia y actualización alcanzado por la industria procesadora (SAGyP, 2009). 


\subsection{Fuentes vegetales de aceites}

Las principales fuentes vegetales de aceite son las semillas y los frutos oleaginosos. La diferente composición y estructura de ambas condiciona el procesado al que se someten con el fin de extraer el aceite.

El proceso estándar de extracción a partir de frutos tales como la aceituna y la palta, consiste en un batido con agua caliente y posterior separación de las fases líquida, acuosa/oleosa, y sólida por distintos procesos como prensado o centrifugación.

El proceso de extracción a partir de semillas depende del tipo y estructura de las mismas. Con las de alto contenido en aceite ( $>20 \%$ base seca) tales como el maní, el proceso clásico usado es la aplicación de una fuerza mecánica a fin de romper las paredes celulares del material vegetal de partida. El aceite es extraído por prensado, obteniéndose el aceite crudo y la torta del prensado, la cual retiene cantidades significativas de aceite residual. En muchos casos, esta torta es tratada posteriormente con solventes orgánicos para extraer este aceite remanente. Con las de bajo contenido graso ( $<20 \%$ base seca) tales como la soja, se emplea la extracción con disolventes orgánicos (hexano). Estos procesos tienen la ventaja de ser operaciones simples con costos de operación relativamente bajos. Sin embargo, presentan algunas desventajas. El capital inicial de instalación para el procesamiento es alto y los productos son crudos, de relativamente bajo valor, y requieren refinación antes de ser usados (Christensen, 1991). Por otro lado, este tipo de procesos involucran manipulación de grandes cantidades de solventes orgánicos, lo cual plantea problemas de seguridad y contaminación ambiental (TanoDebra y Ohta, 1995a y 1995b; Sosulski y Sosulski, 1993).

Antes de la extracción, las semillas deben ser limpiadas, molidas, laminadas y expandidas a fin de mejorar la eficiencia de la extracción por solventes, las células deben romperse para aumentar la transferencia de masa (García Serrato, 1981).

Una alternativa de pretratamiento para facilitar la liberación del aceite desde la semilla podría realizarse por degradación enzimática de sus estructuras celulares. Esta liberación de aceite podría traducirse en términos de mayores rendimientos de extracción y/o disminución de las cantidades de solventes orgánicos empleados. 
Para entender el proceso y el posible rol de las enzimas, es esencial conocer la estructura del material oleaginoso de partida.

\section{i. 1.2.1 Estructura de las oleaginosas}

El principal rasgo característico de las células de las semillas oleaginosas es la existencia de organelas celulares llamadas cuerpos lipídicos y proteínicos, las cuales contienen, respectivamente, la mayoría del aceite y de las proteínas del grano (ver Figura 1.1).

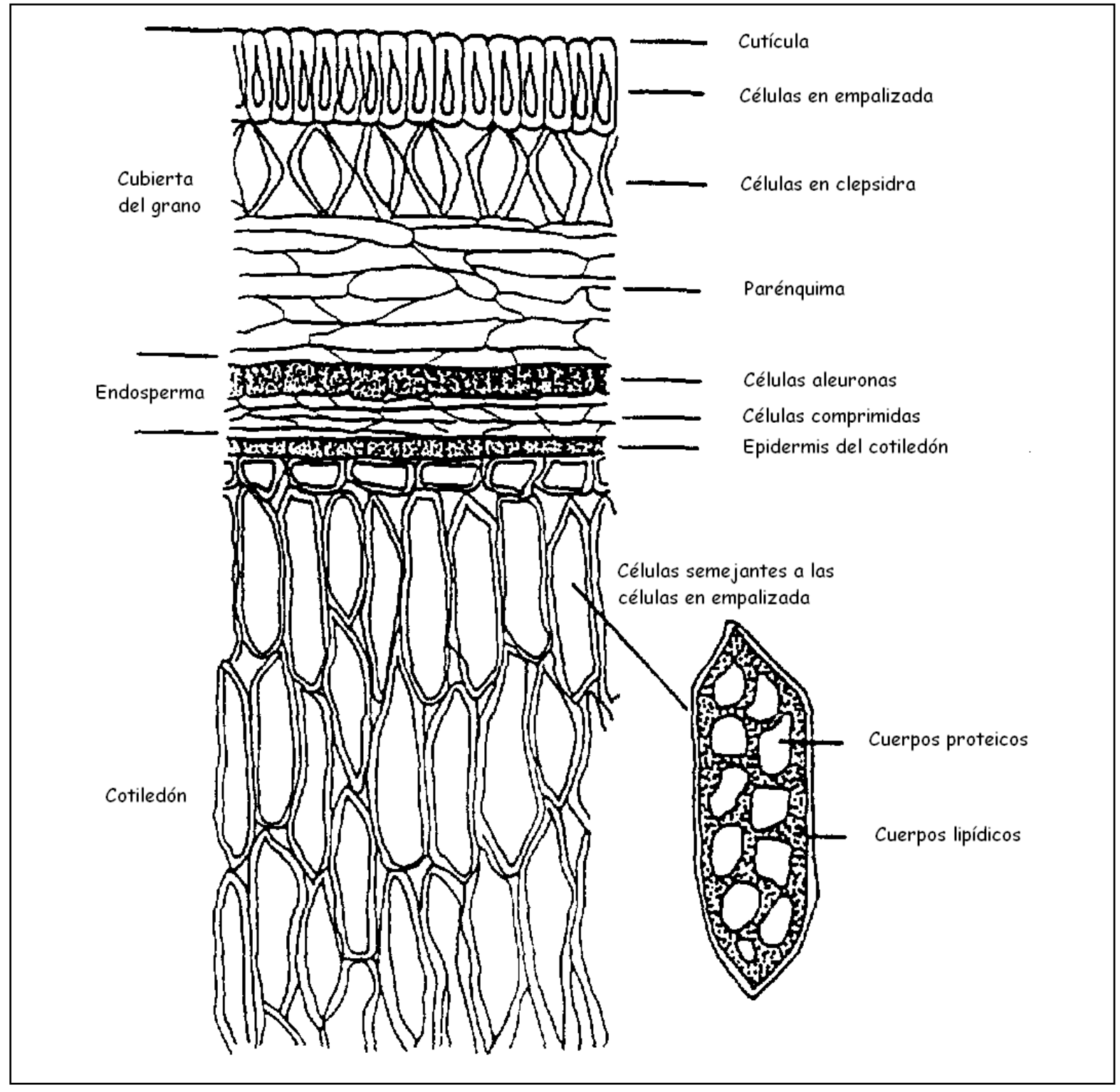

Figura 1.1: Estructura microscópica del cotiledón y endospermo de granos de soja (reproducido de Rosenthal y col., 1996) 
Los cuerpos proteicos varían de tamaño dependiendo de la semilla oleaginosa y también varían de tamaños en un amplio rango dentro de cada tipo de oleaginosa. En el caso de la soja, el cual es similar al caso del maní, el tamaño promedio de los cuerpos proteicos es entre 8 a $10 \mu \mathrm{m}$, pero también se reportan variaciones entre 2 y $20 \mu \mathrm{m}$ (Rosenthal y col., 1996). Estos cuerpos proteicos contienen aproximadamente entre el 60 y el $70 \%$ de la proteína total presente en las semillas oleaginosas.

Los cuerpos lipídicos (también conocidos como oleosomas o esferosomas) son el sitio principal de reserva de lípidos, no sólo en semillas oleaginosas sino también en frutos oleaginosos. Su tamaño frecuente oscila entre 1 a $2 \mu \mathrm{m}$, aunque varía desde 0,2 a $0,4 \mu \mathrm{m}$ en el caso de la soja hasta tamaños tan grandes como $4 \mu \mathrm{m}$ en el caso del algodón. En el caso de frutos oleaginosos como oliva, palta, y palma, los cuerpos lipídicos de almacenamiento son mayores a $20 \mu \mathrm{m}$. En este caso, el tejido que acumula la mayor parte de los lípidos de reserva es, normalmente, el mesocarpio (Zweytick y col., 2000).

Los análisis de microscopia electrónica han mostrado que los cuerpos lipídicos de oleaginosas como la soja y el maní están inmersos en una red citoplasmática, presumiblemente compuesta de proteína. Entonces, los espacios entre los cuerpos proteicos en las células del cotiledón están rellenos de cuerpos lipídicos y de la red citoplasmática (Rosenthal y col., 1996).

A diferencia del citoplasma que se caracteriza por la presencia de lípidos y proteínas, las paredes celulares que rodean la célula son compuestas de celulosa, hemicelulosa y lignina, además de pectina. En la extracción tradicional por solvente, el grano es laminado, lo cual causa ruptura de las paredes celulares; esto expone al aceite localizado en el interior de la célula y también facilita la percolación del solvente, dentro del cual el aceite puede difundir. Para el caso de la soja, el espesor promedio obtenido luego del laminado es de $0,25 \mathrm{~mm}$. Considerando que las células del cotiledón de soja son de cerca de 15 a $20 \mu \mathrm{m}$ de diámetro y de 70 a $80 \mu \mathrm{m}$ de longitud, el tamaño resultante del laminado permite la ruptura de una alta proporción de células. Entonces durante la extracción con solvente, el aceite difunde hacia el solvente, mientras que la proteína se retiene en la harina junto con las fibras y los carbohidratos. 
Los procesos acuosos también involucran la utilización de material molido, a fin de exponer y liberar más fácilmente el aceite y la proteína desde el material de partida. En este caso, sin embargo, mientras los componentes solubles difunden dentro del agua, el aceite liberado forma una fase líquida separada o parcialmente emulsificada con el agua.

Los cuerpos lipídicos de semillas oleaginosas contienen abundante cantidad de proteína llamadas oleosinas, las cuales cumplen, como función principal, el rol de estabilizar estos cuerpos lipídicos. La estructura de la oleosina es generalmente la misma en todas las semillas; consiste en proteínas de bajo peso molecular, en el rango de 15.000 a $26.000 \mathrm{kD}$. La estructura puede ser dividida en tres dominios principales: un dominio anfipático cercano al amino terminal, el cual está probablemente asociado a la superficie del cuerpo lipídico, un dominio central hidrofóbico el cual contiene alrededor de 70 residuos de aminoácidos no polares en sucesión que podrían interactuar fuertemente con la matriz de triacilglicéridos y un dominio anfipático cercano al carboxilo terminal que interactúa con la superficie de la monocapa de fosfolípidos que rodea la matriz de los triglicéridos. Debido a su estructura particular, la oleosina juega un papel fundamental para mantener la integridad de los cuerpos lipídicos durante la desecación que acompaña a la maduración de las semillas previniendo la interacción y la posible coalescencia (Zweytick y col., 2000).

A diferencia de las semillas, los cuerpos lipídicos de los frutos oleaginosos poseen cantidades insignificantes de oleosina. Esto se debe al hecho de que el mesocarpio no sufre desecación ni germinación y por lo tanto no requiere de pequeños cuerpos lipídicos estables (Zweytick y col., 2000). Las enzimas proteolíticas, por lo tanto, no serían útiles para extraer aceite a partir de frutos oleaginosos. Por ello, la emulsión aceite-agua resultante tiende a ser menos estable en el caso de frutos que aquellas que provienen de semillas, lo que permite una separación más fácil del aceite (Rosenthal y col., 1996).

Las diferencias en composición de las diferentes semillas oleaginosas determina la elección de las enzimas a usarse para cada semilla o fruto oleaginoso. Particularmente, en el caso de la soja, el alto contenido de proteína y el bajo contenido en aceite requiere el uso de enzimas proteolíticas para obtener altos rendimientos (Rosenthal y col., 1996). 


\subsection{Procesos de extracción}

\subsubsection{Procesos convencionales}

Históricamente, los tres procesos más comunes para recuperar el aceite a partir de semillas oleaginosas son el prensado hidráulico, el prensado expeller y la extracción con solventes.

El prensado hidráulico, el proceso más antiguo, se originó en Europa en 1795. Debido a la producción intensiva de aceites su uso ha declinado con el paso de los años y actualmente no es muy utilizado.

Las prensas de tornillo como los expellers han reemplazado a los originales equipos hidráulicos y son usadas para una amplia variedad de materiales oleaginosos. Para materiales que contienen relativamente altos contenidos de aceite se llevan a cabo dos procesos, los cuales consisten en una etapa continua de pre-prensado seguida de extracción por solvente. La principal ventaja del pre-prensado es que permite realizar extracción por solvente a materiales que son muy dificultosos de procesar por métodos de extracción directa. Además, los requerimientos de solvente disminuyen en forma considerable. Estos procesos combinados son usados, generalmente, con oleaginosas de alto contenido en aceite (alrededor de $35 \%$ ) como girasol, tung, algodón y germen de maíz. Para soja, se emplea una extracción simple debido al relativamente bajo contenido en aceite, como es evidente de la tabla 1.1.

Tabla 1.1: Contenidos típicos de aceite y proteínas de algunos materiales oleaginosos

\begin{tabular}{lcc}
\hline Material Oleaginoso & Aceite (\%) & Proteína (\%) \\
\hline Soja ${ }^{(1)}$ & 20 & 40 \\
Colza $^{(2)}$ & 40 & 20 \\
Coco desecado $^{(2)}$ & 70 & 6,5 \\
Gérmen de maíz $^{(2)}$ & 35 & 20 \\
Lino $^{(2)}$ & 45 & 25 \\
\hline
\end{tabular}

(1: Mustakas, 1980; 2: Olsen, 1988). 
La extracción por solvente se originó como un proceso en batch en Europa en 1870. Los avances tecnológicos más rápidos se dieron luego de la $2^{\text {da }}$ Guerra Mundial con el desarrollo de sistemas de extracción continua los cuales proveen un buen funcionamiento para materiales oleaginosos de bajos contenidos en aceite. Los procesos basados en extracción por solvente consisten, usualmente, en extracciones sucesivas del material oleaginoso previamente quebrado, laminado, molido o prensado, mediante lavados en contracorriente con hexano. Luego, la harina desengrasada es llevada a un tostador-desolventizador para recuperar el solvente. El hexano es removido del aceite en evaporadores de película y finalmente destilado a vacío.

Un diagrama de flujo básico del proceso combinado de extracción y preprensado se muestra en la figura 1.2.

El aceite crudo obtenido a partir de extracción por solventes contiene cantidades variables y relativamente reducidas de impurezas que no son glicéridos. Algunas de las impurezas afectan la calidad del aceite para su uso comestible y por lo tanto es necesario eliminarlas. Las impurezas son de dos tipos generales: insolubles y solubles en aceite. Las impurezas insolubles consisten en fragmentos de semillas, excedente de humedad y una fracción cerosa que hace que el aceite refrigerado se vea turbio. Las impurezas solubles en aceite son más difíciles de extraer. Incluyen ácidos grasos libres, fosfátidos, sustancias gomosas o mucilaginosas, cuerpos pigmentados, fracciones de proteínas, tocoferoles, esteroles, carbohidratos, cetonas y aldehídos. Estas impurezas pueden estar en una solución real o en suspensión coloidal. Algunas se encuentran en cantidades mínimas.

El propósito de las diferentes operaciones de procesos de refinación es de eliminar estas impurezas indeseables hasta el grado deseado con el menor efecto perjudicial sobre la calidad final del aceite y pérdidas mínimas de producto. Los procesos de refinación incluyen distintas operaciones.

La etapa de desgomado remueve los fosfolípidos y gomas mucilaginosas. La hidratación hace que la mayoría de los fosfátidos y gomas se vuelvan insolubles en el aceite por formación de geles que se aglomeran en forma de partículas floculadas. Industrialmente, se precalienta el aceite a $80{ }^{\circ} \mathrm{C}$, se agrega el agua y se agita la mezcla durante 10 a 15 minutos en un tanque de retención y luego se centrifuga, eliminando la fase pesada que contiene las gomas y fosfolípidos hidratados. 
Los ácidos grasos, colorantes y prooxidantes metálicos se eliminan en distinta medida durante el proceso de neutralización. El tratamiento alcalino, casi siempre con $\mathrm{NaOH}$, produce reacciones químicas y cambios físicos en el aceite. La base se combina con los ácidos grasos libres del aceite para formar jabones, los fosfolípidos y las gomas absorben la base y se coagulan por hidratación o degradación, una parte de la materia colorante es degradada, adsorbida por las gomas o solubilizada en el agua y las materias insolubles son atrapadas por los demás materiales coagulables. Se adiciona la base, en concentración y cantidad calculada, y se agita en una mezcladora de altos esfuerzos cortantes para asegurar el contacto íntimo entre las fases. La mezcla de aceite y jabón se centrifuga en caliente, a $80{ }^{\circ} \mathrm{C}$ aproximadamente, para separar fases. La fase liviana, que contiene el aceite, se lava con agua y se vuelve a centrifugar para eliminar los residuos de jabón.

El aceite aún contiene cuerpos de color, olores y diferentes impurezas que deben removerse para que posea sabor y color aceptables para el consumidor. Algunas de estas impurezas se reducen por medio de un proceso llamado blanqueado. Industrialmente, se lleva a cabo mezclando el aceite con un agente adsorbente a $110 \stackrel{\circ}{ } \mathrm{C}$, aproximadamente. Luego se rocía la mezcla en una torre de blanqueo que opera a vacío y por último, el aceite se filtra para eliminar la tierra adsorbente que retiene las impurezas.

La desodorización es la última etapa de los procesos de refinación que elimina fundamentalmente sustancias volátiles y convierte al aceite en un líquido brillante, transparente y de sabor suave. Los materiales eliminados incluyen ácidos grasos libres; diversos compuestos de sabor y olor clasificados en su mayoría como aldehídos, cetonas, alcoholes e hidrocarburos y otros compuestos formados por descomposición térmica de peróxidos y pigmentos. La desodorización es primariamente un proceso de destilación al vapor, a alta temperatura y de alto vacío. Primero se desairea el aceite, se calienta a la temperatura de desodorización, se retiene a alta temperatura para descomponer térmicamente impurezas no volátiles, luego se separan las impurezas por arrastre con vapor y por último, se enfría el aceite desodorizado (Mustakas, 1980). 


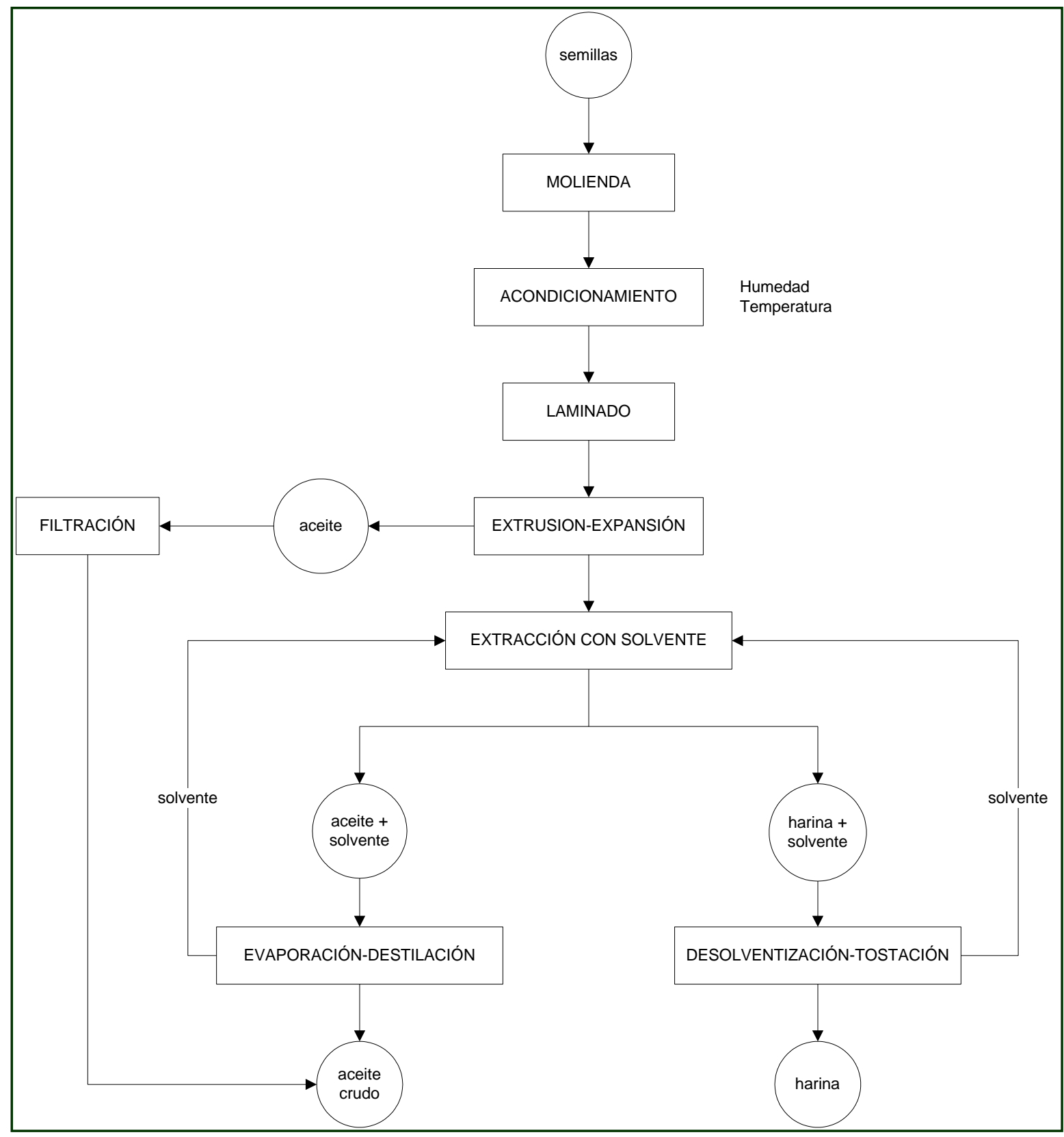

Figura 1.2: Extracción convencional de semillas oleaginosas combinando prensado y extracción por solvente (modificado de Rosenthal y col, 1996)

\subsubsection{Procesos acuosos}

Los procesos de extracción acuosa (AEP, por sus siglas en inglés) fueron sugeridos originalmente como una alternativa a los procesos de extracción por 
solvente en la década de los 50'. Fueron pensados por ser seguros y de bajo costo. Además, sería posible la recuperación simultánea de aceite y proteína (concentrada o aislada) a partir de materiales oleaginosos (Cater y col., 1974).

AEP utiliza un principio muy diferente comparado con los procesos de extracción por solvente, los cuales son basados en la capacidad del aceite de disolverse y ser extraído por el solvente. En AEP, el aceite no posee alta afinidad química por el medio de extracción y, consecuentemente, no hay potencial químico para la disolución del aceite.

La extracción de aceite por AEP esta, consecuentemente, basada más en la insolubilidad del aceite en agua que en la disolución del aceite. En este caso, los componentes de las oleaginosas solubles en agua difunden en el agua más rápidamente que el aceite, liberando aceite que previamente estaba enlazado a la estructura original.

AEP utiliza el mismo principio que la flotación en agua caliente. El proceso involucra mezclado, molienda y descascarado de semillas oleaginosas en agua caliente y la separación del aceite en la superficie (Lusas y Jividen, 1987). El método de flotación en agua caliente para extraer aceites comestibles a partir de oleaginosas es un método tradicional usado en áreas rurales de muchos países en desarrollo. El proceso es acompañado de cinco pasos principales: 1) acondicionamiento con calor de las semillas, 2) molienda, 3) extracción por ebullición, 4) recuperación de aceite y 5) secado. Tradicionalmente, la molienda es llevada a cabo por aplastamiento en molinos. Las semillas molidas son calentadas en agua para liberar el aceite, el cual flota sobre la superficie. El aceite es cuidadosamente removido de la superficie del agua y secado para remover humedad residual (Rosenthal y col., 1996).

La aplicación de procesos acuosos al procesado de diferentes materiales oleaginosos requiere cambios en las condiciones específicas (tales como $\mathrm{pH}$ y temperatura de extracción) debido a las diferencias en la composición química y estructura física de cada semilla (Rosenthal y col., 1996). 


\subsubsection{Extracción por solvente versus procesos de extracción acuosa}

Los principales aspectos de la comparación y contrastación entre la extracción acuosa y la extracción por solvente pueden discutirse en términos ambientales, económicos y de calidad.

\subsubsection{Aspectos económicos y ambientales}

El principal aspecto ambiental relacionado con la extracción convencional basada en solventes es la pérdida de hexano y los problemas de polución asociados a esta pérdida. El hexano, como otros VOCs (compuestos orgánicos volátiles), pueden reaccionar con sustancias tóxica $\mathrm{s}$, principamente óxidos de nitrógeno en presencia de luz solar, para producir ozono $\left(\mathrm{O}_{3}\right)$ y otras especies conocidas colectivamente como oxidantes fotoquímicos. Si bien el ozono es esencial en las capas altas de la atmósfera para filtrar la radiación UV del sol, su exceso es indeseable (FinlaysonPitts y Pitts, 1993).

Por ello, el hexano es un creador fotoquímico potencial de ozono (POP). Esto ha promovido desarrollos en las técnicas para minimizar las emisiones de VOCs, ya que el sector de producción de alimentos es el responsable de cerca del 7,5\% de las emisiones a partir de fuentes estacionarias. Dentro de la industria de los alimentos, el sector aceitero es el principal sector de los altos niveles de emisión de VOCs. Se ha estimado que se emiten, en promedio, 1,5 L de hexano por tonelada de semilla procesada para el caso de plantas industriales modernas y en óptimas condiciones de operación (Mustakas, 1980). Esto indica que es necesario encontrar una alternativa para la extracción de aceites vegetales la cual elimine o reduzca drásticamente el uso de solventes orgánicos volátiles o reduzca significativamente el nivel de su emisión. Sería apropiado que el sector considere el desarrollo de nuevos procesos limpios desde el punto de vista ambiental. Los procesos basados en la extracción acuosa podrían lograr este objetivo (Rosenthal y col., 1996),

Además de los problemas ambientales, el uso de hexano es también peligroso desde el punto de vista de la seguridad. El hexano es altamente inflamable y se 
deben tomar precauciones que eviten los riesgos de explosión y fuego y el peligro de accidentes severos. Los procesos acuosos eliminan el problema de seguridad del solvente, resultando en bajos riesgos de incendio y menores peligros operacionales (Mustakas, 1980).

Los procesos acuosos pueden ser potencialmente más eficientes en el costo considerando los costos relacionados de recuperación de solvente, seguridad de los procesos y sistema de control de pérdidas de solvente. Además, estos procesos permiten el uso de instalaciones más pequeñas, lo cual ofrece ventajas económicas significativas (Lanzani y col., 1975; Cater y col., 1974; Lusas y Jividen, 1987 y Rosenthal y col., 1996).

Los procesos acuosos actuales son procesos de extracción menos eficientes que la extracción por solvente para la mayoría de las oleaginosas. Esto tiene que ver con los costos de demulsificación, remoción de agua de los productos finales, requerimientos de higiene de este tipo de procesos húmedos y producción elevada de efluentes (Rosenthal y col., 1996).

\subsubsection{Calidad de aceite y proteína}

Los procesos empleados corrientemente son optimizados para producir aceites comestibles. Como resultado de esto, se ha dado muy poca atención a la calidad de los residuos de proteínas en el contexto de consumo humano. El residuo de los procesos de extracción por solvente deben ser calentados para remover los residuos de solvente, lo cual requiere un elevado consumo de energía térmica no sólo debido a la extracción del aceite desde la miscela sino también para mejorar la extractabilidad antes de la extracción. En contraste, se sabe bien que los tratamientos térmicos drásticos de semillas oleaginosas reducen la calidad del aceite extraído y de la proteína.

El principal efecto nutricional resultante del calentamiento excesivo en los procesos convencionales es la disminución de la disponibilidad nutricional de algunos aminoácidos esenciales (principalmente lisina), lo cual resulta de la reacción de Maillard entre los grupos aminos de las proteínas y los grupos carbonilos de los azúcares reductores. La calidad global de las proteínas es determinada por la disponibilidad biológica de cada uno de los aminoácidos esenciales que forman la 
proteína. La reacción de Maillard causa, no sólo un efecto nutricional negativo sobre los aminoácidos esenciales involucrados en la reacción, sino también sobre el valor biológico de la proteína. Un efecto similar ocurre a las altas temperaturas generadas en los expellers durante el prensado (Rosenthal y col., 1996).

En contraste, los procesos acuosos evitan daños severos sobre las proteínas de las oleaginosas, lo cual permite la producción de proteínas grado alimentario en lugar de productos grado alimentación animal (Dominguez y col., 1995a). Los procesos acuosos permiten además la inactivación o remoción de factores antinutricionales y otras sustancias indeseables que están presentes en algunas oleaginosas y que pueden reducir la calidad global de los productos o el valor nutricional de sus proteínas y que pueden ser tóxicos para el ser humano (Cater y col., 1974 y Lawhon y col., 1981 a y b)

En general, no se han reportado diferencias significativas entre los aceites obtenidos a partir de semillas tratadas enzimáticamente, tanto en procesos acuosos como en procesos por extracción por solvente (Rosenthal y col., 1996).

\subsubsection{Pretratamientos de uso industrial}

Como se dijo anteriormente, el aceite en las oleaginosas se encuentra en vacuolas dentro de las células de las semillas, y tanto las paredes de las células como las vacuolas deben romperse para mejorar la extracción con solvente. La adecuada preparación de la semilla, previa a su extracción con el solvente, es crítica para maximizar la recuperación de aceite. Dicha preparación consta de: 1) operar a niveles de humedad de 11-13 \% para garantizar las propiedades deseadas de manejo de la semilla en el equipo; 2) romper la semilla; 3) calentarla para obtener una textura plástica y 4) aplastar la soja quebrada y calentada para transformarla en láminas de un espesor de 0,3-0,5 mm de espesor aproximadamente (Asociación Americana de Soja, 1995). 


\subsubsection{Molienda}

Después de la limpieza se procede a quebrar las semillas utilizando rolos corrugados. Se obtienen semillas quebradas en 4-6 partes (Ong, 2002). El objetivo de esta molienda es reducir el tamaño de las partículas y adaptarlas a las condiciones de ingreso a los molinos laminadores, así como preacondicionarlas al tamaño correcto de laminado. En el caso de soja, se emplean molinos quebradores de dos pasos con rodillos estriados (Fetzer, 1998).

\subsubsection{Acondicionamiento}

Para lograr láminas estables con bajo contenido de finos (tapan el drenaje del lecho en el extractor) se acondiciona la soja molida antes del proceso de laminado (Fetzer, 1998). El acondicionamiento consiste en calentamiento hasta $65-70 \stackrel{\circ}{ } \mathrm{C}$ y 11 $-13 \%$ de humedad para lograr la plasticidad requerida en el laminado, en chimeneas de tipo vertical o secadoras giratorias (Mustakas, 1980).

\subsubsection{Laminado}

Las semillas quebradas y acondicionadas son laminadas por presión y fuerzas de cizalla a través del paso por rodillos laminadores lisos de velocidades diferenciales. Durante esta operación las células son deformadas y rotas y es liberado el aceite contenido en los esferosomas. El objetivo del laminado es producir láminas de 4,5 mm de espesor aproximado, tal que favorezca la extracción por ruptura celular y el drenaje del lecho en el extractor (Singh y col., 1999).

\subsubsection{Expandido}

La aplicación más conocida de los expanders es mejorar la preparación de soja para su mejor extracción y aumentar la capacidad de las plantas de molienda de soja existentes. El expander estándar con el que se opera actualmente en la industria de oleaginosas, consiste en un cuerpo tubular con pernos rompetortas entremezclados entre los tramos de helicoide de paso variable, montados sobre el eje principal compuesto por varias piezas desmontables. 
Durante la operación, el material preparado ingresa en el equipo a través de un alimentador separado, o es alimentado por simple succión con conexión directa a un transportador. El material sufre una acción de mezcla y trituración que fractura algunas de las células del aceite. El vapor inyectado directamente se mezcla con el producto y aporta lubricación a la masa de material, al tiempo que eleva su temperatura y humedad. La fricción de las hélices y el cuerpo contra el material contribuye también a incrementar la temperatura.

En el procesamiento de soja, el expander está ubicado inmediatamente después de los molinos laminadores. Una vez que pasa por los expanders, el material se enfría a $60 \stackrel{\circ}{\circ}$ y se corrige la humedad final al $10 \%$. El proceso de expandido genera un material con una estructura esponjosa, la cual posibilita un buen drenaje, inclusive en los extractores de lecho profundo. Al mismo tiempo, dado que la ruptura de las células de aceite es tan completa, el desgrase con solvente del material en proceso se lleva a cabo de manera efectiva.

En Estados Unidos, se utilizan expanders mezclando el material expandido con láminas al $50 \%$. En Sudamérica y otros países, es común pasar todas las láminas a través de expanders.

En la actualidad los expanders se han utilizado para procesar oleaginosas con alto contenido graso, utilizándolos como extractores de aceite a presión reduciendo el contenido de aceite del material antes de la expansión (Pedrotti y Boling, 1999).

\subsubsection{Uso de enzimas en procesos de extracción por solvente y por prensado}

Se puede mejorar la permeabilidad de las paredes celulares de semillas y frutos oleaginosos mediante los tratamientos mecánico y térmico, los cuales constituyen las operaciones de preparación convencionales.

La permeabilidad de semillas y frutos podría aumentarse también por hidrólisis parcial de las paredes celulares de los vegetales oleaginosos mediante el empleo de enzimas apropiadas.

El rol de la mayoría de las enzimas hidrolíticas como las celulasas, hemicelulasas y pectinasas en estos procesos es romper la estructura de las membranas celulares 
del cotiledón. La figura 1.3 muestra el efecto del tratamiento enzimático sobre semillas previamente molidas. Puede verse a partir de la figura 1.3 que la acción enzimática hace a la estructura más permeable; la extensión de este efecto depende del tamaño de partícula. Las enzimas proteolíticas principalmente hidrolizan las proteínas de las membranas celulares así como también las del citoplasma (Rosenthal y col., 1996).

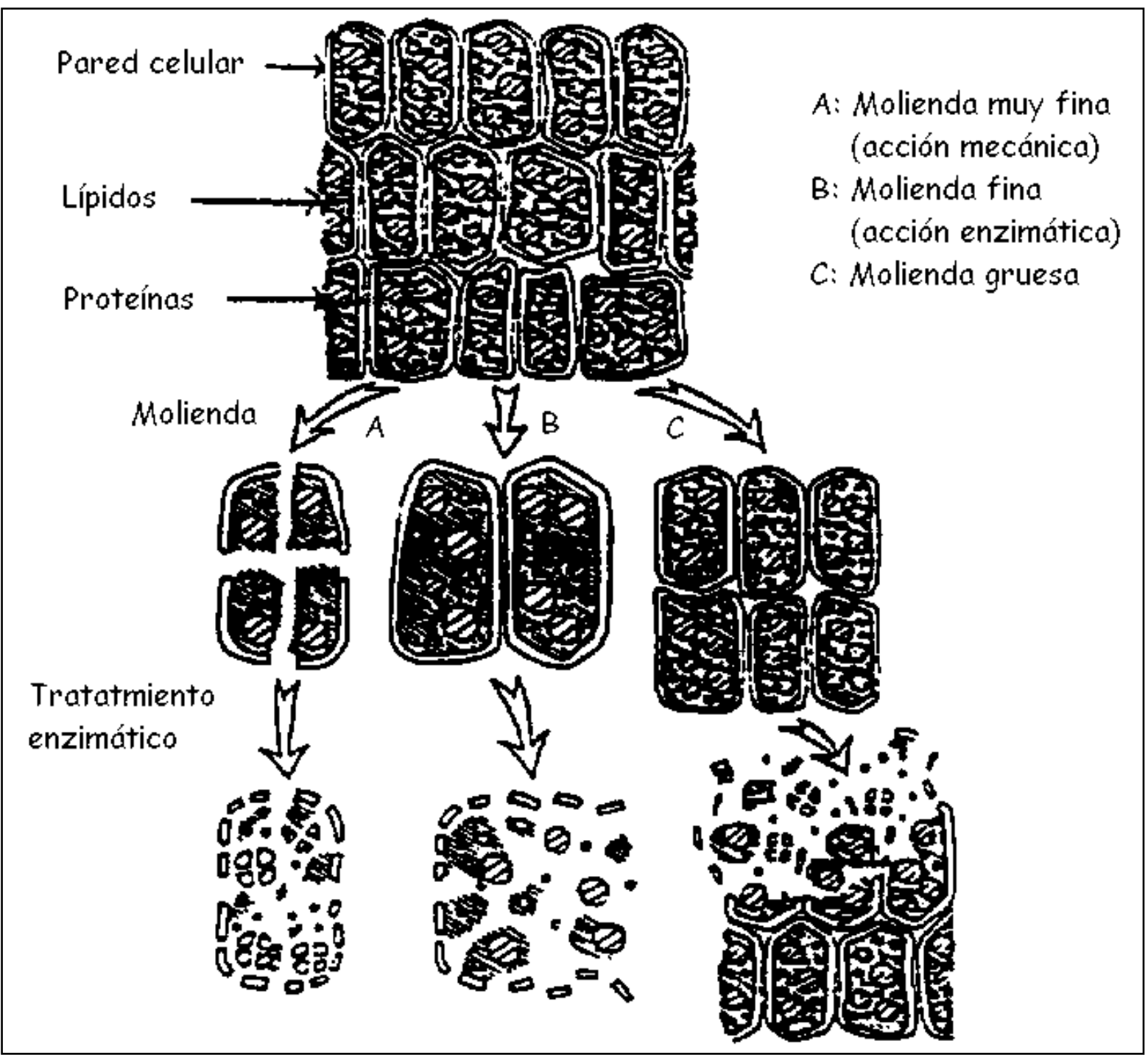

Figura 1.3: Efecto de la molienda y del tratamiento enzimático sobre la estructura de las semillas oleaginosas (reproducido de Christensen, 1991). 
cuerpos lipídicos. Bair y Snyder (1980) y Tzen y Haung (1992) aislaron, respectivamente, cuerpos lipídicos de soja y maíz y llevaron a cabo hidrólisis típicas. Como resultado, ocurrió ruptura de las membranas de cuerpos lipídicos y fue evidente la coalescencia entre los cuerpos lipídicos, en ambos casos. Se puede concluir que el aceite liberado puede separarse más fácilmente a través de un medio acuoso o por un solvente orgánico luego de la acción proteolítica. Las enzimas proteolíticas pueden afectar también la red citoplasmática, la cual esta compuesta por proteínas, en el caso de la soja y otras semillas oleaginosas, lo cual resulta en una estructura más suave y menos compacta que facilita la remoción de la proteína y el aceite desde la célula.

Considerando la especificidad de las carbohidratasas, una elección razonable de enzimas para una semilla o un fruto dado sólo puede hacerse luego de comprender el arreglo complejo de los polisacáridos en las paredes celulares. Las paredes celulares primarias de la mayoría de las plantas superiores poseen una estructura común que consiste en fibras de celulosa enlazadas a cadenas de hemicelulosa.

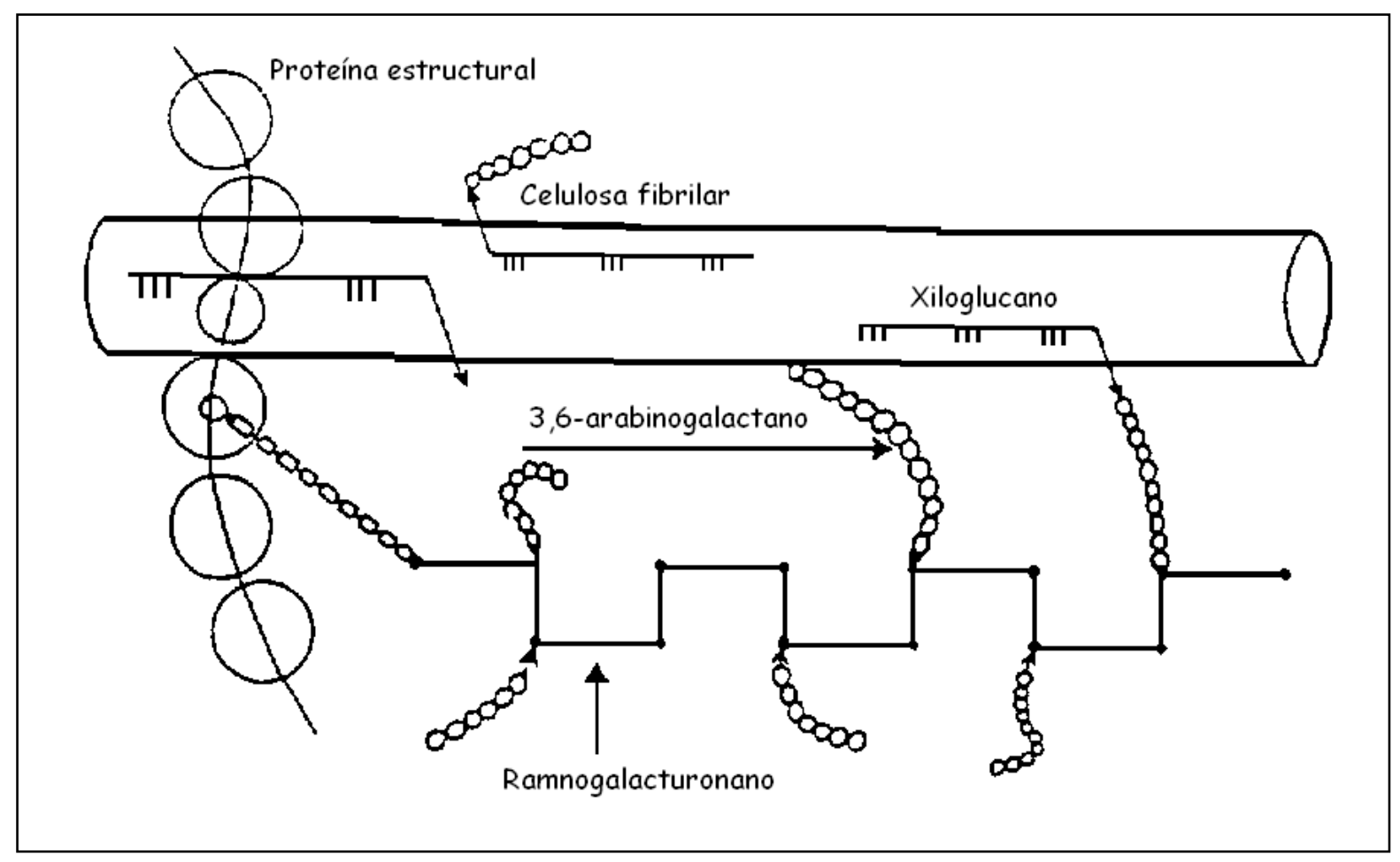

Figura 1.4: Estructura de la pared celular primaria de semillas oleaginosas (reproducido de Christensen, 1991). 
Estas fibras están embebidas en una matriz de sustancias pécticas enlazadas a proteínas estructurales como muestra la figura 1.4. Esto sugiere que las preparaciones enzimáticas capaces de atacar las paredes celulares deben contener una mezcla de celulasas, hemicelulasas, pectinasas y proteasas. Sin embargo, las preparaciones comerciales que contienen estas enzimas frecuentemente no son capaces de hidrolizar estos componentes específicos y puede requerirse un futuro desarrollo para degradar los polisacáridos complejos encontrados en las paredes celulares de materiales vegetales no lignificados (Christensen, 1989).

La posibilidad de liberar parcialmente el aceite desde una harina cruda de soja tratada térmicamente, por el uso de enzimas hidrolíticas fue investigada inicialmente por Sherba y col (1972), como reporta Adler-Nissen (1986). El aceite fue más fácilmente recuperado en una extracción con éter de petróleo. Este desarrollo fue seguido por Fullbrook (1983), quién investigó la hidrólisis acuosa de oleaginosas seguida de extracciones por solvente y luego también llevó a cabo hidrólisis en presencia de solvente para extraer simultáneamente el aceite liberado. Se observó que los rendimientos podían ser mejorados considerablemente si la hidrólisis de harina fina de soja y colza se llevaban a cabo en presencia de solvente. En el caso de colza, se obtuvo $50 \%$ más aceite. Para soja, el incremento en aceite fue alto, resultando en una extracción neta de cerca del $90 \%$ del aceite total extraíble; se utilizó $3 \%$ de una mezcla enzimática obtenida de Aspergillus níger. Olsen (1988) también describió la extracción de semillas de colza descascaradas seguida de extracción del aceite residual con éter de petróleo. La mezcla de hidrólisis incluyó tres enzimas que degradan las paredes celulares: pectinasa, celulasa y hemicelulasa. Esta hidrólisis parcial incrementó la permeabilidad de las paredes celular, lo cual permitió una percolación del solvente y una extracción más eficientes. Sosulsky y col. (1988) evaluaron el efecto de diferentes carbohidrolasas sobre el tiempo y el rendimiento de extracción de aceite de canola. La reacción enzimática fue llevada a cabo sobre láminas de canola previamente autoclavadas y ajustadas en humedad, seguido de un secado y una extracción con hexano. La eficiencia enzimática, basada en el aumento del rendimiento en aceite fue: actividades enzimáticas mezcladas $>\beta$-glucanasa $>$ pectinasa $>$ hemicelulasa $>$ celulasa. El tratamiento enzimático antes de la extracción por Soxhlet para un tiempo dado dio rendimientos $45 \%$ más altos. Por lo tanto, el tiempo para extraer el aceite total extraíble disminuyó comparativamente, indicando un incremento en la velocidad de 
extracción. El máximo rendimiento obtenido para el control en un aparato Goldfish fue aproximadamente $5 \%$ menor, comparado con el obtenido con acción enzimática. En forma similar, Domínguez y col. (1995b) reportaron incrementos en la extractabilidad de soja entre el 8 al $10 \%$ de aceite extraíble y más del $4 \%$ en el caso de aceite de girasol luego del tratamiento enzimático con diferentes enzimas comerciales. Las altas velocidades de extracción resultantes permiten operaciones más cortas para obtener un porcentaje dado del aceite total extraíble.

Bhatnagar y Johari (1987) también verificaron que el tratamiento con enzimas obtenidas de mohos termófilos incrementa la cantidad de aceite extraíble por Soxhlet en el caso de algunas oleaginosas. La recuperación de aceite de algodón se incrementó más del $5 \%$ con acción enzimática previa mientras que para aceite de girasol el rendimiento se incrementó en un 4,2\% luego de otro tratamiento con las enzimas obtenidas de mohos. En el mismo estudio, el rendimiento de aceite fue mayor cuando el tratamiento enzimático fue llevado a cabo en presencia de solvente en lugar de medio acuoso; esto puede atribuirse a la mayor solubilización de tejidos vegetales y proteínas en solventes orgánicos, a las cuales el aceite permanece enlazado en los procesos de extracción convencionales. Tano-Debrah y Ohta (1994 y 1995a) obtuvieron un incremento de alrededor de $20 \%$ en el rendimiento de la extracción por solvente para un pretratamiento de semillas de Butyrospermum paradoxum subespecie parkii con una mezcla de proteasas y carbohidrolasas.

En relación al proceso de prensado, Cheah y col. (1990) extrajeron $97,7 \%$ del aceite a partir de mesocarpio de palma tratado con pectinasa usando una prensa hidráulica en comparación con el 91,1\% obtenido a partir de material no tratado. Bouvier y Entressangles (1992) usaron una preparación de celulasa que redujo en 3 y $18 \%$, respectivamente las pérdidas de aceite de palma de las fibras prensadas y de jugo crudo durante la clarificación, comparados con los procesos tradicionales sin enzimas.

Otro aspecto importante a considerar es la diferencia en el rol de las carbohidrolasas (pectinasas, celulasas y hemicelulasas) y las enzimas proteolíticas. La acción de las carbohidrolasas es hidrolizar específicamente las paredes celulares, lo cual permite una alta liberación del aceite hacia el medio acuoso. Por otro lado, la acción de las enzimas proteolíticas esta relacionada a la hidrólisis de las membranas que rodean los cuerpos lipídicos y las proteínas del citoplasma (Rosenthal y col., 1996). 


\subsubsection{Uso de enzimas en procesos de extracción acuosa}

Las enzimas que degradan las paredes celulares también pueden usarse para extraer aceite por solubilización, en un medio acuoso, de los componentes estructurales de las paredes celulares de las semillas oleaginosas. Esta solubilización requiere un grado de hidrólisis enzimática más completa que en el caso del proceso convencional.

Este concepto se hizo comercial para la producción de aceite de oliva y también ha sido investigado para otros materiales oleaginosos. La tabla 1.2 muestra los rendimientos de la extracción de aceite obtenidos para diferentes materiales usando distintos tipos de enzimas. Como es evidente a partir de esta tabla, las mezclas de enzimas con actividades combinadas, en general, dan rendimientos mayores que las enzimas individuales.

Además, las carbohidrolasas y las enzimas proteolíticas mejoran el rendimiento de proteínas y aceite por hidrólisis de las proteínas fibrosas estructurales en las que están embebidos los glóbulos grasos. Yoon y col (1991) reportaron una mejora en la extracción de lípidos a partir de soja usando sólo enzimas proteolíticas, las cuales resultaron en un rendimiento final de $86 \%$ comparado con el $62 \%$ del proceso llevado a cabo sin enzimas. En el mismo estudio, la extracción de proteínas se incrementó en desde 62 a $89 \%$. En el mismo sentido, Olsen (1988), acordando con Adler-Nissen (1986), llevó a cabo una hidrólisis proteolítica sobre harina de soja lavada con ácido. El lavado inicial con ácido permitió la recuperación de un tercio del aceite originalmente presente en la harina. La hidrólisis de la harina lavada aproximadamente al 10\%) seguida de centrifugación resultó en un 
Tabla 1.2: Extracción acuosa enzimática para diferentes oleaginosas en comparación con el control (Rosenthal y col., 1996).

\begin{tabular}{|c|c|c|c|}
\hline Semilla & Enzima & $\begin{array}{c}\text { Concentración } \\
\text { o actividad }\end{array}$ & $\begin{array}{l}\text { Rendimiento } \\
\text { en aceite (\%) }\end{array}$ \\
\hline \multirow{7}{*}{ Colza } & Control (sin enzimas) & & 53,9 \\
\hline & Pectinasa (Pectinex ultra-sp) & $2 \%$ & 71,4 \\
\hline & Celulasa & 300 unidades & 55,4 \\
\hline & Multi-carbohidrolasas (ViscoZyme 120L) & $2,5 \%$ & 71,3 \\
\hline & Pectinasa (NovoZyme 249) & $0,2 \%$ & 70,0 \\
\hline & Celulasa (NovoZyme 465) & $0,9 \%$ & 54,2 \\
\hline & $\begin{array}{l}\text { Pectinasa (NovoZyme 249) + celulasa (NovoZyme } \\
465)\end{array}$ & $0,4: 0,1 \%$ & 80,2 \\
\hline \multirow[t]{3}{*}{ Soja } & Control (sin enzimas) & & 62,0 \\
\hline & Proteasa (Alcalase) & $0,2 \%$ & 84,0 \\
\hline & Proteasa (Sigma) & $0,2 \%$ & 86,0 \\
\hline \multirow[t]{8}{*}{ Coco } & Control (sin enzimas) & & 12,0 \\
\hline & $\begin{array}{l}\text { Pectinasa (Clarex) }+\alpha \text {-amilasa }(\text { Tanasa) }+ \\
\text { Proteasa (HT-proteolytic) }\end{array}$ & $0,1: 0,1: 0,1 \%$ & 80,0 \\
\hline & $\begin{array}{l}\text { Pectinasa (Irgazyme) }+\alpha \text {-amilasa (Tanasa) }+ \\
\text { Proteasa (HT-proteolytic) }\end{array}$ & $0,1: 0,1: 0,1 \%$ & 89,3 \\
\hline & $\begin{array}{l}\text { Pectinasa (Pectimex) }+ \text { Pectinasa (Clarex) }+\alpha- \\
\text { amilasa (Tanasa) }+ \text { Proteasa (HT-proteolytic) }\end{array}$ & $\begin{array}{c}0,1: 0,1: 0,1: 0,1 \\
\%\end{array}$ & 87,6 \\
\hline & $\begin{array}{l}\text { Pectinasa (Clearzyme) }+ \text { Pectinasa (Clarex) }+\alpha- \\
\text { amilasa (Tanasa) + Proteasa (HT-proteolytic) }\end{array}$ & $\begin{array}{c}0,1: 0,1: 0,1: 0,1 \\
\%\end{array}$ & 89,4 \\
\hline & $\begin{array}{l}\text { Pectinasa (Rohapec) }+\alpha \text {-amilasa (Tanasa) }+ \\
\text { Proteasa (HT-proteolytic) }\end{array}$ & $0,1: 0,1: 0,1 \%$ & 83,5 \\
\hline & $\beta$-Glucanasa (Brew-n-zyme) & $0,3 \%$ & 14,4 \\
\hline & $\begin{array}{l}\beta \text {-Glucanasa (Brew-n-zyme) }+ \text { Pectinasa (Clarex) } \\
+\alpha \text {-amilasa (Tanasa) }+ \text { Proteasa (HT-proteolytic) }\end{array}$ & $\begin{array}{c}0,1: 0,1: 0,1: 0,1 \\
\%\end{array}$ & 93,8 \\
\hline \multirow[t]{4}{*}{ Girasol } & Control (sin enzimas) & & 30,0 \\
\hline & Celulasa (CGA) & $3 \%$ & 44,0 \\
\hline & $\alpha$-1,4-glicanogalacturónido-hidrolasa (Ultrazym) & $3 \%$ & 44,0 \\
\hline & $\begin{array}{l}\text { Celulasa (CGA) + } \alpha-1,4-\text { glicanogalacturónido- } \\
\text { hidrolasa (Ultrazym) }\end{array}$ & $1,5: 1,5 \%$ & 52,0 \\
\hline \multirow[t]{8}{*}{ Maní } & Control (sin enzimas) & & 72,0 \\
\hline & Proteasa (Pepsin-Merck) & $3 \%$ & 78,0 \\
\hline & Celulasa (CGA) & $3 \%$ & 75,0 \\
\hline & $\begin{array}{l}\alpha-1,4-\text { glicanogalacturónido-hidrolasa } \\
(\text { Ultrazym)) }\end{array}$ & $3 \%$ & 74,0 \\
\hline & Proteasa $($ Pepsin-Merck) + Celulasa (CGA) & $1,5: 1,5 \%$ & 78,0 \\
\hline & $\begin{array}{l}\text { Proteasa } \quad \text { (Pepsin-Merck) } \underset{\text { glicanogalacturónido-hidrolasa (Ultrazym }}{+} \alpha-1,4- \\
\text { glis }\end{array}$ & $1,5: 1,5 \%$ & 76,0 \\
\hline & $\begin{array}{l}\text { Celulasa (CGA) + } \alpha-1,4-\text { glicanogalacturónido- } \\
\text { hidrolasa (Ultrazym) }\end{array}$ & $1,5: 1,5 \%$ & 74,0 \\
\hline & $\begin{array}{l}\text { Proteasa (Pepsin-Merck) + Celulasa (CGA) }+\alpha- \\
1,4-\text { glicanogalacturónido-hidrolasa (Ultrazym) }\end{array}$ & $1,0: 1,0: 1,0 \%$ & 78,0 \\
\hline
\end{tabular}


rendimiento del $60 \%$ en aceite. La pasta originada en la centrífuga fue hidrolizada una vez más en forma similar, librando cerca del $99 \%$ del aceite en la fase líquida, el cual estaba parcialmente emulsificado con el hidrolizado de proteína.

Como se observa en la tabla 1.2, diferentes estudios sugieren diferentes combinaciones de enzimas para mejorar la extracción de aceite. Puede notarse que la mayoría de estos estudios emplean diferentes condiciones de extracción como $\mathrm{pH}$, agitación, tamaño de partícula y temperatura de reacción, todo lo cual define resultados altamente específicos para esas condiciones experimentales (Rosenthal y col., 1996).

En el caso de coco, McGlone y col. (1986) y Barrios y col. (1990) incrementaron el rendimiento de extracción de aceite de coco por combinación de tratamiento de poligalacturonasa, $\alpha$-amilasa y proteasa en un sistema acuoso, obteniendo rendimientos finales cercanos al $80 \%$; sin embargo, Christensen (1989) reportó rendimientos de extracción de aceite cercanos al $90 \%$ usando galactomanasa combinada con un complejo de enzimas que degradan polisacáridos. Todos los estudios sostienen que se requieren diferentes enzimas para degradar los componentes de la estructura de la pared celular.

En el caso de palta, Buenrostro y Lopez-Munguía Canales (1986) obtuvieron rendimientos de extracción del $75 \%$ del contenido inicial de aceite empleando sólo $\alpha$-amilasa y del $65 \%$ del contenido inicial de aceite empleando una mezcla enzimática de poligalacturonasa, proteasa y $\alpha$-amilasa.

Cheah y col. (1990) extrajeron el $57 \%$ del aceite de palma en un proceso acuoso luego del tratamiento del mesocarpio de la palma con una preparación de celulasa. El material no tratado y uno tratado con pectinasa resultaron en rendimientos similares del $28 \%$.

Domínguez y col (1995 b) obtuvieron un aumento en el rendimiento de aceite de girasol mayor al $30 \%$ usando mezclas de celulasas y pectinasas.

Bocevska y col (1993) evaluaron un grupo de enzimas comerciales para extracción acuosa de germen de maíz y concluyeron que un complejo de carbohidrolasas (principalmente celulasa) de Trichoderma reesei fue más efectivo liberándose $84,7 \%$ del aceite total, $76,3 \%$ del cual aparece libre luego de la centrifugación. 
En el caso de colza, se obtuvo un rendimiento de $78 \%$ con enzimas proteasas y $\alpha-1,4$-galacturónicoglicano hidrolasa (Lanzani y col., 1975). Un resultado comparable se obtuvo en el mismo estudio con el uso de proteasas solamente. Olsen (1988) describió un proceso de extracción acuoso en el cual enzimas que degradan las paredes celulares (combinaciones de pectinasas, celulasas y hemicelulasas) son usadas para degradar las semillas de colza.

Además del tipo y dosaje de las enzimas empleadas, el grado de molienda tambien afecta el rendimiento en aceite. Se han reportado que los principales parámetros que afectan la extracción acuosa enzimática de colza son el grado de molienda, $\mathrm{pH}$ de la dispersión, temperatura y tiempo de incubación y condiciones de centrifugación. Estas conclusiones confirman que los diferentes resultados de rendimiento en aceite obtenidos con diferentes enzimas para el mismo tipo de semilla oleaginosa no sólo reflejan las diferencias en la eficiencia enzimática con respecto a la liberación de aceite sino también el efecto de otros parámetros sobre la eficiencia del proceso global. Esto significa que los principales parámetros que afectan el proceso de extracción acuosa coinciden con los que afectan el proceso enzimático. Algunos de ellos están relacionados con la extracción en si misma y otros relacionados con las condiciones óptimas para la actividad enzimática. Entonces, el punto principal en el desarrollo de un proceso consistente es considerar simultáneamente los parámetros que satisfacen ambos pasos, la reacción enzimática y la extracción, en lugar de llevarlo a cabo separadamente (Rosenthal y col., 1996). La extracción acuosa de aceites vegetales requiere el reemplazo total de procesos e instalaciones existentes y un ajuste del proceso para aumentar los rendimientos a valores comparables con los obtenidos hoy por la industria convencional de extracción por solvente. Finalmente, los procesos acuosos enzimáticos requieren de etapas de secado, tratamiento de un mayor volumen de efluentes líquidos y consideraciones de seguridad alimentaria debido al alto contenido de humedad durante el desarrollo de los procesos.

Para finalizar, el tratamiento enzimático puede realizarse, entonces, eliminando totalmente el uso de disolventes orgánicos, en presencia de hexano o añadiendo hexano para facilitar la recuperación del aceite. La incorporación durante el procesado convencional (prensado y/o disolvente) podría incrementar la productividad, reducir el tiempo de operación y/o reducir la cantidad de solvente empleado con mínimas alteraciones en el proceso en curso (Sineiro y col., 1998). 
Por ello, el empleo de enzimas como auxiliares tecnológicos en la extracción convencional de aceites vegetales podría representar una nueva perspectiva de desarrollo para las industrias del sector. La degradación enzimática como pretratamiento debería incorporarse a las líneas de proceso que se emplean en la industria con la menor alteración posible de los procesos existentes. Para ello deben estudiarse diversos aspectos del problema.

Primero es necesario definir, tanto las enzimas a emplear, como los parámetros de proceso de la incubación enzimática que maximizen el rendimiento en aceite.

Una vez optimizadas estas variables y determinadas las enzimas a emplear, se deben evaluar los rendimientos en aceite obtenidos a partir de laminado y expandido de soja (sólidos empleados como alimentación de los extractores industriales) hidrolizados. Esto permitirá determinar en qué etapa del procesamiento actual sería más conveniente emplear la incubación enzimática como pretratamiento adicional.

Para medir cuantitativamente la mejora esperada en el rendimiento de aceite extraído a partir de sólidos tratados enzimáticamente es necesario evaluar la influencia de este tratamiento sobre la velocidad de extracción, es decir, estudiar la transferencia de masa en presencia y ausencia de acción enzimática. 


\subsection{TRANSFERENCIA DE MASA EN LA EXTRACCIÓN}

La mayoría de los procesos de separación involucran la transferencia de material de una fase a otra. Algunos procesos incluyen la transferencia entre fluido y sólido, como por ejemplo el secado, la lixiviación y la cristalización.

La lixiviación es la disolución preferente de uno o más componentes de una mezcla sólida por contacto con un disolvente líquido. Esta operación unitaria, una de las más antiguas en la industria química, ha recibido muchos nombres, según la técnica más o menos compleja utilizada para llevarla a cabo. La colada se refería originalmente a la percolación del líquido a través de un lecho fijo del sólido, pero en la actualidad se utiliza para describir la operación en forma general, sin importar la forma en que se realice. Lixiviación se utiliza con menos frecuencia como sinónimo de colada, aunque al principio se refería específicamente a la colada de álcali a partir de cenizas de madera. El término extracción también se emplea por lo común para describir esta operación particular, aunque también se aplica a todas las operaciones de separación, que utilicen métodos de transferencia de masa o mecánicos. La decocción se refiere específicamente al uso del disolvente a su temperatura de ebullición. Cuando el material soluble está sobre la superficie de un sólido insoluble y simplemente se lava con el disolvente, la operación algunas veces recibe el nombre de elusión (Treybal, 1980).

Muchos compuestos orgánicos naturales se separan de sus estructuras originales mediante lixiviación. Por ejemplo, el azúcar se separa por lixiviación de la remolacha con agua caliente; los aceites vegetales se recuperan a partir de semillas, como las de soja y de algodón, mediante lixiviación con disolventes orgánicos; en forma similar muchos productos farmacéuticos se recuperan a partir de raíces y hojas de plantas (Treybal, 1980).

La extracción continua de aceite a partir de semillas fue practicada primero en Europa en el comienzo de 1920 y en Estados Unidos alrededor de 1936. Estos métodos pueden clasificarse como inmersión, donde las partículas son movidas a través del solvente por un transportador a tormillo o por percolación, donde el solvente drena por gravedad a través de lechos móviles de partículas. La superioridad de la percolación se estableció pronto cuando, a fines de la década del treinta, Central Soja, Archer Daniel Midland y Procter \& Gamble estudiaron en 
conjunto la práctica de extracción de semillas oleaginosas y eligieron para sus primeras plantas el extractor vertical de canasta Hansemuhle (Karnofsky, 2001).

Desde el punto de vista de la extracción, los aceites vegetales pueden ser referidos como un componente simple, debido a que todos los glicéridos son fuertemente solubles en hexano. Los otros componentes que son extraídos con alguna dificultad son los fosfátidos, ya que poseen solubilidad limitada (Karnofsky, 2001). Para extraer el aceite de las semillas, deben producirse cuatro pasos bien definidos (figura1.5):

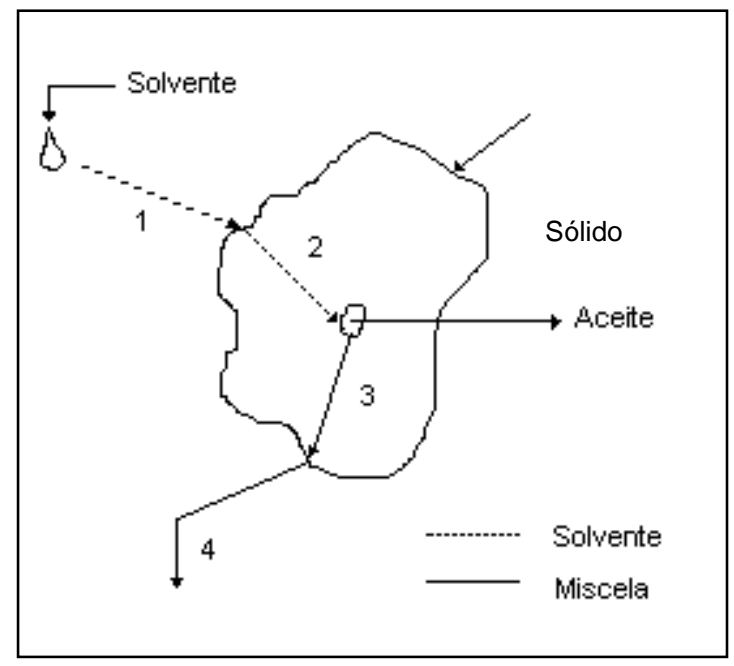

Figura 1.5: Mecanismo de extracción por solvente de aceite a partir de sólidos de soja

1) El solvente debe estar en contacto con la superficie del sólido;

2) El solvente debe difundir dentro del sólido y disolver el aceite;

3) La mezcla de aceite y solvente debe luego difundir nuevamente hacia la superficie y finalmente,

4) La mezcla debe drenar a través de la capa de sólidos.

El objetivo del proceso de extracción es el de reducir el contenido de aceite en el sólido al mínimo nivel posible con el mínimo uso de solvente. Existen dos fuentes para el "aceite residual" que queda en el sólido luego de completarse el proceso de extracción. La primera es el "aceite no extraído" o aquel aceite que no ha sido extraído al experimentar los pasos 1 y 2 y la segunda es el "aceite superficial" 0 aquel aceite que ha completado los pasos 1, 2 y 3, pero no el 4, debido a las características de escaso drenaje de la capa de sólidos en el extractor (ver Figura 
1.4). Para reducir al mínimo el "aceite no extraído", el sólido debe prepararse para romper todas las células oleíferas y proporcionar la mayor área de contacto entre el solvente y el aceite; mientras que para reducir al mínimo el "aceite superficial" el sólido debe prepararse para proporcionar una capa que permita drenaje eficiente. Preparar el sólido para minimizar el "aceite no extraído" dará lugar a un alto porcentaje de "aceite superficial" y viceversa. Para proporcionar la máxima ruptura de células y área de contacto entre el solvente y el aceite sería aconsejable moler el sólido al menor tamaño posible, pero esto resultaría en una capa compacta que no permitiría un buen drenaje. De manera similar, para dar máximo drenaje y, en consecuencia, mínimo "aceite superficial", un sólido grueso sería mejor, pero esto reduciría la ruptura de células y el área de contacto del solvente y el aceite. Las plantas de extracción están diseñadas para calcular el equilibrio adecuado entre el tamaño de partícula deseado del sólido para una más rápida extracción y el requerido para un buen drenaje (Milligan, 1976 y Kulkarni y col., 1955).

\subsubsection{Transporte difusivo}

El éxito de un proceso industrial de extracción es una función de qué tan rápido se disuelve el compuesto a extraer y del equilibrio que se alcanza en la fase del disolvente. Como se dijo anteriormente, diferentes fenómenos están involucrados en el paso del soluto desde el sólido hasta el seno del solvente: el aceite difunde a través de los poros internos hasta la superficie del sólido (transporte de masa interno) y luego pasa al seno del líquido por un mecanismo convectivo producido por la diferencia de concentración entre la solución ocluida en los poros y el seno de la solución (transporte externo). Por lo tanto, deben evaluarse el transporte convectivo de aceite en la fase líquida y el transporte difusivo producido dentro del sólido a fin de caracterizar la transferencia de materia.

La aproximación fickiana tradicional utiliza el gradiente de concentración entre las partículas de material crudo y el seno de la solución como la fuerza impulsora de la extracción, en lugar de la diferencia de potencial químico empleada en otros desarrollos (Doulia y col., 2000). La tendencia de un componente dado a cambiar de fase es medida por su potencial químico, de tal forma que un análisis más riguroso 
podría hacerse en base a la diferencia de potencial químico. Sin embargo, el desarrollo fickiano puede emplearse (asumiendo que no hay cambios en las difusividades efectivas con la concentración de soluto y que la resistencia externa a la transferencia de masa es despreciable) usando un coeficiente de partición o distribución entre 2 fases y trabajando con extractos diluidos. Así, la velocidad de extracción se incrementa con el incremento del gradiente de concentración. También puede aumentarse incrementando el coeficiente de difusión o reduciendo el tamaño de partícula (Cacace y Mazza, 2003).

El coeficiente de difusión es frecuentemente referido como coeficiente de difusión efectiva $D_{\text {ef }}$ (también conocido como coeficiente de difusión aparente $D_{a}$ ó $D_{a p}$ )

$$
D_{e f}=\frac{D . \varepsilon}{\tau}
$$

ecuación 1.1

Donde $\mathrm{D}$ es el coeficiente de difusión molecular, $\varepsilon$ es la porosidad del sólido y $\tau$ es la tortuosidad del material y Def describe la transferencia difusional neta de masa a través de sistemas complejos estructural y químicamente.

$$
\frac{\partial c}{\partial t}=D_{e f} \frac{\partial^{2} c}{\partial x^{2}}
$$

ecuación 1.2

$$
\frac{\partial c}{\partial t}=D_{e f}\left(\frac{\partial^{2} c}{\partial x^{2}}+\frac{\partial^{2} c}{\partial y^{2}}+\frac{\partial^{2} c}{\partial z^{2}}\right)
$$

ecuación 1.3

donde t es el tiempo y x, y, z son las coordenadas espaciales (ecuación 1.3). La forma generalizada de la ecuación de Fick describe el estado trasciende de la difusión de un componente con concentración c en un sistema binario y puede expresarse como la ecuación 1.3. Esta ecuación es aplicable a un medio anisotrópico cuya estructura y propiedades difusionales en la vecindad de cualquier punto son las mismas en todas direcciones. La forma de la Segunda Ley de Fick, que refiere a difusión unidireccional a través de barreras de formas geométricas (ecuación 1.4) puede aplicarse a la difusión de solutos en alimentos sólidos. 
$\frac{\partial c}{\partial t}=\frac{1}{x^{v-1}} \cdot \frac{\partial}{\partial x}\left(x^{\nu-1} D_{e f} \frac{\partial c}{\partial x}\right)$

ecuación 1.4

donde $v=1$ para una lámina, $v=2$ para un cilindro y $v=3$ para una esfera.

Se pueden obtener soluciones generales a la Segunda Ley de Fick para una amplia variedad de condiciones iniciales y límites. Las soluciones analíticas son presentadas como series de la función error o como series de la función de Bessel, según la forma geométrica considerada (Crank, 1959).

\subsubsection{Determinación de coeficientes de difusión}

La estimación de los coeficientes de difusión o difusividades es importante para determinar la velocidad de transferencia de masa. En los materiales celulares, las macromoléculas pueden estar enlazadas químicamente a la matriz sólida, pero la velocidad de estas reacciones pueden ser limitadas por la difusión. Para entender estos procesos se requiere conocimiento sobre la naturaleza y propiedades de los efectos gobernados por la difusión. Se han llevado a cabo muchos estudios experimentales y teóricos sobre la difusión de solutos a través de materiales celulares y biológicos.

La difusión es un proceso físico mediante el cual cierta masa es transferida bajo la influencia de gradientes de concentración. En la industria de alimentos, existen numerosos ejemplos de procesos que dependen de la difusión: extracción de azúcar, jugo de manzana y café por lixiviación; blanqueado de vegetales donde la difusión desde y adentro del alimento es muy importante; conservación por salado y encurtido; operaciones de deshidratación; fritado, donde se toma aceite y se pierde agua simultáneamente; acidificación donde el ácido difunde desde la solución hacia adentro del alimento (Schwartzberg y Chao, 1982).

En las operaciones de lixiviación el sólido a extraer está contenido dentro de una red de sólidos insolubles, conocida como orujo, con solución ocluída y, en algunos casos, sólidos solubles o precursores de solutos. La difusión ocurre primariamente entre la solución ocluída pero el orujo resiste los procesos difusivos y afecta fuertemente la velocidad de difusión. La lixiviación de sólidos secos sólo comienza cuando el sólido está embebido del solvente que disuelve los solutos internos. 
La difusividad molecular a una temperatura constante para concentraciones muy diluidas puede ser predecida adecuadamente usando la bien conocida ecuación de Stoke-Einstein, conociendo el radio molecular del soluto, la viscosidad del solvente y la temperatura absoluta (Cussler, 1984):

$$
D=\frac{k_{B} T}{6 \pi \mu R_{O}}
$$

ecuación 1.5

donde $k_{B}$ es la constante de Bolzman (en g. $\mathrm{m}^{2} \mathrm{~s}^{-2} \mathrm{~K}^{-1}$ ), T es la temperatura absoluta (en K), $\mu$ es la viscosidad de la fase (en $\mathrm{gm}^{-1} \mathrm{~s}^{-1}$ ), y Ro es el radio de la molécula que difunde (en m). Esta ecuación no tiene en cuenta la interacción molecular entre moléculas de soluto y solvente y entre las moléculas de solvente, lo que puede ser significativo en moléculas pequeñas. En consecuencia, la ecuación tiene un uso limitado para predecir las difusividades efectivas en alimentos. Sin embargo, algunos autores predijeron coeficientes de difusión efectiva para proteínas en agua usando un método numérico general, otros predijeron coeficientes de difusión para proteínas por adaptación de la ecuación de Stokes-Eistein a un modelo para una esfera hidrodinámica usando el radio de giro, lo cual fue asumido al tamaño de las moléculas de proteína en solución (Varzakas y col, 2005). Se han desarrollado varias ecuaciones alternativas que incorporan factores para interacciones moleculares e interferencias físicas (Schwartzberg y Chao, 1982). Sin embargo, debido a la dificultad de cuantificar cada factor en sistemas heterogéneos de alimentos y la inherente variabilidad en la composición y estructura de los alimentos, estas ecuaciones poseen pobre confianza de predicción.

Por ello, la difusividad efectiva debe ser determinada experimentalmente usando las ecuaciones fundamentales de difusión para geometrías y condiciones límites apropiadas. La caracterización del proceso de difusión se logra desarrollando perfiles de concentración versus tiempo y cuantificando los coeficientes de difusión, lo cual provee un camino útil para comparar el efecto de las variables importantes del proceso (Varzakas y col., 2005).

El coeficiente de difusión es definido como la razón de la densidad de flujo al gradiente de concentración en la dirección de la difusión (Sherwood y col, 1979), y 
este valor depende del medio específico en el cual tiene lugar el proceso particular. En gases, la velocidad de difusión es del orden de $10^{-5} \mathrm{~m}^{2} \mathrm{~s}^{-1}$, en líquidos es del orden de $10^{-8} \mathrm{~m}^{2} \mathrm{~s}^{-1} \mathrm{y}$ en sólidos del orden de $10^{-11} \mathrm{~m}^{2} \mathrm{~s}^{-1}$ (Cussler, 1984). Un valor típico de difusividades en alimentos que poseen estructura "dura", como nueces, cereales, etc., bajo condiciones de temperatura ambiente y tejidos no tratados, es del orden de magnitud de $10^{-11} \mathrm{~m}^{2} \mathrm{~s}^{-1}$ o menos (Doulia y col., 2000).

En muchos casos, la difusión ocurre como parte integrante de otro fenómeno y como se trata de un proceso lento, frecuentemente representa una limitación a la velocidad global del proceso entero. La difusión a través de una matriz sólida es más complicada que la difusión a través de gases y líquidos. Puede ser que la difusión a través de la matriz sólida no ocurra y lo que tiene lugar es difusión en el líquido contenido en la matriz o difusión a través de la fase gaseosa en los poros del sólido (Varzakas y col., 2005).

Se han usado una gran variedad de métodos para determinar coeficientes de difusión, sin embargo, existe una gran dificultad para comparar los resultados así como para sistematizar la información disponible (Doulia y col., 2000).

\subsubsection{Modelado de la extracción por solvente}

En la extracción por solvente se ponen en contacto semillas oleaginosas pretratadas (matriz sólida porosa) con solvente puro o una mezcla de solvente (miscela) para transferir el aceite desde la matriz sólida hacia el medio fluido. Si bien el principio de la extracción es relativamente simple, se trata de un mecanismo complejo, especialmente para materiales oleaginosos debido a la estructura celular de los cuerpos lipídicos vegetales (ver sección 1.2.1). Por ello, es dificultoso explicar todos los fenómenos que tienen lugar, durante la extracción por solvente, a través de una sola teoría (Carrín y Crapiste, 2008).

Diferentes autores han considerado el modelado matemático de la extracción de aceite vegetal. Los primeros trabajos en esta área presentaron un punto de vista físico de la extracción de aceite a partir de materiales crudos, los cuales están 
compuestos de sólidos laminados. Esta fase sólida es tratada como un componente inerte. El aceite dentro de las láminas fue dividido es dos áreas: de extracción lenta, desde donde el aceite sale difícilmente y de extracción rápida, donde el solvente reemplaza al aceite. Los datos experimentales son presentados para distintos materiales oleaginosos y para láminas de diferente espesor (Thomas y col., 2005). Karnofski (1986) propuso un modelo semiempírico para la extracción de aceite en extractores industriales que está basado en las siguientes consideraciones: el tiempo de retención del aceite es determinado por la velocidad de la solución y la resistencia a la difusión del aceite a través de los bordes de las láminas es relativamente pequeña. El modelo emplea resultados experimentales, los cuales son extendidos para la predicción de las pérdidas de aceite en extractores industriales. Abraham y col. (1988) desarrollaron un modelo para la extracción de aceites vegetales teniendo en cuenta que se trata de una operación que es parte de un proceso más complejo (desolventizador, separación de miscela, separación por membrana, etc). El mismo permite calcular, a partir de un set de ecuaciones algebraicas de equilibrio y de balance de masa, las velocidades de flujo y las concentraciones de sólido, solvente y aceite de todas las corrientes de entrada y salida de cada una de las operaciones que forman parte del proceso completo. La extracción fue modelada como una operación multietapa. Los experimentos se llevaron a cabo con láminas de semillas de algodón que se extrajeron en ensayos con hexano y con etanol en columna de lecho fijo. También determinaron experimentalmente las relaciones de equilibrio para ambos solventes y curvas de velocidad de drenaje. El modelo permitió obtener parámetros que podrían emplearse para escalar datos de planta piloto a escala de extractores industriales y analizar alternativas de procesamiento, incluyendo el punto de vista económico.

Majumdar y col. (1995) desarrollaron un esquema adimensional basado en un modelo no estacionario unidimensional para el proceso de extracción de aceite en una columna empacada. Emplearon salvado de arroz para extraer aceite vegetal con hexano a $30{ }^{\circ} \mathrm{C}$ en un extractor de lecho fijo. La relación de equilibrio entre el contenido de aceite residual en el sólido y la concentración de aceite de la miscela estancada en los poros del material sólido fue determinada experimentalmente. En el desarrollo del modelo propuesto asumieron que las estructuras celulares del salvado de arroz estaban completamente rotas por lo que no consideraron el fenómeno de difusión en el sólido. En contraparte, la formulación matemática incluyó 
la difusión en el líquido entre la miscela estancada en los poros y la miscela del seno de la solución y el transporte convectivo a lo largo de la longitud de la columna de extracción. Los parámetros adimensionales que describieron el modelo fueron los números iniciales de Reynolds y de Schmidt, la fracción vacía del lecho, la porosidad de las partículas, la relación diámetro de partícula/diámetro de la columna, relación longitud/diámetro de la columna, relación área superficial de las partículas/sección transversal de la columna y coeficientes de reciclo de solvente y coeficiente de distribución. Los autores concluyeron que, para lograr un determinado contenido de aceite residual en el sólido, altos números iniciales de Reynolds y bajos números iniciales de Schmidt se asociaron a menores tiempos de extracción; el resto de los parámetros ejercieron baja o despreciable influencia. Altas porosidades de lecho, mayores áreas superficiales de las partículas, bajas porosidades de partícula y pequeñas relaciones diámetro de partícula/diámetro de la columna, longitud/diámetro de la columna y bajos coeficientes de distribución de equilibrio fueron también asociados a menores tiempos de extracción.

Un análisis similar lo realizaron Pramparo y colaboradores (2002) para determinar la influencia del modo de contacto, percolación o inmersión, pero incluyeron la resistencia a la transferencia de masa dentro de la partícula. El lecho fijo de la columna de extracción estaba constituído por láminas de soja provistas por una industria local y el aceite fue extraído con hexano grado técnico con contacto por inmersión y por percolación. Las extracciones fueron llevadas a cabo a temperatura constante y para simular extractores de lecho profundo y poco profundo, emplearon diferentes relaciones longitud/diámetro de la columna. Los resultados experimentales fueron explicados en términos del fenómeno básico de transferencia de materia que ocurre durante la extracción. Se asumió que el lecho de extracción estaba constituido por partículas sólidas, esféricas, isotrópicas y porosas, con una porosidad de partícula y una porosidad del lecho. El modelo unidimensional y en estado no estacionario fue desarrollado a partir del balance de materia para el aceite en la fase ocluida y en el seno de la solución para contacto por inmersión y por percolación. Se consideró la resistencia a la transferencia de masa dentro de las partículas de sólido. Los coeficientes de difusión empleados en los cálculos de concentración de aceite en la miscela de salida del extractor fueron estimados por correlaciones empíricas y resultaron en el rango de $10^{-10} \mathrm{~m}^{2} \mathrm{~s}^{-1}$. A partir de los resultados experimentales y los simulados, los autores concluyeron que el modo de 
contacto por inmersión produce miscelas de concentraciones más altas a lo largo de todo el período de la extracción. Por otro lado, demostraron que el modo de contacto por inmersión es mejor que la percolación para el caso de lechos profundos, mientras que no se encontraron diferencias significativas para el caso de lechos poco profundos.

Veloso y col. (2005) desarrollaron un modelo para la extracción de aceite vegetal en un extractor industrial "De Smet" para predecir la distribución de concentraciones en las distintas secciones de percolación y de salida del sistema. También consideraron las pérdidas de aceite. El modelo incorporó flujo a contracorriente entre el sólido poroso y la miscela, la transferencia de masa entre las láminas expandidas y la miscela, la difusión en el lecho entero de extracción, el transporte de la miscela entre las distintas secciones de percolación, la influencia de las zonas de carga y drenaje y régimen no estacionario en el extractor. El modelo se integró con submodelos para las secciones de percolación, las bandejas colectoras, las zonas de carga y de drenaje. Los autores asumieron, acorde a Majumdar y col. (1995), que las células estaban destruidas y que las láminas expandidas tenían dos tipos de porosidad, del lecho y de la partícula. El submodelo para el lecho lo desarrollaron a partir de ecuaciones para extracción no estacionaria en dos dimensiones tomando en cuenta el desplazamiento del sólido y emplearon una relación de equilibrio entre las fases sólida y líquida en forma volumétrica, determinada experimentalmente. El submodelo para la zona de drenaje consideró que sólo drena la fase líquida del seno de la miscela, se consideró aceite perdido al contenido en la fase sólida y en el líquido en los poros; en esta zona se asumió que no hay transferencia de aceite entre la fase de los poros y el seno de la miscela. Para el submodelo de la zona de descarga se asumió que la concentración es uniforme pero que depende del tiempo para régimen no estacionario y se obtuvo del balance de masa para el aceite aplicado al volumen de descarga. Para el submodelo de la zona de carga se tuvieron en cuenta hipótesis simplificadas debido a que el proceso que se lleva a cabo en esta zona es muy complejo. Los autores propusieron considerar que no tiene lugar transferencia debido a que el equilibrio entre la concentración de aceite en los poros y en el seno de la miscela se alcanza rápidamente y los poros del sólido se llenan completamente. Los submodelos fueron acoplados aplicando condiciones de contorno y reflejando las particularidades del flujo en contracorriente. El algoritmo de cálculo se basó en el método de líneas. También se presentó la verificación del 
modelo incluyendo una comparación de datos experimentales con simulaciones numéricas en estado no estacionario. Los autores concluyeron que el modelo predice la distribución espacial de los principales parámetros del lecho del extractor así como las pérdidas de aceite. Además, fue sensible a la alteración de la porosidad, de las principales dimensiones del extractor y de los parámetros operacionales del régimen. El modelo podría utilizarse para el diseño y manejo de extractores que funcionen con distintos tipos de solventes y láminas; sin embargo, se requieren algunos datos que se obtienen en condiciones de laboratorio.

Carrín y Crapiste (2008) también desarrollaron un modelo para la extracción de aceite en un extractor industrial tipo De Smet, basándose en el propuesto por Veloso y col. (2005), pero con algunas modificaciones. Los autores representaron el proceso de extracción por un modelo bidimensional en estado no estacionario, introduciendo el concepto de dos categorías de aceite propuesto anteriormente por Fan y col. (1948): aceite libre que es fácilmente extraído desde las partículas sólidas y aceite enlazado, difícilmente extraído. El aceite es extraído a partir del sólido poroso por difusión paralela de ambas categorías de aceite. Se planteó un balance de materia para las partículas de sólido poroso en estado estacionario con transporte de masa convectivo desde la superficie de la matriz sólida hasta el seno de la solución y balances de materia para la fase líquida del seno de la solución, la fase sólida en movimiento, la fase de la miscela ocluída en los poros y la zona de descarga (bandejas colectoras) considerando a contracorriente los flujos de solvente y de sólido. A diferencia de otros autores, el modelo tuvo en cuenta la resistencia a la transferencia de masa en el interior del sólido. Los coeficientes de difusión del sólido fueron determinados experimentalmente en ensayos batch y resultaron en el orden de magnitud de $10^{-10} \mathrm{~m}^{2} . \mathrm{s}^{-1}$. Se realizaron extracciones con hexano a partir de pellets de girasol. Las concentraciones experimentales de aceite en la miscela para cada etapa del extractor se recogieron de datos industriales. El modelo fue resuelto numéricamente para predecir las concentraciones de aceite en la miscela y en el sólido en cada una de las etapas de percolación y a la salida del extractor. El uso del modelo podría extenderse, con pequeñas modificaciones al estudio de la extracción diferencial de otros componentes minoritarios de interés, tales como ceras y fosfolípidos. La analogía introducida, tratar al período de lavado como un proceso difusivo, podría usarse para simular separaciones no ideales y obtener el contenido de soluto crítico que es responsable de ese comportamiento no ideal. Los autores 
concluyeron que la categoría de aceite enlazado o difícilmente extraíble controló el proceso al final de la extracción y predijeron que una modificación en el pretratamiento del material sólido podría alterar la proporción relativa entre ambas categorías de aceite.

Por último, es posible trasladar modelos simplificados desarrollados por otros autores (Espinoza-Pérez y col., 2007) para el caso de lixiviación de granos de café, los cuales se basaron en soluciones analíticas de ecuaciones de transferencia de masa macroscópica, tanto para el sólido como para el solvente empleado en el proceso de descafeinización modelado. Los autores obtuvieron coeficientes de difusión experimentales en el orden de magnitud de $10^{-10} \mathrm{~m}^{2} . \mathrm{s}^{-1}$ para los granos de café y a partir de estos datos experimentales y el modelo propuesto ajustaron coeficientes de transferencia de masa interna. Al mismo tiempo desarrollaron en forma paralela un modelo más riguroso basado en una ecuación de difusión en estado no estacionario para el sólido acoplada a una ecuación de transferencia de masa macroscópica en el líquido. Concluyeron que el modelo simplificado describió adecuadamente la cinética experimental del soluto cafeína en ambas fases.

\subsubsection{Transferencia de masa interfacial}

Cuando un material es transferido desde una fase a otra, la resistencia a la transferencia de masa en cada fase origina un gradiente de concentración entre ellas.

Las concentraciones del material que difunde en las dos fases inmediatamente adyacentes a la interfase generalmente son desiguales, aunque expresadas en las mismas unidades. Usualmente, se asume que están relacionadas entre si por las leyes del equilibrio termodinámico. Entonces, se supone que se logra un equilibrio termodinámico en la interfase inmediatamente después que las fases sólida y líquida son puestas en contacto.

Para sistemas en los que las concentraciones de soluto en las fases sólida y líquida son diluídas, la velocidad de transferencia puede expresarse por medio de ecuaciones que predicen que la velocidad de transferencia de masa es proporcional 
a la diferencia entre la concentración del bulk y la concentración de la interfase líquído-sólido (Geankoplis, 1998) . Por lo tanto:

$$
N_{A}=k_{S}\left(c_{S}-c_{S i}\right)=k_{L}\left(c_{L i}-c_{L}\right) \quad \text { ecuación } 1.6
$$

Donde $\mathrm{N}_{\mathrm{A}}=$ velocidad de transferencia de masa, $\mathrm{k}_{\mathrm{S}}=$ coeficiente de transferencia de masa en la fase sólida, $\mathrm{k}_{\mathrm{L}}=$ coeficiente de transferencia de masa en la fase líquida, $\mathrm{C}_{\mathrm{S}}=$ concentración de soluto en el sólido, $\mathrm{C}_{\mathrm{Si}}=$ concentración de soluto en la fase sólida de la interfase, $C_{L}=$ concentración de soluto en el bulk de la fase líquida y $C_{L i}=$ concentración de soluto en el líquido de la interfase. Esta expresión puede escribirse alternativamente en función de las fracciones molares de soluto en las fases sólida y líquida y en la interfase.

La ecuación 1.6 puede emplearse para encontrar las concentraciones interfaciales correspondientes a cualquier conjunto de valores de concentraciones en ambas fases, conociendo los coeficientes de transferencia de masa.

El coeficiente de transferencia de masa en el sólido puede calcularse a partir de los coeficientes de difusión efectiva, mientras que el coeficiente de transferencia de masa en el líquido pueden estimarse a partir de correlaciones empíricas.

\subsubsection{Correlaciones para transferencia de masa}

Debido a la gran importancia de la transferencia de masa en ingeniería química, se han determinado, a través de numerosos estudios, coeficientes de transferencia de masa tanto teórica como empíricamente. Para geometrías simples, pueden determinarse formas teóricas para las correlaciones de transferencia de masa. Para formas complejas, sólo pueden encontrarse formas empíricas. En sistemas de complejidad media, se pueden determinar correlaciones semiempíricas a partir de teorías y coeficientes determinados experimentalmente.

Para elegir la correlación más adecuada, algunos aspectos a tener en cuenta son: 1 - Los coeficientes de transferencia de masa son obtenidos a partir de modelos. Se debe emplear, por lo tanto, un modelo similar. 
2 - Las correlaciones semiempíricas son mejores que las puramente teóricas o puramente empíricas. Las correlaciones empíricas son peligrosas en las extrapolaciones. Las puramente teóricas predicen tendencias con buena precisión pero pueden dar coeficientes de transferencia de masa de ordenes de magnitud distintos.

3 - Las correlaciones con bases de datos amplias son preferibles.

4 - La analogía entre transferencias de masa y calor poseen rangos más amplios que la analogía entre transferencia de masa y de momento. Los datos de transferencia de masa (en ausencia de radiación) pueden utilizarse para predecir coeficientes de transferencia de masa.

5 - Se prefieren siempre datos nuevos contra datos más antiguos, ya que los nuevos se construyen sobre los antiguos, los efectos finales son mejor comprendidos y se disponen de mejores técnicas de medición.

6 - Con geometrías complejas, como en los lechos rellenos, se necesita conocer el producto del área interfacial por el volumen y el coeficiente de transferencia de masa (Baehr y Stephan, 2006).

\subsubsection{Determinación del equilibrio}

La extracción es considerada como un proceso de transferencia de masa entre las siguientes fases: una fase sólida (matriz sólida insoluble), una fase líquida ocluida 0 estancada (la miscela ocluida en el interior de los poros dentro de la partícula) y una fase fluida en el seno del líquido (la miscela que se mueve a través de los espacios entre partículas) (Cacace y Mazza, 2003). Entre las partículas, el aceite difunde a través de la fase ocluida hacia el seno de la fase líquida. En cualquier punto, la concentración de la fase estancada es considerada en equilibrio con aceite en la matriz sólida, según una relación que se determina experimentalmente:

$$
\mathrm{C}_{\mathrm{S}}=\mathrm{K} \cdot \mathrm{C}_{\mathrm{L}} \quad \text { ecuación } 1.7
$$

donde: $c_{S}=$ concentración de aceite en la fase sólida a la posición radial $r=R$, $\mathrm{K}=$ constante de equilibrio de partición, 
$C_{L}=$ concentración de aceite en la fase ocluida a la misma posición radial $R$, es decir, en la interfase (Majumdar y col. ,1995; Pramparo y col., 2002; Thomas y col, 2005; Espinoza-Pérez, 2007; Carrín y Crapiste, 2008).

El equilibrio se alcanza, entonces, entre el solvente en los poros de las partículas y el aceite contenido en el sólido.

\subsubsection{Balance macroscópico para transferencia de masa}

Para obtener un modelo matemático que describa el proceso de extracción de aceite a partir de semillas de soja, pretratadas enzimáticamente o no, deben analizarse los fenómenos de transferencia de masa que implica dicho proceso en sí y las posibles resistencias a la transferencia de masa en la fase sólida, el sólido de soja y en la fase líquida, el hexano.

Para el transporte del soluto aceite hasta el seno del fluido hexano desde el interior de las partículas de los sólidos de soja, aparecen las siguientes etapas de transferencia de masa:

- Transferencia de masa entre partículas, se refiere a la difusión y mezcla del soluto en el fluido que ocupa los espacios entre las partículas. Suele resultar significativa en los casos en los que el fluido se pone en contacto con el sólido existiendo movimiento relativo entre ambos, como es el caso de operaciones en lechos fijos y lechos fluidizados.

- Transferencia de masa en la interfase, suele ser tratada como la transferencia en la película del fluído que rodea a las partículas sólidas.

- Transferencia de masa en la partícula, que consiste en la difusión del soluto en el sólido, en principio en los poros y puede incluso existir en la superficie del mismo (Rivero Martinez, 2002).

En la extracción sólido-líquido en lecho fijo la difusión y la mezcla del soluto en el fluido ocurre como resultado de los gradientes de concentración y de la falta de uniformidad en el flujo del fluido. Estos efectos provocan la dispersión del soluto, que 
puede tener lugar a lo largo de la dirección del flujo, llamada dispersión axial, y en la dirección perpendicular al mismo, llamada dispersión radial. Generalmente en un lecho fijo, la dispersión radial se ignora, ya que el diámetro del lecho es lo suficientemente mayor al diámetro de partícula (varios órdenes de magnitud).

Para describir completamente el fenómeno de extracción debe plantearse un modelo que describa tanto el fenómeno difusivo y como el convectivo ya que ambos determinan la transferencia de masa. Conociendo el mecanismo de esta transferencia es posible determinar las velocidades de extracción (Espinoza-Pérez y col., 2007) y establecer si el proceso es dominado por la resistencia a la transferencia de masa en la fase líquida o la resistencia a la transferencia de masa en el material sólido. 
Capítulo 2

Materiales y Metologías Generales 


\section{Materiales y Metodologías Generales}

\subsection{MATERIALES}

2.1.1 Laminado de soja: se utilizaron muestras de láminas de soja obtenidas de la planta industrial de Aceitera Bunge Argentina S.A., localizada en la ciudad de Tancacha en la Provincia de Córdoba. Este material se obtiene como resultado de la aplicación de los pretratamientos de molienda, acondicionamiento y laminado, cuyas operaciones se describen en la sección 1.3.4.

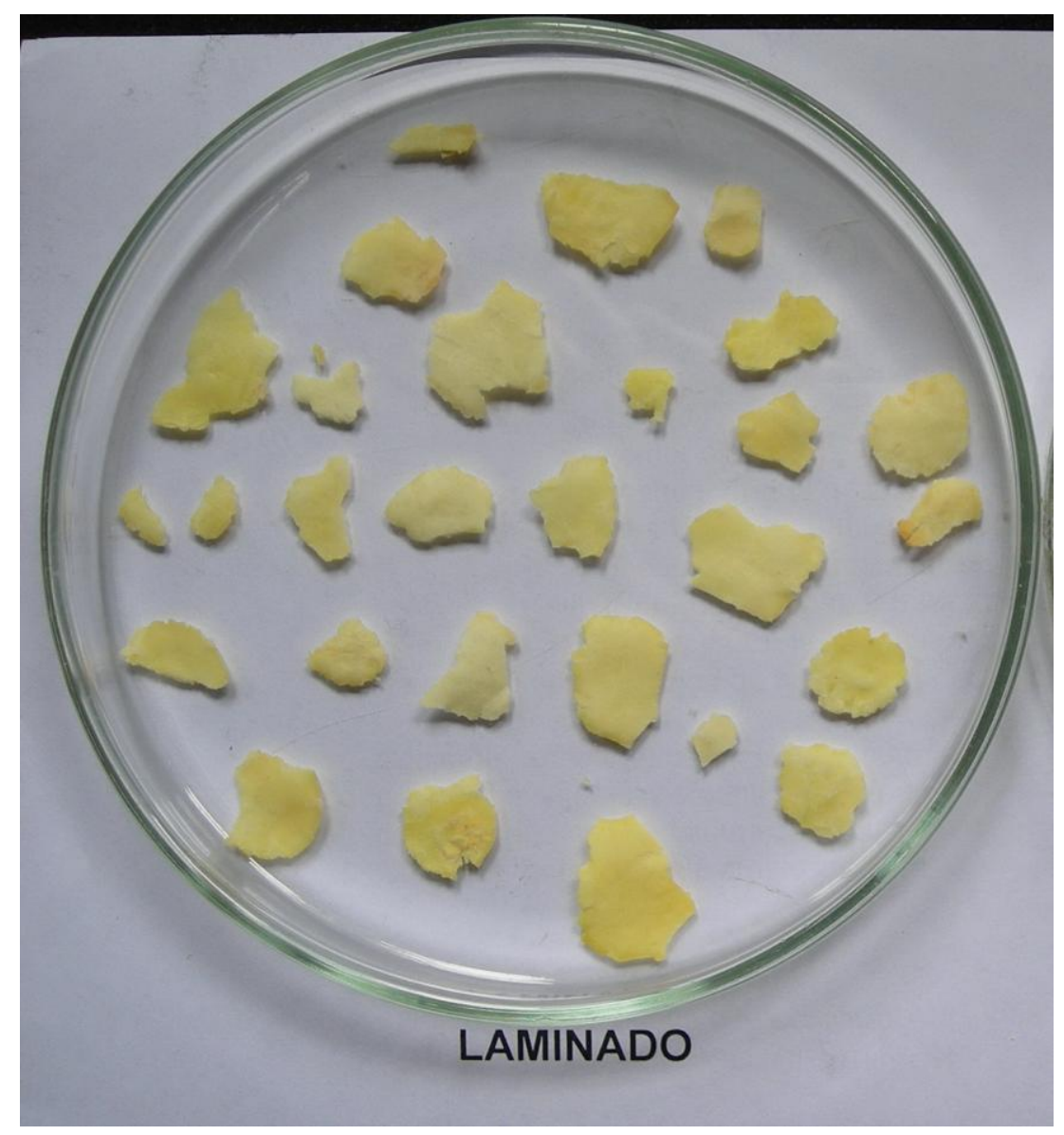

Figura 2.1: Laminado de soja. 
2.1.2 Expandido de soja: se utilizaron muestras de expandido de soja obtenidas de la planta industrial de Aceitera Bunge Argentina S.A., localizada en la ciudad de Tancacha en la Provincia de Córdoba. Este material se obtiene como resultado de la aplicación de los pretratamientos de molienda, acondicionamiento, laminado y expandido, cuyas operaciones se describen en la sección 1.3.4.

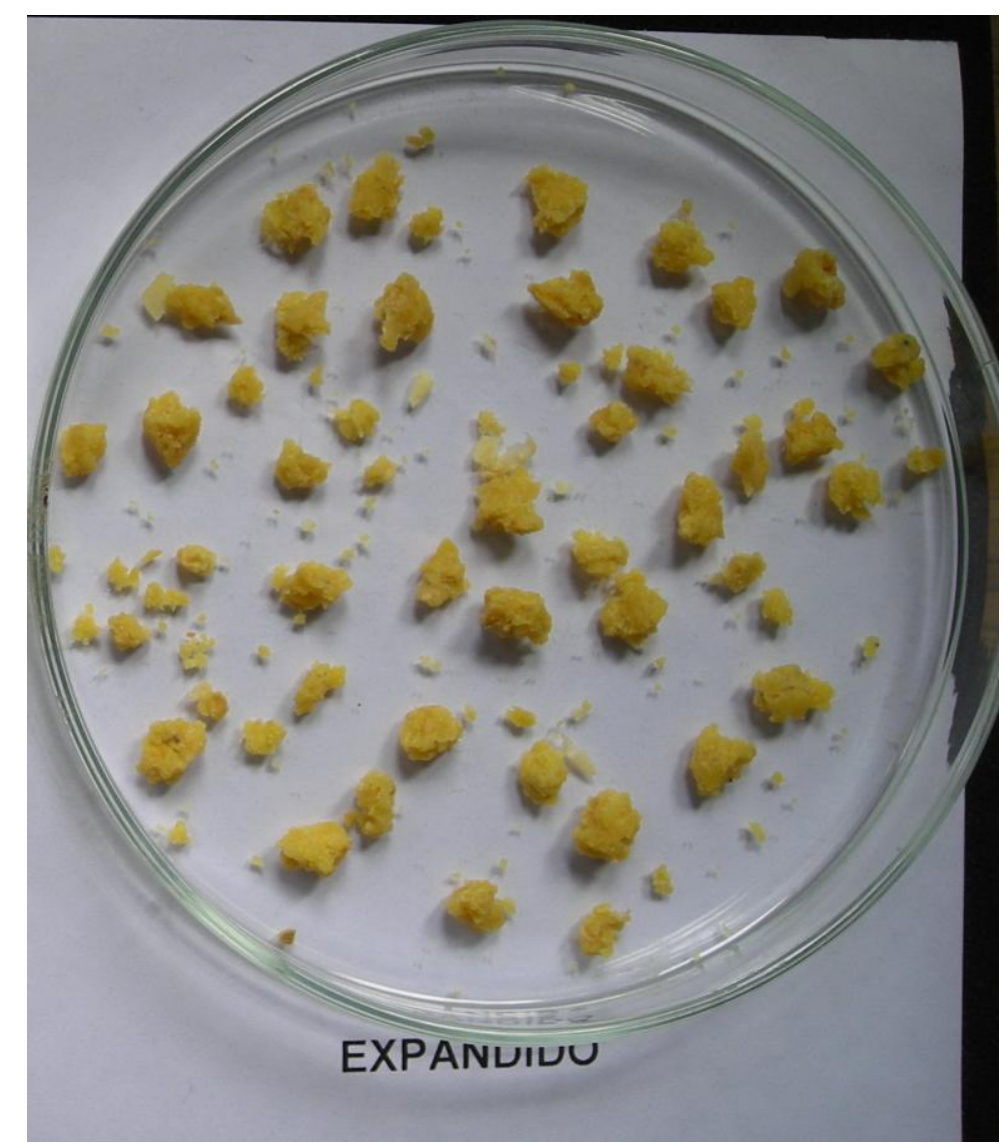

Figura 2.2: Expandido de soja.

2.1.3 Enzimas: todas las enzimas utilizadas son de grado industrial y fueron provistas por GENENCOR INTERNATIONAL.

- Actividad $\alpha$-amilasa: la marca comercial de la enzima es SPEZYME FRED. Se trata de una $\alpha$-amilasa que hidroliza al almidón con alta estabilidad a altas temperaturas y a bajos $\mathrm{pH}$, derivada de Bacillus licheniformis modificado genéticamente. Es una endo-amilasa que hidroliza aleatoriamente enlaces $\alpha$-glucosídicos para reducir la viscosidad de almidón produciendo dextrinas y oligosacáridos (Hoja Técnica Spezyme Fred, Genencor, 2001). 


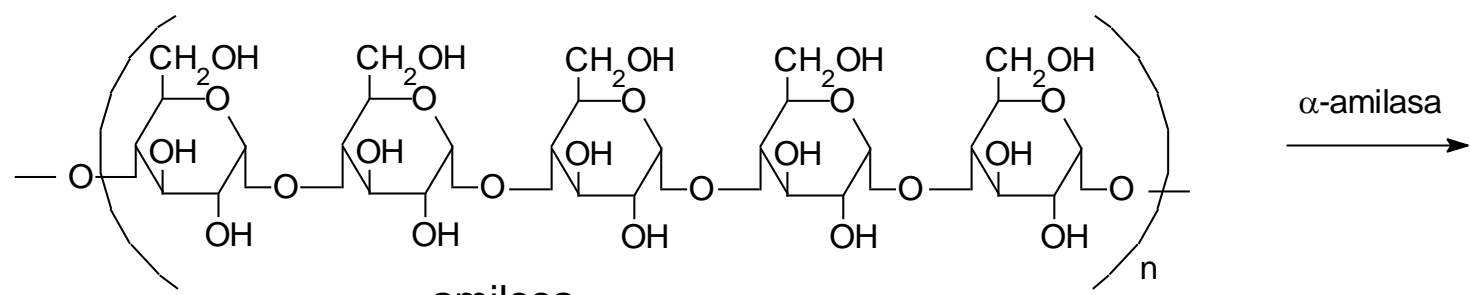

amilosa

(a)

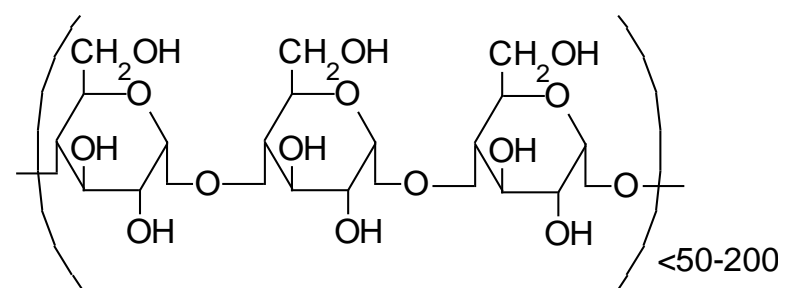

dextrinas y oligosacáridos

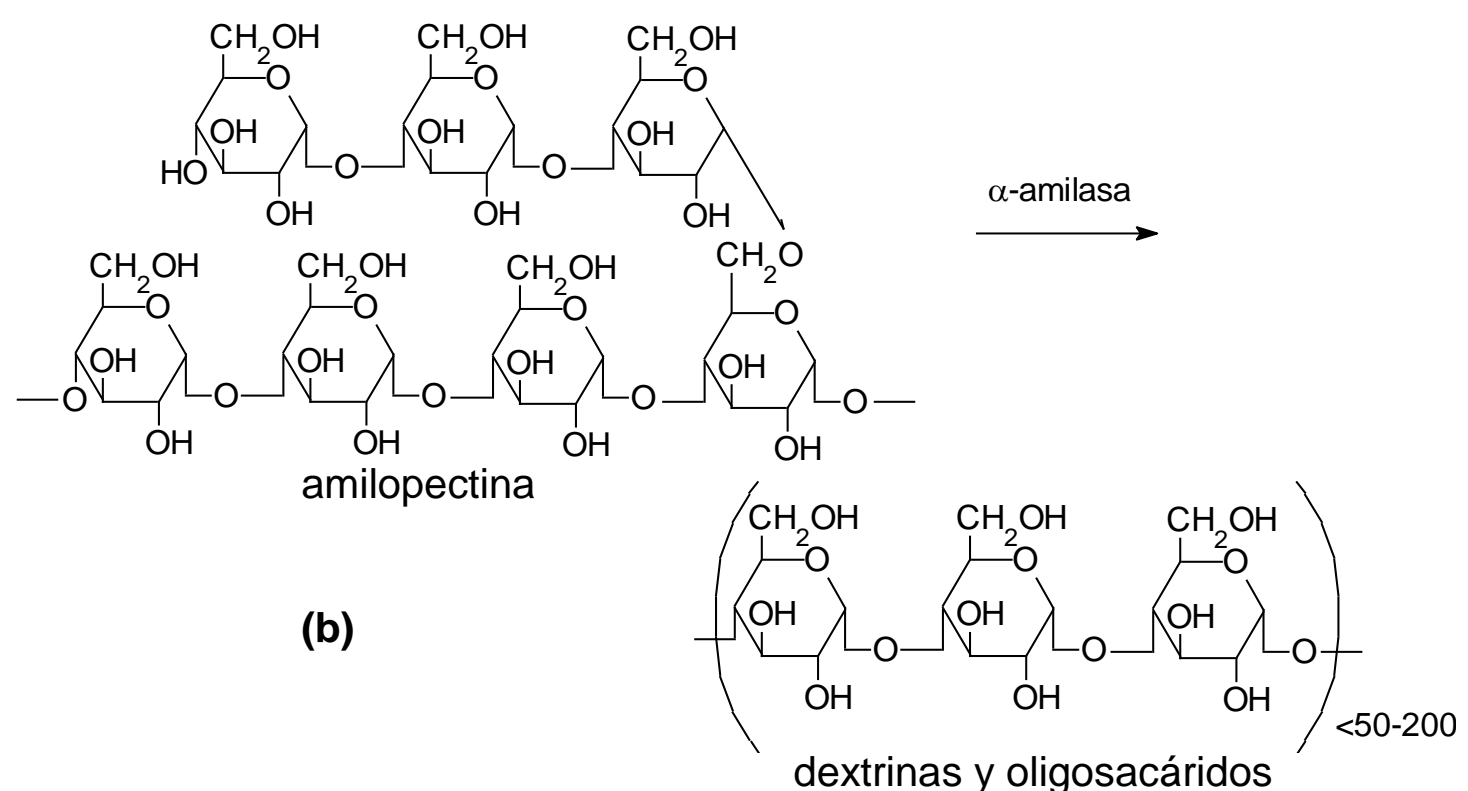

Figura 2.3: a) Acción de la $\alpha$-amilasa sobre la porción de amilosa.

b) Acción de la $\alpha$-amilasa sobre la porción de amilopectina.

- Actividad glucoamilasa: la marca comercial de la enzima es OPTIDEX L-400. Se trata de una enzima empleada en la producción de glucosa a partir de almidón licuado. Es una 1,4- $\alpha$-glucanoglucohidrolasa fúngica comúnmente referida como glucoamilasa o amiloglucosidasa. Es una exo-amilasa que cataliza la liberación de unidades sucesivas de glucosa desde el extremo no reductor de dextrinas y cadenas de oligosacáridos por hidrólisis de los enlaces $(\alpha-1,4)$ y $(\alpha-1,6)$. Es producida por fermentación controlada de cepas 
seleccionadas de Aspergillus Níger (Hoja Técnica Optidex L-400, Genencor, 2001).

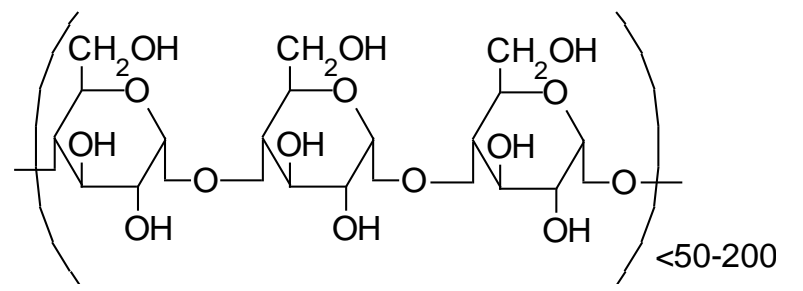

dextrinas y oligosacáridos

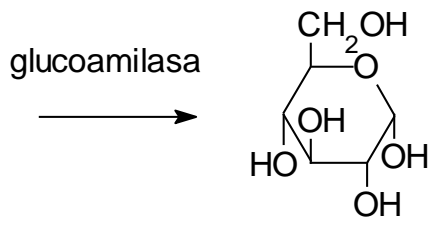

glucosa

Figura 2.4: Acción de la glucoamilasa sobre las porciones solubles constituidas por dextrinas y oligosacáridos

- Actividad pectinasa: la marca comercial de la enzima es PEKTOZYME ULTRA C. Se trata de un complejo enzimático pectolítico obtenido por fermentación de hongos seleccionados (Hoja Técnica Pektozyme Ultra C, Genencor, 2004).

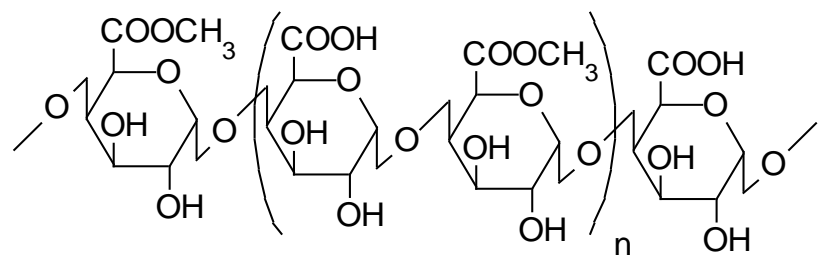

pectina

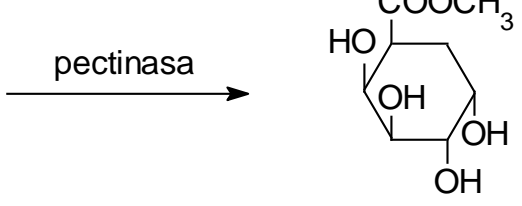

ácido galacturónico

Figura 2.5: Acción de la pectinasa sobre pectina.

- $\quad$ Actividad hemicelulasa: la marca comercial de esta preparación enzimática es GC 440. Contiene una combinación de enzimas con capacidad de modificar e hidrolizar carbohidratos del material estructural de las células vegetales, que no sean almidón. Es producida por fermentación sumergida de cepas genéticamente modificadas de Tricoderma longibrachiatum. GC 440 es efectiva especialmente sobre celulosa, hemicelulosa y $\beta$-glucanos (Hoja Técnica GC 440, Genencor, 2004). 


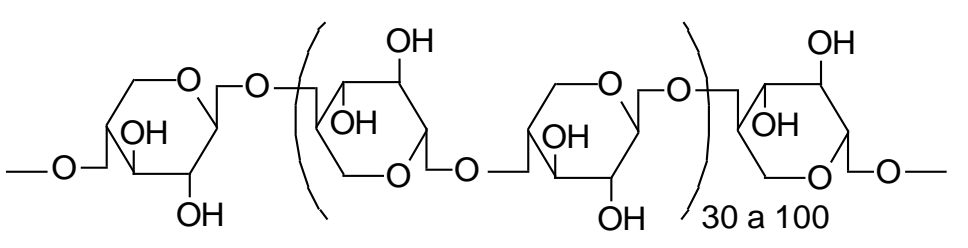

xilano

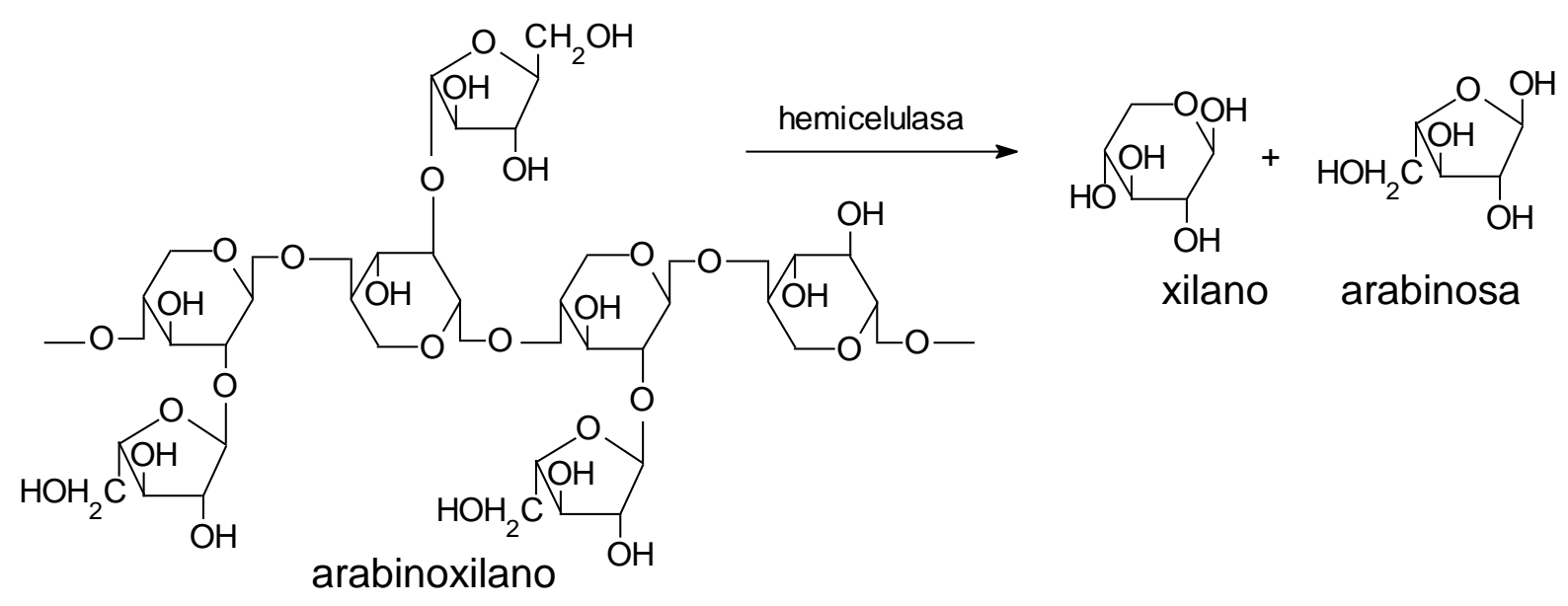

Figura 2.6: a) Acción de la hemicelulasa sobre xilano.

b) Acción de la hemicelulasa sobre arabinoxilano.

- $\quad$ Actividad celulasa: la marca comercial de esta enzima es MULTIFETC GC. Esta enzima es una celulasa derivada de cepas seleccionadas de Tricoderma reesei. Contiene grandes cantidades de actividad $\beta$-glucanasa. Por ello, es capaz de hidrolizar tanto celulosa de fibras vegetales como $\beta$ glucanos (Hoja Técnica Multifect GC, Genencor, 2001).

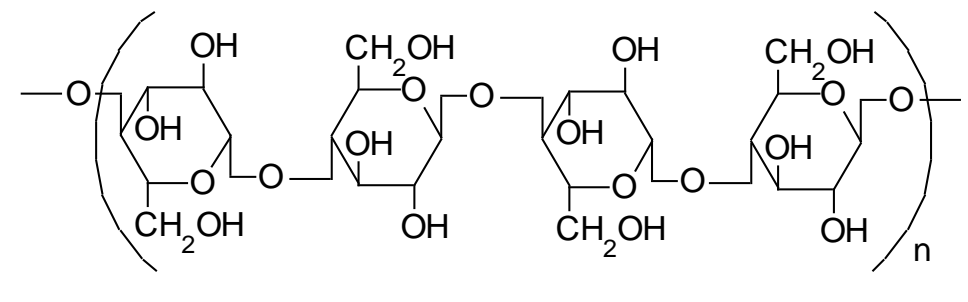

celulosa

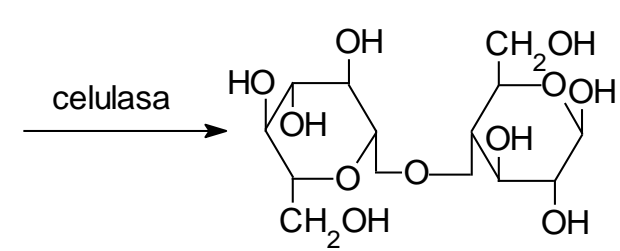

celobiosa

Figura 2.7: Acción de la celulasa sobre celulosa. 
Actividad proteasa: la marca comercial de esta enzima es MULTIFECT NEUTRAL. Se trata de una preparación enzimática bacteriana neutra obtenida por fermentación controlada de cepas no modificadas genéticamente de Bacillus amyloliquefaciens. Este producto es capaz de hidrolizar muchos tipos de sustratos a pH neutro. Los típicos sustratos hidrolizados por esta preparación incluyen caseína, harina, soja, gelatina y granos (Hoja Técnica Multifect Neutral, Genencor, 2004).

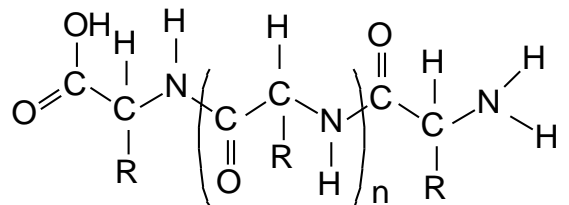

proteína<smiles>[R]C(N)C(=O)O</smiles>

aminoácidos

Figura 2.8: Acción de la proteasa neutra sobre proteína.

2.1.4 Reactor: para todas las incubaciones enzimáticas se utilizaron frascos erlenmeyer de vidrio de $150 \mathrm{~mL}$.

2.1.5 Sistema de calefacción y agitación: se utilizó un rotavapor con baño termostatizado eléctrico y agitación suave (100 rpm).

2.1.6 Reactivos: las drogas usadas fueron de grado analítico provistas por Sigma y Merck. Se utilizaron soluciones buffer de $\mathrm{pH} 4,5 ; 5,0 ; 5,8 ; 6,6$ y 7,2, las cuales se prepararon a partir de soluciones de $\mathrm{KH}_{2} \mathrm{PO}_{4} 1 / 15$ molL $^{-1}$ y Na $\mathrm{HPO}_{4}$ 1/15 $\mathrm{molL}^{-1}$. El solvente $\mathrm{n}$-hexano empleado para las extracciones fue grado analítico. 


\subsection{METODOLOGÍAS}

\subsubsection{Almacenamiento de las muestras}

Las muestras de laminado y expandido de soja son obtenidas de un solo lote. Las mismas son secadas en estufa a $60 \stackrel{\circ}{\circ}$ a fin de evitar su deterioro y luego almacenadas en bolsas de polietileno con cierre hermético y conservadas en freezer $\mathrm{a}-15^{\circ} \mathrm{C}$.

\subsubsection{Extracción de aceite con pretratamiento enzimático}

La extracción con ayuda de soluciones acuosas de enzimas involucra los siguientes pasos (ver Figura 2.9):

A) Pretratamiento de la muestra sólida: Consiste en un tratamiento hidrotérmico para inactivar las enzimas nativas (lipasas naturales) en el material a extraer. Las mismas pueden generar, después de la extracción, reacciones de hidrólisis lipídicas, con el consiguiente deterioro de la calidad del aceite liberado. Dicho proceso se lleva a cabo mezclando $10 \mathrm{~g}$ del sólido de soja con $40 \mathrm{ml}$ de solución buffer al $\mathrm{pH}$ de trabajo, para su calentamiento a $90 \stackrel{\circ}{\mathrm{C}}$ por espacio de 15 minutos y luego se enfría.

B) Incubación con enzimas: Se ajusta el pH al valor requerido por el ensayo y la relación sólido/líquido a 7:1 para cada ensayo. La mezcla es tratada entonces con la preparación enzimática correspondiente, a la temperatura y tiempo de incubación definido para el ensayo. Para cada experimento se utilizaron $500 \mathrm{mg}$, para las preparaciones enzimáticas sólidas y $500 \mu$, para las preparaciones enzimáticas líquidas, de cada una de la o las actividades empleadas en cada ensayo individual. El pH y la temperatura son mantenidos constantes durante todo el período de reacción. 


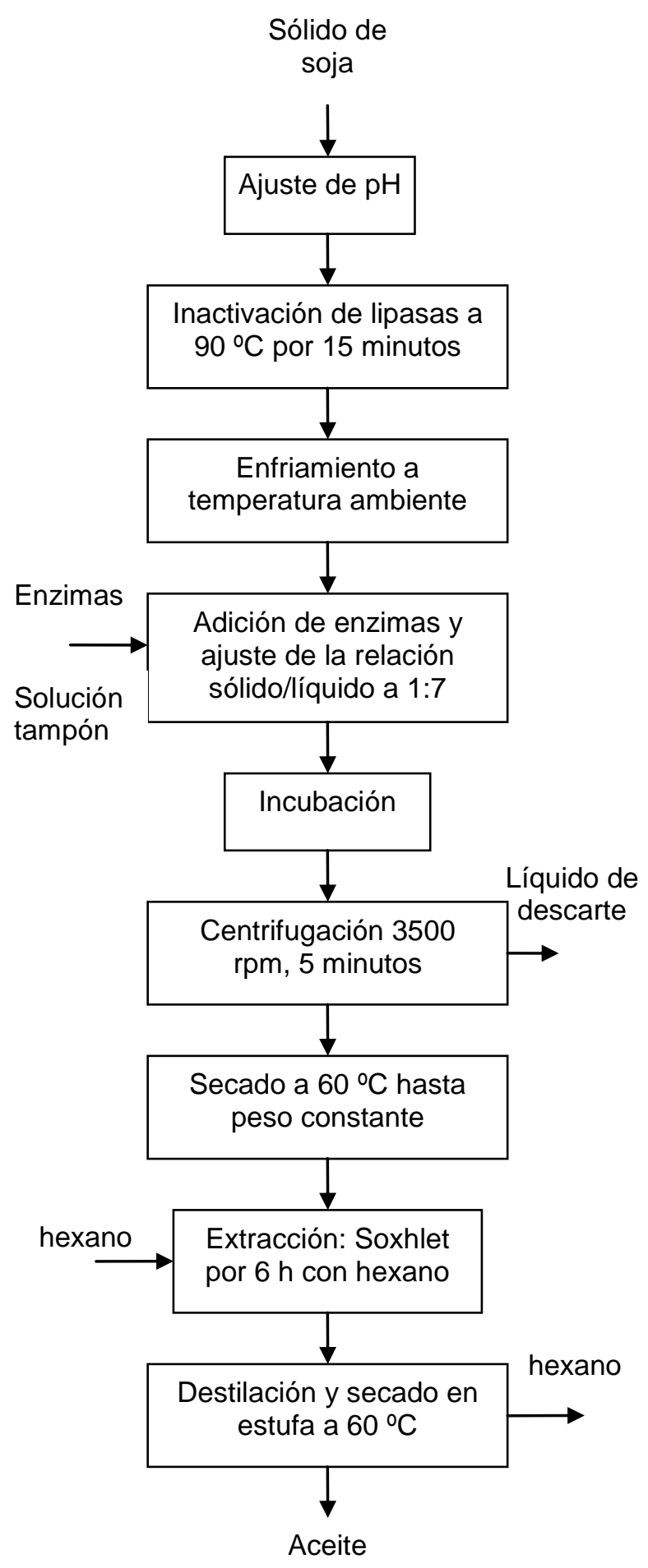

Figura 2.9: Diagrama de flujo para un ensayo estándar de extracción de aceite con hexano y pretratamiento enzimático.

C) Recuperación de aceite y otras fracciones: La muestra es centrifugada durante 5 minutos a $3500 \mathrm{rpm}$. Los productos de reacción son decantados y 
centrifugados a temperatura ambiente con la finalidad de separar las fases. La suspensión centrifugada se separa en dos fases: una líquida y otra sólida. La fase líquida está compuesta por agua, buffer, solutos solubles obtenidos por la acción de la hidrólisis enzimática y aceite en suspensión. La cantidad de aceite en la fase líquida es determinada por extracción con hexano, en ampolla de decantación, en tres extracciones líquido-líquido sucesivas, con $40 \mathrm{ml}$ de solvente por vez. Este aceite es cuantificado como pérdida en la fase líquida en relación a la cantidad de aceite inicial contenido en el sólido.

D) Secado de la fracción sólida: La fracción sólida hidrolizada es secada durante 2 horas aproximadamente en estufa a $60 \stackrel{\circ}{\circ} \mathrm{C}$ o hasta peso constante, a fin de no alterar el sólido y disminuir el contenido de humedad para el paso siguiente de extracción con solvente. El contenido de humedad del sólido que ingresa al extractor empleado no puede superar el $11 \%$, a fin de evitar los efectos negativos sobre la velocidad y la eficiencia de la extracción. Si la humedad es excesiva se producen escurrimientos y rociado irregulares que evitan el contacto eficiente entre el sólido a extraer y el solvente extractor (Dominguez y col, 1995b).

E) Extracción con solvente: El sólido seco es extraído en un equipo Butt o Soxhlet con hexano durante 6 horas (ver sección 2.2.3), a fin de evaluar la extractabilidad del aceite a partir de las muestras con los distintos pretratamientos enzimáticos.

F) Recuperación del aceite: El aceite es recuperado por evaporación de la miscela a vacío y desolventización total en estufa a $40{ }^{\circ} \mathrm{C}$. La cantidad de aceite extraído se determina por pesada directa. El rendimiento de cada extracción se calcula sobre base seca. 


\subsubsection{Determinación del contenido de aceite}

El contenido de aceite se determina como "grasa cruda" y se incluyen en la determinación los triglicéridos, que constituyen cerca del $99 \%$, y el $1 \%$ restante constituido por diglicéridos, monoglicéridos, fosfolípidos, pigmentos liposolubles, vitaminas liposolubles, esteroles, alcoholes de alto peso molecular, etc. El contenido de grasa cruda se determina por extracción directa con un disolvente orgánico, tal como éter de petróleo y hexano. El éter de petróleo (fracción 40-60 ํㅡ) es el mejor agente de extracción directa de la grasa a partir de materiales secos, es más eficiente pero extrae también sustancias no grasas. Los métodos de referencia implican la determinación por pesada de la materia grasa. El método se realiza de la manera más conveniente utilizando extractores del tipo Butt (figura 2.10.a) o del tipo Soxhlet (figura 2.10.b) (Pearson, 1981 y Horwitz, AOAC, 1998).



(a) SOXHLET

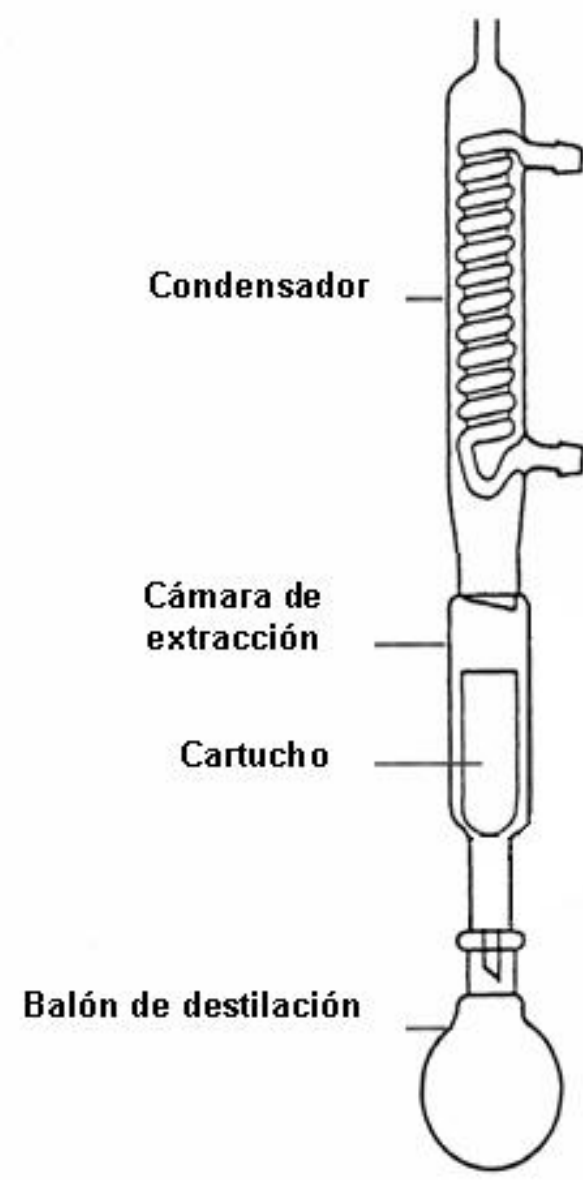

(b) BUTT

Figura 2.10: Esquema de los equipos empleados para determinar materia grasa. 
Ambos equipos funcionan con el mismo principio, la diferencia en el diseño del aparato Butt es que este carece de tubuladura lateral o sifón. El tiempo estimado para extraer el contenido graso de una muestra sólida es el mismo para ambos equipos, al igual que los solventes que pueden utilizarse.

Procedimiento: se coloca la muestra sólida seca en el cartucho de papel de filtro y se pesa. Colocar un segundo cartucho de papel de filtro para prevenir pérdidas de muestra, dejando abierta la parte superior del cartucho. Colocar una pieza de algodón adsorbente en la boca abierta del cartucho, a fin de distribuir el goteo del solvente. Colocar un volumen de hexano en el balón de destilación previamente tarado. Asegurarse que el volumen empleado es suficiente como para evitar que el balón se seque y/o el material extraído se sobrecaliente. Armar el equipo y calentar el hexano sobre una placa eléctrica. Mantener el goteo de solvente a una velocidad $\geq 150$ gotas por minuto durante $6 \mathrm{~h}$. Desarmar el equipo y destilar el hexano contenido en el balón. Completar la eliminación del solvente en estufa a $102 \stackrel{\circ}{\circ}$ hasta peso constante (1 a 2 h). Enfriar en desecador y pesar. El contenido graso se calcula según:

$$
\% \text { Contenido graso }=\frac{\left(P_{2}-P_{1}\right) \cdot 100}{P_{M}}
$$

Donde $\mathrm{P}_{1}=$ peso en $\mathrm{g}$ del balón de destilación empleado, $\mathrm{P}_{2}=$ peso del balón en $\mathrm{g}$ conteniendo el extracto y $\mathrm{P}_{\mathrm{M}}=$ peso en $g$ de la muestra (Horwitz, AOAC, 1998).

\subsubsection{Caracterización de la calidad del aceite extraído}

La calidad del aceite extraído se determinó mediante la medición de índice de acidez, índice de iodo, índice de saponificación e índice de peróxido.

2.2.4.1 Indice de acidez: La acidez es una expresión convencional del contenido en porcentaje de ácidos grasos libres, que normalmente se expresa como porcentaje de ácido oleico. También se denomina grado de acidez y es una medida del deterioro de una grasa por hidrólisis química o enzimática. Se debe disolver adecuadamente la muestra de aceite empleando una mezcla neutra de disolventes y se valoran los ácidos grasos libres presentes por neutralización con hidróxido de potasio etanólico 
empleando fenolftaleína como indicador (Métodos Analíticos en Alimentaria, 1987 y Pearson, 1981).

Preparación de la solución etanólica: llevar a ebullición con reflujo durante una hora $1000 \mathrm{~mL}$ de etanol con $8 \mathrm{~g}$ de hidróxido de potasio y 0,5 g de viruta de aluminio. Destilar inmediatamente de terminado el reflujo y disolver en el líquido destilado la cantidad requerida de hidróxido de potasio. Dejar reposar durante varios días y decantar el líquido claro sobrenadante separándolo del precipitado de carbonato de potasio.

Mezcla disolvente: obtener una mezcla disolvente de etanol $(95 \% \mathrm{v} / \mathrm{v})$ y éter dietílico en proporción de volumen 1:1. Neutralizar exactamente la mezcla obtenida en el momento de su utilización en presencia de $0,3 \mathrm{ml}$ de indicador fenolftaleína al 1\% en etanol por cada $100 \mathrm{~mL}$ de mezcla disolvente.

Valoración: en un erlenmeyer se pesa con exactitud la muestra filtrada según el grado de acidez previsto (ver Tabla 2.1).

\section{Tabla 2.1: Peso de muestra para determinación de acidez}

(Métodos Analíticos en Alimentaria, 1987)

\begin{tabular}{cc}
\hline Grado de acidez previsto & Peso de la muestra $(\mathrm{g})$ \\
\hline$<1$ & 20 \\
1 a 4 & 10 \\
4 a 15 & 2,5 \\
15 a75 & 0,5 \\
$>75$ & 0,1 \\
\hline
\end{tabular}

Se disuelve la misma con 50 a $150 \mathrm{~mL}$ de la mezcla disolvente previamente neutralizada. Valorar, agitando, con solución de hidróxido de potasio etanólico 0,2 N hasta el viraje del indicador, considerándose el punto final cuando la coloración rosa persiste por 10 segundos.

La acidez se calcula según:

$$
\text { Acidez }=\frac{V \cdot c \cdot P M}{10 . P}
$$

Donde $\mathrm{V}=$ volumen en $\mathrm{mL}$ de la solución valorada de hidróxido de potasio etanólico gastados en la titulación, $c=$ concentración en moles $L^{-1}$ de la solución de hidróxido 
de potasio empleada, $M$ = peso molecular del ácido graso en el que se expresa la acidez (para el caso de ácido oleico es 282) y $\mathrm{P}=$ peso de la muestra empleada (Métodos Analíticos en Alimentaria, 1987 y Horwitz, AOAC, 1998).

2.2.4.2 Indice de iodo: El índice de yodo es una medida del grado de insaturación de los componentes de una grasa. Será tanto mayor cuanto mayor sea el número de dobles enlaces por unidad de grasa, utilizándose por ello para comprobar la pureza y la identidad de las grasas. El iodo por sí mismo no reacciona con los dobles enlaces. En su lugar se utilizan bromo o halogenados mixtos como $\mathrm{ICl}$ o $\mathrm{IBr}$. El método recibe distintos nombres dependiendo del reactivo empleado. La adición de halógenos a los dobles enlaces depende de la constitución y configuración de los compuestos insaturados, del tipo de halógeno y de disolvente, así como de las condiciones externas. La reacción no es cuantitativa. Por ello, para que los resultados sean repetibles, hay que establecer exactamente las condiciones de trabajo estandarizadas e indicar la metodología utilizada.

El método de Hanus tiene la ventaja de que el reactivo se prepara muy fácilmente, por ello se seleccionó este método. En condiciones normalizadas, los glicéridos de los ácidos grasos insaturados presentes en un aceite, se unen a una cantidad definida de halógeno contenido en la solución de Hanus de monobromuro de iodo. El grado de absorción se estima valorando el iodo en exceso con tiosulfato. Cada aceite posee un cierto rango de índice de iodo, el cual, por consiguiente, sirve de ayuda en su identificación (Pearson, 1981).

Obtención de la solución de Hanus: medir $825 \mathrm{~mL}$ de ácido acético y disolver 13,615 $\mathrm{g}$ de iodo sólido con ayuda de calentamiento. Enfriar la solución y titular una porción de $25 \mathrm{~mL}$ con solución $0,1 \mathrm{~N}$ de $\mathrm{Na}_{2} \mathrm{~S}_{2} \mathrm{O}_{3}$. Por otro lado, medir una porción de 200 $\mathrm{mL}$ de ácido acético y adicionar $3 \mathrm{~mL}$ de Br líquido. Tomar una porción de $5 \mathrm{~mL}$ de esta solución y adicionarle $10 \mathrm{~mL}$ de una solución al 15\% de $\mathrm{Kl}$ y titular esta mezcla con solución $0,1 \mathrm{~N} \mathrm{Na}_{2} \mathrm{~S}_{2} \mathrm{O}_{3}$. Calcular el volumen de la solución de $\mathrm{Br}$ requerida para igualar el contenido del iodo en la solución remanente de iodo según: $X=B / C$, donde $\mathrm{X}$ es el volumen de la solución de $\mathrm{Br}$ requerido, $\mathrm{B}=800 \times$ equivalentes de $\mathrm{Na}_{2} \mathrm{~S}_{2} \mathrm{O}_{3}$ requeridos en la titulación de $1 \mathrm{~mL}$ de la solución de I y $\mathrm{C}=$ equivalentes de $\mathrm{Na}_{2} \mathrm{~S}_{2} \mathrm{O}_{3}$ requeridos en la titulación de $1 \mathrm{~mL}$ de la solución de $\mathrm{Br}$. Si es necesario reducir la concentración del reactivo de Hanus, diluir con ácido acético. 
Tratamiento de la muestra: En un erlenmeyer de tapón esmerilado se pesan con exactitud en balanza analítica $0,2000 \mathrm{~g}$ de aceite anotando el peso exacto tomado. Para disolver el aceite se añaden $10 \mathrm{~mL}$ de cloroformo medidos en probeta y $15 \mathrm{~mL}$ de reactivo Hanus (monobromuro de yodo $2 \%(\mathrm{p} / \mathrm{v})$ en ácido acético glacial) medidos desde una bureta. A otro erlenmeyer de tapón esmerilado se añaden los $10 \mathrm{~mL}$ de cloroformo y los $15 \mathrm{~mL}$ de reactivo Hanus pero no el aceite (blanco). Se tapan los erlenmeyers, se agitan suavemente y se dejan en reposo y oscuridad durante 45 minutos.

Valoración: Transcurrido este tiempo se añade a cada uno de los erlenmeyers aproximadamente $10 \mathrm{~mL}$ de $\mathrm{KI} 15 \%(\mathrm{p} / \mathrm{v})$ medidos en probeta, $50 \mathrm{~mL}$ de agua destilada y 20 gotas de almidón $1 \%$. Se homogeniza y carga la bureta con tiosulfato sódico $0,1 \mathrm{~N}$ previamente valorado. Se va dejando caer la disolución poco a poco y agitando vigorosamente sobre la mezcla hasta desaparición del color azul anotando en la libreta de laboratorio el volumen de tiosulfato sódico 0,1 N gastado. Debe tenerse en cuenta que el yodo es más retenido por la fase orgánica (cloroformo) que por la acuosa, por lo que puede darse el caso de que la fase acuosa esté decolorada mientras que la fase clorofórmica siga azul cuando no se ha agitado suficientemente en las adiciones del tiosulfato. En el punto final la decoloración debe ser total en las dos fases. Se realiza la valoración con la muestra de aceite tomada y en el blanco de reactivos. Calcular el porcentaje en peso del iodo absorbido (Indice de iodo, método de Hanus) según:

$$
I=\frac{\left[\left(V_{B}-V_{M}\right) \cdot N \cdot 12,69\right]}{g \text { de muestra }}
$$

Donde $\mathrm{V}_{\mathrm{B}}$ es el volumen de $\mathrm{Na}_{2} \mathrm{~S}_{2} \mathrm{O}_{3}$ expresado en $\mathrm{mL}$ gastados en la titulación del blanco, $\mathrm{V}_{\mathrm{M}}$ es el volumen de $\mathrm{Na}_{2} \mathrm{~S}_{2} \mathrm{O}_{3}$ expresado en $\mathrm{mL}$ gastados en la titulación de la muestra y $\mathrm{N}$ es la normalidad de la solución de $\mathrm{Na}_{2} \mathrm{~S}_{2} \mathrm{O}_{3}$ (Métodos Analíticos en Alimentaria, 1999 y Horwitz, AOAC, 1998).

2.2.4.3 Indice de saponificación: es una determinación química muy común, es una medida de la cantidad de triglicéridos y la composición de los ácidos grasos presentes en el aceite. Este índice varía entre 160 y 250. Para los aceites vegetales, en general, oscila alrededor de 190. A mayor índice de saponificación corresponde un mayor contenido de ácidos grasos de bajo peso molecular. El aceite se saponifica 
calentándolo con un exceso de base alcohólica. La cantidad de base consumida se calcula valorando por retroceso con ácido clorhídrico. El índice de saponificación está definido como el peso de hidróxido en $\mathrm{mg}$ que se requieren para saponificar $1 \mathrm{~g}$ de aceite (Pearson, 1981).

Preparación de la solución etanólica: llevar a ebullición con reflujo durante 30 minutos $1,2 \mathrm{~L}$ de etanol con $10 \mathrm{~g}$ de hidróxido de potasio y $6 \mathrm{~g}$ de aluminio granulado. Destilar y colectar $1 \mathrm{~L}$, descartando los primeros $50 \mathrm{~mL}$. Disolver en el líquido destilado $40 \mathrm{~g}$ de hidróxido de potasio, manteniendo la temperatura por debajo de $15 \stackrel{\circ}{\circ}$ durante la disolución.

Tratamiento de la muestra: se pesa una muestra filtrada de $5 \mathrm{~g}$ de aceite en un erlenmeyer. Todas las operaciones siguientes se efectúan en otro ensayo paralelo sin muestra. Se añaden $50 \mathrm{~mL}$ de la disolución alcohólica de $\mathrm{KOH}$. Se adapta un condensador a reflujo y se mantiene el contenido del matraz en franca ebullición durante 60 minutos agitándolo frecuentemente durante el calentamiento para garantizar la completa saponificación de la muestra.

Valoración: Se añaden $0,5 \mathrm{~mL}$ de indicador fenolftaleína al $1 \%$ en etanol y se valora cuidadosamente, aún caliente, con $\mathrm{HCl} 0,5 \mathrm{~N}$ el exceso de $\mathrm{KOH}$, resultante de la saponificación, hasta el viraje del indicador, considerándose el punto final cuando la coloración rosa persiste por 10 segundos. . Calcular el índice de saponificación según:

$$
\text { Indice de saponificacion }=\frac{28,05 \cdot\left(V_{B}-V_{M}\right)}{\text { peso de la muestra }}
$$

Donde $\mathrm{V}_{\mathrm{B}}=$ volumen en $\mathrm{mL}$ de la solución $0,5 \mathrm{~N}$ de $\mathrm{HCl}$ gastados en la valoración del blanco y $\mathrm{V}_{\mathrm{M}}=$ volumen en $\mathrm{mL}$ de la solución $0,5 \mathrm{~N}$ de $\mathrm{HCl}$ gastados en la valoración de la muestra (Pearson, 1981 y Horwitz, AOAC, 1998).

2.2.4.4 Indice de peróxido: Es una medida de la rancidez oxidativa de los productos grasos. La rancidez oxidativa implica transformaciones químicas provocadas por exposición al aire y efecto catalítico de distintos agentes (metales, radiaciones, calor, humedad). La unión de oxígeno sobre los aceites provoca importantes cambios organolépticos. El indice de peróxido se define como la cantidad de miliequivalente 
de oxígeno activo por kg de aceite que ocasionan la oxidación del ioduro de potasio en las condiciones de trabajo del método analítico (Pearson, 1981).

Preparación del indicador: mezclar el mínimo de volumen de agua destilada con $1 \mathrm{~g}$ de almidón soluble. Mezclar hasta formar una pasta. Agitar la pasta con $500 \mathrm{~mL}$ de agua hirviendo y hervir la mezcla durante 1-2 minutos. Si la disolución no está clara dejar en reposo hasta que se deposite. Usar el líquido claro que sobrenada.

Preparación de la solución saturada de $\mathrm{KI}$ : disolver un exceso de $\mathrm{KI}$ en agua destilada. Debe quedar el exceso presente en la solución. Almacenar en oscuridad.

Tratamiento de la muestra: se pesa en un matraz erlenmeyer una muestra de aceite filtrada de acuerdo a la tabla 2.2. Se añaden $0,5 \mathrm{~mL}$ de la solución saturada de $\mathrm{KI}$ y $20 \mathrm{~mL}$ de mezcla disolvente (2:1 ácido acético glacial/cloroformo). Se cierra el matraz y se agita durante 1 minuto. Mantener en la oscuridad 5 minutos exactamente a una temperatura comprendida entre 15 y $25 \stackrel{\circ}{\circ}$.

\section{Tabla 2.2: Peso de muestra para determinación de peróxido}

(Métodos Analíticos en Alimentaria, 1987)

\begin{tabular}{cc}
\hline $\begin{array}{c}\text { Indice de peróxido previsto } \\
\left(\text { meq } \mathrm{O}_{2} / \mathrm{kg}\right)\end{array}$ & Peso de la muestra $(\mathrm{g})$ \\
\hline de 0 a 12 & de 5 a 2 \\
de 12 a 20 & de 2 a 1,2 \\
de 20 a 30 & de 1,2 a 0,8 \\
de 30 a 50 & de 0,8 a 0,5 \\
de 50 a 90 & de 0,5 a 0,3 \\
\hline
\end{tabular}

Valoración: Agregar $30 \mathrm{~mL}$ de agua destilada. Valorar lentamente con solución $0,1 \mathrm{~N}$ de $\mathrm{Na}_{2} \mathrm{~S}_{2} \mathrm{O}_{3}$ agitando vigorosamente hasta que comience a desaparecer el color amarillo. Adicionar $0,5 \mathrm{~mL}$ de solución de indicador almidón y continuar la valoración hasta desaparición del color azul. Agitar vigorosamente durante toda la valoración. Debe tenerse en cuenta que el iodo es más retenido por la fase orgánica (cloroformo) que por la acuosa por lo que puede darse el caso de que la fase acuosa esté decoloreada mientras que la fase clorofórmica siga azul cuando no se ha agitado suficientemente en las adiciones del tiosulfato. En el punto final la decoloración debe ser total en las dos fases. Calcular el índice de peróxidos según: 


$$
\text { Indice de peroxido }=\frac{V \cdot N .1000}{\text { peso de la muestra }}
$$

Donde $\mathrm{V}=$ volumen en $\mathrm{mL}$ de la solución valorada de $\mathrm{Na}_{2} \mathrm{~S}_{2} \mathrm{O}_{3}$ gastados en la titulación de la muestra y $\mathrm{N}=$ normalidad exacta de la solución de $\mathrm{Na}_{2} \mathrm{~S}_{2} \mathrm{O}_{3}$ empleada (la solución debe titularse siempre antes de usarse o puede corregirse su normalidad llevando un ensayo blanco en paralelo al tratamiento de la muestra) (Métodos Analíticos en Alimentaria, 1987 y Horwitz, AOAC, 1998).

\subsubsection{Determinación de pérdidas de aceite en la fase líquida}

El líquido de descarte (ver Figura 2.9) de cada ensayo se empleó para determinar las pérdidas de aceite por solubilización en dicha fase. Esta fase líquida se extrajo en ampolla de decantación con porciones de $30 \mathrm{~mL}$ de hexano en 3 extracciones sucesivas. Se eliminaron los restos de agua empleando $\mathrm{Na}_{2} \mathrm{SO}_{4}$ como agente desecador. Luego se eliminó el solvente por evaporación y se pesó el extracto. Se calcularon las pérdidas de aceite como porcentaje de la masa de aceite total. 
Capítulo 3

Efecto de las variables de la hidrólisis enzimática sobre el rendimiento en aceite de la extracción con hexano 


\section{Efecto de las variables de la hidrólisis enzimática sobre el rendimiento en aceite de la extracción con hexano.}

La soja necesita, al igual que otras semillas, ciertas operaciones de pretratamiento para facilitar la extracción del aceite ya sea por medios mecánicos o por extracción con solventes. La soja es extraída convencionalmente con hexano, mientras que la extracción por prensado no es practicada comercialmente. Los pretratamientos convencionales para soja incluyen descascarado, reducción de tamaño, molienda, pulverización o flaking, así como también tratamiento térmico/hidrotérmico, cocinado o tratamiento con vapor (Smith y col., 1993).

La hidrólisis enzimática es otra opción para pretratamiento de semillas de soja, que tiene como objetivo lisar las paredes celulares mediante biodegradación. Este proceso también rompe las moléculas complejas de lipoproteínas y lipopolisacáridos (aceite no extraíble) en moléculas más simples, liberando aceite "extra" para la extracción (Smith y col., 1993).

El tratamiento enzimático puede incorporarse durante el procesado convencional con disolvente para incrementar la productividad, reducir el tiempo de operación y/o reducir la cantidad de solvente empleado con mínimas alteraciones en el proceso en curso. Para ello, es necesario definir las condiciones de trabajo.

Los objetivos específicos del presente capítulo son:

Seleccionar la mezcla de actividades enzimáticas óptima para lograr el máximo rendimiento en aceite, extraído con solvente, partiendo de los sólidos de soja hidrolizados. 
- Establecer la influencia que ejercen las variables operacionales temperatura, $\mathrm{pH}$ y tiempo de incubación enzimática sobre la eficiencia del pretratamiento para encontrar las condiciones óptimas que produzcan el rendimiento máximo en aceite.

Determinar el efecto del pretratamiento enzimático sobre la calidad del aceite obtenido por extracción con solvente. 


\subsection{PARTE EXPERIMENTAL}

3.1.1 Materiales ver Capítulo 2, Materiales y Métodos Generales.

\subsubsection{Metodologías}

\subsubsection{Selección de mezclas enzimáticas}

La extracción con ayuda de soluciones acuosas de enzimas involucra los pasos descritos en el Capítulo 2, Materiales y Metodologías Generales (ver Figura 2.1).

La tabla 3.1 muestra el listado de incubaciones realizadas con diferentes actividades enzimáticas sobre laminado y expandido de soja a fin de seleccionar la mezcla enzimática óptima.

Tabla 3.1: Referencias de los ensayos de selección de enzimas.

\begin{tabular}{cl}
\hline № de ensayo & Enzimas utilizadas \\
\hline 0 & Control sin incubación \\
2 & Control con incubación, sin enzimas \\
3 & Celulasa \\
4 & Proteasa neutra \\
5 & Pectinasa \\
6 & Hemicelulasa \\
7 & Glucoamilasa \\
8 & Proteasa + glucoamilasa \\
9 & Celulasa + proteasa neutra \\
10 & $\alpha$-Amilasa + hemicelulosa \\
11 & Proteasa $+\alpha$-amilasa \\
12 & Celulasa + proteasa $+\alpha$-amilasa \\
13 & Celulasa $+\alpha$-amilasa + pectinasa \\
14 & Celulasa + proteasa + hemicelulasa + glucoamilasa \\
15 & Todas las enzimas \\
\hline
\end{tabular}


Los ensayos 2 a 7 consistieron en incubaciones de las enzimas individuales, los ensayos 8 a 14 fueron incubaciones con combinaciones enzimáticas elegidas en función de la composición de la semilla de soja y el ensayo 15 fue con incubación de todas las enzimas empleadas.

\subsubsection{Optimización del tratamiento enzimático}

El ajuste de las condiciones de $\mathrm{pH}$, temperatura y tiempo de incubación para cada ensayo es determinado según un diseño experimental compuesto centrado de 3 variables (Tabla 3.2).

Tabla 3.2: Variables naturales y niveles de factores

\begin{tabular}{|l|c|c|c|c|c|}
\hline \multirow{2}{*}{$\begin{array}{l}\text { Variables } \\
\text { Naturales }\end{array}$} & \multicolumn{5}{|c|}{ Niveles de Factores } \\
\cline { 2 - 6 } & $-1,682$ & -1 & 0 & +1 & $+1,682$ \\
\hline Temperatura $(\mathrm{T})\left({ }^{\circ} \mathrm{C}\right)$ & 16,4 & 30 & 50 & 70 & 83,6 \\
\hline $\mathrm{pH}$ & 4,45 & 5 & 5,8 & 6,6 & 7,15 \\
\hline Tiempo (t) (h) & 1,3 & 4 & 8 & 12 & 14,7 \\
\hline
\end{tabular}

Variables codificadas: $\mathrm{X}_{1}=(\mathrm{T}-50): 20 ; \mathrm{X}_{2}=(\mathrm{pH}-5,8): 0,8 ; \mathrm{X}_{3}=(\mathrm{t}-8): 4$

El diseño experimental está basado en la metodología de superficies de respuesta (MSR). Esta es una técnica estadística muy utilizada para investigar procesos complejos. Consiste en un grupo de procedimientos matemáticos y estadísticos que pueden usarse para estudiar la relación entre una o más respuestas (variables dependientes) y un cierto número de factores (variables independientes). Los niveles de estos factores son cuidadosamente elegidos según la bibliografía disponible y experiencias previas. Cuando se selecciona un diseño de superficies de respuesta, algunas de las características de un diseño deseable son que:

- Proporcione una distribución razonable de puntos de datos en toda la región de interés,

- Permita investigar la idoneidad del modelo, incluyendo la falta de ajuste,

- Permita la realización de experimentos en bloques,

- Permita la construcción secuencial de diseños de orden superior, 
- Proporcione una estimación de error interna,

- No requiera un número grande de experimentos,

- $\quad$ No requiera demasiados niveles de las variables independientes,

- $\quad$ Asegure simplicidad de los cálculos de los parámetros del modelo.

Se desarrolla esta técnica para el rendimiento en aceite en base seca (\%BS) como función cuadrática del $\mathrm{pH}$, la temperatura y el tiempo de incubación enzimática, empleando técnicas de regresión múltiple. Este procedimiento permite determinar el máximo rendimiento esperado en aceite. El diseño seleccionado consiste en tres tipos de experimentos:

\# Ensayos factoriales: son los experimentos llevados a cabo a los niveles más bajo y más alto de las variables diseñadas (8 experimentos).

\# Ensayos centrales: son las replicaciones del experimento llevado a cabo en el punto central del diseño (6 experimentos).

\# Ensayos axiales: son los experimentos llevados a cabo a una distancia uniforme del centro del diseño. Para un diseño de tres variables esta distancia $(\alpha)$ es 1,41 (6 experimentos) (Montgomery, 1991).

La introducción de puntos axiales permite convertir el diseño a rotable. La rotabilidad es una propiedad muy importante en la elección de un diseño de superficie de respuesta, ya que proporciona estimaciones igualmente precisas en todas las direcciones. Por otro lado, las replicaciones del punto central permiten que el diseño sea ortogonal con lo cual se minimiza la varianza de los coeficientes de regresión (Montgomery, 1991).

Se determinan el ajuste del modelo, la falta de adecuación y si las variables estudiadas, términos simples y cuadráticos, y sus interacciones son significativas empleando la técnica de análisis de varianza (ANOVA).

Es posible representar gráficamente la superficie de respuesta como una superficie sólida en un espacio tridimensional. Por lo general, se emplea un polinomio de orden bajo sobre alguna región de las variables independiente. Cuando existe curvatura en el sistema, se debe emplear un polinomio de mayor grado que uno. Es improbable que un modelo polinomial sea una aproximación razonable de la relación funcional real sobre todo el dominio de las variables independientes. Sin 
embargo, funcionan muy bien en regiones relativamente pequeñas de las variables independientes.

El método de mínimos cuadrados sirve para estimar los parámetros del polinomio de aproximación. El análisis de la superficie de respuesta se hace luego en términos de la superficie ajustada. Tal análisis es aproximadamente equivalente al análisis del sistema real, si la superficie ajustada es una aproximación adecuada a la función de respuesta real. La estimación de los parámetros del modelo se hace más eficazmente si se utilizan los diseños experimentales apropiados para recopilar los datos (Montgomery, 1991).

El diseño consiste en 20 corridas experimentales en total para cada uno de los tipos de sólido. En la Tabla 3.2 se muestran las condiciones experimentales para cada ensayo. Todos los ensayos fueron realizados por duplicado y conducidos con la mezcla enzimática óptima, seleccionada anteriormente: hemicelulasa $(500 \mathrm{mg})$, celulasa $(500 \mathrm{mg})$, proteasa $(500 \mathrm{mg})$, glucoamilasa $(500 \mu \mathrm{l})$, amilasa $(500 \mu \mathrm{l})$ y pectinasa $(500 \mu \mathrm{l})$. 


\subsection{RESULTADOS Y DISCUSIÓN}

\subsubsection{Selección de mezclas enzimáticas}

Los resultados de la selección enzimática apropiada para el pretratamiento propuesto se muestran en la Tabla 3.3 tanto para laminado como para expandido de soja. Cada ensayo se realizó por duplicado. Se calcularon las pérdidas de aceite por liberación directa a la fase líquida. También se muestra el aumento en el rendimiento de extracción obtenido para cada ensayo en comparación con el control sin ningún tipo de incubación (Ensayo 0).

Las mayores pérdidas de aceite no coincidieron con los mayores rendimientos de extracción obtenidos (Tabla 3.3). Esto significa que las pérdidas de aceite no sólo están influenciadas por la liberación del aceite por la acción degradativa sino también por la estabilización de la emulsión que se forma en la fase líquida acuosa. Esta fase líquida contiene todos los componentes solubles en agua que son liberados por la acción enzimática, además de las propias enzimas. Muchos de estos componentes tienen propiedades emulsificantes, por ello su presencia aumenta la cantidad de aceite que es mantenido en fase acuosa (Rosenthal y col, 1996).

Tomando como base la cantidad de aceite del control sin incubación, se obtiene el mayor incremento en el rendimiento: $8,15 \%$ para laminado con hidrólisis multienzimática y $5,2 \%$ para expandido con hidrólisis multienzimática, con respecto al proceso tradicional de extracción con solvente. Esto se debe a que la acción degradativa de las enzimas libera aceite que forma parte de moléculas complejas en las estructuras celulares. Este aceite no puede ser extraído durante procesos convencionales, ya que se halla enlazado químicamente (Shankar y col., 1997). De la observación de los resultados de la Tabla 3.3, puede verse el efecto positivo sobre el rendimiento de extracción que tiene lugar cuando se emplea proteasa (Ensayo 3) en el tratamiento enzimático. Esto puede explicarse teniendo en cuenta la estructura celular que aloja a los aceites dentro de las semillas oleaginosas. Como se presenta en la Introducción, los lípidos se encuentran alojados en cuerpos lipídicos, estabilizados y mantenidos por medio de la presencia de proteínas llamadas oleosinas. Estas oleosinas podrían ser hidrolizadas por la acción de las proteasas, 
produciendo liberación de los lípidos contenidos en estos oleosomas (Zweytick, D. y col., 2000). Esta liberación se traduce en un aumento de la cantidad de aceite que puede extraerse. Las enzimas proteolíticas pueden afectar también la red citoplasmática, la cual está compuesta por proteínas, como es el caso de la soja y otras semillas oleaginosas, lo cual resulta en una estructura más abierta y menos compacta que facilita la remoción del aceite desde la célula.

Tabla 3.3: Resultados de los ensayos con diferentes enzimas.

\begin{tabular}{c|c|c|c|c|c|c}
\hline \multirow{2}{*}{ Ensayo } & \multicolumn{2}{|c|}{$\begin{array}{c}\text { Rendimiento } \\
\%(\mathrm{BS})^{*}\end{array}$} & \multicolumn{2}{c|}{$\begin{array}{c}\text { Pérdidas en la } \\
\text { fase líquida }(\%)\end{array}$} & \multicolumn{2}{|c}{$\begin{array}{l}\text { Incremento en } \\
\text { el rendimiento }\end{array}$} \\
\cline { 2 - 8 } & $\mathrm{L}$ & $\mathrm{E}$ & $\mathrm{L}$ & $\mathrm{E}$ & $\mathrm{L}$ & $\mathrm{E}$ \\
\hline 0: Control sin incubación & 16 & 18,54 & - & - & - & - \\
1: Control con incubación, sin enzimas & 11,27 & 11,85 & 0,44 & 0,23 & - & - \\
2: Celulasa & 14,65 & 15,62 & 2,9 & 0,59 & - & - \\
3: Proteasa neutra & 16,28 & 19,07 & 2,9 & 3,71 & 0,28 & 0,53 \\
4: $\alpha$-Amilasa & 11,30 & 13,78 & 2,24 & 1,98 & - & - \\
5: Pectinasa & 11,50 & 14,05 & 0,72 & 0,86 & - & - \\
6: Hemicelulasa & 12,29 & 14,89 & 0,7 & 0,82 & - & - \\
7: Glucoamilasa & 15,82 & 17,58 & 3,4 & 2,8 & - & - \\
8: Proteasa + glucoamilasa & 19,17 & 20,61 & 4,31 & 3,22 & 3,17 & 2,07 \\
9: Celulasa + proteasa neutra & 18,43 & 20,26 & 1,55 & 1,74 & 2,43 & 1,72 \\
10: $\alpha$-Amilasa + hemicelulasa & 12,94 & 14,73 & 2,16 & 2,51 & - & - \\
11: Proteasa + $\alpha$-Amilasa & 19,38 & 21,31 & 1,11 & 0,9 & 3,38 & 2,77 \\
12: Celulasa + proteasa + $\alpha$-Amilasa & 18,71 & 20,47 & 1,39 & 1,96 & 2,71 & 1,93 \\
13: Celulasa + $\alpha$-Amilasa + pectinasa & 18,69 & 20,39 & 1,35 & 1,7 & 2,69 & 1,85 \\
14: Celulasa + proteasa + hemicelulasa + & 20,54 & 21,81 & 3,1 & 2,38 & 4,54 & 3,27 \\
glucoamilasa & & & & & & \\
15: Todas las enzimas & 24,15 & 23,74 & 1,7 & 2,25 & 8,15 & 5,2 \\
\hline
\end{tabular}

(para un ensayo estandar se utilizaron $500 \mathrm{mg}$ para las preparaciones sólidas y $500 \mu \mathrm{L}$ para las preparaciones líquidas, de cada enzima)

* los porcentajes son calculados en base seca.

${ }^{* *}$ calculados sobre el resultado del ensayo 0.

$\mathrm{L}=$ Laminado; $\mathrm{E}=$ Expandido 
Un análisis similar puede hacerse con respecto al efecto de las celulasas y las hemicelulasas. Si bien cuando se emplean solas las celulasas (Ensayo 2) y hemicelulasas (Ensayo 6) no se observa un incremento en el rendimiento de aceite, cuando son empleadas en combinación con las proteasas (Ensayos 9, 12, 13, 14 y 15), se observa un aumento de la porción de aceite extraíble. Esto puede explicarse a partir del hecho de que las paredes celulares primarias de la mayoría de las plantas superiores poseen una estructura común que consiste en fibras de celulosa enlazadas a cadenas de hemicelulosa. Estas fibras están embebidas en una matriz de sustancias pécticas enlazadas a proteínas estructurales (Rosenthal y col, 1996). Por ello, las actividades enzimáticas (Ensayos 12, 13, 14 y 15) capaces de hidrolizar estos polisacáridos complejos de membranas y paredes celulares aumentan la permeabilidad de la célula a la salida del aceite (Rosenthal y col, 1996).

Las diferencias en composición de las diferentes semillas oleaginosas determina la elección de las enzimas a usarse para cada semilla o fruto oleaginoso. Particularmente, en el caso de la soja, el alto contenido de proteína requiere el uso de enzimas proteolíticas para obtener altos rendimientos (Rosenthal y col, 1996).

Los resultados muestran un incremento general del aceite extraíble, siendo el valor más alto alcanzado para el ensayo con todas las enzimas (Ensayo 15), aunque la eficiencia de la extracción no es consecuencia de la sumatoria de las actividades individuales (Düsterhöft, 1993).

Esto indica que sería posible reducir el tiempo y/o la cantidad de solvente utilizado durante el proceso convencional y que la hidrólisis enzimática en medio acuoso es un pretratamiento viable, en términos técnicos, en la extracción de aceite de soja.

\subsubsection{Caracterización de la calidad del aceite extraído}

La Tabla 3.4 presenta la evaluación de los parámetros de calidad para algunos de los aceites obtenidos. También se incluye en la tabla un valor de referencia obtenido de bibliografía para aceite crudo (Mustakas, 1980), es decir, del aceite que sale directamente de la extracción luego de la destilación para eliminar el hexano. Los resultados experimentales son el promedio de tres determinaciones. La comparación de los resultados indica que la calidad final del aceite extraído con 
ayuda enzimática no es afectada significativamente por el pretratamiento. Se observa que los valores de acidez resultaron más altos que lo esperado para un aceite crudo sin refinar, probablemente debido a una deficiente inactivación de las lipasas nativas o a un cierto grado de hidrólisis debido a la temperatura de incubación y al medio acuoso necesario para llevar a cabo el tratamiento enzimático. En cambio, el índice de peróxido se mantuvo menor a 20 meq de peróxido/Kg de muestra en los ensayos con mayor número de actividades hidrolasas (ver Tabla3.4), considerado estándar para un aceite crudo sin refinar (AOAC, 1980). Con respecto a los índices de saponificación y de iodo, se mantuvieron dentro del rango para este tipo de aceite, evidenciando que no hay pérdida de sus características.

Tabla 3.4: Parámetros de calidad para el aceite obtenido en diferentes ensayos.

\begin{tabular}{lcccc}
\hline & $\begin{array}{c}\text { Indice de } \\
\text { Iodo }^{(1)}\end{array}$ & $\begin{array}{c}\text { Indice de } \\
\text { Acidez }^{(2)}\end{array}$ & $\begin{array}{c}\text { Indice de } \\
\text { Saponificación }^{(3)}\end{array}$ & $\begin{array}{c}\text { Indice de } \\
\text { Peróxido }^{(4)}\end{array}$ \\
\hline Control & $140 \pm 4,5$ & $2,44 \pm 0,2$ & $190 \pm 3,8$ & $23 \pm 0,9$ \\
Ensayo 12 & $124 \pm 3,8$ & $1,88 \pm 0,1$ & $160 \pm 7,4$ & $26 \pm 1,2$ \\
Ensayo 13 & $108 \pm 0,9$ & $1,80 \pm 0,3$ & $156 \pm 5,2$ & $14 \pm 1,4$ \\
Ensayo 14 & $131 \pm 2,2$ & $2,00 \pm 0,06$ & $193 \pm 6,5$ & $14 \pm 2,0$ \\
Ensayo 15 & $138 \pm 1,8$ & $2,87 \pm 0,08$ & $155 \pm 5,6$ & $10 \pm 1,3$ \\
Aceite & $120-145$ & $<0,2$ & $189-195$ & $<20$ \\
crudo & & & & \\
\hline
\end{tabular}

Referencias: $(1)=\mathrm{mg}$ de iodo por $\mathrm{g}$ de muestra, método de Hanus.

(2) $=\%$ expresado en ácido oleico.

(3) $=\mathrm{mg}$ de $\mathrm{KOH}$ por $\mathrm{g}$ de muestra.

(4) = meq de peróxido por $\mathrm{Kg}$ de muestra.

(5) AOAC, 1980.

\subsubsection{Optimización del tratamiento enzimático}

La cantidad de aceite que puede extraerse de las láminas de soja por el método Soxhlet es $16 \%$ en base seca (BS) y $18,54 \%$ (BS) para el caso de expandido de soja. Para todas las corridas experimentales con pretratamiento enzimático se observa un incremento en el rendimiento (ver Tabla 3.5). 
El análisis MSR permitió obtener las condiciones experimentales para el pretratamiento acuoso enzimático mediante el cual se obtiene el máximo rendimiento teórico en aceite (\%BS) para cada tipo de material de partida.

Tabla 3.5: Rendimientos en \% de aceite para los 20 ensayos del diseño experimental

\begin{tabular}{|c|c|c|c|c|c|}
\hline \multirow[t]{2}{*}{$\begin{array}{c}\text { № } \\
\text { ensayo }\end{array}$} & \multicolumn{3}{|c|}{ Variables Codificadas } & \multicolumn{2}{|c|}{$\begin{array}{c}\text { Rendimiento Y } \\
\text { (\% Aceite) }\end{array}$} \\
\hline & $X_{1}$ & $X_{2}$ & $X_{3}$ & Laminado & Expandido \\
\hline 1 & $-1,68$ & 0 & 0 & 25,79 & 24,26 \\
\hline 2 & $+1,68$ & 0 & 0 & 21,39 & 21,58 \\
\hline 3 & 0 & $-1,68$ & 0 & 28,02 & 24,93 \\
\hline 4 & 0 & $+1,68$ & 0 & 25,53 & 25,30 \\
\hline 5 & 0 & 0 & $-1,68$ & 25,31 & 24,37 \\
\hline 6 & 0 & 0 & $+1,68$ & 26,85 & 26,01 \\
\hline 7 & -1 & -1 & -1 & 25,45 & 25,83 \\
\hline 8 & +1 & -1 & -1 & 22,00 & 25,46 \\
\hline 9 & -1 & +1 & -1 & 24,00 & 25,01 \\
\hline 10 & +1 & +1 & -1 & 23,62 & 23,19 \\
\hline 11 & -1 & -1 & +1 & 26,13 & 24,33 \\
\hline 12 & +1 & -1 & +1 & 21,55 & 23,11 \\
\hline 13 & -1 & +1 & +1 & 26,47 & 23,14 \\
\hline 14 & +1 & +1 & +1 & 23,87 & 25,98 \\
\hline 15 & 0 & 0 & 0 & 27,88 & 26,19 \\
\hline 16 & 0 & 0 & 0 & 26,28 & 26,73 \\
\hline 17 & 0 & 0 & 0 & 26,34 & 26,78 \\
\hline 18 & 0 & 0 & 0 & 26,47 & 26,38 \\
\hline 19 & 0 & 0 & 0 & 28,46 & 26,65 \\
\hline 20 & 0 & 0 & 0 & 26,62 & 26,68 \\
\hline
\end{tabular}

1 a 6 = ensayos axiales; 7 a 14 = ensayos factoriales; 15 a 20 = replicaciones del punto central.

La Tabla 3.6 muestra los resultados del ANOVA para cada diseño experimental. A partir de este análisis se definen los coeficientes del polinomio de la función objetivo. La respuesta $\mathrm{Y}$ puede describirse como una función de los factores 
seleccionados: $X_{1}, X_{2}$ y $X_{3}$. La relación empírica muestra efectos individuales y cruzados de cada variable, en un modelo de segundo orden con efectos de primer orden $\left(\beta_{1}, \beta_{2}, \beta_{3}\right)$; efectos de segundo orden $\left(\beta_{11}, \beta_{22}, \beta_{33}\right)$ y términos de interacción $\left(\beta_{12}, \beta_{23}, \beta_{13}\right)$ :

$Y=\beta_{0}+\beta_{1} X_{1}+\beta_{2} X_{2}+\beta_{3} X_{3}+\beta_{11} X_{1}^{2}+\beta_{22} X_{2}^{2}+\beta_{33} X_{3}^{2}+\beta_{12} X_{1} X_{2}+\beta_{23} X_{2} X_{3}+\beta_{13} X_{1} X_{3}+$ error

A) Laminado: Los efectos tanto lineal como cuadrático de la temperatura son significativos con un nivel mayor al 95\% de confianza en ambos casos, al igual que el efecto cuadrático del tiempo de incubación. Para la variable restante, $\mathrm{pH}$, la variación es estadísticamente no significativa $(p>0,05)$. También puede deducirse que no existen efectos significativos para los términos de interacción entre las variables. Por lo tanto la función objetivo, eliminados los términos no significativos, queda definida por la siguiente expresión:

$$
Y(\%)=27,055-0,06 \mathrm{~T}-3,68 \mathrm{~T}^{2}-0,04 \mathrm{t}^{2}+\text { error }
$$

B) Expandido: Los efectos cuadráticos de la temperatura y del $\mathrm{pH}$ de incubación son significativos con un nivel mayor al $98 \%$ de confianza en ambos casos, al igual que el efecto cruzado del $\mathrm{pH}$ y el tiempo de incubación. Para los demás términos lineales, la variación es estadísticamente no significativa $(p>0,05)$. También puede deducirse que no existen efectos significativos para los términos de interacción entre las variables temperatura y tiempo de incubación. Por lo tanto la función objetivo, eliminados los términos no significativos, queda definida por la siguiente expresión:

$$
Y(\%)=26,566+0,186 \mathrm{pH} . \mathrm{t}-3,10 \mathrm{~T}^{2}-0,7274 \mathrm{pH}^{2}+\text { error }
$$


Tabla 3.6: Resultados de ANOVA para optimización del rendimiento en aceite.

A) Laminado de soja

\begin{tabular}{lccccc}
\hline & SC & GL & MC & relación F & valor-p \\
\hline Modelo & 67,089 & 9 & 7,454 & 5,534 & 0,0066 \\
Error & 13,471 & 10 & 1,347 & & \\
Ajuste total & 80,569 & 19 & 4,240 & & \\
\hline Cuadrático & 39,932 & 6 & 6,655 & 4,941 & 0,0134 \\
\hline Falta de ajuste & 9,158 & 5 & 1,832 & 2,123 & 0,2401 \\
Error puro & 4,313 & 5 & 0,863 & & \\
Error total & 13,471 & 10 & 1,347 & & \\
\hline
\end{tabular}

B) Expandido de soja

\begin{tabular}{lccccc}
\hline & SC & GL & MC & relación F & valor-p \\
\hline Modelo & 32,550 & 9 & 3,617 & 4,188 & 0,0178 \\
Error & 8,636 & 10 & 0,864 & & \\
Ajuste total & 41,186 & 19 & 2,168 & & \\
\hline Cuadrático & 30,609 & 6 & 5,102 & 5,907 & 0,0072 \\
\hline Falta de ajuste & 8,364 & 5 & 1,673 & 30,729 & 0,0009 \\
Error puro & 0,272 & 5 & 0,054 & & \\
Error total & 8,636 & 10 & 0,864 & & \\
\hline
\end{tabular}

En la primera parte de la tabla ANOVA se resume la significancia del modelo global para cada uno de los materiales de partida ensayados. Por comparación de la relación $\mathrm{F}\left(\mathrm{MC}_{\text {regresión }} / \mathrm{MC}_{\text {error }}\right.$ ) con el valor-p (distribución $\mathrm{F}$ con $\mathrm{G} \mathrm{L}_{\text {regresión }} \mathrm{y} \mathrm{GL}_{\text {error }}$ ) es posible determinar la significancia de la regresión cuadrática; el mismo análisis puede hacerse para el modelo propuesto y la falta de ajuste. Como puede observarse, el estadístico $\mathrm{p}$ indica que el modelo es significativo para todos los casos con más del $98 \%$ de confianza. Por otro lado, se comprueba la adecuación del modelo cuadrático con un $98 \%$ de confianza, un error total de 1,347 para laminado y 0,864 para expandido y una falta de ajuste no significativa con una confianza mayor a $96 \%$ para los dos materiales de partida. En las figuras 3.1, 3.2 y 3.3 se representan la función que describe el rendimiento en aceite (\%BS) de la extracción con pretratamiento acuoso enzimático para laminado de soja. 


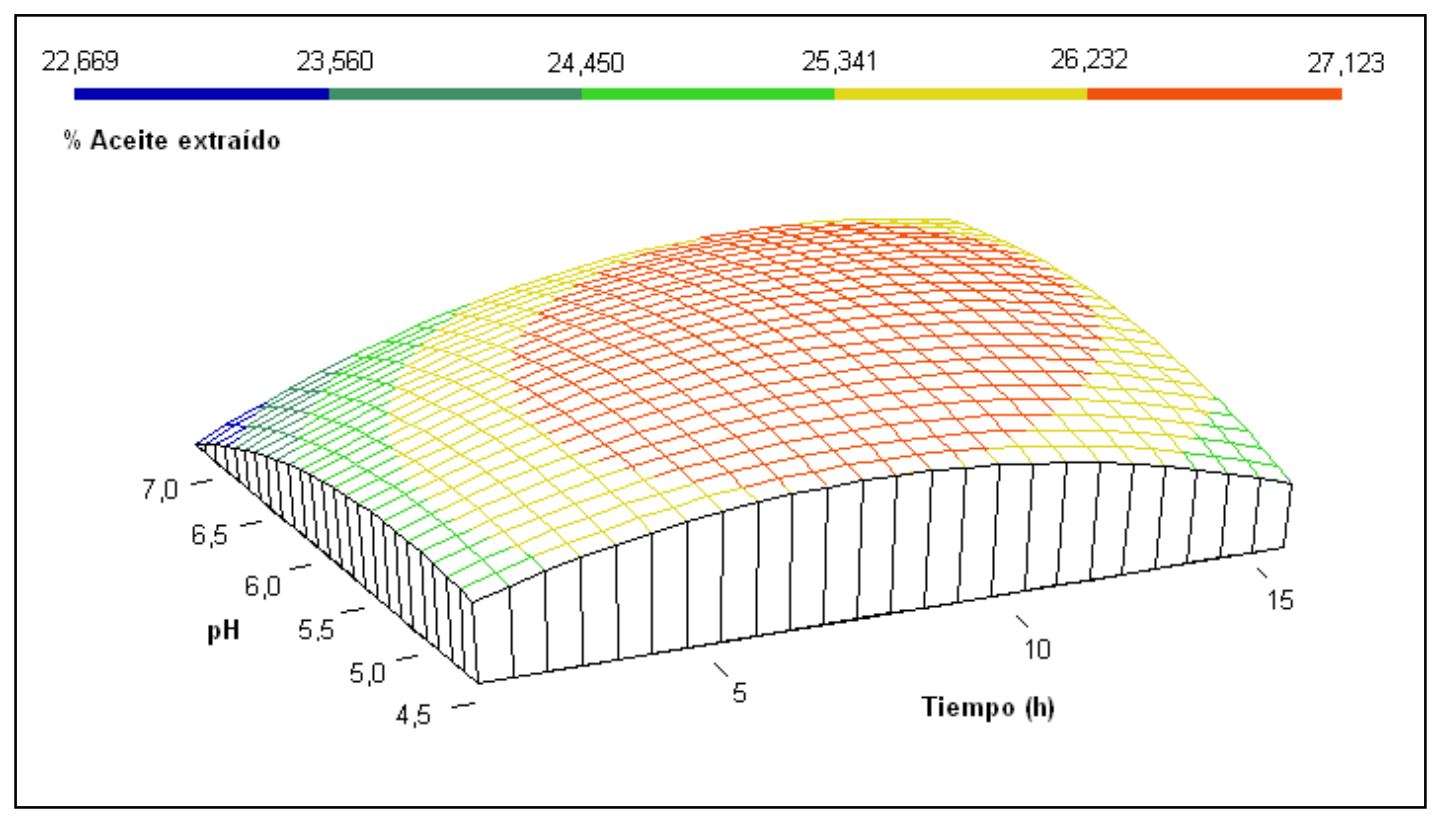

Figura 3.1: Superficie de respuesta para \% de aceite extraído a partir de laminado de soja, en función del pH y el tiempo de incubación enzimática.

Temperatura constante $=50^{\circ} \mathrm{C}$

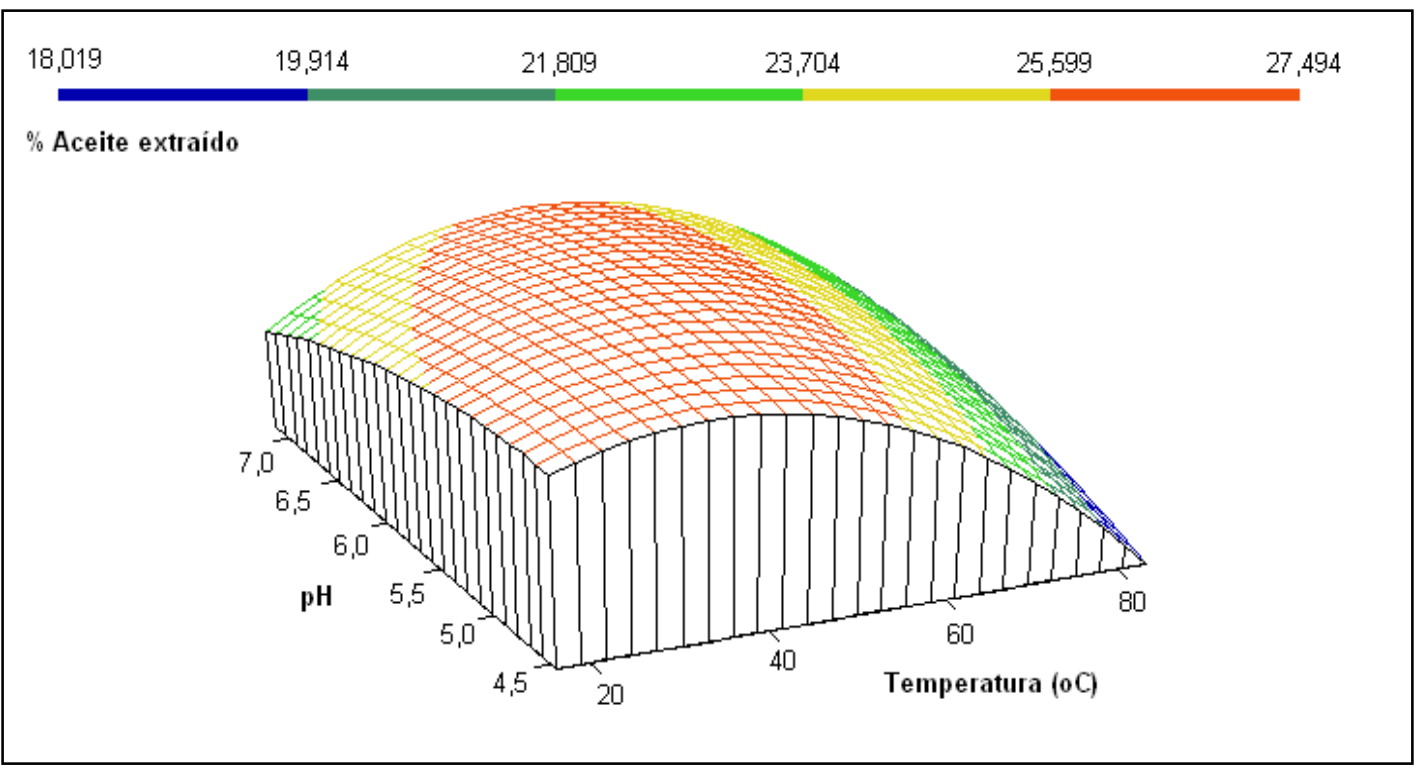

Figura 3.2: Superficie de respuesta para \% de aceite extraído a partir de laminado de soja, en función del pH y la temperatura de incubación enzimática.

Tiempo constante $=8 \mathrm{~h}$ 


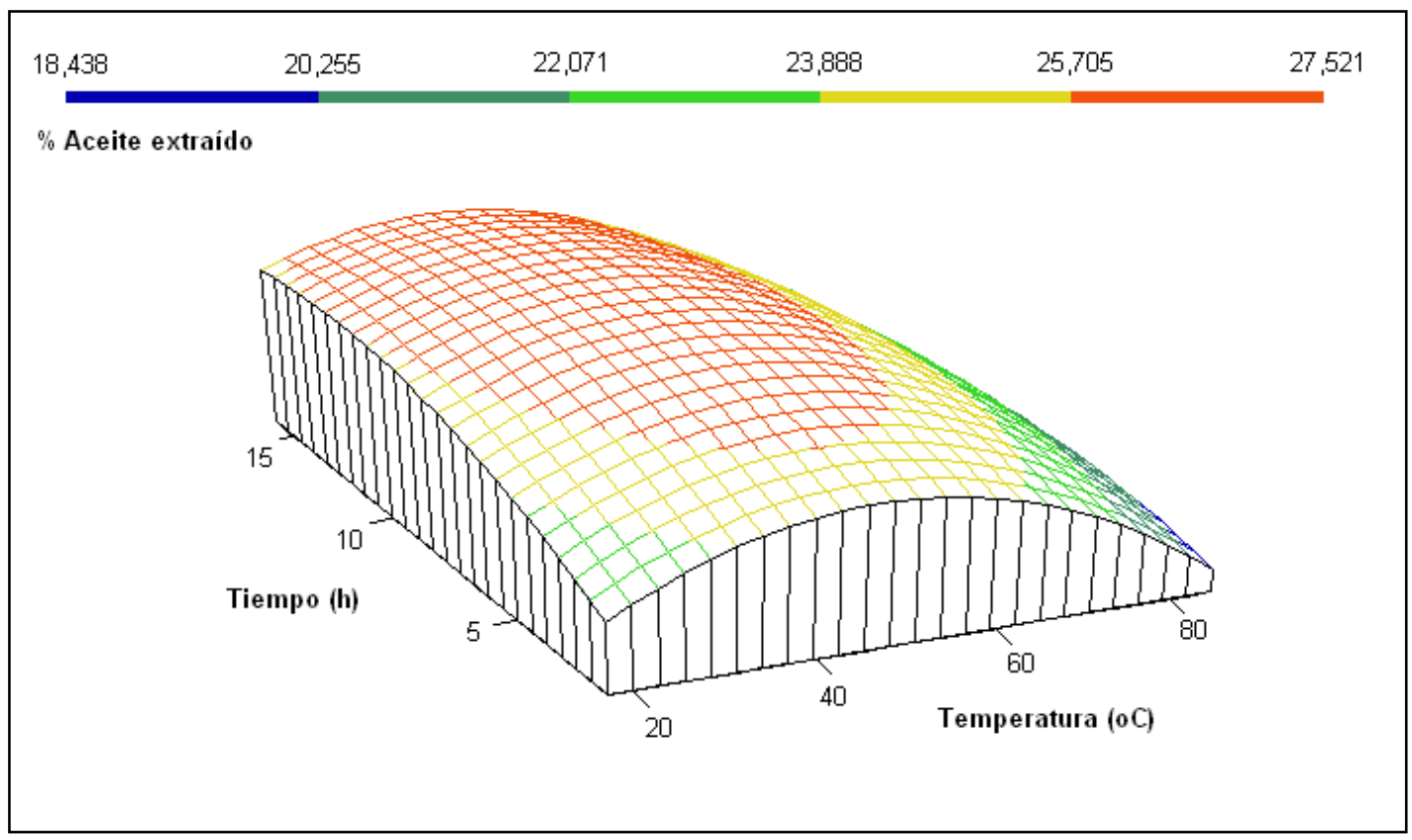

Figura 3.3: Superficie de respuesta para \% de aceite extraído a partir de laminado de soja, en función del tiempo y la temperatura de incubación enzimática.

$$
\mathrm{pH} \text { constante }=5,8
$$

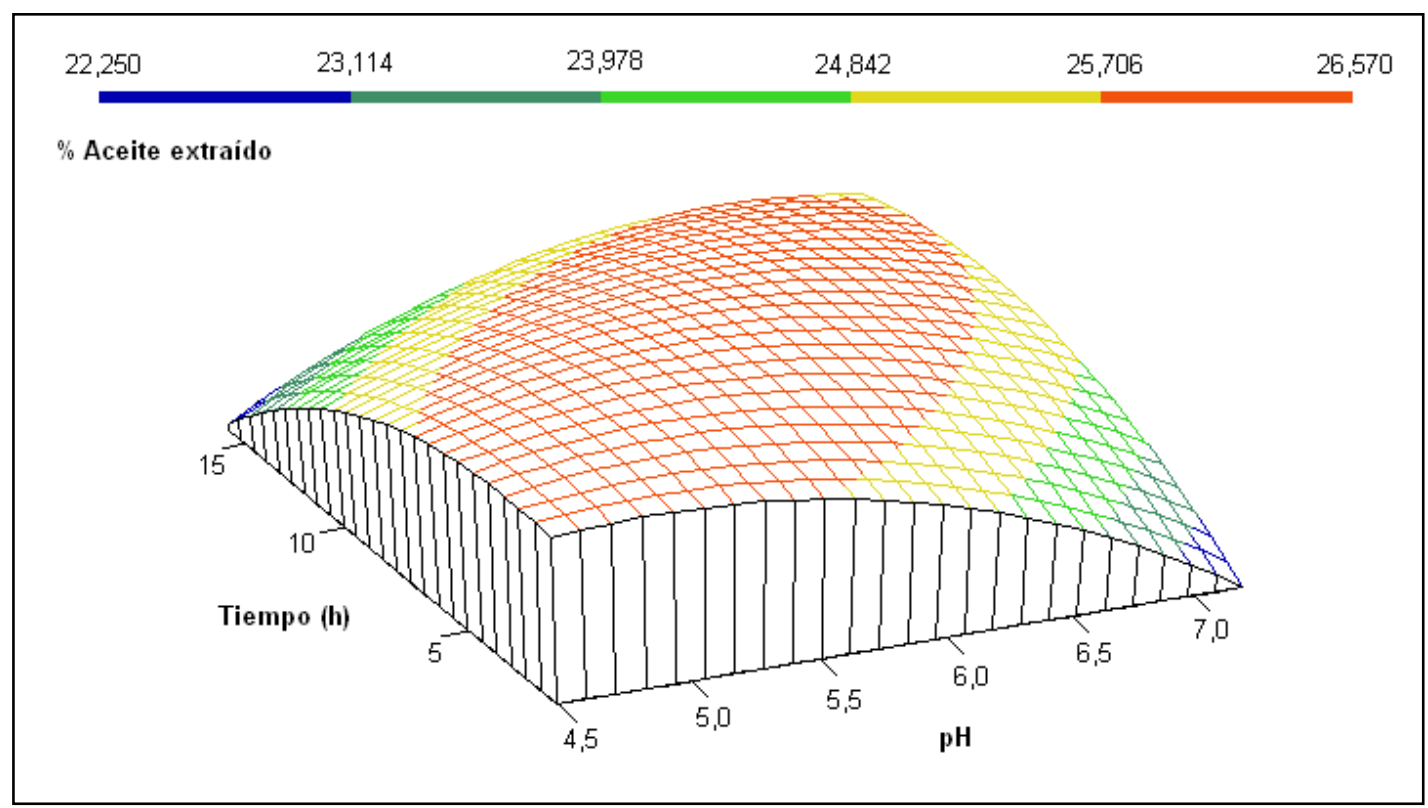

Figura 3.4: Superficie de respuesta para \% de aceite extraído a partir de expandido de soja, en función del tiempo y el pH de incubación enzimática.

Temperatura constante $=50^{\circ} \mathrm{C}$ 


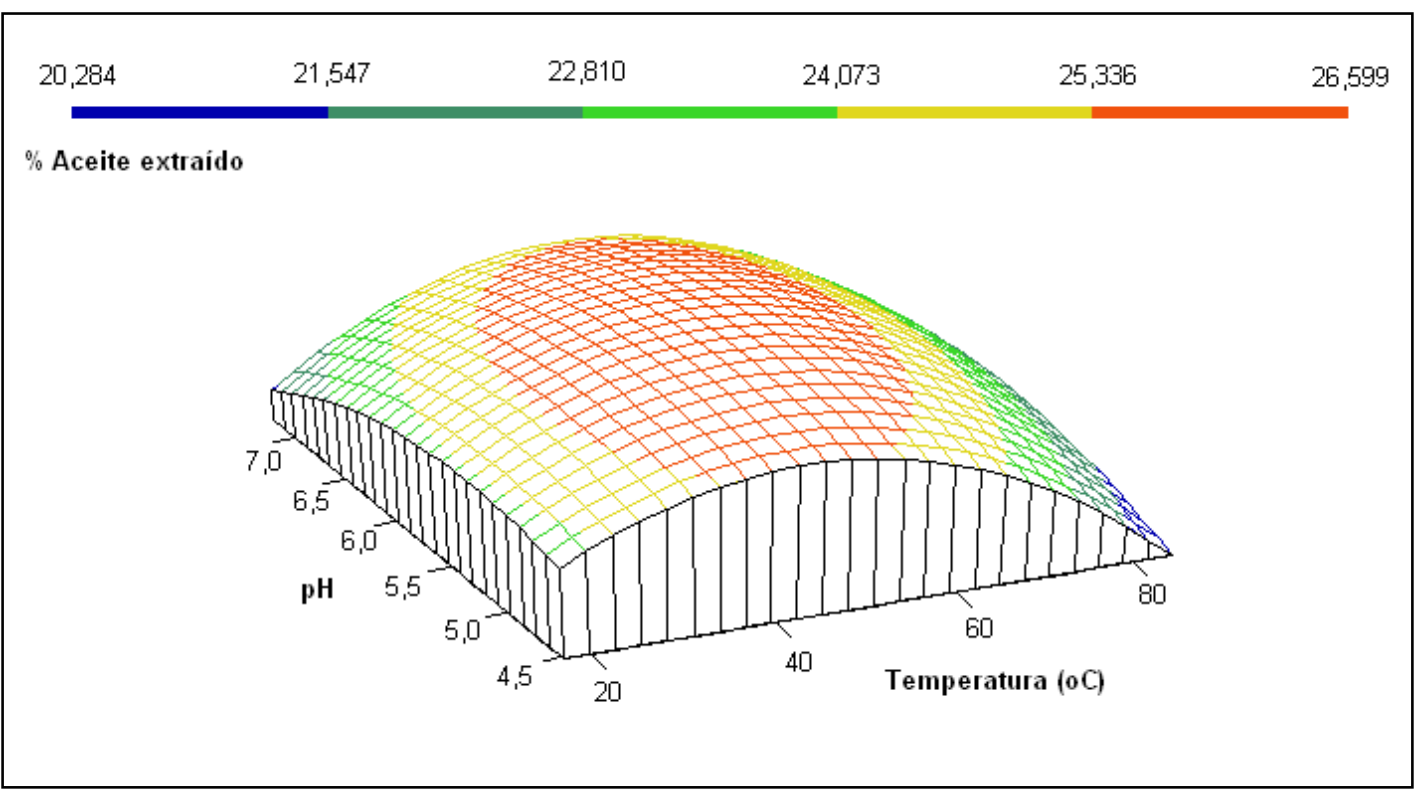

Figura 3.5: Superficie de respuesta para \% de aceite extraído a partir de expandido de soja, en función del pH y de la temperatura de incubación enzimática.

Tiempo constante $=8 \mathrm{~h}$

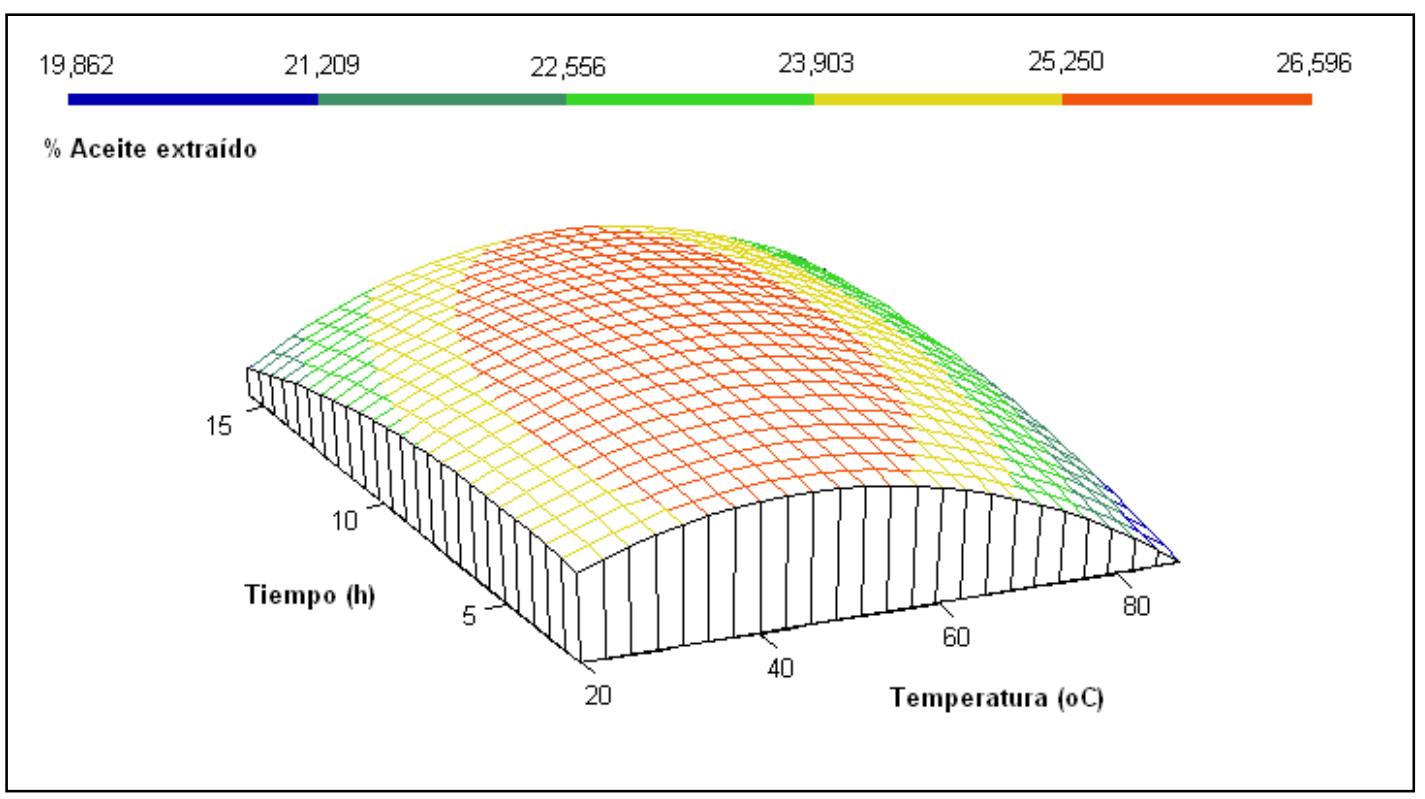

Figura 3.6: Superficie de respuesta para \% de aceite extraído a partir de expandido de soja, en función del tiempo y de la temperatura de incubación enzimática.

$\mathrm{pH}$ constante $=5,8$ 
La figura 3.1 representa las superficies de la respuesta para temperatura constante $\left(50^{\circ} \mathrm{C}\right.$ ), la figura 3.2 para tiempo constante (8 horas) y la figura 3.3 para $\mathrm{pH}$ constante $(5,8)$. En todos los casos, las superficies representadas corresponden a los valores del punto central para cada variable que se mantiene constante (ver Tabla 3.2).

Para laminado de soja, la variable que mayor influencia ejerce es la temperatura (ver figuras 3.1 a 3.3); la mayor parte de las enzimas utilizadas en los ensayos tienen rangos de temperaturas óptimas cercanos (ver Anexo I), coincidentes con la temperatura de máximo rendimiento. Este rendimiento es función directa de la actividad enzimática conjunta, ya que facilita la liberación del aceite por degradación de las estructuras celulares. No se observa una variación importante del rendimiento en relación al cambio de $\mathrm{pH}$. Esto puede deberse al rango estrecho de estudio y la gran variedad de enzimas utilizadas. Cada una de ellas presenta su propio pH óptimo: cuando una se encuentra en actividad máxima, las demás presentan actividades menores, al no encontrarse en su pH óptimo. Esta suposición es reforzada por el hecho de que la eficiencia de la extracción no es consecuencia de la sumatoria de las actividades individuales (Düsterhöft, 1993).

En las figuras $3.4,3.5$ y 3.6 se representan la función que describe el rendimiento en aceite (\%BS) de la extracción con pretratamiento acuoso enzimático para expandido de soja.

La figura 3.4 representa las superficies de la respuesta para temperatura constante $\left(50^{\circ} \mathrm{C}\right.$ ), la figura 3.5 para tiempo constante (8 horas) y la figura 3.6 para $\mathrm{pH}$ constante $(5,8)$. En todos los casos, las superficies representadas corresponden a los valores del punto central para cada variable que se mantiene constante (Tabla 3.3).

Para expandido de soja, las tres variables estudiadas resultan significativas en distintos grados. La mayor diferencia se observa en el caso de la variable $\mathrm{pH}$ de hidrólisis multienzimática. Esto puede deberse a la diferente estructura del sólido. El expandido de soja se obtiene por combinación de tratamientos hidrotérmico y mecánico. Los materiales tratados térmicamente exhiben mayor influencia respecto de la variable $\mathrm{pH}$ probablemente debido a que la acción de las proteasas sobre el rendimiento es más importante que las actividades carbohidratasas en este tipo de materiales (Tabla 3.3) (Rosenthal y col, 2001). El pH óptimo para las proteasas 
empleadas se encuentra en el rango de 5,5 a 6, mientras que las carbohidratasas exhiben rangos de $\mathrm{pH}$ óptimos más cercanos a 5 (ver Anexo I).

En la Tabla 3.7 se resumen las condiciones óptimas encontradas para obtener el máximo rendimiento en aceite para cada uno de los materiales sólidos ensayados. Estas condiciones óptimas son determinadas por derivación e igualación a cero de la función respuesta (punto estacionario).

Tabla 3.7: Condiciones óptimas de incubación enzimática para la obtención del máximo rendimiento teórico en aceite.

\begin{tabular}{l|c|c|c|}
\cline { 2 - 4 } & $\mathbf{p H}$ & Temperatura $\left(^{\circ} \mathbf{C}\right)$ & Tiempo (horas) \\
\hline Laminado & 5,4 & 38 & 9,7 \\
\hline Expandido & 5,8 & 43,5 & 5,8 \\
\hline
\end{tabular}

Se obtienen mejores rendimientos para laminado de soja $(27,59 \%$ BS en condiciones óptimas), la combinación de varios pretratamientos produce una mejora del rendimiento. En el caso expandido de soja, que es el material que ingresa directamente a la extracción con solvente, se obtiene un rendimiento menor $(26,64 \%$ BS en condiciones óptimas) comparado con el laminado. Estos resultados concuerdan con los obtenidos por Rosenthal y col. (2001), quienes obtuvieron mayores rendimientos de extracción a partir de materiales no tratados térmicamente (laminado) que los obtenidos a partir de materiales tratados térmicamente (expandido). Esto puede atribuirse a velocidades de hidrólisis menores para sustratos desnaturalizados por calor que las obtenidas con materiales no tratados térmicamente (Rosenthal y col., 2001). 


\subsection{CONCLUSIONES PARCIALES}

- El pretratamiento enzimático para alcanzar el máximo rendimiento de aceite extraído con hexano a partir, tanto de laminado como de expandido de soja, se obtiene por incubación con una mezcla de actividades enzimáticas celulasa, proteasa neutra, $\alpha$-amilasa, pectinasa, hemicelulasa y glucoamilasa.

- La calidad del aceite obtenido es similar a la obtenida para un aceite de soja crudo, sin refinar. El pretratamiento enzimático no afecta en forma significativa la calidad final del aceite extraído con enzimas como coadyuvantes tecnológicos.

- Se define una función polimómica, para cada tipo de sólido de soja, que establece las relaciones significativas entre las variables operacionales ensayadas y el rendimiento en aceite.

a Para el caso de laminado de soja, se encontró que el tiempo y la temperatura de incubación fueron variables significativas, siendo esta última la que mayor influencia ejerce sobre el rendimiento en aceite.

a Para el caso de expandido de soja, se encontró que las tres variables fueron significativas, identificando al $\mathrm{pH}$ como la variable que mayor influencia ejerce sobre el rendimiento en aceite.

- La optimización de variables operacionales de hidrólisis enzimática condujo a la obtención del máximo rendimiento en aceite para la extracción con hexano a partir de sólidos pretratados con las actividades multienzimáticas seleccionadas previamente.

- Con pretratamiento enzimático se obtienen rendimientos de aceite mayores a los obtenidos para extracción convencional sin tratamiento enzimático para ambos sólidos ensayados, laminado y expandido de soja. 
口 El pretratamiento enzimático sobre laminado de soja permite obtener rendimientos en aceite superiores a los obtenidos por extracción de expandido de soja hidrolizado. 
Capítulo 4

Efectos del pretratamiento enzimático sobre la velocidad de extracción de aceite de soja con hexano. 


\section{Efectos del pretratamiento enzimático sobre la velocidad de extracción de aceite de soja con hexano.}

Muchos compuestos orgánicos naturales se separan de sus estructuras originales mediante lixiviación. Los aceites vegetales se recuperan industrialmente a partir de las semillas oleaginosas, como la soja, mediante lixiviación con disolventes orgánicos, como el hexano (Treybal, 1980).

Para el presente caso en estudio, el sólido posee estructura celular, entonces la difusión interna dentro de los poros de esta matriz sólida es el paso determinante de la velocidad ya que ella resiste el proceso difusivo. En los fenómenos de difusión relacionados con el procesamiento de alimentos, el gradiente de concentración, que es la fuerza impulsora, generalmente depende del tiempo. Por ello, este tipo de fenómenos es bien representado por la 2da Ley de Difusión de Fick para estado no estacionario (Varsakas y col., 2005).

El desarrollo más conocido para los cálculos de lixiviación o extracción sólido-líquido está basado en determinar experimentalmente la cinética del proceso extractivo. Estos datos experimentales unidos a un modelo matemático que describa el fenómeno difusivo se emplean para obtener los coeficientes de difusión efectiva.

El pretratamiento enzimático provoca cambios en la estructura celular de la matriz sólida que contiene el aceite. Es necesario determinar la influencia de este cambio estructural que ocurre en el sólido sobre la velocidad de extracción. Por lo tanto, deben estimarse los coeficientes de difusión efectiva para cada tipo de sólidos: con y sin hidrólisis enzimática.

Los objetivos del presente capítulo son: 
- Modelizar la difusión en estado no estacionario que ocurre como parte del proceso de extracción de aceite a partir de sólidos con distintos grados de pretratamiento.

- Estimar coeficientes de difusión efectiva de aceite en hexano para laminado y expandido de soja con y sin tratamiento enzimático, a distintas temperaturas de extracción.

- Medir el efecto del pretratamiento enzimático sobre la velocidad de extracción por estimación de los coeficientes de difusión para todos los sólidos ensayados.

- Determinar la influencia de la temperatura sobre el fenómeno difusivo y proponer la aplicación del modelo de Arrhenius. 


\subsection{PARTE EXPERIMENTAL}

\subsubsection{Materiales.}

4.1.1.1 Laminado de soja: se utilizaron muestras de láminas de soja obtenidas de la planta industrial de Aceitera Bunge Argentina S.A., localizada en la ciudad de Tancacha en la Provincia de Córdoba. Este material se obtiene como resultado de la aplicación de los pretratamientos de molienda, acondicionamiento y laminado, cuyas operaciones se describen en la sección 1.3.4.

A fin de obtener una descripción cualitativa de la estructura celular del sólido (Tano-Debrah y col., 1996), se realizó microscopía óptica, tratando las muestras con colorantes específicos de las paredes celulares y de los lípidos. La figura 4.1 muestra imágenes de microscopía óptica 400x del material laminado de soja.

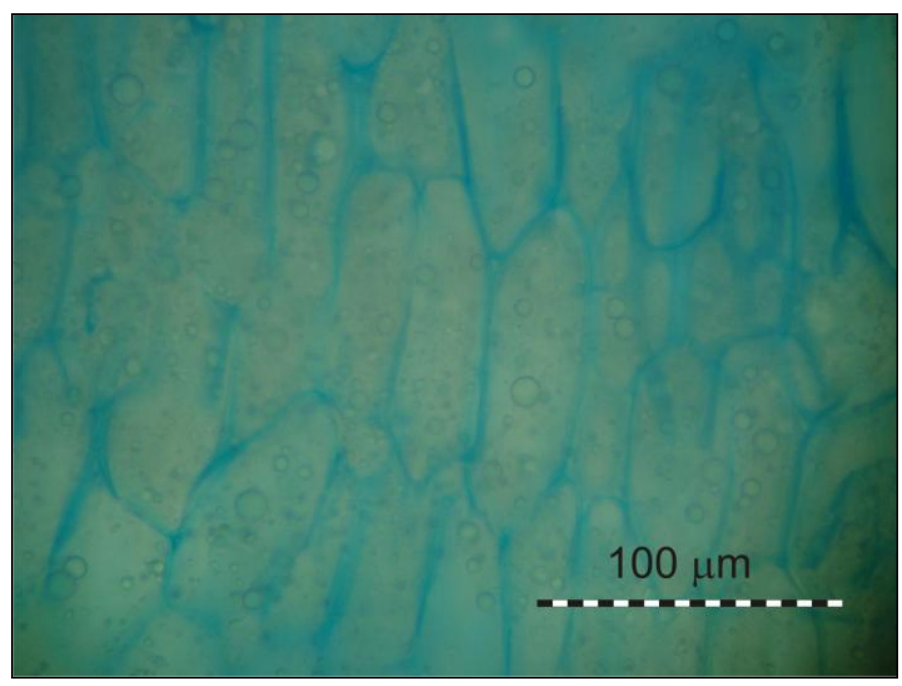

Figura 4.1: Microscopía óptica 400x de laminado de soja tratado con Azul Astral.

En las figuras 4.1 a 4.4 pueden observarse las células del cotiledón de soja de los distintos sólidos en corte longitudinal, las estructuras de los cuerpos proteicos y cuerpos lipídicos, la integridad de las membranas celulares teñidas mediante el empleo del colorante Azul Astral y pequeñas gotas libres de aceite, probablemente liberadas por la aplicación de los diferentes tratamientos fisicos, térmicos, mecánicos y enzimáticos según el tipo de sólido considerado. 
4.1.1.2 Expandido de soja: se utilizaron muestras de expandido de soja obtenidas de la planta industrial de Aceitera Bunge Argentina S.A., localizada en la ciudad de Tancacha en la Provincia de Córdoba. Este material se obtiene como resultado de la aplicación de los pretratamientos de molienda, acondicionamiento, laminado y expandido, cuyas operaciones se describen en la sección 1.3.4.

Para el material expandido se procedió de forma similar al anterior y se obtuvo la imagen de microscopía óptica mostrada en la Figura 4.2.

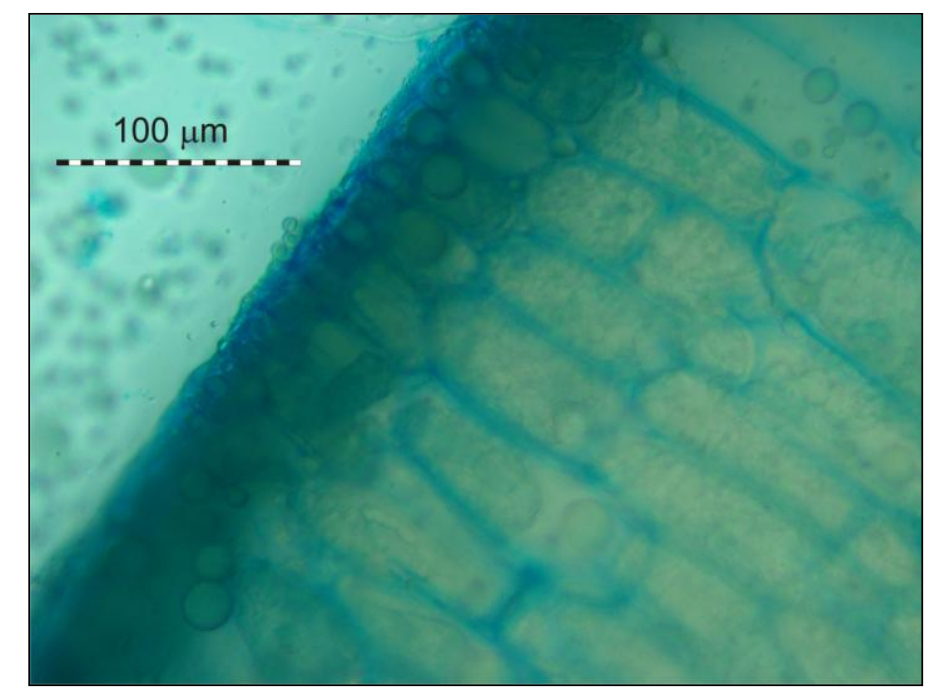

Figura 4.2: Microscopía óptica 400x de expandido de soja tratado con Azul Astral.

En este material, también puede observarse que las paredes celulares han conservado un alto grado de integridad, se pueden distinguir las células del cotiledón en corte longitudinal y los cuerpos proteicos y lipídicos. Sin embargo, se evidencia más aceite libre por la presencia de gotas de mayor tamaño con respecto al material sólo laminado, probablemente debido a la acción termomecánica del tratamiento de expandido.

4.1.1.3 Laminado de soja hidrolizado: se emplean muestras de laminado de soja hidrolizado obtenidas por aplicación del pretratamiento enzimático óptimo determinado en el Capítulo 3 sobre el material descripto en la sección 4.1.1.1.

En la figura 4.3 se muestra la microscopía óptica realizada sobre laminando hidrolizado, en la cual puede observarse que el tejido vegetal se encuentra menos 
compacto, estando las células de cotiledón menos adheridas entre sí. Además se observan algunas con su pared celular parcialmente destruida, probablemente debido a la acción hidrolasa de las enzimas empleadas durante el pretratamiento. En la figura 4.5 a) puede observarse una imagen de tamaño real del mismo material.

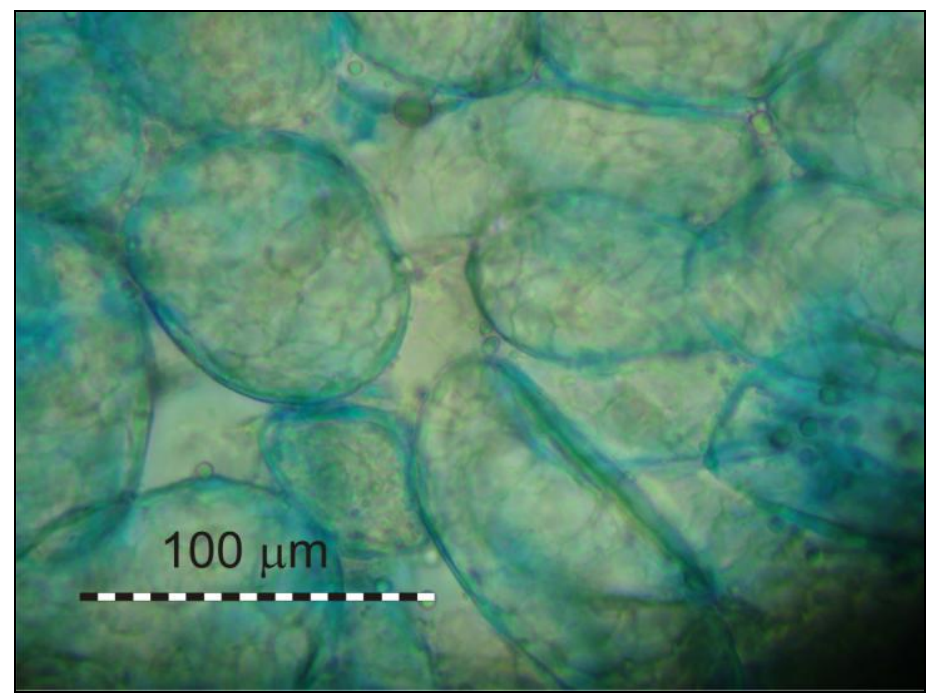

Figura 4.3: Microscopía óptica 400x de laminado de soja hidrolizado tratado con Azul Astral.

4.1.1.4 Expandido de soja hidrolizado: se emplean muestras de expandido de soja hidrolizado obtenidas por aplicación del pretratamiento enzimático óptimo determinado en el Capítulo 3 (ver condiciones de la incubación enzimática en Tabla 3.7) sobre el material descripto en la sección 4.1.1.2.

Finalmente, en la figura 4.4 se muestra la microscopía óptica realizada sobre expandido hidrolizado, en la cual puede observarse que la total falta de adhesión del tejido vegetal. Además se observa una mayor degradación de las paredes de las células individuales en comparación con los demás sólidos, probablemente por tratarse del material con mayor número de tratamientos aplicados. En la figura 4.5 A) puede observarse una imagen de tamaño real del mismo material. 


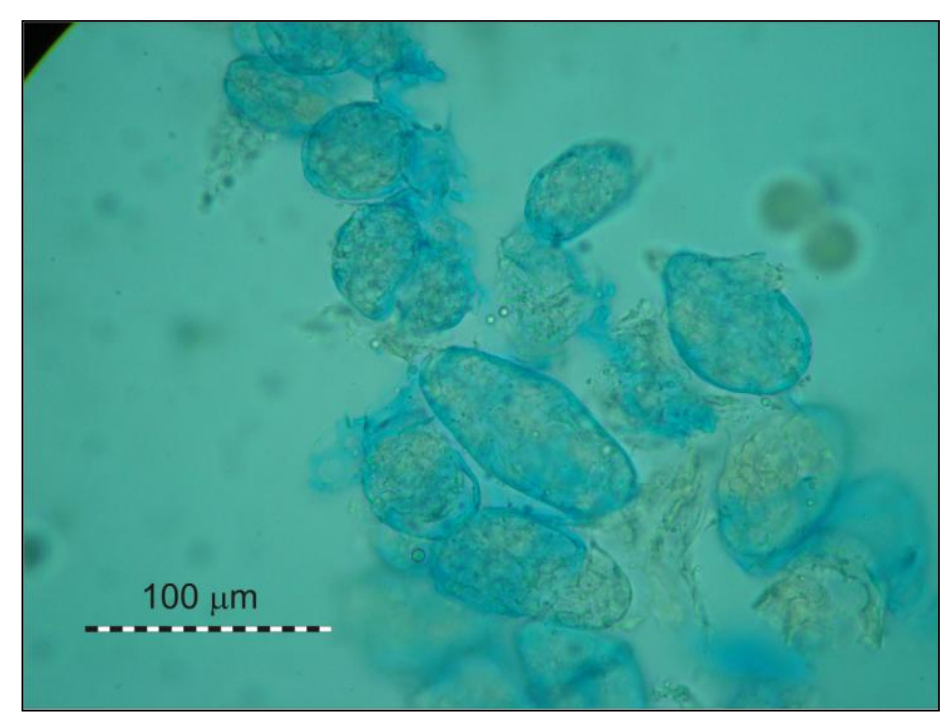

Figura 4.4: Microscopía óptica 400x de expandido de soja hidrolizado tratado con Azul Astral.

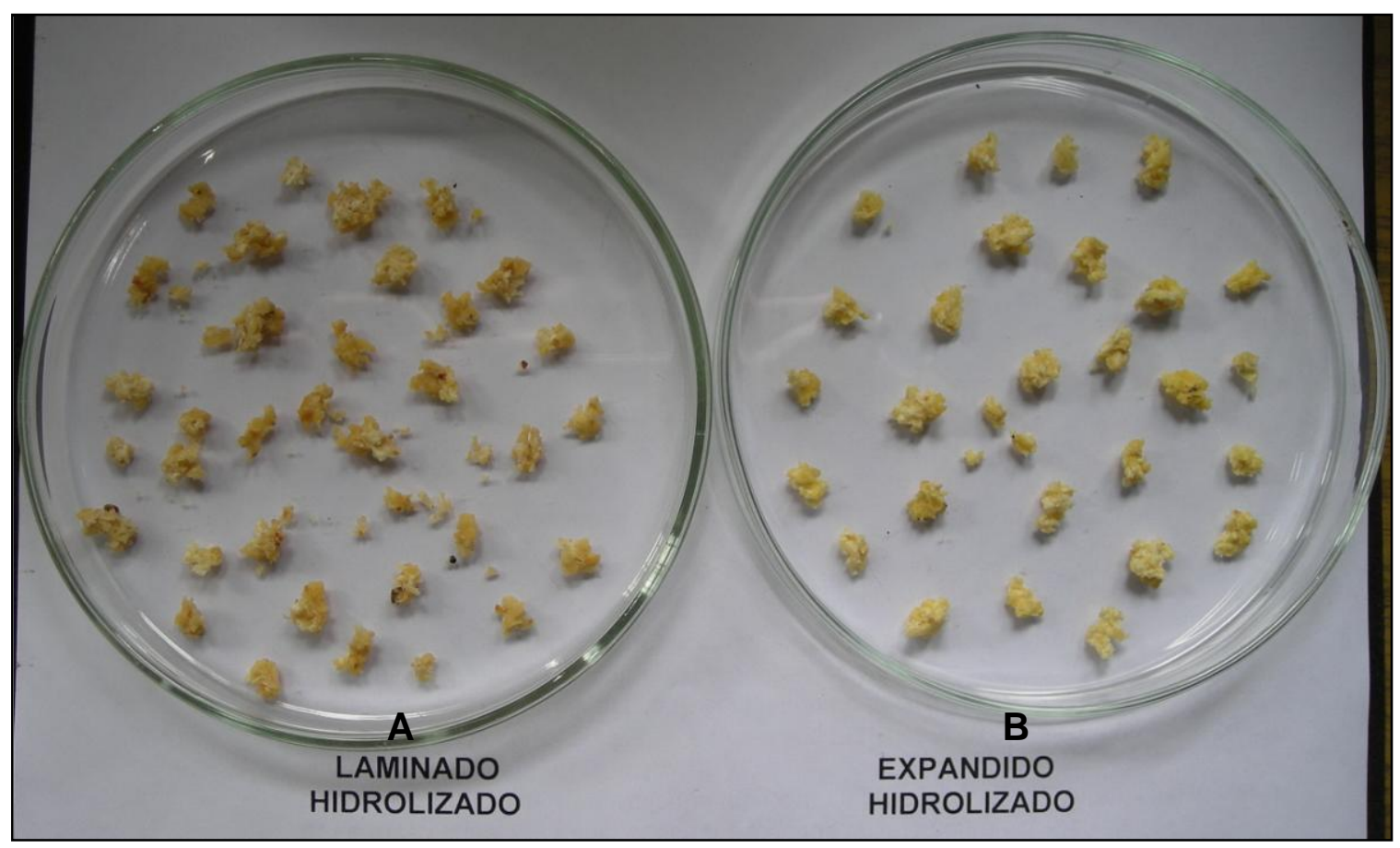

Figura 4.5: Sólidos de soja con incubación enzimática:

A) Laminado de soja hidrolizado.

B) Expandido de soja hidrolizado. 


\subsubsection{Metodologías}

4.1.2.1 Pretratamiento enzimático. Ver Metodologías Generales del Capítulo 2.

\subsubsection{Modelo difusional y determinación de coeficientes de difusión efectiva.}

Para medir la influencia de la hidrólisis enzimática sobre la velocidad de extracción, se debe conocer el mecanismo de difusión. Una manera de caracterizar y cuantificar este fenómeno es a través de la estimación de coeficientes de difusión efectiva para el aceite que difunde durante la extracción con hexano a partir de sólidos de soja con y sin hidrólisis enzimática.

Se han usado una gran variedad de métodos para determinar coeficientes de difusión, sin embargo, existe una gran dificultad para comparar los resultados así como de sistematizar la información disponible (Doulia y col., 2000).

Fan y col. (1948) midieron coeficientes de difusión de aceite a partir de láminas de maní empleando distintos solventes de extracción, entre ellos hexano. Utilizaron el tratamiento teórico de la Segunda Ley de Fick y obtuvieron correlación entre los datos experimentales y las curvas teóricas predichas por el modelo fickiano. Determinaron la evolución de la cantidad de aceite en función del tiempo para diferentes contenidos iniciales de humedad en las láminas de maní. Los coeficientes de difusión que estimaron fueron de orden de magnitud de $10^{-11} \mathrm{~m}^{2} \mathrm{~s}^{-1}$. El método de cálculo involucró aplicar la solución a la Segunda Ley de Fick a tiempos largos aplicando logaritmos naturales seguido de una regresión lineal de la concentración adimensional de soluto respecto del tiempo.

Un método similar de cálculo de difusividad efectiva emplearon Sineiro y colaboradores (1996) para medir el efecto del flujo pulsado del solvente sobre la velocidad de extracción de polifenoles con etanol a partir de semillas de girasol desengrasadas. Las difusividades efectivas calculadas fueron en el orden de magnitud de $10^{-12}$ a $10^{-13} \mathrm{~m}^{2} \mathrm{~s}^{-1}$ y se identificaron dos zonas de distinto comportamiento y para cada una de ellas se estimó un coeficiente de difusión efectiva. 
En el caso de girasol, otros autores trabajaron a partir de harina y extrajeron aceite empleando hexano en una operación en batch (Carrín y Capriste, 2008). Obtuvieron coeficientes de difusión por comparación de los datos experimentales con la solución de Crank (1959) para difusión en estado no estacionario. Los valores de difusividad de aceite en hexano fueron en el orden de magnitud de $10^{-10} \mathrm{~m}^{2} \mathrm{~s}^{-1}$.

Smith (1952) determinó una constante K, basada en la Segunda Ley de Fick. Los ensayos de extracción de aceite se realizaron sobre láminas de maní empleando tricloroetileno como solvente extractor. Los valores de esta constante $\mathrm{K}$ fueron determinados para experimentos en batch, semibatch y percolación. El coeficiente de partición puede usarse para describir las condiciones de equilibrio de un soluto difundiendo desde un sólido hacia una solución acuosa. Este es definido como la relación entre la concentración de soluto en el sólido y la concentración de soluto en el medio cuando la difusión ha terminado (Varzakas y col., 2005).

Para obtener la difusión acorde a la Segunda Ley de Fick, tal como han planteado numerosos autores (Fan y col., 1948; Carrín y Crapiste, 2008; Smith, 1952; Sineiro y col., 1996; Şaşmaz, 1996), deben darse las siguientes condiciones:

1 - El coeficiente de difusión debe ser una constante independiente del espesor o del radio de la partícula sólida.

2 - La estructura del sólido debe ser razonablemente homogénea e isotrópica.

3 - La distribución de aceite en la célula debe ser uniforme.

4 - El espesor de la lámina debe ser despreciable con respecto al largo de la misma, cuando el sólido se considere que es una lámina.

5 - Para el caso de láminas, el espesor de las mismas debe ser uniforme y el mismo para todas las láminas extraídas al mismo tiempo.

6 - Para el caso de esferas, el radio del sólido debe ser uniforme y el mismo para todas las partículas sólidas extraídas al mismo tiempo.

La transferencia de masa desde la fase sólida a la líquida se asume dominada por la resistencia interna. En el caso de una lámina, (ver Figura 3.1, laminado de soja) como el área superficial en las dos caras de la misma es mucho mayor que el área a lo largo del borde, es razonable suponer que la transferencia de masa se lleva a cabo principalmente en dirección perpendicular a las caras. Por eso, en este caso, se puede considerar sólo difusión unidireccional (Hinnes y Maddox, 1984).

$\mathrm{Si}$ estas condiciones son asumidas, entonces, la ecuación para difusión en una lámina infinita con espesor 2l, puede escribirse como la ecuación 4.1: 
$\frac{\partial c}{\partial t}=\operatorname{Def} \frac{\partial^{2} c}{\partial x^{2}}$

ecuación 4.1

Con las siguientes condiciones iniciales y límites, para un volumen ilimitado y perfectamente agitado del seno del líquido, en el cual la concentración inicial de soluto es 0 :

Para $\mathrm{t}=0 \quad \mathrm{C}=\mathrm{C}_{\mathrm{o}}$

Para $t>0 \quad c=0 \quad$ en $x=-1$ y $x=1$

La solución de la ecuación es entonces:

$\frac{c}{c_{o}}=\frac{4}{\pi} \sum_{n=0}^{\infty} \frac{(-1)^{n}}{(2 n+1)} \cdot \exp \left[\frac{-\operatorname{Def}(2 n+1)^{2} \pi^{2} t}{4 l^{2}}\right] \cdot \frac{\cos (2 n+1) \pi x}{2 l}$

ecuación 4.2

Donde $c_{0}$ es la concentración inicial de soluto; I es el semiespesor de la lámina; $t$ es el tiempo de difusión y Def es el coeficiente de difusión efectivo del soluto. La cantidad de soluto que queda en el sólido en cualquier momento dado, tomando el tiempo constante, se puede determinar al integrar la relación de concentraciones $\mathrm{c} / \mathrm{c}_{0}$ sobre el espesor:

$\frac{c}{c_{0}}=\frac{4}{\pi} \int_{0}^{l} \sum_{n=0}^{\infty} \frac{(-1)^{n}}{(2 n+1)} \exp \left[\frac{-\operatorname{Def}(2 n+1)^{2} \pi^{2} t}{4 l^{2}}\right] \cos \frac{(2 n+1) \pi t}{2 l}$ ecuación 4.3

resolviendo la integral anterior se tiene:

$$
\frac{q}{q_{0}}=\frac{8}{\pi^{2}} \sum_{n=0}^{n=\infty} \frac{1}{(2 n+1)^{2}} e^{-(2 n+1)^{2} \pi^{2} \frac{D_{e f} t}{(2 l)^{2}}}
$$

ecuación 4.4

donde:

$q$ = cantidad de aceite por unidad de peso del sólido a t segundos luego de que la difusión se ha iniciado,

$\mathrm{q}_{0}=$ cantidad inicial de aceite en el sólido $\mathrm{a} t=\mathrm{t}_{0}$, 
$2 \mathrm{l}$ = espesor de la lámina

$D_{\text {ef }}=$ constante de difusión efectiva en $\mathrm{m}^{2} \mathrm{~s}^{-1}$.

Crank (1959) y Carslaw y Jaeger (1959) proporcionan soluciones gráficas para la ecuación 4.4 en el caso del problema análogo de transferencia de calor.

Debido a que los triglicéridos que componen un aceite vegetal poseen estructuras y pesos moleculares diferentes, resulta menos engorroso a los fines de cálculo medir cantidad de aceite respecto de la masa del sólido. Por ello, se convierte la relación de concentraciones $\mathrm{c} / \mathrm{c}_{\circ}$ en una relación de cantidades $\mathrm{q} / \mathrm{q}_{\mathrm{o}}$ (Fan y col., 1948).

A tiempos largos la serie converge y, por lo tanto, pocos términos son suficientes para la mayoría de los cálculos prácticos. En efecto, todos los términos de la serie, excepto el primero, son despreciables. La ecuación se reduce a:

$$
\frac{q}{q_{0}}=\frac{8}{\pi^{2}} e^{-\pi^{2} \frac{D_{e} t}{(2 l)^{2}}}
$$

ecuación 4.5

La ecuación 4.5 es linealizada aplicando logaritmo y graficada en función del tiempo t. La pendiente de esta recta puede usarse para evaluar la constante de difusión D.

$$
\log \frac{q}{q_{0}}=-0,0911-4,286 \frac{D_{e f} t}{(2 l)^{2}}
$$

ecuación 4.6

La recta es ajustada siguiendo el procedimiento que se describió en la sección 4.1.2.2.1.

Por otro lado, si una esfera (ver Figura 2.2, expandido de soja y Figura 4.5, sólidos hidrolizados) con macroporos grandes que comienzan en la superficie y atraviesan el sólido en forma radial hasta el centro, inicialmente con una concentración uniforme, se sumerge repentinamente en un volumen grande de liquido perfectamente agitado, la transferencia de masa desde la fase sólida hasta la fase líquida se supone dominada por la resistencia interna. La difusividad efectiva del sólido es constante a través de la esfera y se puede escribir la ecuación diferencial que describe el proceso de difusión en coordenadas esféricas como (Hinnes y Maddox, 1984): 
$\frac{\partial c}{\partial t}=D e f\left(\frac{\partial^{2} c}{\partial r^{2}}+\frac{2}{r} \cdot \frac{\partial c}{\partial r}\right)$

ecuación 4.7

Con las siguientes condiciones iniciales y límites, para un volumen ilimitado y perfectamente agitado del seno del líquido, en el cual la concentración inicial de soluto es 0 :

Para $t=0$

$\mathrm{C}=\mathrm{C}_{0}$

Para $t>0$

$\mathrm{C}=0$

en $r=a$

La solución a la ecuación 4.7 es entonces:

$\frac{c}{c_{0}}=\frac{2 a}{\pi} \sum_{n=1}^{\infty} \frac{(-1)^{n}}{n} \cdot \exp \left[-\frac{D e f \cdot n^{2} \cdot \pi^{2} \cdot t}{a^{2}}\right] \cdot \operatorname{sen} \frac{n \cdot \pi \cdot r}{a}$

ecuación 4.8

Donde $\mathrm{c}_{0}$ es la concentración inicial de soluto; a es el radio de la esfera; $\mathrm{t}$ es el tiempo de difusión y Def es el coeficiente de difusión efectivo del soluto. La cantidad de soluto que queda en el sólido en cualquier momento dado, tomando el tiempo constante, se puede determinar al integrar la relación de concentraciones $c / c_{0}$ en todo el volumen de la esfera:

$\frac{c}{c_{0}}=\frac{2 a}{\pi} \int_{n=1}^{\infty} \frac{(-1)^{n}}{n} \cdot \exp \left[-\frac{D e f \cdot n^{2} \cdot \pi^{2} \cdot t}{a^{2}}\right] \cdot \operatorname{sen} \frac{n \pi r}{a}$

ecuación 4.9

Entonces, la cantidad de soluto que queda en el sólido a un tiempo t respecto al inicial es:

$\frac{q}{q_{0}}=\frac{6}{\pi^{2}} \sum_{n=1}^{n=\infty} \frac{1}{n^{2}} e^{-n^{2} \pi \frac{D e f . t}{r^{2}}}$

ecuación 4.10

Las soluciones gráficas para la ecuación 4.10 son dadas por Crank (1959) en forma de perfiles de concentración para diferentes relaciones $r / a$, es decir, distintas distancias desde o hacia el centro de la esfera porosa. Como se discutió para el caso de lámina, convierte la relación de concentraciones $c / c_{0}$ en una relación de cantidades q/qo (Fan y col., 1948). 
La serie converge a tiempos suficientemente largos, por lo tanto el primer término es suficiente:

$$
\frac{q}{q_{0}}=\frac{6}{\pi^{2}} e^{-\pi^{2} \frac{\text { Def.t }}{r^{2}}}
$$

Esta ecuación es linealizada y graficada en función al tiempo t. Como en el caso anterior, la pendiente de esta recta puede usarse para evaluar el coeficiente de difusión:

$$
\log \frac{q}{q_{0}}=-0,216-9,869 \frac{\text { Def.t }}{r^{2}}
$$

La recta es ajustada siguiendo el procedimiento que se describió en la sección

\subsubsection{1.}

En el caso de laminado de soja sin hidrolizar se emplea la forma geométrica de placa plana (ver Figura 2.1) mientras que para el resto de los sólidos ensayados (laminado hidrolizado, expandido sin hidrolizar y expandido hidrolizado) se emplea la forma geométrica de esfera. En el caso de laminado tratado con enzimas, se emplea la forma geométrica de esfera, debido a la disgregación del sólido que es provocada intrínsecamente por el tratamiento enzimático y por la incubación en medio acuoso. Luego del secado se obtuvieron partículas sólidas porosas que pueden asimilarse a la forma de esfera (ver Figura 4.5). Todas las partículas esféricas se seleccionaron en función de su tamaño por medio de tamices de diámetros entre 0,005 y 0,01 m. La longitud equivalente empleada para estos sólidos, a los fines del cálculo, fue el promedio de los radios de esfera máximos y mínimos de los tamices empleados en la selección de muestra (ver Tablas 4.6 a 4.8).

\subsection{Ajuste lineal}

Para ajustar los datos experimentales a rectas se utilizó el criterio de cuadrados mínimos, que exige que la suma de los cuadrados de las desviaciones de los puntos observados con respecto al promedio de la línea recta $(y=a+b x)$ para un 
mismo valor $x$ sea mínima. Para determinar la pendiente b, llamada también coeficiente de regresión se empleó la expresión:

$b=\frac{\sum(x-\bar{x}) \cdot(y-\bar{y})}{\sum(x-\bar{x})^{2}}$

ecuación 4.13

Para establecer el intervalo de confianza para el parámetro de regresión poblacional $\beta$, estimado por b, se utilizó la siguiente ecuación:

$$
I C(\beta)=b \pm \frac{t_{0,05} \cdot S_{X . Y}}{\sqrt{\sum(x-\bar{x})^{2}}}
$$

ecuación 4.14

donde $s_{X . Y}$ es la desviación estándar de y manteniendo $x$ constante y $t_{0,05}$ es el valor t tabulado para n-2 grados de libertad y $95 \%$ de confianza, siendo $n$ el número de pares de datos experimentales.

La desviación estándar o error estándar se determinó a partir de la raíz cuadrada de la estimación insesgada de la varianza en torno a la regresión, como el cuadrado de los residuos con ( $\mathrm{n}-2)$ grados de libertad según:

$$
s_{X . Y}=\sqrt{\frac{\sum(y-\hat{y})^{2}}{n-2}}
$$

ecuación 4.15

Se pueden estimar los valores $\hat{y}$ para la variable dependiente a partir de la expresión de la ecuación de regresión $\bar{y}=\bar{y}+b \cdot(x-\bar{x})$ ya que la recta de regresión pasa por la media muestral (Steel y Torrie, 1997).

\subsection{Consideraciones y estrategias experimentales}

El objetivo primario del componente experimental de las determinaciones de coeficientes de difusión es la selección y obtención de una serie de curvas de concentración versus tiempo, que deben ser adecuadas al modelo elegido. 


\section{Preparación de muestra}

La primera consideración es asegurar que las variaciones de concentración de soluto son sólo debidas al proceso difusivo. En algunos casos, el proceso de corte o molienda puede liberar algunos solutos. Deben usarse muestras de una sola variedad del material, de madurez consistente e idealmente obtenidas de la misma fuente. Los materiales vegetales deben obtenerse idealmente de un solo batch y almacenadas bajo condiciones que promuevan la mínima actividad metabólica.

La preparación de la muestra se requiere para obtener una sección de tejido que sea de forma geométrica consistente con el modelo usado. Se pueden obtener cilindros de dimensiones consistentes usando un molde circular de diámetro fijo. Las láminas pueden obtenerse por corte de rodajas a partir de los cilindros y registrar el promedio estadístico del espesor. Si el experimento se lleva a cabo con partículas pequeñas, entonces el material debe molerse y obtener una distribución de tamaños de partícula adecuada al modelo.

Como los tejidos presentan heterogeneidad estructural, las regiones que posean diferente estructura deben evitarse a no ser que el efecto de cada región sea el objeto de estudio (Fan y col., 1948). En el caso de estructuras anisotrópicas, hay que tener cuidado de aplicar el instrumento de corte en el mismo eje cada vez. Pueden ocurrir variaciones intrínsecas entre las distintas muestras. Sin embargo, esto puede reducirse determinando adecuadamente el tamaño de la muestra base, la cual se elige aleatoria y repetidamente para obtener una variación aceptable en el contenido de soluto (Varzakas y col., 2005).

\section{Medio líquido de difusión}

$\mathrm{Si}$ el material tiene una densidad igual o menor que la densidad de la muestra, hay que hacer dos consideraciones importantes. La primera es que el material necesita mantenerse dentro del bulk del solvente por algún tipo de red o soporte (Binkley y Wiley, 1981). Segundo, el sólido debe estar embebido de solvente si se realizan mediciones sobre el sólido durante este período, ya que se pueden producir disminuciones de concentración de soluto que pueden atribuirse falsamente al proceso difusivo. Se puede emplear un paso de pre-inmersión para aliviar estos efectos y permitir un período de tiempo definido de contacto con el solvente, 
suficiente para asegurar que el solvente ha desplazado el aire en los espacios vacíos (Valzakas y col., 2005).

\section{Agitación}

El medio líquido de difusión debe estar agitado por algún método para alcanzar la distribución de calor y satisfacer el requerimiento del modelo de ausencia de resistencia externa a la transferencia de masa.

\section{Muestreo para determinación de concentración}

La extensión de la difusión puede monitorearse por determinación de concentraciones de soluto en la fase sólida o en la fase líquida. Las concentraciones en fase líquida son relativamente fáciles de medir y el error involucrado no es significativo. Sin embargo, esto podría implicar que las condiciones límite cambian con el tiempo y entonces debe emplearse un modelo difusivo más complicado.

En la práctica, se utiliza un gran exceso de volumen tal que los cambios en la concentración de la fase líquida durante el experimento sean despreciables. La extensión de la difusión es determinada por recolección de muestras sólidas y determinación de la cantidad de soluto remanente. Este método simplifica la matemática pero pueden producirse errores en el muestreo debido a falta de homogeneidad (Varzakas y col., 2005).

\subsubsection{Efecto de la temperatura}

La difusividad es una función de la temperatura, presión y concentración. Frecuentemente, la relación entre la difusividad efectiva y la temperatura absoluta sigue un proceso de primer orden descripto por la relación de Arrhenius, donde Aa es el factor preexponencial:

$$
D_{e f}=A_{a} \cdot e^{\frac{-E a}{R T}}
$$

ecuación 4.16

Esta relación puede caracterizarse numéricamente por determinación de la energía de activación, Ea $\left(\mathrm{KJmol}^{-1}\right.$ ) (Varzakas y col., 2005). La energía de activación del proceso difusivo puede determinarse linealizando la expresión de la ecuación 4.16 y 
graficando el In $D_{\text {ef }}$ en función de $1 / T$. La pendiente de esta recta permite el cálculo de la energía de activación a partir de los datos experimentales.

Se utilizan baños termostatizados para contener directamente un volumen infinito de solvente o para mantener los recipientes que contienen la cantidad de muestra apropiada junto con un volumen finito del solvente. En el último caso, es importante prevenir las pérdidas de solvente por evaporación. Si el material tiene dimensiones pequeñas o tiene una estructura relativamente abierta, entonces se alcanza rápidamente la temperatura deseada por inmersión en el solvente y el tiempo requerido para alterar la temperatura medida es mínimo (Varsakas y col., 2005).

\subsubsection{Procedimiento experimental}

4.1.2.4.1 Tratamiento enzimático: El pretratamiento enzimático de los sólidos se realiza como se describe en la sección 3.1.2.2. Se emplean las condiciones experimentales encontradas óptimas en el desarrollo del capítulo 3. Las mismas se resumen en la Tabla 4.1. Los sólidos hidrolizados son secados en estufa durante 1 hora a $120^{\circ} \mathrm{C}$.

Tabla 4.1: Condiciones óptimas para el pretratamiento de diferentes materiales de partida.

\begin{tabular}{l|c|c|c}
\hline Material de partida & $\begin{array}{c}\text { Temperatura } \\
\left({ }^{\circ} \mathrm{C}\right)\end{array}$ & $\mathrm{pH}$ & Tiempo (h) \\
\hline Laminado & 38 & 5,4 & 9,7 \\
Expandido & 43,5 & 5,4 & 5,8 \\
\hline
\end{tabular}

4.1.2.4.2. Determinación de la evolución de la concentración con el tiempo: Las muestras fueron secadas en estufa durante 1 hora a $120{ }^{\circ} \mathrm{C}$ para remover restos de humedad y trabajar a contenidos de humedad constante en todos los ensayos (< 10\%). Para determinar la evolución de la concentración con el tiempo, se colocó un pequeño cartucho de tela conteniendo la muestra sólida dentro de un frasco erlenmeyer. El peso promedio de sólido utilizado por cartucho fue entre 2 y $3 \mathrm{~g}$. Se adicionaron $500 \mathrm{ml}$ de hexano y se agitó para eliminar la resistencia externa a la transferencia de masa. Tanto el hexano como los cartuchos fueron precalentados hasta la temperatura de trabajo. Cada experimento fue conducido a una temperatura 
definida y fue mantenida constante durante todo el ensayo; se realizaron ensayos a 25,40 y $50 \stackrel{\circ}{\circ}$. Al final del tiempo t, el cartucho con la muestra fue removido del sistema. Se trabajó a intervalos de 5 minutos durante los primeros 30 minutos y luego a intervalos de 10 minutos hasta completar 60 minutos totales de extracción. Cada muestra fue drenada y secada durante 1 hora a $120^{\circ} \mathrm{C}$ para eliminar restos de solvente y humedad. Luego se pesó y se colocó en un frasco con solvente puro para extracción completa en batch durante $24 \mathrm{~h}$. Se necesitaron 2 extracciones y un lavado final para remover completamente el aceite remanente en la muestra. Este procedimiento fue verificado contra la extracción estándar en equipo Soxhlet por $8 \mathrm{~h}$. El cartucho y la muestra fueron secados nuevamente y pesados para obtener el peso de la muestra libre de aceite. La diferencia en peso de la muestra antes y después de la extracción completa en batch fue tomada como el contenido en aceite de la muestra al tiempo t de remoción fuera del extractor. La concentración inicial de aceite en la muestra $q_{\circ}$ fue determinada por la pérdida de peso durante la extracción completa en batch de una muestra tomada al azar para el experimento.

4.1.2.4.3 Determinación del efecto de la temperatura: Se determinaron curvas de concentración versus tiempo para tres temperaturas diferentes: 25,40 y $50 \stackrel{\circ}{\circ}$. La temperatura máxima ensayada no puede superar la temperatura de ebullición del hexano para evitar variaciones de volumen y pérdidas de solvente por evaporación. El procedimiento experimental empleado para cada ensayo se describió en la sección anterior. 


\subsection{RESULTADOS Y DISCUSIÓN}

\subsubsection{Modelo difusional y determinación de coeficientes de difusión efectiva}

En las tablas 4.2 a 4.13 se muestran las masas de aceite residual determinadas experimentalmente por diferencia de peso para distintos tiempos de extracción para cada material sólido ensayado y para cada una de las temperaturas de extracción empleadas. Cada ensayo se realizó por triplicado. Se incluyen además, los contenidos iniciales de aceite para cada ensayo. Se calcularon el contenido residual de aceite como fracción en masa por unidad de masa de sólido empleado (q) y la fracción en masa adimensional respecto de la fracción de masa de aceite inicial $\left(\mathrm{q} / \mathrm{q}_{0}\right)$.

Tabla 4.2: Valores experimentales de aceite remanente en el laminado de soja sin hidrolizar para extracción con hexano a $25 \stackrel{\circ}{\circ}\left({ }^{*} q_{0}=0,246 \mathrm{~g}\right)$.

\begin{tabular}{ccccc}
\hline Tiempo $(\mathrm{min})$ & Sólido $(\mathrm{g})$ & Aceite residual $(\mathrm{g})$ & $\mathrm{q}$ & $\mathrm{q} / \mathrm{q}_{\mathrm{o}}{ }^{*}$ \\
\hline 0 & 2,6378 & 0,6489 & 0,246 & 1 \\
2 & 2,3119 & 0,3259 & 0,1410 & 0,5730 \\
4 & 2,1569 & 0,2589 & 0,1200 & 0,4880 \\
6 & 1,9094 & 0,1869 & 0,0979 & 0,3980 \\
8 & 1,9206 & 0,1729 & 0,0900 & 0,3660 \\
10 & 2,1308 & 0,1787 & 0,0839 & 0,3410 \\
15 & 2,0256 & 0,1600 & 0,0790 & 0,3210 \\
20 & 2,1633 & 0,1687 & 0,0780 & 0,3170 \\
25 & 2,4226 & 0,1842 & 0,0760 & 0,3090 \\
30 & 2,3933 & 0,1749 & 0,0731 & 0,2970 \\
40 & 2,2945 & 0,1496 & 0,0652 & 0,2650 \\
50 & 2,1083 & 0,1032 & 0,0490 & 0,1990 \\
60 & 2,322 & 0,0903 & 0,0389 & 0,1580
\end{tabular}


Tabla 4.3: Valores experimentales de aceite remanente en el laminado de soja sin hidrolizar para extracción con hexano a $40{ }^{\circ} \mathrm{C}\left({ }^{*} q_{0}=0,2502 \mathrm{~g}\right)$.

\begin{tabular}{ccccc}
\hline Tiempo $(\mathrm{min})$ & Sólido $(\mathrm{g})$ & Aceite residual $(\mathrm{g})$ & $\mathrm{q}$ & $\mathrm{q} / \mathrm{q}^{*}$ \\
\hline 0 & 2,436 & 0,609 & 0,2502 & 1 \\
2 & 2,141 & 0,2952 & 0,1379 & 0,5510 \\
4 & 1,7393 & 0,1292 & 0,0743 & 0,2970 \\
6 & 1,884 & 0,1211 & 0,0643 & 0,2570 \\
8 & 2,1044 & 0,1290 & 0,0613 & 0,2450 \\
10 & 1,6342 & 0,0953 & 0,0583 & 0,2330 \\
15 & 1,6723 & 0,0862 & 0,0515 & 0,2060 \\
20 & 2,151 & 0,0979 & 0,0455 & 0,1820 \\
25 & 1,5249 & 0,0614 & 0,0403 & 0,1610 \\
30 & 2,012 & 0,0720 & 0,0358 & 0,1430 \\
40 & 2,2851 & 0,0640 & 0,0280 & 0,1120 \\
50 & 2,3431 & 0,0516 & 0,0220 & 0,0880 \\
60 & 1,8477 & 0,0319 & 0,0173 & 0,0690 \\
\hline
\end{tabular}

Tabla 4.4: Valores experimentales de aceite remanente en el laminado de soja sin hidrolizar para extracción con hexano a $50{ }^{\circ} \mathbf{C}\left({ }^{*} q_{0}=0,2653 \mathrm{~g}\right)$.

\begin{tabular}{ccccc}
\hline Tiempo $(\mathrm{min})$ & Sólido $(\mathrm{g})$ & Aceite residual $(\mathrm{g})$ & $\mathrm{q}$ & $\mathrm{q} / \mathrm{q}_{\circ}{ }^{*}$ \\
\hline 0 & 2,2993 & 0,6101 & 0,2653 & 1 \\
2 & 2,1168 & 0,1825 & 0,0862 & 0,3250 \\
4 & 2,0467 & 0,1113 & 0,0544 & 0,2050 \\
6 & 2,1282 & 0,0932 & 0,0438 & 0,1650 \\
8 & 1,707 & 0,0725 & 0,0424 & 0,1600 \\
10 & 1,7187 & 0,0675 & 0,0393 & 0,1480 \\
15 & 2,3301 & 0,0804 & 0,0345 & 0,1300 \\
20 & 1,5108 & 0,0429 & 0,0284 & 0,1070 \\
25 & 1,7283 & 0,0385 & 0,0223 & 0,0840 \\
30 & 2,0005 & 0,0425 & 0,0212 & 0,0800 \\
40 & 2,1567 & 0,0338 & 0,0157 & 0,0590 \\
50 & 2,0617 & 0,0213 & 0,0103 & 0,0390 \\
60 & 2,118 & 0,0163 & 0,0077 & 0,0290 \\
\hline
\end{tabular}


Tabla 4.5: Valores experimentales de aceite remanente en el expandido de soja sin hidrolizar para extracción con hexano a $25{ }^{\circ} \mathrm{C}\left({ }^{*} \mathrm{q}_{0}=0,2633 \mathrm{~g}\right)$.

\begin{tabular}{ccccc}
\hline Tiempo $(\mathrm{min})$ & Sólido $(\mathrm{g})$ & Aceite residual $(\mathrm{g})$ & $\mathrm{q}$ & $\mathrm{q} / \mathrm{q}_{\circ}{ }^{*}$ \\
\hline 0 & 2,5118 & 0,6614 & 0,2633 & 1 \\
2 & 2,3043 & 0,2075 & 0,0900 & 0,3420 \\
4 & 1,8774 & 0,1256 & 0,0669 & 0,2540 \\
6 & 2,1911 & 0,0987 & 0,0450 & 0,1710 \\
8 & 2,2634 & 0,0930 & 0,0411 & 0,1560 \\
10 & 2,1414 & 0,0846 & 0,0395 & 0,1500 \\
15 & 2,5118 & 0,0833 & 0,0332 & 0,1260 \\
20 & 2,7877 & 0,0888 & 0,0319 & 0,1210 \\
25 & 2,5595 & 0,0667 & 0,0261 & 0,0990 \\
30 & 2,2043 & 0,0546 & 0,0248 & 0,0940 \\
40 & 2,3735 & 0,0500 & 0,0211 & 0,0800 \\
50 & 2,6146 & 0,0551 & 0,0211 & 0,0800 \\
60 & 2,6059 & 0,0487 & 0,0187 & 0,0710 \\
\hline
\end{tabular}

Tabla 4.6: Valores experimentales de aceite remanente en el expandido de soja sin hidrolizar para extracción con hexano a $40 \stackrel{\circ}{ }{ }^{*}\left({ }^{*} q_{0}=0,2587 \mathrm{~g}\right)$

\begin{tabular}{ccccc}
\hline Tiempo $(\mathrm{min})$ & Sólido $(\mathrm{g})$ & Aceite residual $(\mathrm{g})$ & $\mathrm{q}$ & $\mathrm{q} / \mathrm{q}^{*}$ \\
\hline 0 & 2,2633 & 0,5855 & 0,2587 & 1 \\
2 & 2,1289 & 0,1344 & 0,0631 & 0,2440 \\
4 & 2,4034 & 0,1094 & 0,0455 & 0,1760 \\
6 & 1,76 & 0,0660 & 0,0375 & 0,1450 \\
8 & 2,3641 & 0,0826 & 0,0349 & 0,1350 \\
10 & 1,9508 & 0,0641 & 0,0329 & 0,1270 \\
15 & 1,9839 & 0,0580 & 0,0292 & 0,1130 \\
20 & 2,5213 & 0,0613 & 0,0243 & 0,0940 \\
25 & 2,5898 & 0,0476 & 0,0184 & 0,0710 \\
30 & 2,345 & 0,0322 & 0,0137 & 0,0530 \\
40 & 2,0294 & 0,0226 & 0,0111 & 0,0430 \\
50 & 2,4018 & 0,0199 & 0,0083 & 0,0320 \\
60 & 2,681 & 0,0173 & 0,0065 & 0,0250 \\
\hline
\end{tabular}


Tabla 4.7: Valores experimentales de aceite remanente en el expandido de soja sin hidrolizar para extracción con hexano a $50{ }^{\circ} \mathbf{C}\left({ }^{*} q_{0}=0,2689 \mathrm{~g}\right)$.

\begin{tabular}{ccccc}
\hline Tiempo $(\mathrm{min})$ & Sólido $(\mathrm{g})$ & Aceite residual $(\mathrm{g})$ & $\mathrm{q}$ & $\mathrm{q} / \mathrm{q}{ }^{*}$ \\
\hline 0 & 2,0487 & 0,5509 & 0,2689 & 1 \\
2 & 1,9343 & 0,1144 & 0,0592 & 0,2200 \\
4 & 2,5207 & 0,0962 & 0,0382 & 0,1420 \\
6 & 2,0252 & 0,0539 & 0,0266 & 0,0990 \\
8 & 2,1185 & 0,0518 & 0,0245 & 0,0910 \\
10 & 2,131 & 0,0453 & 0,0212 & 0,0790 \\
15 & 2,4191 & 0,0306 & 0,0126 & 0,0470 \\
20 & 2,3934 & 0,0290 & 0,0121 & 0,0450 \\
25 & 2,2814 & 0,0221 & 0,0097 & 0,0360 \\
30 & 2,0944 & 0,0141 & 0,0067 & 0,0250 \\
40 & 2,0845 & 0,0084 & 0,0040 & 0,0150 \\
50 & 2,3197 & 0,0050 & 0,0022 & 0,0080 \\
60 & 2,3576 & 0,0025 & 0,0011 & 0,0040 \\
\hline
\end{tabular}

Tabla 4.8: Valores experimentales de aceite remanente en el laminado de soja hidrolizado para extracción con hexano a $25{ }^{\circ} \mathbf{C}\left({ }^{*} q_{0}=0,3385 \mathrm{~g}\right)$.

\begin{tabular}{ccccc}
\hline Tiempo $(\mathrm{min})$ & Sólido $(\mathrm{g})$ & Aceite residual $(\mathrm{g})$ & $\mathrm{q}$ & $\mathrm{q} / \mathrm{q}^{*}$ \\
\hline 0 & 2,3805 & 0,8058 & 0,3385 & 1 \\
2 & 2,203 & 0,1775 & 0,0806 & 0,2380 \\
4 & 1,5097 & 0,1160 & 0,0768 & 0,2270 \\
6 & 2,0278 & 0,1181 & 0,0582 & 0,1720 \\
8 & 1,9057 & 0,1103 & 0,0579 & 0,1710 \\
10 & 2,0185 & 0,0957 & 0,0474 & 0,1400 \\
15 & 2,1418 & 0,1044 & 0,0487 & 0,1440 \\
20 & 1,8011 & 0,0823 & 0,0457 & 0,1350 \\
25 & 1,7492 & 0,0705 & 0,0403 & 0,1190 \\
30 & 1,8953 & 0,0770 & 0,0406 & 0,1200 \\
40 & 2,078 & 0,0563 & 0,0271 & 0,0800 \\
50 & 2,0098 & 0,0483 & 0,0240 & 0,0710 \\
60 & 2,6033 & 0,0538 & 0,0206 & 0,0610 \\
\hline
\end{tabular}


Tabla 4.9: Valores experimentales de aceite remanente en el laminado de soja hidrolizado para extracción con hexano a $40 \stackrel{\circ}{ } \mathbf{C}\left({ }^{*} q_{0}=0,3358 \mathrm{~g}\right)$.

\begin{tabular}{ccccc}
\hline Tiempo $(\min )$ & Sólido $(\mathrm{g})$ & Aceite residual $(\mathrm{g})$ & $\mathrm{q}$ & $\mathrm{q} / \mathrm{q}_{\mathrm{o}}{ }^{*}$ \\
\hline 0 & 2,4273 & 0,8151 & 0,3358 & 1 \\
2 & 2,1618 & 0,2655 & 0,1228 & 0,3657 \\
4 & 1,9859 & 0,1484 & 0,0747 & 0,2225 \\
6 & 2,1986 & 0,0816 & 0,0371 & 0,1105 \\
8 & 2,0741 & 0,0628 & 0,0303 & 0,0901 \\
10 & 2,8885 & 0,0600 & 0,0208 & 0,0619 \\
15 & 2,5244 & 0,0330 & 0,0131 & 0,0389 \\
20 & 2,7269 & 0,0183 & 0,0067 & 0,02 \\
25 & 2,1681 & 0,0081 & 0,0037 & 0,0111 \\
30 & 2,2248 & 0,0033 & 0,0015 & 0,0044 \\
40 & 2,5405 & 0,0017 & 0,0007 & 0,002 \\
50 & 2,668 & 0,0002 & 0,0001 & 0,0002 \\
60 & 2,8439 & 0,0002 & 0,0001 & 0,0002
\end{tabular}

Tabla 4.10: Valores experimentales de aceite remanente en el laminado de soja hidrolizado para extracción con hexano a $50 \stackrel{\circ}{ }{ }^{\circ}\left({ }^{*} q_{0}=0,3387 \mathrm{~g}\right)$.

\begin{tabular}{ccccc}
\hline Tiempo $(\mathrm{min})$ & Sólido $(\mathrm{g})$ & Aceite residual $(\mathrm{g})$ & $\mathrm{q}$ & $\mathrm{q} / \mathrm{qo}$ \\
\hline 0 & 2,3119 & 0,7830 & 0,3387 & 1 \\
2 & 2,1095 & 0,2024 & 0,0960 & 0,2833 \\
4 & 2,4501 & 0,1363 & 0,0556 & 0,1643 \\
6 & 2,0754 & 0,0526 & 0,0253 & 0,0748 \\
8 & 2,2181 & 0,0307 & 0,0138 & 0,0408 \\
10 & 2,5062 & 0,0319 & 0,0127 & 0,0376 \\
15 & 2,3694 & 0,0161 & 0,0068 & 0,02 \\
20 & 2,3849 & 0,0079 & 0,0033 & 0,0098 \\
25 & 2,3937 & 0,0019 & 0,0008 & 0,0024 \\
30 & 2,5196 & 0,0019 & 0,0007 & 0,0022 \\
40 & 2,045 & 0,0002 & 0,0001 & 0,0003 \\
50 & 1,9885 & 0,0001 & 0,0001 & 0,0002 \\
60 & 2,0246 & $2,02.10^{-5}$ & 0,0000 & 0,0000295 \\
\hline
\end{tabular}


Tabla 4.11: Valores experimentales de aceite remanente en el expandido de soja hidrolizado para extracción con hexano a $25{ }^{\circ} \mathbf{C}\left({ }^{*} q_{0}=0,3622 \mathrm{~g}\right)$.

\begin{tabular}{ccccc}
\hline Tiempo $(\mathrm{min})$ & Sólido $(\mathrm{g})$ & Aceite residual $(\mathrm{g})$ & $\mathrm{q}$ & $\mathrm{q} / \mathrm{q}^{*}$ \\
\hline 0 & 2,7024 & 0,9788 & 0,3622 & 1 \\
2 & 2,1143 & 0,5881 & 0,2782 & 0,7680 \\
4 & 2,2845 & 0,5925 & 0,2593 & 0,7160 \\
6 & 2,1265 & 0,4198 & 0,1974 & 0,5450 \\
8 & 2,1045 & 0,4360 & 0,2072 & 0,5720 \\
10 & 2,2578 & 0,4530 & 0,2007 & 0,5540 \\
15 & 2,0093 & 0,3370 & 0,1677 & 0,4630 \\
20 & 2,2143 & 0,3152 & 0,1423 & 0,3930 \\
25 & 2,1733 & 0,2251 & 0,1036 & 0,2860 \\
30 & 2,1966 & 0,2061 & 0,0938 & 0,2590 \\
40 & 2,4016 & 0,2018 & 0,0840 & 0,2320 \\
50 & 1,8599 & 0,1253 & 0,0674 & 0,1860 \\
60 & 2,2447 & 0,1195 & 0,0532 & 0,1470 \\
\hline
\end{tabular}

Tabla 4.12: Valores experimentales de aceite remanente en el expandido de soja hidrolizado para extracción con hexano a $40{ }^{\circ} \mathrm{C}\left({ }^{*} \mathrm{q}_{0}=0,2971 \mathrm{~g}\right)$.

\begin{tabular}{ccccc}
\hline Tiempo (min) & Sólido $(\mathrm{g})$ & Aceite residual $(\mathrm{g})$ & $\mathrm{q}$ & $\mathrm{q} / \mathrm{qo}$ \\
\hline 0 & 2,4704 & 0,734 & 0,2971 & 1 \\
2 & 2,1289 & 0,3415 & 0,1604 & 0,5400 \\
4 & 2,4034 & 0,2488 & 0,1035 & 0,3485 \\
6 & 1,76 & 0,1386 & 0,0787 & 0,2650 \\
8 & 2,3641 & 0,1538 & 0,0651 & 0,2190 \\
10 & 1,9508 & 0,1269 & 0,0651 & 0,2190 \\
15 & 1,9839 & 0,1026 & 0,0517 & 0,1740 \\
20 & 2,5213 & 0,1094 & 0,0434 & 0,1460 \\
25 & 2,5898 & 0,0800 & 0,0309 & 0,1040 \\
30 & 2,345 & 0,0585 & 0,0250 & 0,0840 \\
40 & 2,0294 & 0,0344 & 0,0169 & 0,0570 \\
50 & 2,4018 & 0,0214 & 0,0089 & 0,0300 \\
60 & 2,681 & 0,0159 & 0,0059 & 0,0200 \\
\hline
\end{tabular}


Tabla 4.13: Valores experimentales de aceite remanente en el expandido de soja hidrolizado para extracción con hexano a $50 \stackrel{\circ}{ } \mathbf{C}\left({ }^{*} q_{0}=0,3647 \mathrm{~g}\right)$.

\begin{tabular}{ccccc}
\hline Tiempo $(\mathrm{min})$ & Sólido $(\mathrm{g})$ & Aceite residual $(\mathrm{g})$ & $\mathrm{q}$ & $\mathrm{q} / \mathrm{q}^{*}$ \\
\hline 0 & 2,1805 & 0,7952 & 0,3647 & 1 \\
2 & 1,9343 & 0,2462 & 0,1273 & 0,3490 \\
4 & 2,5207 & 0,1949 & 0,0773 & 0,2120 \\
6 & 2,0252 & 0,1056 & 0,0522 & 0,1430 \\
8 & 2,1185 & 0,0858 & 0,0405 & 0,1110 \\
10 & 2,131 & 0,0769 & 0,0361 & 0,0990 \\
15 & 2,4191 & 0,0273 & 0,0113 & 0,0310 \\
20 & 2,3934 & 0,0428 & 0,0179 & 0,0490 \\
25 & 2,2814 & 0,0266 & 0,0117 & 0,0320 \\
30 & 2,0944 & 0,0176 & 0,0084 & 0,0230 \\
40 & 2,0845 & 0,0084 & 0,0040 & 0,0110 \\
50 & 2,3197 & 0,0051 & 0,0022 & 0,0060 \\
60 & 2,3576 & 0,0026 & 0,0011 & 0,0030 \\
\hline
\end{tabular}

En las figuras 4.2 y 4.3 se muestran el contenido residual de aceite como variable adimensional $\left(\mathrm{q} / \mathrm{q}_{0}\right)$ sobre una ordenada logarítmica versus el tiempo de extracción, para los materiales laminado y expandido de soja sin pretratamiento enzimático a 25 ${ }^{\circ} \mathrm{C}$. Las líneas continuas representan las curvas obtenidas a partir del modelo difusional empleado y los puntos discontinuos representan los datos experimentales con las correspondientes barras de error. Se incluyen en cada uno de los gráficos el valor del coeficiente de correlación obtenido por el método de cuadrados mínimos. En las figuras 4.4 y 4.5 se representan las extracciones a $40 \stackrel{\circ}{C}$ y en las figuras 4.6 y 4.7 las correspondientes a los ensayos realizados a $50 \stackrel{\circ}{ } \mathrm{C}$.

En las figuras 4.8 y 4.9 se representan las curvas linealizadas para los materiales laminado y expandido con pretratamiento enzimático a las condiciones óptimas determinadas en el Capítulo 3 (ver Resultados y Discusión). La extracción con hexano, tanto de expandido como de laminado hidrolizados, se llevó a cabo a $25{ }^{\circ} \mathrm{C}$. En las figuras 4.10 y 4.11 se representan las extracciones a $40{ }^{\circ} \mathrm{C}$ y en las figuras 4.12 y 4.13 , las curvas de extracción a $50 \stackrel{\circ}{ } \mathrm{C}$. 


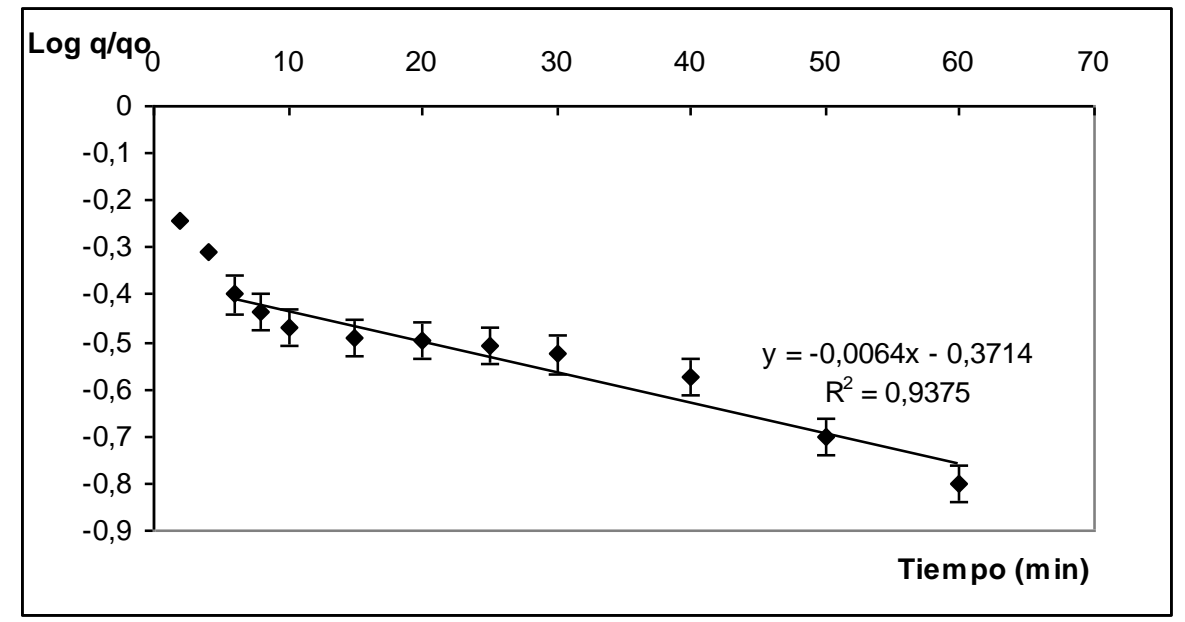

Figura 4.2: Contenido de aceite residual en función del tiempo de extracción para laminado de soja sin hidrolizar a $25^{\circ} \mathrm{C}\left(\right.$ Def $=0,88 \cdot 10^{-11} \pm 1,86 \cdot 10^{-12} \mathrm{~m}^{2} \mathrm{~s}^{-1}$ ).

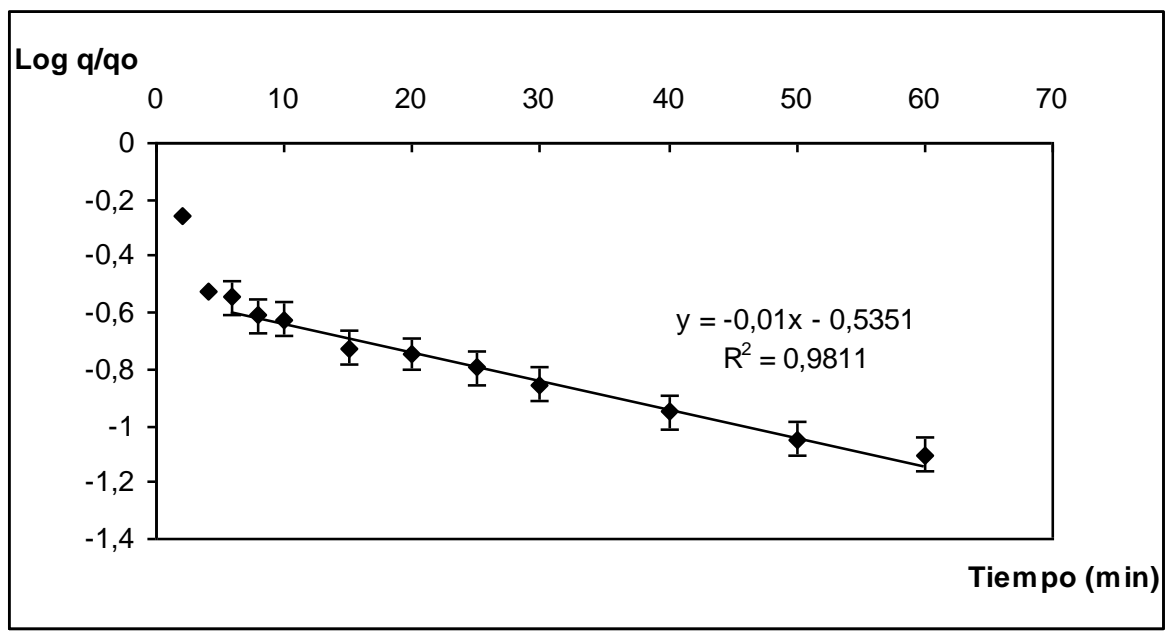

Figura 4.3: Contenido de aceite residual en función del tiempo de extracción para laminado de soja sin hidrolizar a $40{ }^{\circ} \mathrm{C}\left(\right.$ Def $\left.=1,45.10^{-11} \pm 1,21.10^{-12} \mathrm{~m}^{2} \mathrm{~s}^{-1}\right)$.

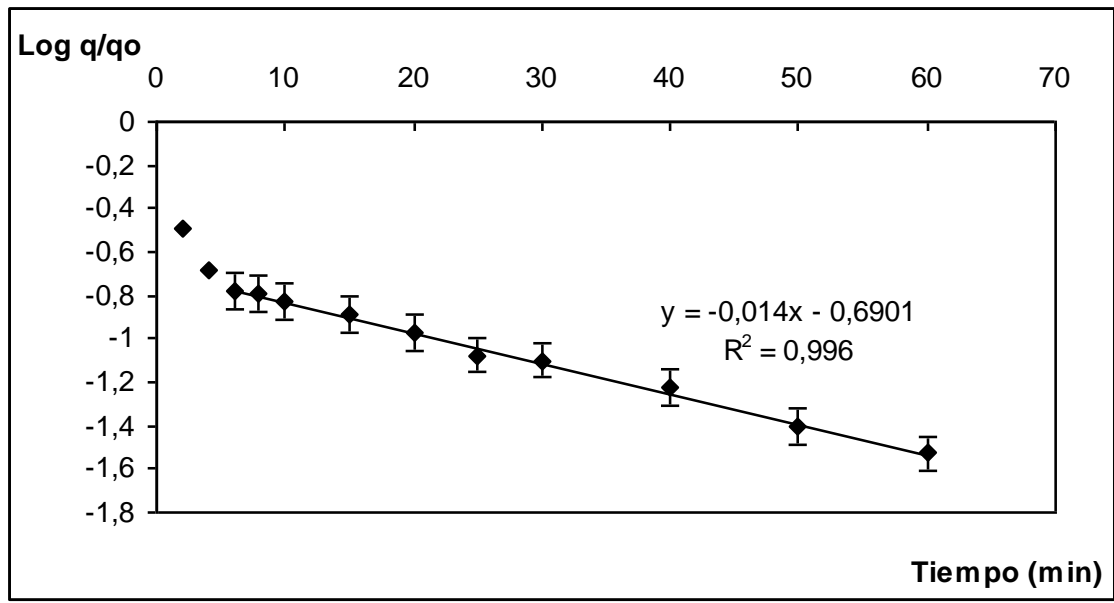

Figura 4.4: Contenido de aceite residual en función del tiempo de extracción para laminado de soja sin hidrolizar a $50 \stackrel{\circ}{\circ}\left(\right.$ Def $\left.=1,92.10^{-11} \pm 9,93.10^{-13} \mathrm{~m}^{2} \mathrm{~s}^{-1}\right)$. 


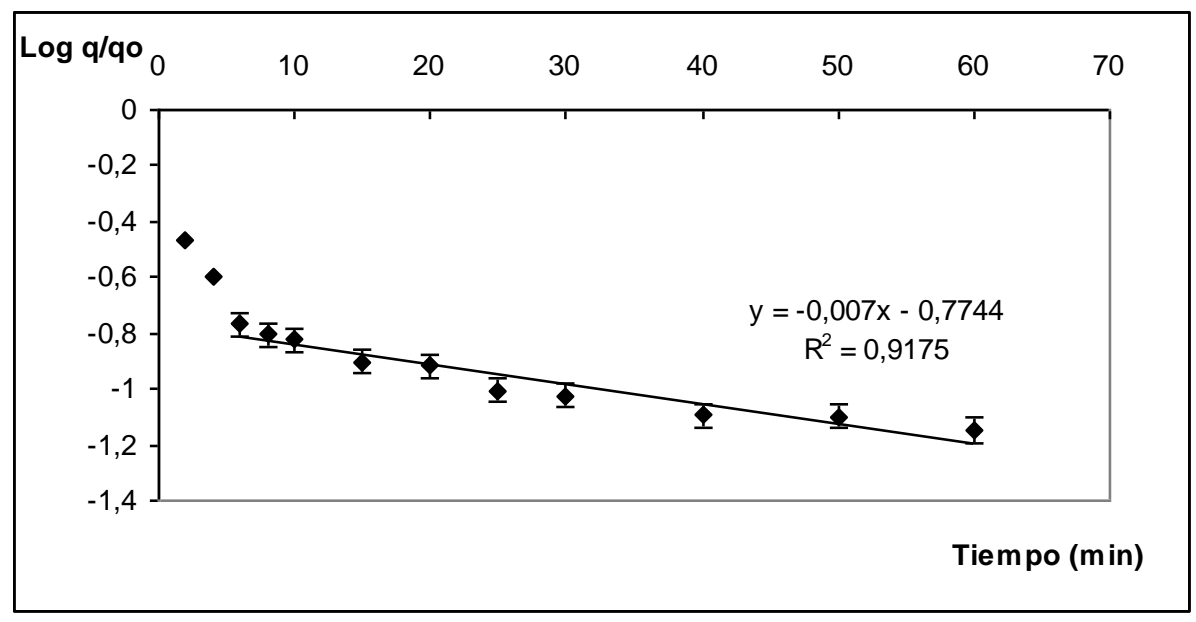

Figura 4.5: Contenido de aceite residual en función del tiempo de extracción para expandido de soja sin hidrolizar a $25^{\circ} \mathrm{C}\left(\right.$ Def $\left.=1,67.10^{-10} \pm 4,07.10^{-12} \mathrm{~m}^{2} \mathrm{~s}^{-1}\right)$.

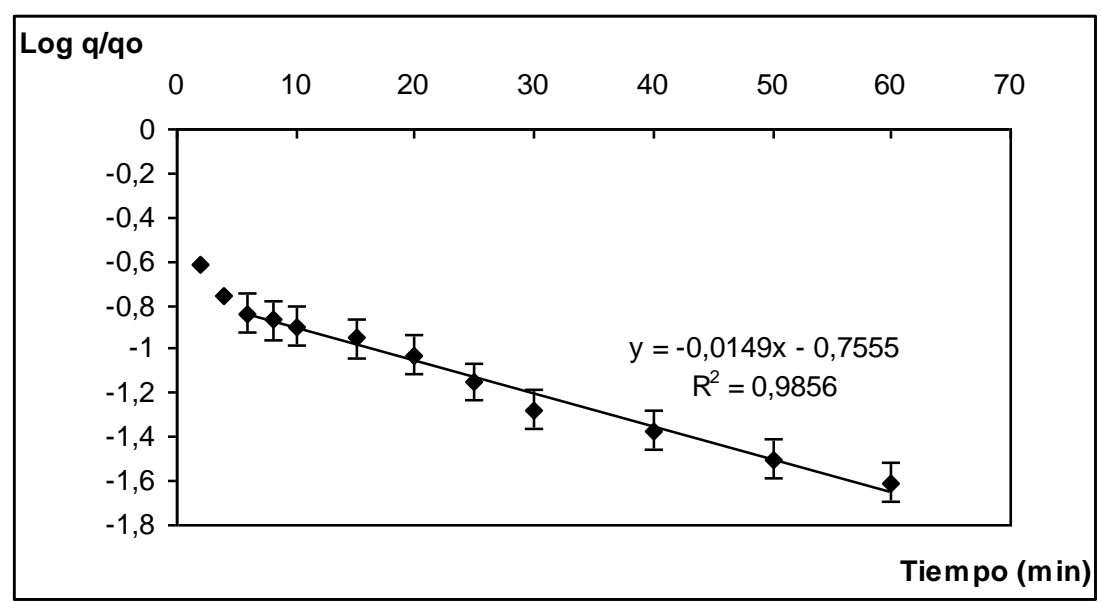

Figura 4.6: Contenido de aceite residual en función del tiempo de extracción para expandido de soja sin hidrolizar a $40 \stackrel{\circ}{\circ}\left(\right.$ Def $\left.=3,41.10^{-10} \pm 3,44.10^{-11} \mathrm{~m}^{2} \mathrm{~s}^{-1}\right)$.

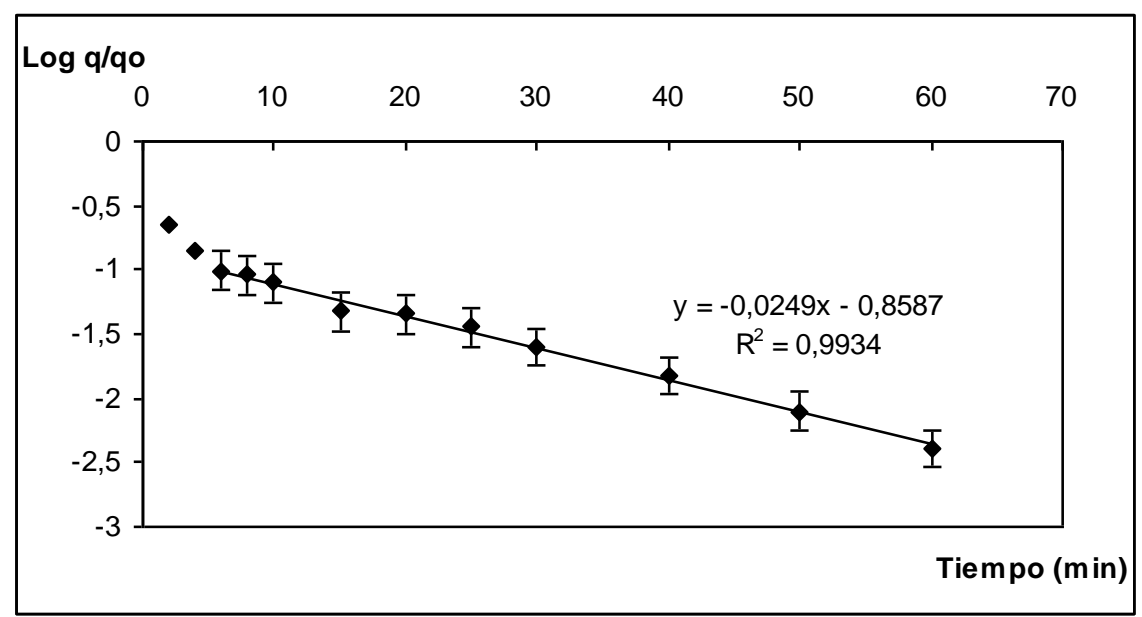

Figura 4.7: Contenido de aceite residual en función del tiempo de extracción para expandido de soja sin hidrolizar a $50 \stackrel{\circ}{\circ}\left(\right.$ Def $\left.=5,79.10^{-10} \pm 8,48.10^{-12} \mathrm{~m}^{2} \mathrm{~s}^{-1}\right)$. 


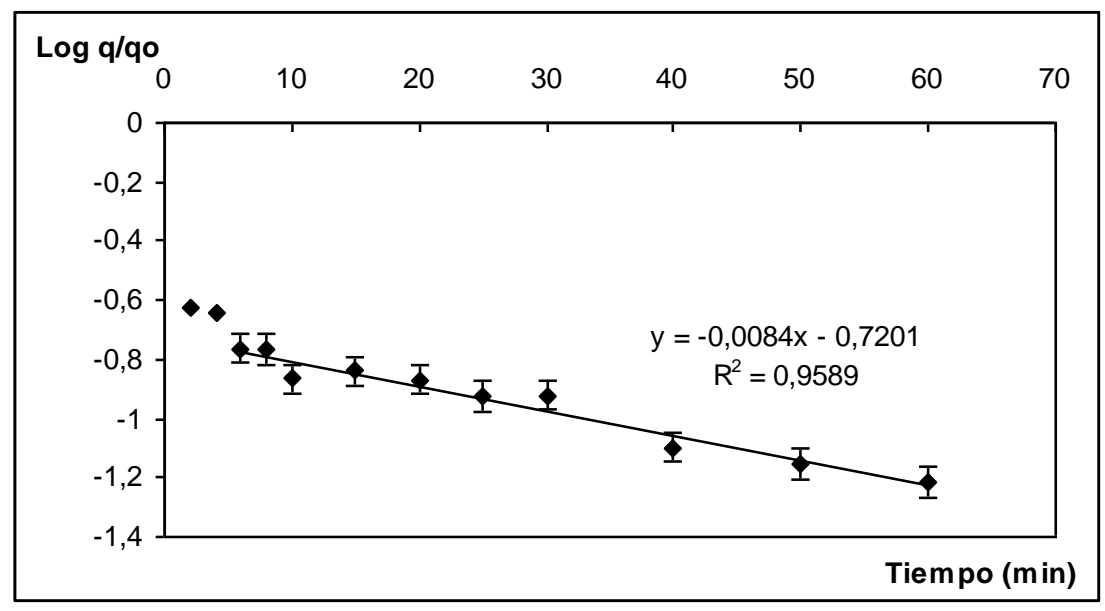

Figura 4.8: Contenido de aceite residual en función del tiempo de extracción para laminado de soja hidrolizado a $25 \stackrel{\circ}{\circ} \mathrm{C}\left(\right.$ Def $\left.=4,60.10^{-11} \pm 7,20.10^{-12} \mathrm{~m}^{2} \mathrm{~s}^{-1}\right)$.

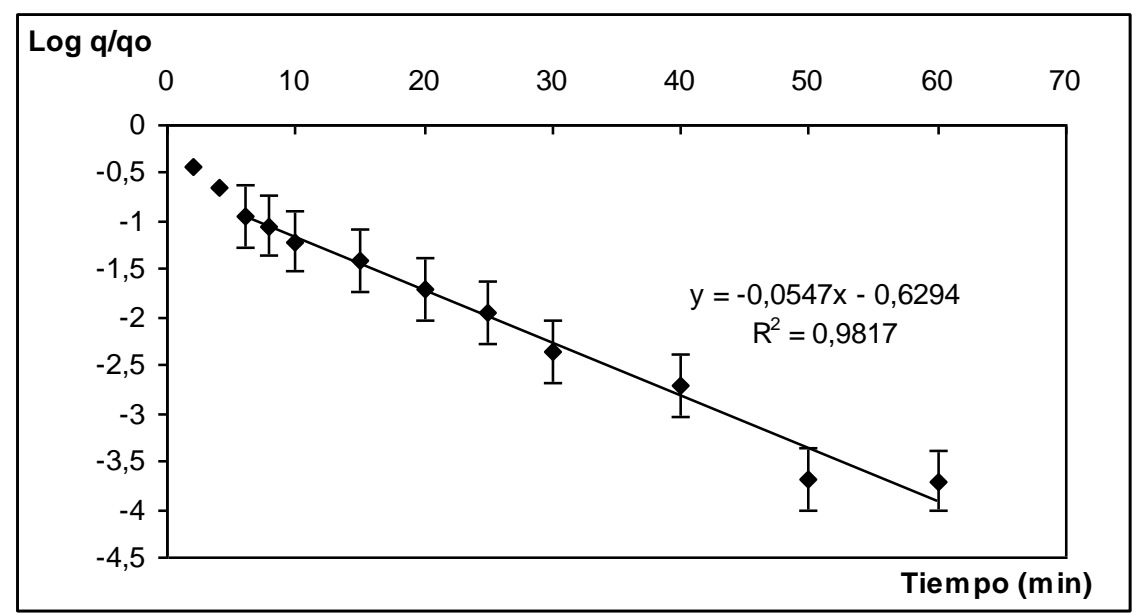

Figura 4.9: Contenido de aceite residual en función del tiempo de extracción para laminado de soja hidrolizado a $40{ }^{\circ} \mathrm{C}\left(\right.$ Def $\left.=7,03.10^{-11} \pm 1,86.10^{-13} \mathrm{~m}^{2} \mathrm{~s}^{-1}\right)$.

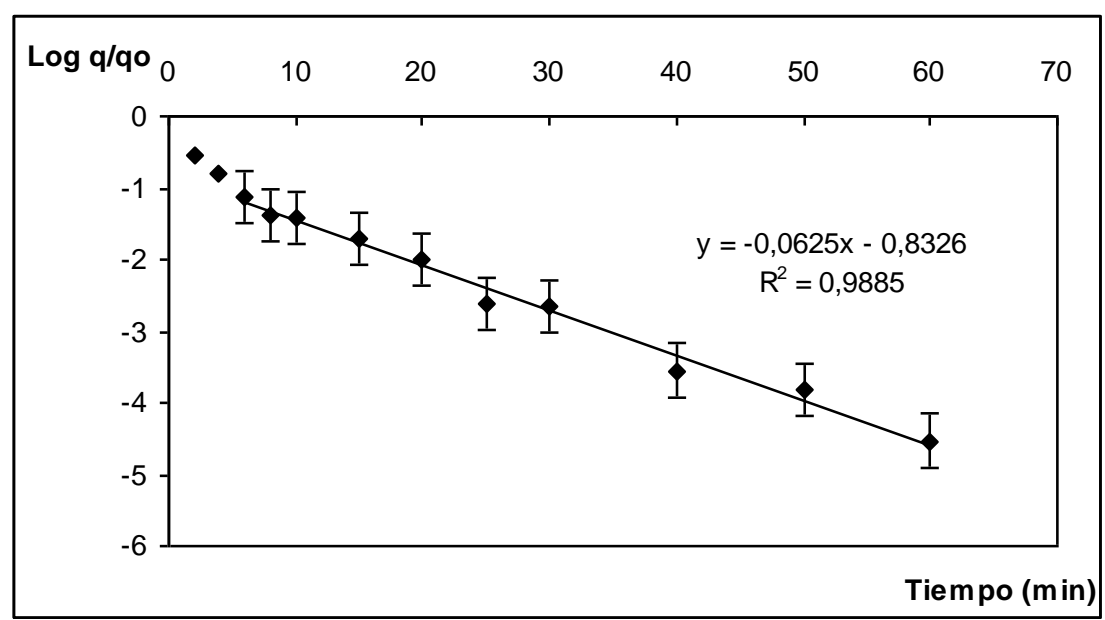

Figura 4.10: Contenido de aceite residual en función del tiempo de extracción para laminado de soja hidrolizado a $50{ }^{\circ} \mathrm{C}\left(\right.$ Def $\left.=8,45 \cdot 10^{-11} \pm 2,02 \cdot 10^{-13} \mathrm{~m}^{2} \mathrm{~s}^{-1}\right)$. 


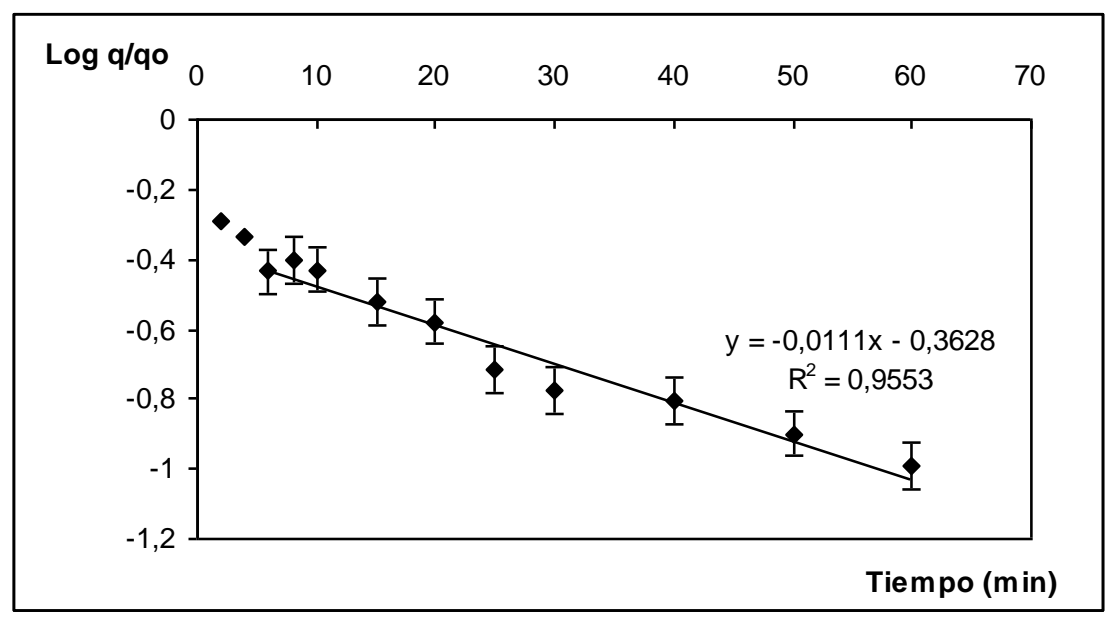

Figura 4.11: Contenido de aceite residual en función del tiempo de extracción para expandido de soja hidrolizado a $25^{\circ} \mathrm{C}$ (Def $=2,63 \cdot 10^{-10} \pm 8,42.10^{-12} \mathrm{~m}^{2} \mathrm{~s}^{-1}$ ).

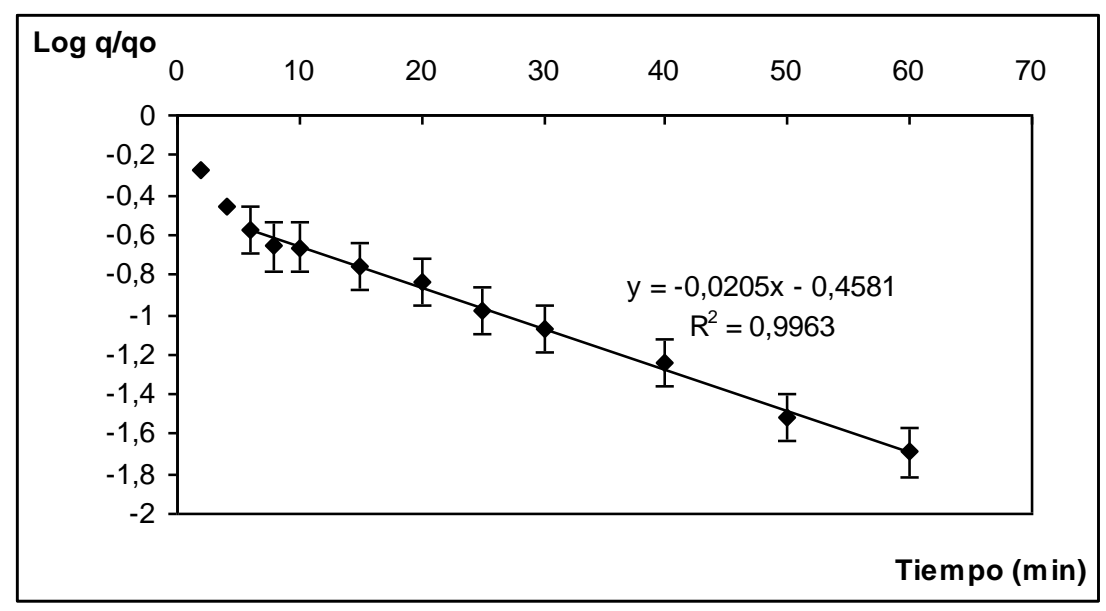

Figura 4.12: Contenido de aceite residual en función del tiempo de extracción para expandido de soja hidrolizado a $40{ }^{\circ} \mathrm{C}$ (Def $=4,79.10^{-10} \pm 2,2.10^{-13} \mathrm{~m}^{2} \mathrm{~s}^{-1}$ ).

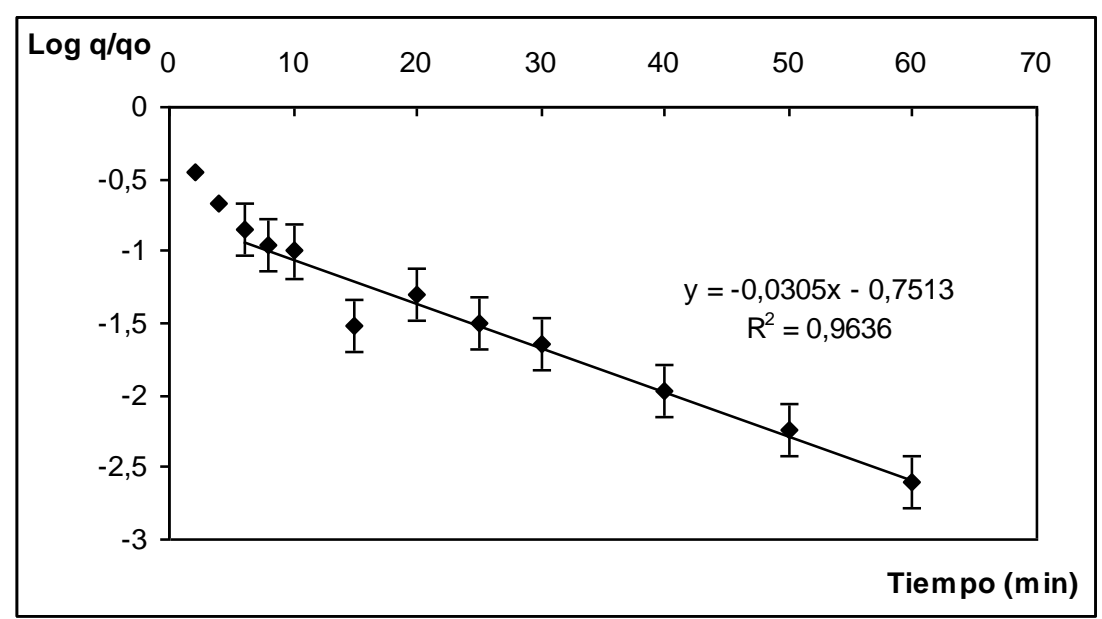

Figura 4.13: Contenido de aceite residual en función del tiempo de extracción para expandido de soja hidrolizado a 50 으 (Def $=7,57.10^{-10} \pm 1,59.10^{-12} \mathrm{~m}^{2} \mathrm{~s}^{-1}$ ). 
En todos los casos, se observa que las curvas experimentales son lineales en la representación semilogarítmica luego de $t=6$ minutos. Como es sabido, a cortos tiempos la serie no converge y se necesitan un alto número de términos para obtener la solución, por esa razón los puntos experimentales no se ajustan a la recta. Puede observarse que luego de 6 minutos la difusión en el material celular puede representarse por el primer término de la serie, fenómeno que fue observado también por otros autores (Fan col., 1948 y Varzakas y col., 2005). Se observa una correlación superior al 90 \% para todos los casos, luego de los 6 minutos de extracción, lo que indica un buen ajuste del modelo lineal.

En las tablas $4.14,4.15$ y 4.16 se observan los coeficientes de difusión efectiva calculados y su intervalo de confianza estimado según las ecuaciones 4.13 y 4.14, para todos los materiales en ausencia de resistencia externa al transporte de masa y cuando el transporte interno de material es debido exclusivamente a procesos difusionales. Cada una de las tablas muestra los valores de Def para las tres temperaturas ensayadas $\left(25,40\right.$ y $\left.50^{\circ} \mathrm{C}\right)$. Los valores de los coeficientes son calculados a partir de la pendiente estimada para cada una de las rectas ajustadas. Como puede observarse, el orden de magnitud de los coeficientes de difusión calculados se encuentra entre $10^{-11}$ a $10^{-10} \mathrm{~m}^{2} \mathrm{~s}^{-1}$, lo cual se corresponde con los datos de bibliografía (Doulia y col., 2000; Pajonk y col., 2003; Simeonov y col., 1999; Cacace y Mazza, 2003; Perez-Galindo y col., 2000; Seikova y col., 2004; WeltiChanes y col., 2005; Chalermchat y col., 2004; Mantell y col., 2002). Varzakas y col. (2005) compilaron coeficientes de difusión efectivo en órdenes de magnitud de $10^{-12}$ a $10^{-10} \mathrm{~m}^{2} \mathrm{~s}^{-1}$ para una amplia variedad de alimentos sólidos, al igual que Doulia y col. (2000). La difusión a través de sólidos es más compleja que la difusión a través de gases o líquidos, por ello se observan, en la mayoría de los casos, coeficientes de difusión más pequeños y por ende, la transferencia de masa ocurre más lentamente. 
Tabla 4.14: Coeficientes calculados de difusión efectiva a $25{ }^{\circ} \mathrm{C}$ $\mathrm{R}=$ radio de esfera; $\mathrm{I}$ = espesor lámina

\begin{tabular}{|l|c|c|c|}
\hline & Pendiente & $\begin{array}{c}\text { Dimensión } \\
\text { equivalente }(\mathbf{m})\end{array}$ & $\begin{array}{c}\text { Coeficiente de } \\
\text { difusión efectiva }\left(\mathbf{m}^{2} \mathbf{s}^{-1}\right)\end{array}$ \\
\hline $\begin{array}{l}\text { Laminado sin } \\
\text { hidrolizar (lámina) }\end{array}$ & $-0,0064$ & $\mathrm{I}=0,00045$ & $0,88.10^{-11} \pm 1,86.10^{-12}$ \\
\hline $\begin{array}{l}\text { Expandido sin } \\
\text { hidrolizar (esfera) }\end{array}$ & $-0,007$ & $\mathrm{R}=0,00375$ & $1,67.10^{-10} \pm 4,07.10^{-12}$ \\
\hline $\begin{array}{l}\text { Laminado hidrolizado } \\
\text { (esfera) }\end{array}$ & $-0,0084$ & $\mathrm{R}=0,00375$ & $4,60.10^{-11} \pm 7,20.10^{-12}$ \\
\hline $\begin{array}{l}\text { Expandido hidrolizado } \\
\text { (esfera) }\end{array}$ & $-0,0111$ & $\mathrm{R}=0,00375$ & $2,63.10^{-10} \pm 8,42.10^{-12}$ \\
\hline
\end{tabular}

Tabla 4.15: Coeficientes calculados de difusión efectiva a $40 \stackrel{\circ}{ } \mathrm{C}$ $\mathrm{R}=$ radio de esfera; $\mathrm{I}$ = espesor lámina

\begin{tabular}{|l|c|c|c|}
\hline & Pendiente & $\begin{array}{c}\text { Dimensión } \\
\text { equivalente }(\mathbf{m})\end{array}$ & $\begin{array}{c}\text { Coeficiente de difusión } \\
\text { efectivo }\left(\mathbf{m}^{2} \mathbf{s}^{-1}\right)\end{array}$ \\
\hline $\begin{array}{l}\text { Laminado sin } \\
\text { hidrolizar (lámina) }\end{array}$ & $-0,0106$ & $\mathrm{I}=0,00045$ & $1,45.10^{-11} \pm 1,21.10^{-12}$ \\
\hline $\begin{array}{l}\text { Expandido sin } \\
\text { hidrolizar (esfera) }\end{array}$ & $-0,0144$ & $\mathrm{R}=0,00375$ & $3,41.10^{-10} \pm 3,44.10^{-11}$ \\
\hline $\begin{array}{l}\text { Laminado hidrolizado } \\
\text { (esfera) }\end{array}$ & $-0,0514$ & $\mathrm{R}=0,00375$ & $7,03.10^{-11} \pm 1,86.10^{-13}$ \\
\hline $\begin{array}{l}\text { Expandido hidrolizado } \\
\text { (esfera) }\end{array}$ & $-0,0020$ & $\mathrm{R}=0,00375$ & $4,79.10^{-10} \pm 2,2.10^{-13}$ \\
\hline
\end{tabular}

Tabla 4.16: Coeficientes calculados de difusión efectiva a $50{ }^{\circ} \mathrm{C}$ $\mathrm{R}=$ radio de esfera; $\mathrm{I}$ = espesor lámina

\begin{tabular}{|l|c|c|c|}
\hline & Pendiente & $\begin{array}{c}\text { Dimensión } \\
\text { equivalente }(\mathbf{m})\end{array}$ & $\begin{array}{c}\text { Coeficiente de difusión } \\
\text { efectivo }\left(\mathbf{m}^{2} \mathbf{s}^{-1}\right)\end{array}$ \\
\hline $\begin{array}{l}\text { Laminado sin } \\
\text { hidrolizar (lámina) }\end{array}$ & $-0,01406$ & $\mathrm{I}=0,00045$ & $1,92.10^{-11} \pm 9,93.10^{-13}$ \\
\hline $\begin{array}{l}\text { Expandido sin } \\
\text { hidrolizar (esfera) }\end{array}$ & $-0,0244$ & $\mathrm{R}=0,00375$ & $5,79.10^{-10} \pm 8,48.10^{-12}$ \\
\hline $\begin{array}{l}\text { Laminado hidrolizado } \\
\text { (esfera) }\end{array}$ & $-0,0618$ & $\mathrm{R}=0,00375$ & $8,45.10^{-11} \pm 2,02.10^{-13}$ \\
\hline $\begin{array}{l}\text { Expandido hidrolizado } \\
\text { (esfera) }\end{array}$ & $-0,0319$ & $\mathrm{R}=0,00375$ & $7,57.10^{-10} \pm 1,59.10^{-12}$ \\
\hline
\end{tabular}

En todos los casos estudiados, considerando difusión unidireccional y geometrías de lámina y esfera para el sólido de partida, la extracción de aceite con hexano se 
ajustó al modelo de difusión en estado no estacionario propuesto por la 2da ley de Fick.

El coeficiente de difusión efectivo para la transferencia interna de masa es afectado por la estructura del sólido a extraer y es directamente proporcional al pretratamiento al cual es sometido (Sineiro y col, 1998 y Chalermchat y col., 2004). La velocidad de extracción puede entonces incrementarse por aumento de la permeabilidad de la estructura del sólido obtenido como resultado del ataque enzimático.

Los resultados observados pueden explicarse teniendo en cuenta que la velocidad de extracción es más lenta para el laminado debido a que el material posee sus estructuras celulares con mayor grado de integridad. Las láminas expandidas poseen mayores superficies de contacto con el solvente, no sólo debido a la disminución del tamaño de partícula sino también al aumento en la porosidad del material y a la degradación y deformación de las estructuras celulares (Varzakas y col., 2005).

Se puede observar que el coeficiente de difusión efectivo es mayor para los sólidos que han sufrido más número de pretratamientos, lo cual es consistente con el grado de degradación de las estructuras celulares. Si el material de partida es un sólido pretratado enzimáticamente que posee sus estructuras celulares degradadas, este material presenta una permeabilidad mayor al solvente de extracción y el movimiento de las moléculas de aceite hacia el seno de la solución posee menos barreras físicas. Por lo tanto, el aceite se puede extraer a mayor velocidad cuando el proceso extractivo es dominado por el fenómeno de difusión.

\subsubsection{Efecto de la temperatura}

En las figuras 4.14 a 4.17 se pueden observar los resultados de la variación del coeficiente de difusión efectiva con la temperatura. Se les aplicó logaritmo a los coeficientes calculados a partir de los datos experimentales (Figuras 4.5 a 4.13) para tres temperaturas diferentes y fueron graficados en función de la inversa de las temperaturas absolutas. Como se muestra, el efecto de la temperatura sobre los coeficientes de difusión efectiva sigue la relación de Arrhenius descripta por la ecuación 4.16. Cada uno de los gráficos fue ajustado por mínimos cuadrados a la 
forma lineal de esta ecuación, como se describe en la sección 4.1.2.2.1. La Tabla 4.17 resume los valores de energías de activación calculados para cada uno de los sólidos ensayados.

Tabla 4.17: Energías de activación del proceso difusivo en sólidos con diferentes pretratamientos

\begin{tabular}{l|c}
\hline Tipo de sólido & Ea (KJmol \\
& -1 \\
Laminado sin hidrolizar & 25,04 \\
Laminado hidrolizado & 19,69 \\
Expandido sin hidrolizar & 39,05 \\
Expandido hidrolizado & 14,57 \\
\hline
\end{tabular}

Efecto de la temperatura sobre el coeficiente de difusión efectivo (Laminado sin hidrolizar)

Ln D

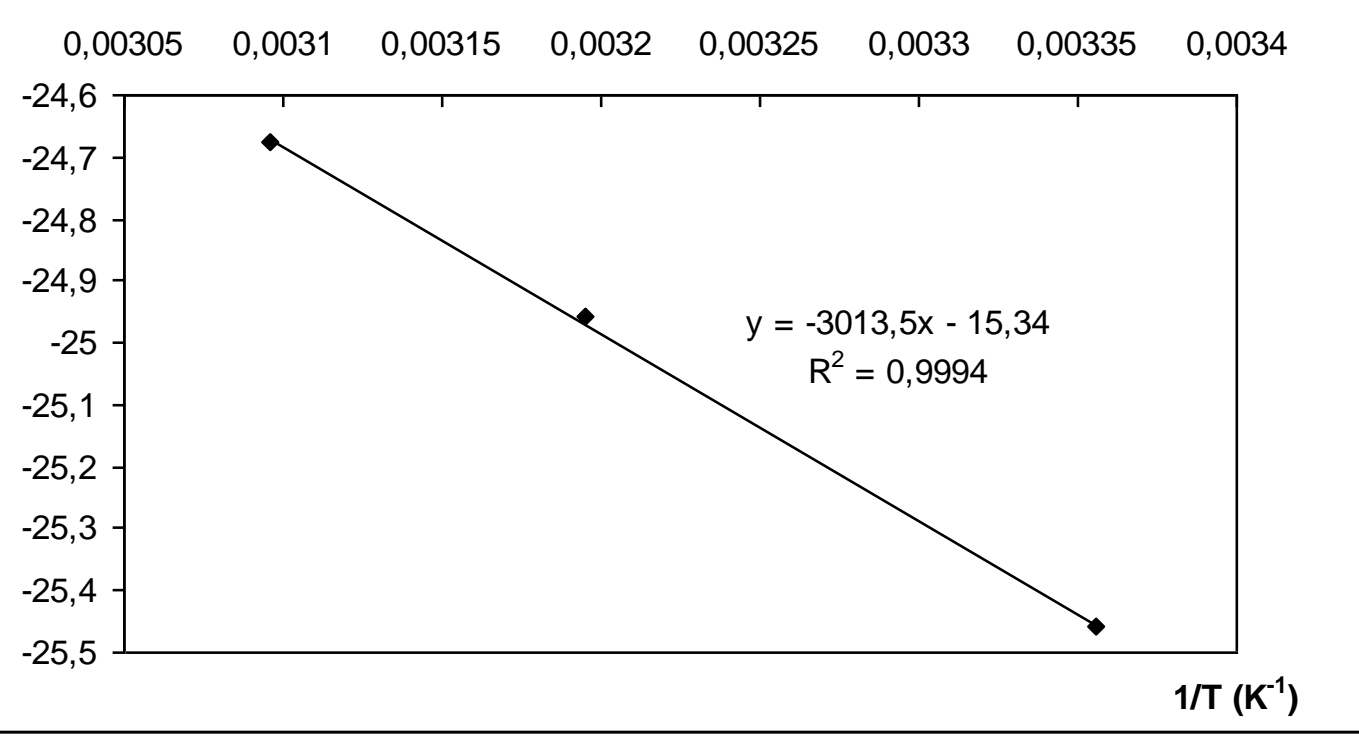

Figura 4.14: Relación de Arrhenius linealizada para laminado sin hidrolizar $\left(\mathrm{Ea}=25,04 \mathrm{KJmol}^{-1}\right)$ 


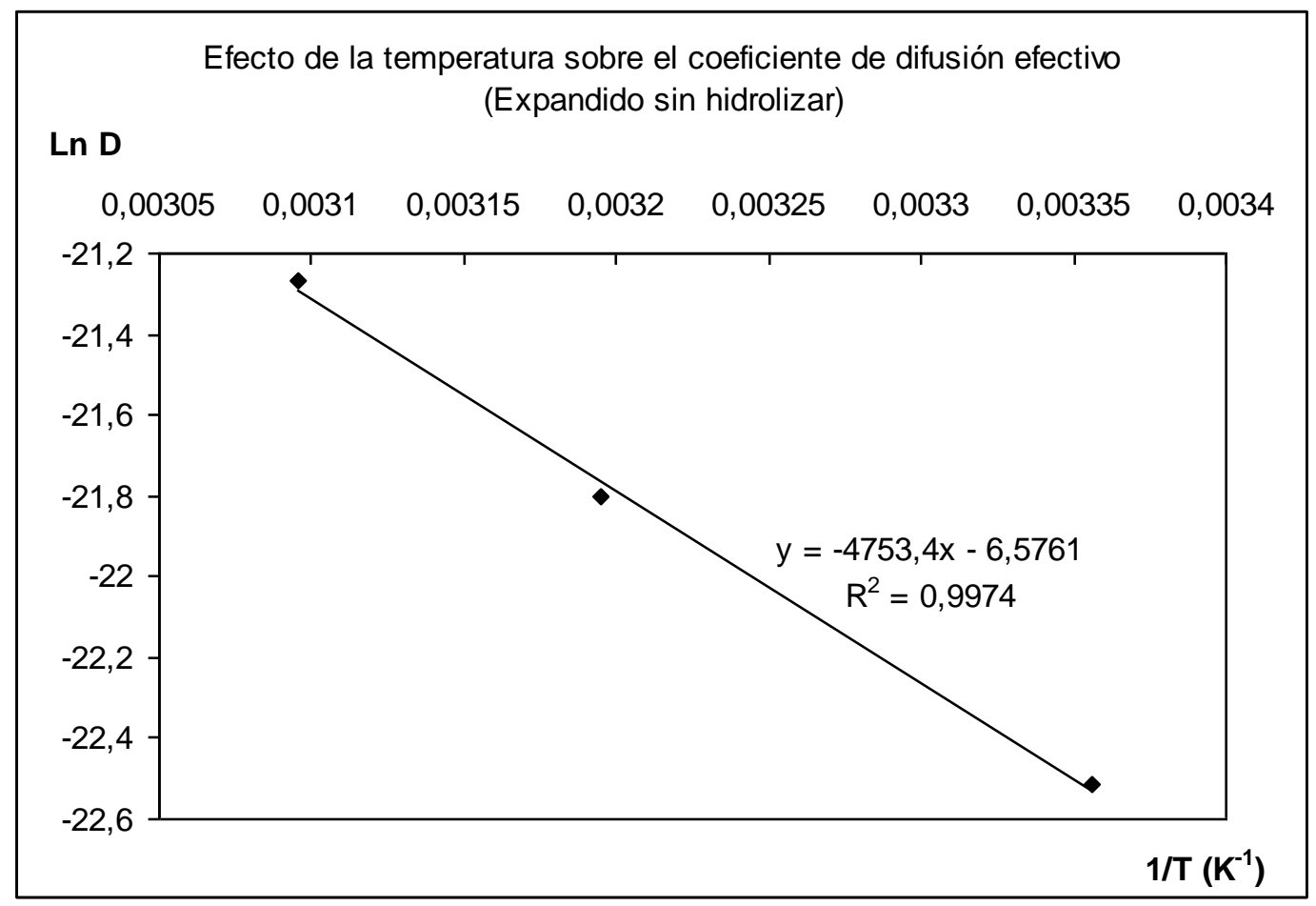

Figura 4.15: Relación de Arrhenius linealizada para expandido sin hidrolizar $\left(\mathrm{Ea}=39,5 \mathrm{KJmol}^{-1}\right)$

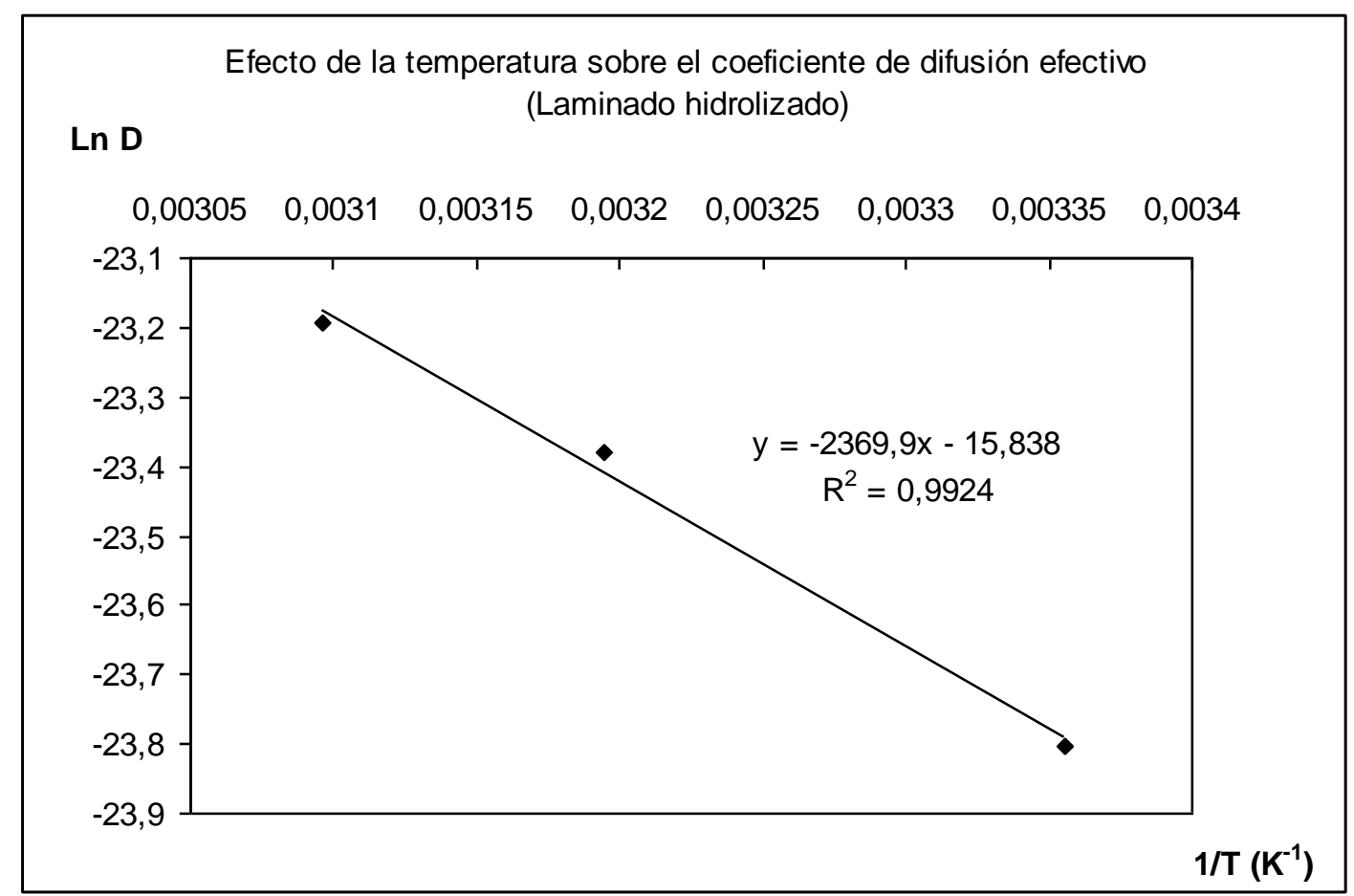

Figura 4.16: Relación de Arrhenius linealizada para laminado hidrolizado $\left(\mathrm{Ea}=19,69 \mathrm{KJmol}^{-1}\right)$ 


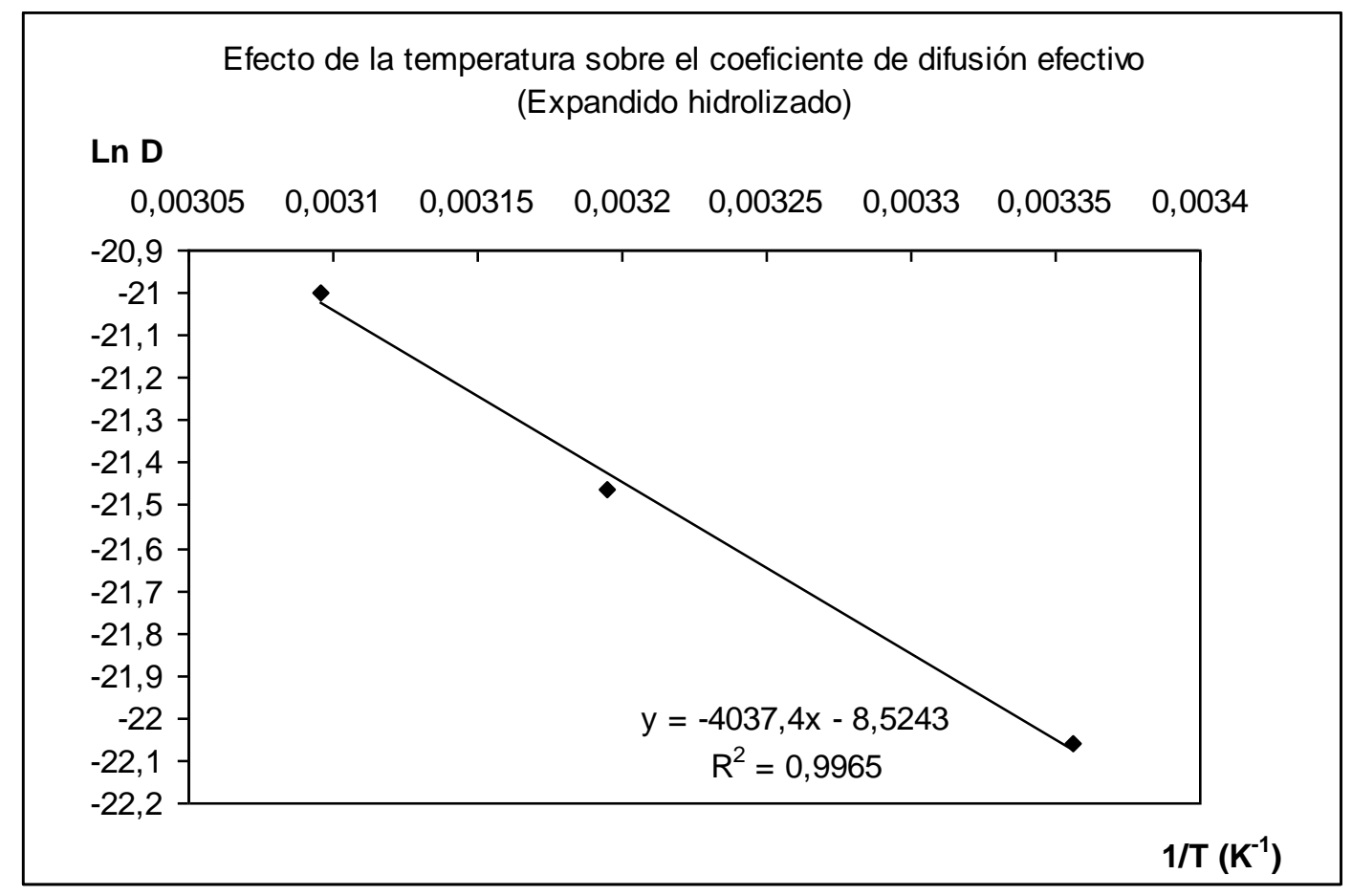

Figura 4.17: Relación de Arrhenius linealizada para expandido hidrolizado $\left(E a=14,57 \mathrm{KJmol}^{-1}\right)$

Como puede observarse, en todos los tipos de sólidos ensayados se obtuvieron coeficientes de correlación elevados, lo que indica un buen ajuste de los ensayos al modelo exponencial propuesto. El aumento de la temperatura de la extracción incrementó en todos los casos la difusividad efectiva. Este resultado puede explicarse teniendo en cuenta la disminución de la resistencia viscosa a la difusión por disminución de la viscosidad del solvente con el aumento de la temperatura y el aumento de la energía térmica de las moléculas del soluto aceite (Chang, 1986) tal como puede deducirse de la interpretación de la ecuación de Stokes-Einstein (ver sección 1.4.1.1) para partículas esféricas de soluto.

Las energías de activación de cada uno de los procesos difusivos fueron estimadas a partir de la pendiente de esta curva linealizada. Los valores de energías de activación oscilaron entre 14 y $39 \mathrm{KJmol}^{-1}$ (ver Tabla 4.17). Este rango se corresponde al orden de magnitud de energías de activación para procesos dominados por la difusión encontrados por otros autores (Cacace y Mazza, 2003; Spiro y Selwood, 1984; Kincal y Kaymak, 1990). Para el caso de sólidos hidrolizados, se obtuvieron energías de activación menores si se comparan con los mismos sin pretratamiento enzimático. Puede explicarse esta diferencia teniendo en 
cuenta la apertura de las estructuras celulares en el sólido lograda mediante el tratamiento enzimático. La disminución de la resistencia del sólido a la difusión podría ser la causante de la disminución en las energías de activación, dando un proceso difusivo menos dependiente de la temperatura de la extracción. 


\subsection{CONCLUSIONES PARCIALES}

- Se comprobó la validez del modelo desarrollado aplicando la 2da ley de Fick al sistema de extracción de aceite con hexano para los sólidos de soja con diferentes pretratamientos incluyendo la incubación enzimática. El modelo fue válido para todas las temperaturas de extracción ensayadas.

- Se lograron estimar coeficientes de difusión efectiva a partir de los datos cinéticos experimentales para cada tipo de sólido ensayado y para cada temperatura empleada.

口 El análisis de los coeficientes de difusión efectiva calculados permitió establecer que la hidrólisis enzimática disminuye la integridad de los tejidos vegetales aumentando la permeabilidad de estas estructuras respecto del aceite, dando coeficientes de difusión mayores y por lo tanto, mayores velocidades de extracción para el caso de extracción en batch, en ausencia de resistencia externa al transporte del aceite. Un efecto similar se observó para los pretratamientos físicos de laminación y extrusión. El expandido hidrolizado presentó las mayores velocidades de extracción.

- Se comprobó la validez de la ecuación de Arrhenius para representar la dependencia de la difusión respecto de la variación de la temperatura. La aplicación de este modelo permitió determinar las energías de activación asociadas al proceso difusivo a distintas temperaturas cuando la extracción de aceite con hexano es dominada por la difusión. La menor energía de activación se obtuvo para el expandido de soja hidrolizado, indicando que el proceso difusivo es más rápido en el caso de los sólidos con mayor extensión de ruptura celular.

- A partir de los resultados obtenidos para las energías de activación de los procesos difusivos que tienen lugar en cada tipo de sólido, se puede concluir que los sólidos con estructuras celulares más abiertas (hidrolizados) son menos sensibles a los cambios de temperatura. 
- Los resultados obtenidos en cuanto a velocidades de extracción indican que el pretratamiento enzimático produce un aumento en la velocidad de extracción de aceite con hexano a partir de soja y que esta hidrólisis enzimática debería realizarse en planta sobre el expandido de soja. 
Capítulo 5

Extracción de aceite de soja en columna de lecho fijo: influencia del material de partida. 


\section{Extracción de aceite de soja en columna de lecho fijo: influencia del material de partida.}

Es indudable la importancia del estudio de la transferencia de masa en la mayoría de los procesos de separación en los que hay involucradas más de una fase. Comprender la naturaleza y la magnitud de las resistencias a la transferencia de masa es una de las claves para predecir en forma segura y confiable dicha transferencia. Debido a que las condiciones que rodean la interfase son difíciles de observar es útil desarrollar un modelo matemático del proceso, a partir de los hechos básicos conocidos (Sherwood y col, 1979).

La extracción con solvente es el principal proceso industrial para extraer aceites a partir de vegetales oleaginosos. Para el caso de aceite de soja, la lixiviación con hexano es un proceso de extracción sólido-líquido, en el cual los sólidos pretratados de soja son puestos en contacto con hexano para transferir el aceite desde la matriz sólida al fluido.

Para evaluar el comportamiento de los sólidos hidrolizados enzimáticamente durante la extracción se realizan ensayos en columna de lecho fijo, donde el lecho lo constituyen los distintos tipos de sólidos.

Si bien el principio de la extracción con solvente es relativamente simple, conlleva un mecanismo complejo. La velocidad de extracción de aceite con hexano a partir de sólidos de soja en una sección de un lecho fijo tiene un componente debido al transporte de masa difusivo que ocurre en el sólido y otro componente debido al transporte de masa convectivo en la fase líquida.

Los objetivos del presente capítulo son:

Obtener un modelo matemático que describa el sistema de extracción de aceite con hexano en una sección de un lecho fijo, donde se considera que la concentración de aceite en el líquido es muy pequeña. 
- Cuantificar las resistencias interna y externa a la transferencia de masa durante la extracción de aceite de soja con hexano en la sección del lecho fijo.

- Determinar la influencia que ejerce el pretratamiento enzimático sobre la transferencia de masa en el sistema de extracción en una sección de lecho fijo, considerando tanto la resistencia interna como la resistencia externa.

- Explorar la influencia que ejercen cada uno de los parámetros del modelo sobre la velocidad de extracción para el sistema de lecho fijo en estudio.

- Concluir, en base a los resultados obtenidos, la posible adaptación de la operación de pretratamiento enzimático a los procesos existentes para la extracción industrial de aceite de soja con hexano. 


\subsection{PARTE EXPERIMENTAL}

5.1.1 Materiales ver Materiales del Capítulo 2.

5.1.1.1 Reactor: para todas las incubaciones enzimáticas se utilizaron frascos erlenmeyer de vidrio de $150 \mathrm{ml}$.

5.1.1.2 Sistema de calefacción y agitación: se utilizó un rotavapor para la incubación enzimática con baño termostatizado eléctrico y agitación suave (100 rpm).

5.1.1.3 Sistema de extracción: la extracción con hexano se llevo a cabo en una columna, que puede considerarse una sección de un lecho fijo, en la cual el lecho fijo lo constituyen los diferentes sólidos de soja. El extractor vertical posee un refrigerante de reflujo para evitar las pérdidas de solvente por evaporación. La temperatura se mantuvo constante mediante circulación de agua caliente por un encamisado exterior que posee el extractor. El calentamiento del agua circulada por la camisa se realizó en forma externa por medio de un serpentín de cobre sumergido en un baño termostatizado eléctrico. El solvente hexano empleado se alimentó por medio de una bomba peristáltica. En la tabla 5.1 se muestran las características operacionales de la columna y en la figura 5.1 se presenta un esquema del sistema experimental.

Tabla 5.1: Características operacionales de la columna de extracción

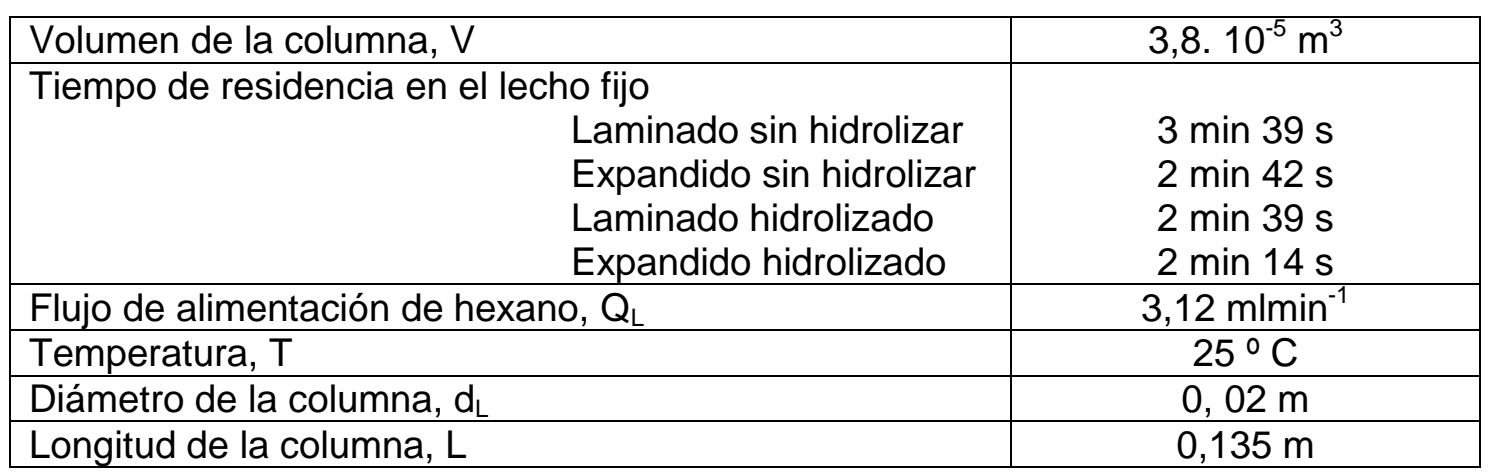




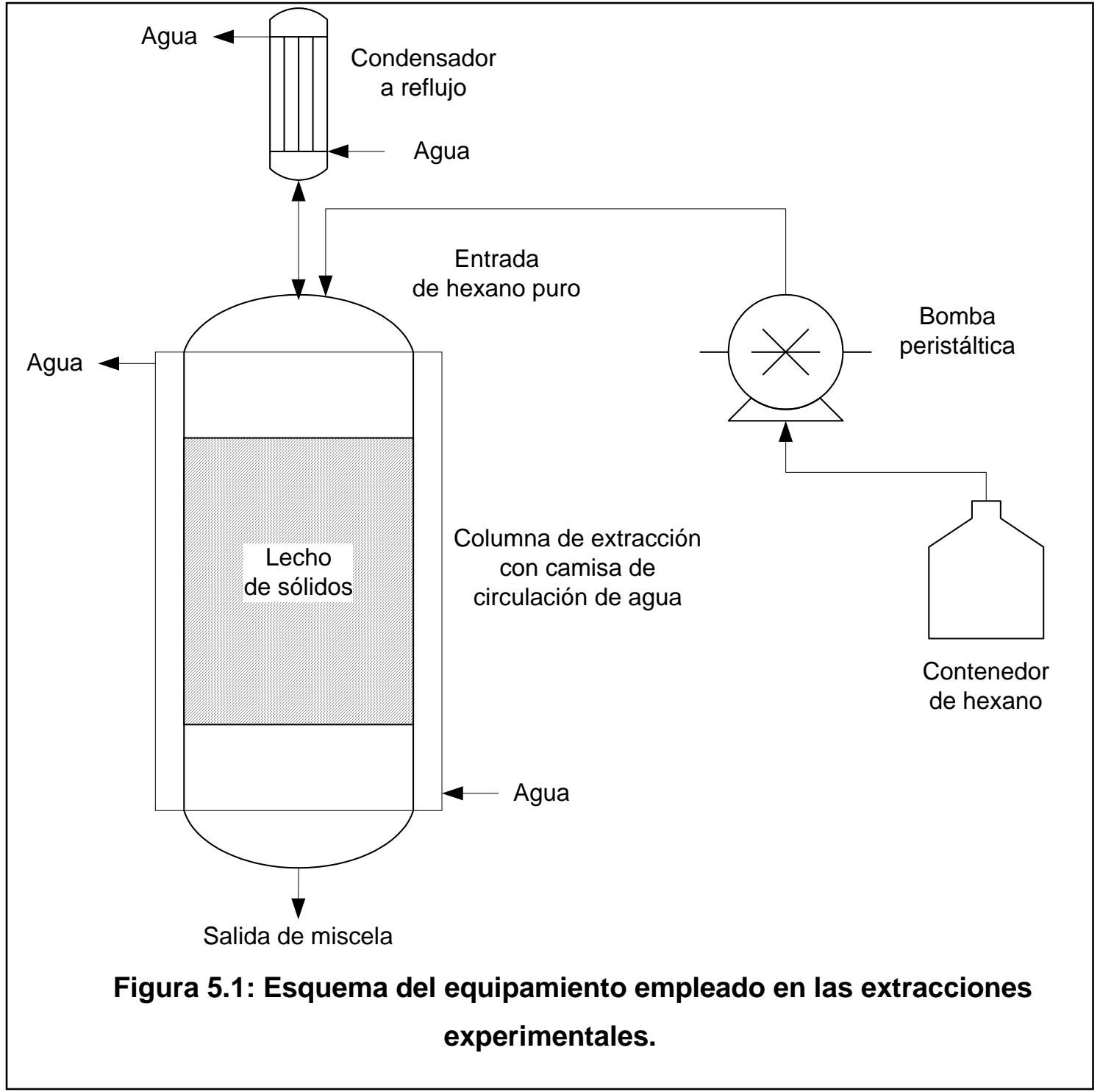

\subsubsection{Metodologías}

\subsubsection{Procedimiento experimental}

5.1.2.1.1 Pretratamiento enzimático. Ver la sección Metodologías del Capítulo 2.

\subsection{Determinación de curvas patrón}

Para cuantificar el contenido de aceite en la miscela a la salida de la columna de extracción se empleó un método espectrofotométrico. Para ello, se determinaron las 
correspondientes curvas patrón para aceite proveniente de laminado y para aceite proveniente de expandido. Las soluciones de concentración conocida se prepararon a partir de aceite crudo obtenido por el método Soxhlet desde muestras de laminado y expandido con solvente hexano. Las concentraciones de las soluciones estándares empleadas fueron: 0,$5 ; 1 ; 2 ; 3 ; 4 ; 5 ; 6 ; 7$ y $8 \% \mathrm{v} / \mathrm{v}$. Las lecturas espectrofotométricas se realizaron a 225 y $300 \mathrm{~nm}$, dependiendo de la sensibilidad requerida (Wiese y Snyder, 1987).

\subsection{Cálculo de la porosidad del lecho}

La fracción de espacio vacío del lecho constituido por cada tipo de sólido ensayado se determina por comparación del volumen de cada sólido finamente molido y totalmente compactado y la fracción de volumen de la columna ocupada por el sólido según (Geankoplis, 1998):

$$
\varepsilon=\frac{V_{\text {poros }}}{V_{\text {lecho }}}=1-\frac{\rho_{\text {lecho }}}{\rho_{\text {particula }}}
$$

ecuación 5.1

reemplazando y reordenando, se obtiene:

$$
\varepsilon=\frac{V_{\text {lecho }}-V_{\text {particula }}}{V_{\text {lecho }}} \quad \text { ecuación } 5.2
$$

Empleando la ecuación 5.2 se obtuvieron las porosidades para los lechos empacados de los distintos sólidos ensayados (ver tabla 5.2).

Tabla 5.2: Porosidades de lecho

\begin{tabular}{l|l}
\hline Laminado sin hidrolizar & 0,78 \\
Expandido sin hidrolizar & 0,66 \\
Laminado hidrolizado & 0,75 \\
Expandido hidrolizado & 0,65 \\
\hline
\end{tabular}

5.1.2.1.4 Determinación de cinética de extracción 
Los sólidos de soja con diferentes pretratamientos físico-mecánicos constituyeron el lecho fijo del extractor. La columna se rellenó con estos sólidos previamente pesados. El solvente utilizado fue hexano, el cual se alimentó puro a una temperatura y caudal definidos desde la cabeza del extractor. Se tomaron muestras de la miscela (mezcla de aceite disuelto en hexano) a la salida del extractor. El tiempo total de extracción fue de 60 minutos. Se extrajeron alícuotas de $1 \mathrm{~mL}$ por muestra a intervalos de 2 minutos durante los primeros 30 minutos y a intervalos de 5 minutos durante los 30 minutos posteriores. Las miscelas obtenidas en cada corrida experimental se evaporaron hasta sequedad en estufa. La concentración en aceite de las miscelas obtenidas se determinaron espectrofotométricamente a 280 y $300 \mathrm{~nm}$, dependiendo de la sensibilidad requerida. Antes de la lectura en el espectrofotómetro, las muestras de aceite se diluyeron cada una con $3 \mathrm{~mL}$ de hexano inmediatamente antes de realizar las mediciones, a fin de evitar errores en las lecturas por variaciones de volumen por pérdidas de solvente por evaporación.

\subsection{Determinación del equilibrio}

Las corridas experimentales para determinación del equilibrio se realizaron con 200, 300,400 y $500 \mathrm{~mL}$ de solvente hexano para $10 \mathrm{~g}$ de soja laminada y expandida con y sin pretratamiento enzimático. El sólido fue contenido dentro de cartuchos de tela permeable al hexano. Ambas fases se mantuvieron en contacto sin agitación y a temperatura constante de $25^{\circ} \mathrm{C}$. Al cabo de 24 hs se separaron ambas fases y se determinó el contenido de aceite en cada una de ellas. Para cuantificar el aceite transferido a la fase líquida, el solvente se destiló y se completó el secado del aceite en estufa para eliminar los restos de hexano. La cantidad de aceite se determinó por pesada directa y a partir de este dato, se calculó el porcentaje de aceite presente en la miscela en equilibrio con el aceite contenido en el sólido. Para cuantificar el aceite residual contenido en el sólido, el cartucho fue lavado rápidamente con hexano para eliminar restos de miscela que permanecen embebiendo el sólido y luego fue secado en estufa hasta sequedad. El sólido seco fue sometido a una extracción por el método Soxhlet y por diferencia de peso antes y después de la extracción se determinó el peso de aceite contenido en la fase sólida.

\subsubsection{Transferencia de masa en el extractor}


El sistema empleado para las extracciones se ha descripto en la sección 5.1.1.3. En la figura 5.1 se esquematiza el equipo utilizado. El lecho fijo del extractor vertical estaba constituido por los sólidos laminado y expandido de soja con y sin pretratamiento enzimático según el ensayo. El solvente hexano se alimentaba por la parte superior del extractor, parte del hexano penetraba en los poros del sólido y disolvía el aceite instantáneamente. El remanente del hexano fluia hacia abajo a través de los espacios vacíos entre partículas como una fase continua. La mezcla del solvente hexano y el aceite disuelto, llamada miscela se descargaba por la parte inferior de la columna.

Para obtener un modelo matemático que describa el comportamiento del sistema es necesario analizar el proceso de extracción con los fenómenos de transferencia de masa que implica y las posibles resistencias a esta transferencia tanto en la fase líquida, Ilamada miscela, como de la fase sólida, laminado y expandido de soja con y sin pretratamiento enzimático. Para conocer la evolución del contenido de aceite en el hexano que deja el sistema y la variación del contenido de aceite residual en el sólido que constituye el lecho fijo se deben plantear balances de materia para cada una de las fases.

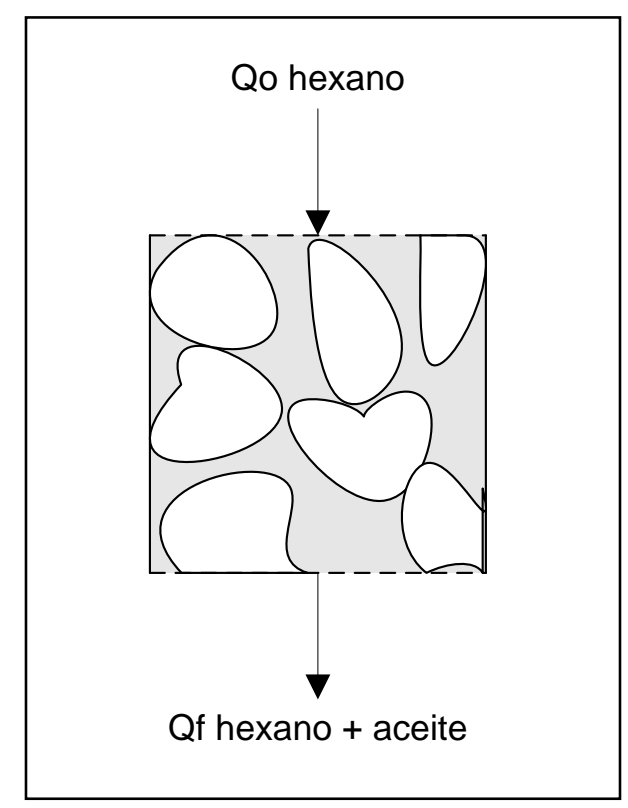

Figura 5.2: Sección de lecho fijo constituido por el sólido de soja

El balance de masa permite estimar la variación temporal de la masa de aceite en la fase líquida como (Majumdar y col, 1995): 


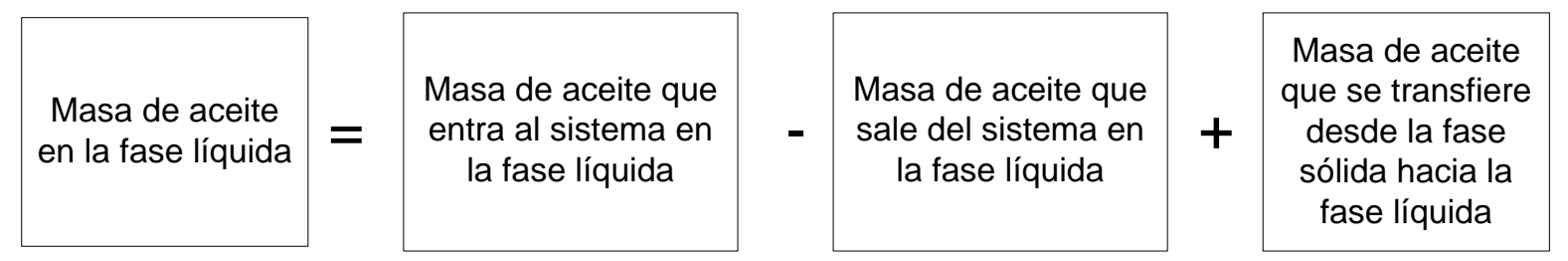

Si se considera al lecho fijo empleado como una sección de una columna de extracción de volumen constante (ver Figura 5.2), en la cual se alimenta un caudal constante de hexano, $Q_{L}$, y se retira del sistema el mismo caudal de miscela, $Q_{L}$, se puede escribir el balance de masa como sigue (Majumdar y col, 1995; EspinosaPérez y col., 2007; Veloso y col, 2005):

$V_{L} \cdot \frac{d c_{L}}{d t}=Q_{L o} \cdot c_{L o}-Q_{L} \cdot c_{L}+k_{L} \cdot A\left(c_{L i}-c_{L}\right)$

ecuación 5.3

donde $Q_{L \circ}$ es el caudal volumétrico de entrada de hexano $\left(\mathrm{m}^{3} \mathrm{~s}^{-1}\right), \mathrm{C}_{\mathrm{L}}$ es la concentración de aceite en el hexano $\left(\mathrm{kgm}^{-3}\right), C_{\llcorner o}$ es la concentración de aceite en la alimentación $\left(\mathrm{kg}^{-3} \mathrm{~m}^{-3}\right), \mathrm{C}_{\mathrm{Li}}$ es la concentración de aceite en la interfase $\left(\mathrm{kgm}^{-3}\right)$ y $Q_{L}$ es el caudal volumétrico de salida de la miscela del sistema $\left(\mathrm{m}^{3} \mathrm{~s}^{-1}\right)$. El primer término del segundo miembro de la ecuación 5.3 representa el aporte de masa del fluido extractor que se alimenta y es cero debido a que el hexano que se emplea en los ensayos es puro, $C_{L o}=0$. El segundo término de la derecha representa la masa de aceite que se retira del sistema en la corriente de salida de la columna y el tercer término representa la transferencia de aceite desde la fase sólida hacia la fase líquida según la ecuación 1.5 (Geankoplis, 1998). La concentración de aceite en la interfase líquida, $\mathrm{C}_{\mathrm{L}}$, puede escribirse en función de la ecuación 1.7

$$
C_{s}=K \cdot C_{L}
$$

ecuación 1.7

que describe el equilibrio (Majumdar y col. ,1995; Pramparo y col., 2002; Cacace y Mazza, 2003; Thomas y col, 2005; Espinoza-Pérez y col., 2007; Carrín y Crapiste, 2008).

Reemplazando y reordenando se tiene:

$$
\frac{d c_{L}}{d t}=-\frac{Q_{L} \cdot c_{L}}{V_{L}}+\frac{k_{L} \cdot A}{V_{L}}\left(\frac{\hat{c}_{S}}{K}-c_{L}\right)
$$


donde $\mathrm{K}$ es la constante de equilibrio determinada experimentalmente y $\hat{\mathrm{c}}_{\mathrm{S}}$ es la concentración promedio de aceite contenida en el sólido $\left(\mathrm{kgm}^{-3}\right)$.

Para la fase sólida se puede escribir la variación temporal de la masa de aceite en dicha fase según (Majumdar y col, 1995; Thomas y col, 2005; Veloso y col, 2005):

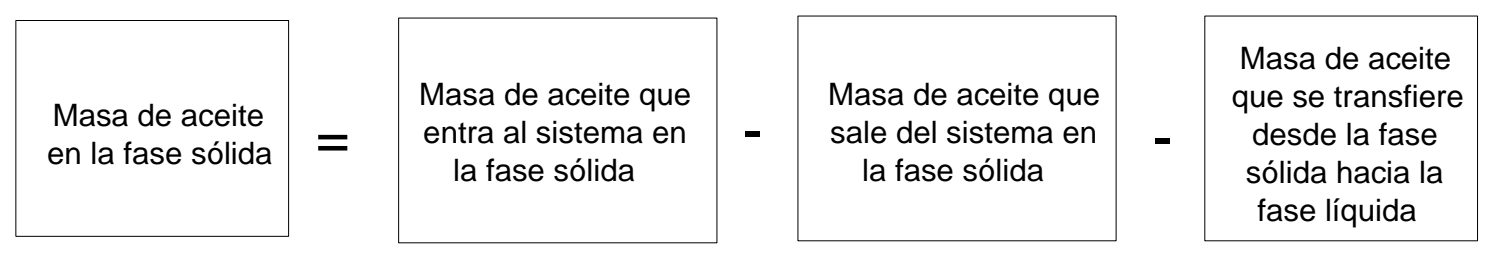

La variación de la cantidad de aceite en la fase sólida es solamente debida a la transferencia de masa a través de la interfase desde el sólido hacia la fase líquida extractora. Para el sólido, el primer y segundo término de la derecha del balance mostrado arriba son cero. El balance de masa se reduce a:

$V_{S} \cdot \frac{d \hat{c}_{S}}{d t}=-k_{S} \cdot A\left(\hat{c}_{S}-c_{S i}\right)$

ecuación 5.5

donde $\mathrm{V}_{\mathrm{S}}$ es el volumen de sólidos $\left(\mathrm{m}^{3}\right), \frac{d \hat{c}_{S}}{d t}$ es la variación temporal de la concentración media en el solido, $\hat{c}_{S}$ es la concentración promedio de aceite contenida en el sólido $\left(\mathrm{kgm}^{-3}\right)$, $\mathrm{C}_{\mathrm{Si}}$ es la concentración de aceite en la interfase $\left(\mathrm{kgcm}^{3}\right), \mathrm{k}_{\mathrm{s}}$ es el coeficiente de transferencia de masa en el sólido $\left(\mathrm{ms}^{-1}\right)$ y $\mathrm{A}$ es el área total disponible para la transferencia de masa $\left(\mathrm{m}^{3} \mathrm{Kg}^{-1}\right)$. La concentración de aceite en la interfase sólida, $\mathrm{C}_{\mathrm{S}}$, puede escribirse en función de la ecuación 1.8 que describe el equilibrio (Majumdar y col. ,1995; Pramparo y col., 2002; Cacace y Mazza, 2003; Thomas y col, 2005; Espinoza-Pérez y col., 2007; Carrín y Crapiste, 2008). Reemplazando y reordenando se tiene:

$$
V_{S} \cdot \frac{d \hat{c}_{S}}{d t}=-k_{S} \cdot A\left(\hat{c}_{S}-K \cdot c_{L}\right)
$$

ecuación 5.6 
donde $\mathrm{K}$ es la constante de equilibrio determinada experimentalmente.

En el planteo de los balances de masa, se asumió que:

- el lecho estaba constituido de partículas porosas, isotrópicas y esféricas para el caso de los sólidos expandido con y sin pretratamiento enzimático y laminado con tratamiento enzimático (Capítulo 4);

$\checkmark$ el contenido de aceite en cada uno de los sólidos ensayados es uniforme en todas las partículas. En la tabla 5.3 se muestran los contenidos iniciales de aceite para cada uno de los sólidos;

$\checkmark$ el aceite se comporta como un solo componente debido a que todos los triglicéridos que lo componen son fuertemente solubles en hexano y que los fosfolípidos no bloquean el acceso del hexano al aceite (Fan y col, 1948);

- los sólidos poseen macroporos en los cuales residen los glóbulos de aceite. El solvente entra en estos poros y disuelve instantáneamente el aceite formando la miscela (fase estancada) (Majundar y col., 1995; Carrín y Crapiste, 2008);

$\checkmark$ se establece una relación de equilibrio entre el contenido de aceite en la fase estancada en los poros y el contenido de aceite residual en el sólido (Majumdar y col. ,1995; Pramparo y col., 2002; Thomas y col, 2005; EspinozaPérez y col., 2007; Carrín y Crapiste, 2008);

$\checkmark$ la transferencia de aceite ocurre desde los poros al seno de la miscela debido al gradiente de concentración de aceite;

- la relación longitud de la columna-diámetro de partícula, $\mathrm{L} / \mathrm{d}_{\mathrm{L}}$, (ver Tabla 5.1) es suficientemente grande como para despreciar el gradiente de concentración radial en la columna;

$\checkmark$ las porosidades de lecho y de la partícula son uniformes y constantes a lo largo del proceso de extracción;

$\checkmark$ no se produce calor de mezclado;

$\checkmark$ la temperatura es constante y uniforme durante toda la extracción;

$\checkmark$ la relación de equilibrio determinada experimentalmente incluye el efecto de la humedad del sólido; 
$\checkmark$ el flujo volumétrico es constante ya que el mismo caudal de alimentación de hexano puro se retira del sistema en forma de miscela de salida (aceite + hexano), $\mathrm{V}_{\mathrm{Li}}=\mathrm{V}_{\mathrm{Lf}}$. Se considera despreciable el aporte de volumen que se debe al aceite extraído, disuelto en la miscela.

Tabla 5.3: Contenidos iniciales de aceite

\begin{tabular}{lc}
\hline \multicolumn{1}{c}{ Sólidos } & $\mathbf{q}_{\mathbf{0}}$ \\
\hline Laminado de soja sin hidrolizar & 0,246 \\
Expandido de soja sin hidrolizar & 0,2633 \\
Laminado de soja hidrolizado & 0,3385 \\
Expandido de soja hidrolizado & 0,3622 \\
\hline
\end{tabular}

Las áreas interfaciales de cada tipo de sólido fueron determinadas por el método de BET, el cual implica la determinación de la cantidad de nitrógeno, empleado como absorbato, requerida para formar una capa de espesor monomolecular sobre la superficie de la muestra a temperatura determinada. Las áreas se calcularon a partir del volumen de gas inerte que formó la monocapa. Se empleó el equipo Pulse Chemisorb 2700, de Micromeritics. En la tabla 5.4 se resumen las áreas específicas de cada uno de los sólidos ensayados.

\section{Tabla 5.4: Areas específicas}

\begin{tabular}{cc}
\hline Sólidos & A/Vs $\left(\mathbf{m}^{-1}\right)$ \\
\hline Laminado de soja sin hidrolizar & 207,2 \\
Expandido de soja sin hidrolizar & 507,4 \\
Laminado de soja hidrolizado & 510,6 \\
Expandido de soja hidrolizado & 1368,8 \\
\hline
\end{tabular}

A partir de las ecuaciones 5.4 y 5.6 es posible estimar la evolución de la cantidad de aceite en la miscela de salida del sistema de extracción y la evolución del contenido de aceite residual en el sólido con el tiempo.

Este sistema de ecuaciones diferenciales se resolvió numéricamente empleado el programa MATLAB® R2008b. El método empleado (ode15s) es de orden variable, 
basado en fórmulas de diferenciación numérica y/o de diferencias hacia atrás, también conocido como método de Gear (Matlab®, 2008).

\subsubsection{Obtención de parámetros asociados al modelo}

La representación de la transferencia de masa empleando el balance de masa descripto en la sección precedente requiere el cálculo de los parámetros asociados, los cuales son:

$\square$ Difusividad efectiva en el sólido, $\mathrm{D}_{\mathrm{ef}}$

$\square$ Difusividad molecular en el solvente, $D_{L}$

- Coeficiente de transferencia de masa en el líquido, $\mathrm{k}_{\mathrm{L}}$

Coeficiente de transferencia de masa en el sólido, $\mathrm{k}_{\mathrm{s}}$

5.1.2.2.1Difusividad efectiva en el sólido, $D_{\text {ef. }}$ El cálculo del coeficiente de difusión efectiva asociada al transporte de masa interno que tiene lugar dentro del sólido se abordó en el Capítulo 4, donde se estimaron los coeficientes de difusión efectiva en ambos sólidos (ver Tablas 4.14 a 4.16), laminado y expandido, con y sin pretratamiento enzimático para distintas temperaturas de trabajo, así como también las energías de activación asociadas al fenómeno difusivo que ocurre dentro del sólido.

5.1.2.2.2 Difusividad molecular en el solvente, $D_{L}$. La difusión en fase líquida es más difícil de abordar teóricamente que en fase gaseosa para la cual existe una teoria cinética rigurosa, debido a que la naturaleza del estado líquido exige la definición de una función de potencial que sea representativa de las interacciones entre las moléculas. Ello ha determinado que no exista un método suficientemente fiable para estimar difusividades en fase líquida a partir de una teoría básica molecular o a partir de otras propiedades del sistema (Rivero Martinez, 2002).

La difusividad molecular o coeficiente de difusión molecular en fase líquida puede estimarse mediante una serie de correlaciones empíricas y semiempíricas. Éstas se dividen en dos grupos: para electrolitos y para no electrolitos y cada unos de ellos, a 
su vez, están subdivididas en soluciones diluídas y concentradas (Sherwood y col, 1979).

La primitiva ecuación de Stokes-Einstein, basada en un modelo en el que se considera que una esfera de soluto se mueve en el seno de un solvente considerado continuo, es:

$$
D_{L}=\frac{k T}{6 \pi r_{0} \mu}
$$

ecuación 5.7

Donde $r_{0}$ es el radio de la esfera. Esta ecuación ha sido posteriormente modificada por Wilke-Chang en 1955 con el objetivo de obtener un procedimiento de estimación útil. Para el caso del presente estudio, la ecuación más general es:

$$
D_{L}=117,3 \cdot 10^{-18}\left[\left(\phi M_{L}\right)^{1 / 2} \frac{T}{\mu_{L} V_{A}^{0,6}}\right]
$$

ecuación 5.8

Donde:

$D_{\mathrm{L}} \quad$ es el coeficiente de difusión mutua del soluto en el solvente líquido, $\left(\mathrm{m}^{2} \mathrm{~s}^{-1}\right)$.

$\phi \quad$ es el parámetro de asociación para el solvente.

$\mathrm{M}_{\mathrm{L}} \quad$ es la masa molecular del solvente, $\left(\mathrm{kgmol}^{-1}\right)$.

$\mathrm{T} \quad$ es la temperatura absoluta, $(\mathrm{K})$.

$\mu_{\mathrm{L}} \quad$ es la viscosidad del solvente, $\left(\mathrm{kgm}^{-1} \mathrm{~s}^{-1}\right)$.

$\mathrm{V}_{\mathrm{A}}$ es el volumen molar del soluto a su temperatura de ebullición normal, $\left(\mathrm{m}^{3} \mathrm{kmol}^{-1}\right)$.

5.1.2.2.3 Coeficiente de transferencia de masa en el líquido, $k_{L}$. La resistencia en la película viene determinada por las condiciones hidrodinámicas del proceso. Cada partícula en el lecho está rodeada de una película de líquido en la que tiene lugar la transferencia de materia (Rivero Martinez, 2002). La resistencia a la transferencia de masa está confinada a una delgada región adyacente a la interfase. La resistencia en este caso se refiere a la relación del gradiente de un adecuado potencial al flujo de masa, donde "flujo" significa velocidad de transporte por unidad de área. El flujo de interés es el neto, normal al límite entre las fases y el gradiente se define en términos de la distancia a éste. El hecho de que la resistencia a la transferencia de masa se localice esencialmente en una región muy próxima a la frontera entre fases, 
sugiere la idea de una fina película estancada o en reposo adyacente a una superficie sobre la cual el flujo es turbulento (Sherwood y col, 1975). El espesor adecuado para justificar la magnitud de la resistencia a la transferencia de masa observada viene determinado por las condiciones hidrodinámicas, es decir por las condiciones de la corriente y por lo tanto del número de Reynolds (Rivero Martinez, 2002 y Sherwood y col., 1979). Algunos estudios para el caso de lechos empacados y fluidizados se presentan en la tabla 5.4.

Este coeficiente de transferencia de materia puede determinarse mediante el empleo de la correlación empírica para lechos fijos propuesta por Geankoplis (1998) (ver Tabla 5.4):

$$
\begin{gathered}
S h=\frac{1,09}{\varepsilon} \cdot \operatorname{Re}^{1 / 3} \cdot S c^{1 / 3} \\
S h=\frac{k_{L} \cdot d_{p}}{D_{L}} \\
\operatorname{Re}=\frac{d_{p} \cdot \rho_{L} \cdot v}{\mu_{L}} \\
S c=\frac{\mu_{L}}{D_{L} \cdot \rho_{L}}
\end{gathered}
$$

Donde:

Sh es el número de Sherwood

Sc es el número de Schmidt

Re es el número de Reynolds

$\mathrm{d}_{\mathrm{p}} \quad$ es el diámetro de partícula

a es el área superficial externa para la convección (para el caso de partículas esféricas el área es a $=3 /$ radio de la partícula) (Rivero Martinez, 2002)

$\mu_{\mathrm{L}} \quad$ es la viscosidad dinámica del solvente hexano

$\rho_{\mathrm{L}} \quad$ es la densidad del solvente hexano

v es la velocidad superficial del fluído (flujo volumétrico/área transversal de la columna de extracción perpendicular a la dirección del flujo de hexano).

Tabla 5.4: Correlaciones de Transferencia de Masa para lechos fijos y fluidizados (reproducido de Baehr y Stephan, 2006) 


\begin{tabular}{|c|c|c|}
\hline Situación & Correlación & $\begin{array}{c}\text { Comentarios } \\
\text { E = Empírica } \\
\text { S = Semiempírica } \\
T=\text { Teórica }\end{array}$ \\
\hline $\begin{array}{l}\text { Transferencia de } \\
\text { masa o calor en } \\
\text { lechos empacados } \\
\text { para líquidos y } \\
\text { gases } \\
\\
\text { (factor de forma, } \Psi \text { ) }\end{array}$ & $\begin{array}{l}S h=0.91 \Psi \operatorname{Re}^{0.49} S c^{1 / 3} \\
\text { Para 0,01 }<\operatorname{Re}<50 \\
S h=0.61 \Psi \operatorname{Re}^{0.59} S c^{1 / 3} \\
\text { Para } 50<\operatorname{Re}<1000 \\
\text { Partícula }=1,00 \\
\text { Esfera }=0,91 \\
\text { Cilindro }=0,81\end{array}$ & $\begin{array}{l}\text { (E) Diferentes constantes y } \\
\text { factores de forma son } \\
\text { reportados por otros autores. } \\
S h=\frac{k d_{p}}{D} \operatorname{Re}=\frac{v \rho}{\mu \Psi a} \\
\text { a=superficie /volumen } \\
\mathrm{d}_{\mathrm{p}}=\text { diametro para esfera }\end{array}$ \\
\hline $\begin{array}{l}\text { Correlación de } \\
\text { Gupta y Thodos, } \\
\text { para gases y } \\
\text { lechos fluidizados y } \\
\text { fijos }\end{array}$ & $\begin{array}{l}S h=\frac{2,06}{\varepsilon} \cdot \operatorname{Re}^{0,425} S c^{1 / 3} \\
\text { Existen resultados gráficos disponibles para } \\
\text { Re desde } 1900 \text { a } 10300 .\end{array}$ & $\begin{array}{l}\text { (E) Para esferas } \\
S h=\frac{k d_{p}}{D} \operatorname{Re}=\frac{v d_{p} \rho}{\mu}\end{array}$ \\
\hline $\begin{array}{l}\text { Correlación de } \\
\text { Petrovic y Thodos, } \\
\text { para gases y } \\
\text { lechos fijos }\end{array}$ & $\begin{array}{l}S h=\frac{0,357}{\varepsilon} \operatorname{Re}^{0,641} S c^{1 / 3} \\
\text { Para } 3<\operatorname{Re}<900\end{array}$ & $\begin{array}{l}\text { (E) Para esferas empacadas, } \\
\text { lechos profundos, se puede } \\
\text { extrapolar para } R e<2000 \text {. }\end{array}$ \\
\hline $\begin{array}{l}\text { Correlación de } \\
\text { Wilson y } \\
\text { Geankoplis, para } \\
\text { líquidos y lechos } \\
\text { fijos. }\end{array}$ & $\begin{array}{c}S h=\frac{1,09}{\varepsilon} \operatorname{Re}^{1 / 3} S c^{1 / 3} \\
\text { Para } 0,0016<\operatorname{Re}<55 \\
0,35<\varepsilon<0,753 \\
165<\mathrm{Sc}<70600 \\
S h=\frac{0,25}{\varepsilon} \operatorname{Re}^{0,69} S c^{1 / 3} \\
\text { Para } 55<\operatorname{Re}<1500 \\
165<\mathrm{Sc}<10690\end{array}$ & $\begin{array}{l}\text { (E) Lechos de esferas } \\
S h=\frac{k d_{p}}{D} \operatorname{Re}=\frac{v d_{p} \rho}{\mu}\end{array}$ \\
\hline $\begin{array}{l}\text { Correlación de } \\
\text { Ohashi y col., para } \\
\text { líquidos y lechos } \\
\text { fijos }\end{array}$ & $\begin{array}{l}S h=\frac{k d_{p}}{D}=0,51\left(\frac{E^{1 / 3} d_{p}^{4 / 3} \rho}{\mu}\right)^{0,60} S c^{1 / 3} \\
\mathrm{E}=\text { velocidad de disipación de energía por } \\
\text { unidad de masa de fluido }\end{array}$ & $\begin{array}{l}\text { (S) Correlación con gran } \\
\text { cantidad de datos publicados. }\end{array}$ \\
\hline $\begin{array}{l}\text { Correlación de } \\
\text { Rahman y Streat, } \\
\text { para líquidos y } \\
\text { lechos fluidizados y } \\
\text { fijos }\end{array}$ & $\begin{array}{l}S h=\frac{0,86}{\varepsilon} \operatorname{Re} S c^{1 / 3} \\
\text { Para } 2<\operatorname{Re}<25\end{array}$ & $\begin{array}{l}\text { (E) Puede extrapolarse para } \\
R e=2000\end{array}$ \\
\hline $\begin{array}{l}\text { Correlación de } \\
\text { Marshall y Ranz, } \\
\text { para líquidos y } \\
\text { gases }\end{array}$ & $S h=\frac{k d}{D}=2+0,6 \operatorname{Re}^{1 / 2} S c^{1 / 3}$ & $\begin{array}{l}\text { (E) Basado en esferas que } \\
\text { evaporan en caída libre. } \\
\text { Puede aplicarse a lechos fijos }\end{array}$ \\
\hline $\begin{array}{l}\text { Correlación de } \\
\text { Wakao y Funazkri, } \\
\text { para liquídos y } \\
\text { gases }\end{array}$ & $\begin{array}{l}S h=2,0+1,1 \operatorname{Re}^{0,6} S c^{1 / 3} \\
\text { Para } 3<\operatorname{Re}<10000\end{array}$ & $\begin{array}{l}\text { (E) Correlación con } 20 \\
\text { estudios con gases y } 16 \\
\text { estudios con líquidos. }\end{array}$ \\
\hline
\end{tabular}

Para el caso de partículas no esféricas, se calcula un diámetro equivalente teniendo en cuenta la misma área superficial externa calculada para partículas esféricas:

$$
d_{p}=\frac{6(1-\varepsilon)}{a}
$$


5.1.2.2.4 Coeficiente de transferencia de masa en el sólido, $k_{S}$. Se puede establecer una relación entre el fenómeno microscópico de difusión dentro del sólido y el fenómeno macroscópico de transferencia de masa desde la fase sólida hacia la fase líquida (Espinoza-Pérez y col, 2008). Los modelos desarrollados por otros autores incluyen movimiento del sólido (Carrín y Crapiste, 2008; Veloso y col, 2005) y variación de las condiciones del equilibrio (Thomas y col, 2005). Para el presente caso, considerando que el sistema es del tipo batch respecto del sólido, es posible determinar la concentración interfacial de aceite a partir de las soluciones analíticas de las ecuaciones 4.1 y 4.7 para lámina y esfera respectivamente, cuando la concentración de aceite en la interfase es constante en $z=L$ ó $r$, a tiempo $\geq 0$ (Espinoza-Pérez y col., 2008):

A) Para lámina:

$\frac{\hat{c}_{S}-c_{S i}}{c_{S o}-c_{S i}}=\frac{8}{\pi^{2}} \sum_{n=0}^{\infty} \frac{1}{(2 n+1)^{2}} \cdot \exp \left[-\frac{\operatorname{Def}(2 n+1)^{2} \pi^{2} t}{4 l^{2}}\right]$

ecuación 5.14

Despreciando para tiempos largos los términos superiores y tomando derivada:

$$
\frac{d \hat{c}_{S}}{d t}=-\frac{\pi^{2} a D e f}{4 l(1-\varepsilon)} \cdot\left(\hat{c}_{S}-c_{S i}\right)
$$

Cuando se establece el equilibrio, la concentración de aceite en la interfase se relaciona con la concentración de aceite en el seno de la miscela a través de la constante de equilibrio según la expresión (Geankoplis, 1998):

$$
c_{s}=K \cdot c_{L}
$$

ecuación 1.7

Igualando la ecuación 5.15 correspondiente al transporte difusivo en el sólido y el balance de masa en el mismo descripto por la ecuación 5.3 se obtiene: 


$$
\frac{\pi^{2} \cdot \operatorname{Def}}{4 l^{2}}\left(\hat{c}_{S}-\text { Keq.c } c_{L}\right)=\frac{k_{S} \cdot A}{V_{S}}\left(\hat{c}_{S}-\text { Keq. } c_{L}\right)
$$

ecuación 5.16

A partir de esta expresión es posible estimar el coeficiente de transferencia de masa en las láminas conociendo el coeficiente de difusión efectiva, según:

$$
k_{S}=\frac{\pi^{2} \cdot \operatorname{Def} \cdot V_{S}}{4 l^{2} \cdot A}
$$

ecuación 5.17

B) Para esfera porosa:

$$
\frac{\hat{c}_{S}-c_{S i}}{c_{S o}-c_{S i}}=\frac{6}{\pi^{2}} \sum_{n=1}^{\infty} \frac{1}{n^{2}} \cdot \exp \left[-\frac{D e f \cdot n^{2} \cdot \pi^{2} \cdot t}{r^{2}}\right]
$$

ecuación 5.18

Despreciando para tiempos largos los términos superiores y tomando derivada:

$$
\frac{d \hat{c}_{S}}{d t}=-\frac{\pi^{2} \cdot D e f}{r^{2}} \cdot\left(\hat{c}_{S}-c_{S i}\right)
$$

Considerando que en el equilibrio la concentración de aceite en la interfase se relaciona con la concentración de aceite en el seno de la miscela a través de la constante de equilibrio, según la ecuación 1.8, se obtiene (Geankoplis, 1998):

$$
\frac{\pi^{2} \cdot \operatorname{Def}}{r^{2}}\left(\hat{c}_{S}-\text { Keq. } c_{L}\right)=\frac{k_{S} A}{V_{S}}\left(\hat{c}_{S}-\text { Keq. } c_{L}\right)
$$

A partir de la expresión de la ecuación 5.20 es posible estimar el coeficiente de transferencia de masa en el sólido conociendo el coeficiente de difusión efectiva, según:

$$
k_{S}=\frac{\pi^{2} \cdot \operatorname{Def} \cdot V_{S}}{r^{2} \cdot A}
$$




\subsection{Resultados y Discusión}

5.2.1 Determinación de curvas patrón 
Se obtuvieron dos curvas patrones para aceite obtenido a partir de laminado a 225 y 300 nm según la concentración a medir (ver Figuras 5.3 y 5.4).

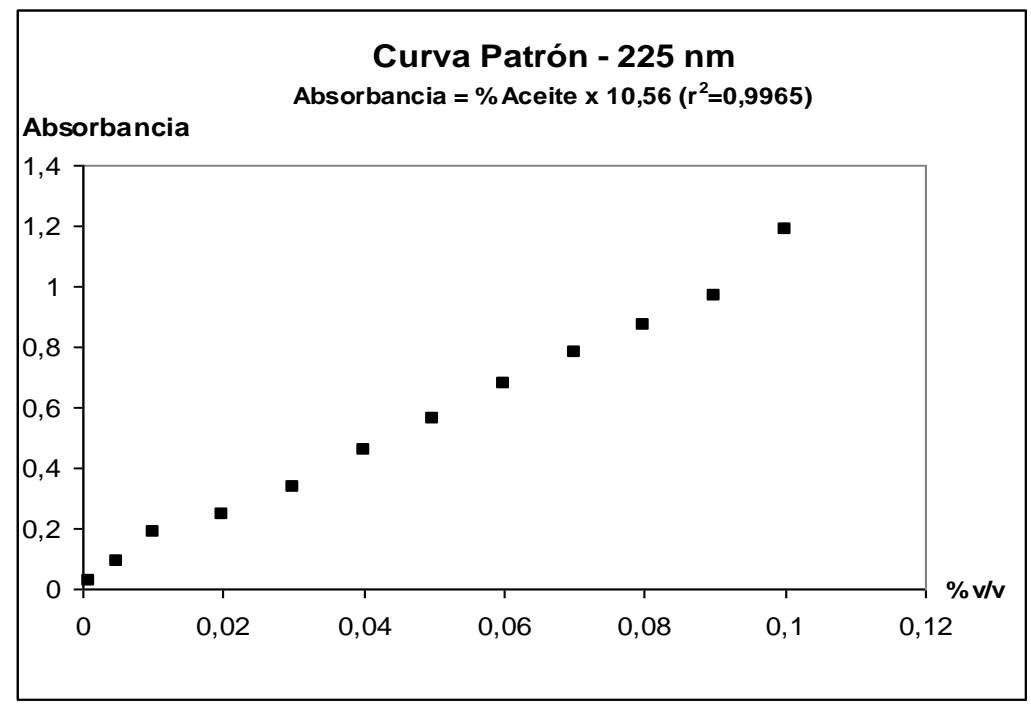

Figura 5.3: Curva patrón a $225 \mathrm{~nm}$ para aceite crudo obtenido a partir de laminado de soja.

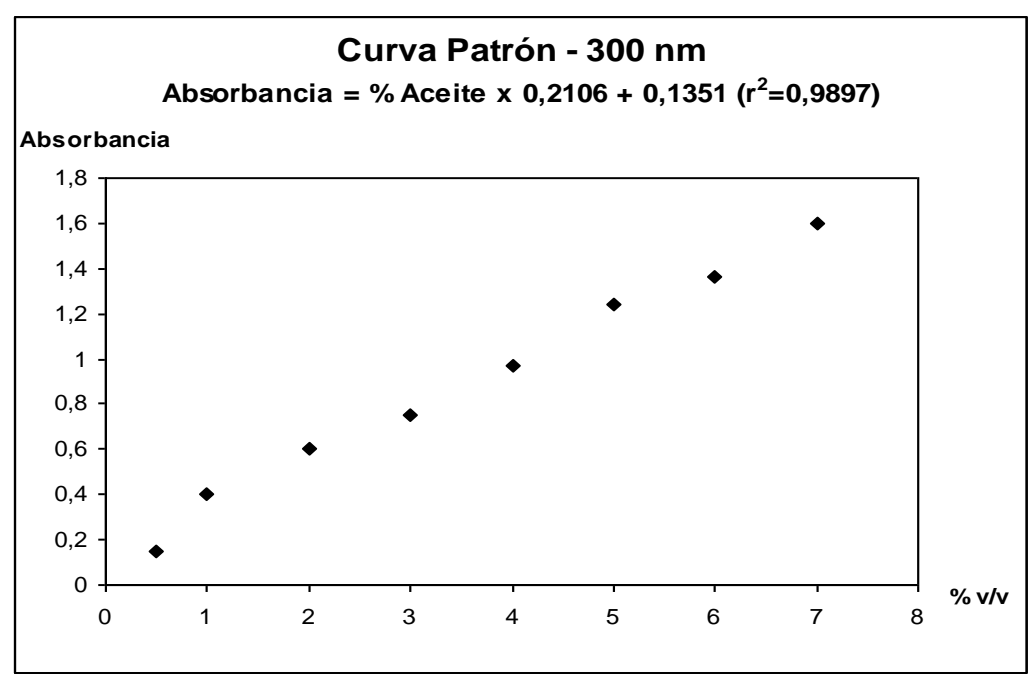

Figura 5.4: Curva patrón a $300 \mathrm{~nm}$ para aceite crudo obtenido a partir de laminado de soja

Para el caso de aceite obtenido a partir de expandido, sólo fue necesaria la curva patrón a 300 nm (ver Figura 5.5).

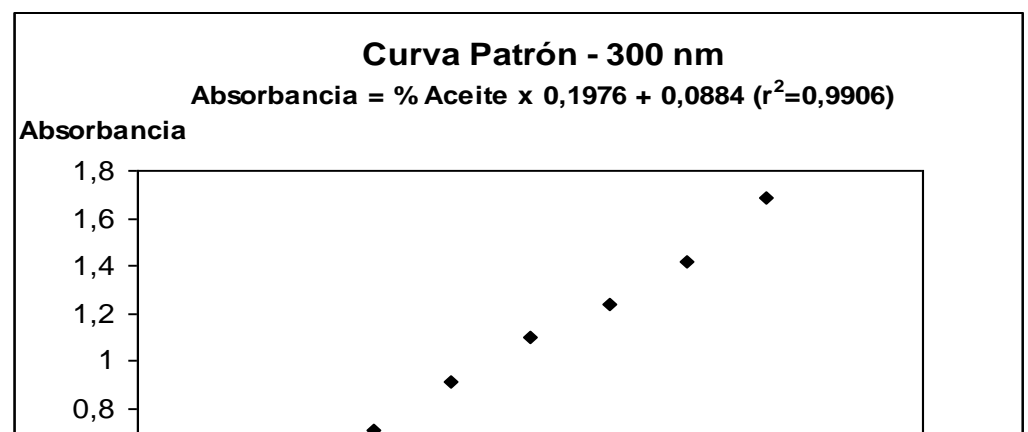


Figura 5.5: Curva patrón a $300 \mathrm{~nm}$ para aceite crudo obtenido a partir de expandido de soja.

\subsubsection{Determinación del equilibrio}

Las figuras 5.6 y 5.7 representan las concentraciones de aceite para la fase sólida en equilibrio con la fase líquida para los sólidos sin pretratamiento enzimático y las figuras 5.8 y 5.9 representan las correspondientes curvas para laminado y expandido hidrolizados enzimáticamente.

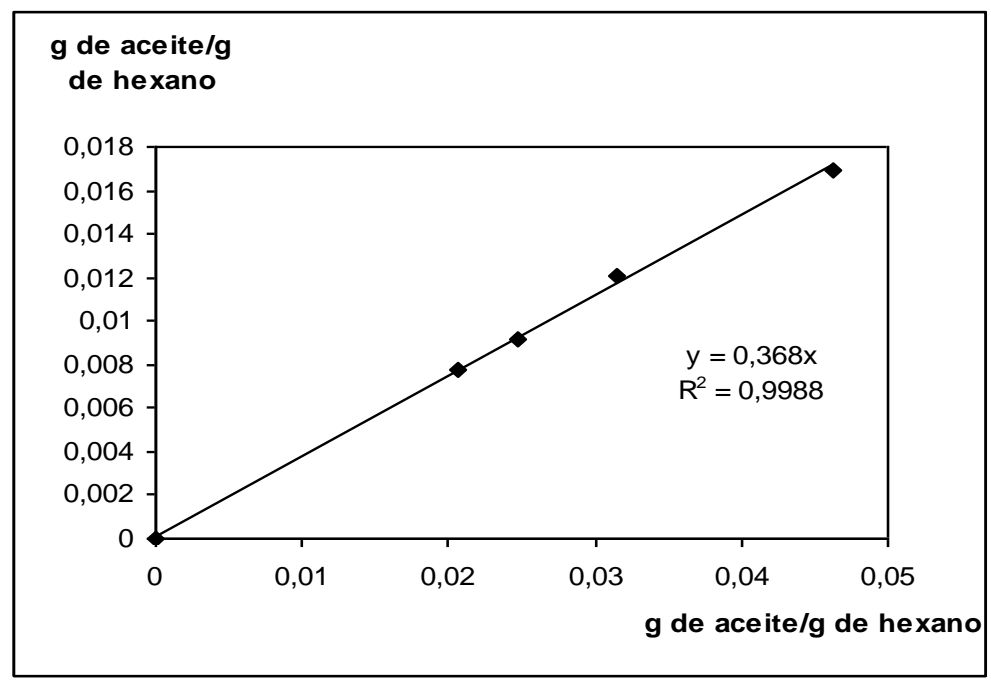

Figura 5.6: Concentración de aceite en laminado sin hidrolizar en equilibrio con solvente hexano.

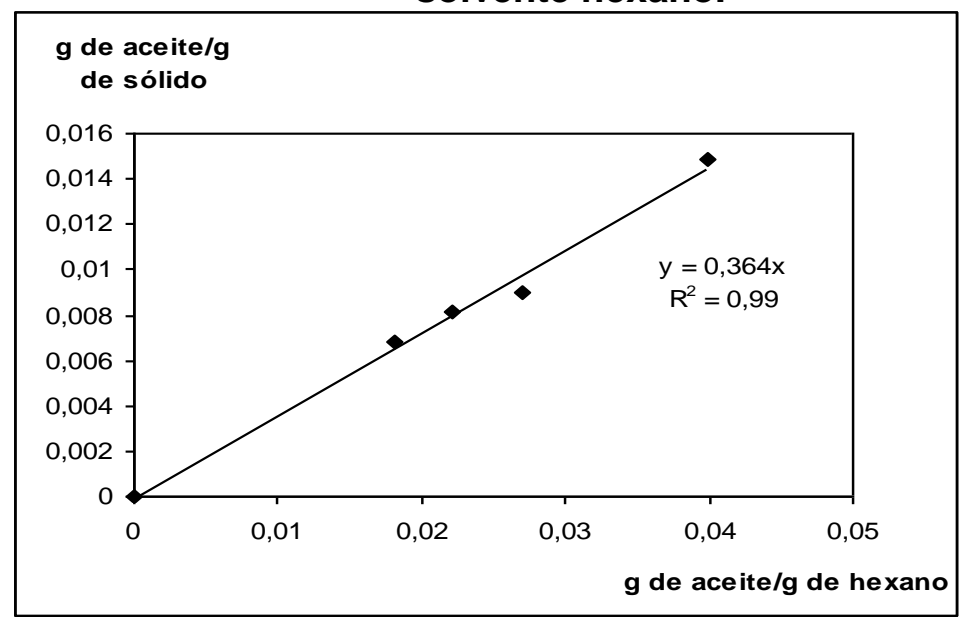


Figura 5.7: Concentración de aceite en expandido sin hidrolizar en equilibrio con solvente hexano.

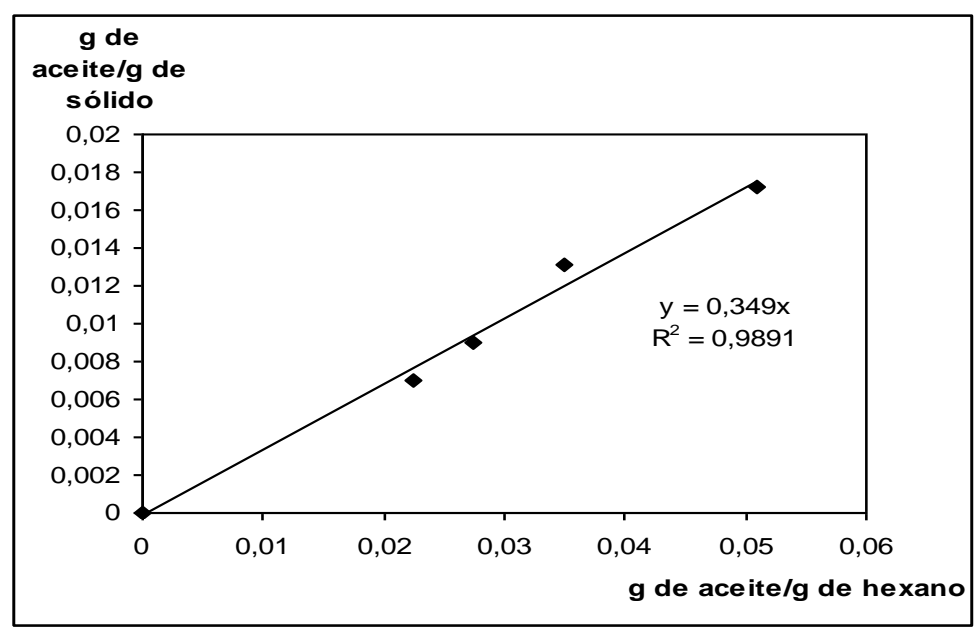

Figura 5.8: Concentración de aceite en laminado hidrolizado en equilibrio con solvente hexano.

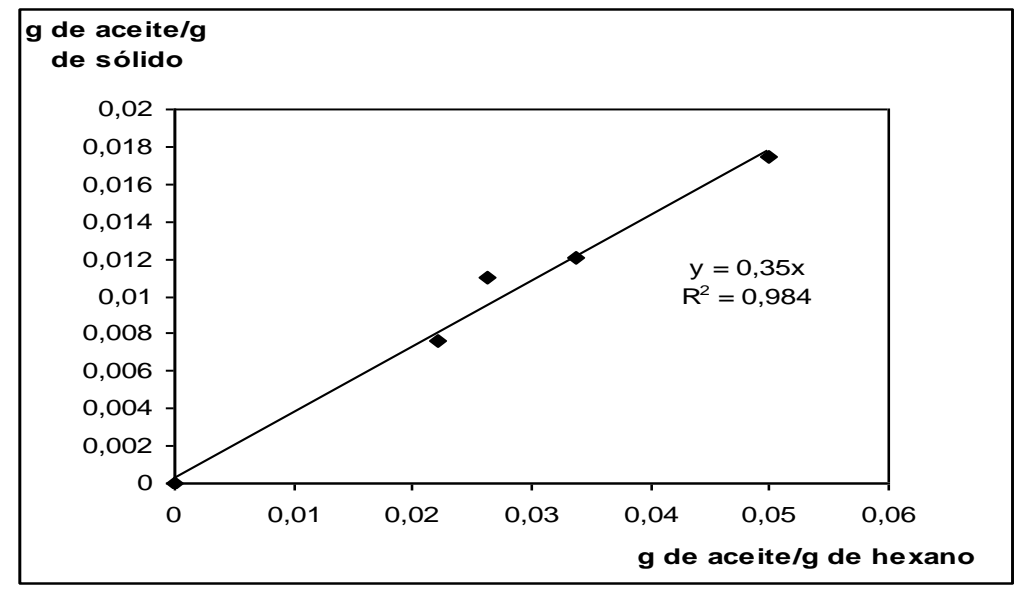

Figura 5.9: Concentración de aceite en expandido hidrolizado en equilibrio con solvente hexano.

A partir del ajuste lineal realizado, se determina para cada uno de los sólidos ensayados el valor de la constante de distribución, K. Así, en concentración de saturación de aceite en hexano se obtiene:

A) Para laminado sin hidrolizar: $c_{S}=0,368 . C_{L}$ 
B) Para expandido sin hidrolizar: $C_{s}=0,364 . C_{L}$

C) Para laminado hidrolizado: $\quad c_{s}=0,349 . c_{L}$

D) Para expandido hidrolizado: $c_{s}=0,35 . C_{L}$

\subsubsection{Determinación de parámetros asociados al modelo}

5.2.3.1 Difusividad efectiva en el sólido, $D_{\text {ef: }}$ Se estimaron coeficientes efectivos para cada tipo de sólido ensayado con y sin hidrólisis enzimática en el Capítulo 3.

5.2.3.2 Difusividad efectiva en el líquido, $D_{L}$ : Se empleó la correlación empírica descripta por la ecuación 5.8 utilizando los valores listados a continuación.

$\phi \quad$ 1, para solventes no asociados como el hexano (Treybal, 1980).

$\mathrm{M}_{\mathrm{L}} \quad 0,8610 \mathrm{kgmol}^{-1}$.

T $\quad 298 \mathrm{~K}\left(25^{\circ} \mathrm{C}\right)$.

$\mu_{\mathrm{L}} \quad 3,258.10^{-4} \mathrm{kgm}^{-1} \mathrm{~s}^{-1}$ a $25 \stackrel{\circ}{\circ} \mathrm{C}$ (Lange, 1961).

$V_{\mathrm{A}} \quad 1,258 \mathrm{~m}^{3} \mathrm{kmol}^{-1}$, calculado por el método de Le Bas, tomando como base los volúmenes atómicos (Reid y col., 1987).

5.2.3.3 Coeficiente de transferencia de masa en el líquido, $k_{L}$ : Se empleó la correlación empírica descripta en las ecuaciones 5.9 a 5.12. Las variables y los números adimensionales empleados se detallan a continuación.

$v \quad 1,656.10^{-4} \mathrm{~ms}^{-1}$, calculada como el flujo volumétrico por unidad de área transversal de la columna perpendicular al flujo de solvente.

$\rho \mathrm{L} \quad 659 \mathrm{kgm}^{-3}$ (Lange, 1961).

$\mu \mathrm{L} \quad 3,258.10^{-4} \mathrm{kgm}^{-1} \mathrm{~s}^{-1}$ a $25 \stackrel{\circ}{\circ}$ (Lange, 1961).

$d_{p} \quad 0,0075 \mathrm{~m}$ para expandido sin y con hidrólisis enzimática y para laminado hidrolizado, determinado experimentalmente. 
0,0042 m para laminado sin hidrólisis, calculado como diámetro equivalente para partículas no esféricas por la ecuación 5.13.

$R e=2,52$ para expandido sin y con hidrólisis enzimática, calculado a partir de la ecuación 5.11

= 2,82 para laminado sin hidrólisis enzimática, calculado a partir de la ecuación

\subsection{1}

Sc $=569,7$, calculado a partir de la ecuación 5.12

Sh $=27,28$ para todos los sólidos, calculado a partir de la ecuación 5.9.

Finalmente, a partir de la ecuación 5.10 y el número de Sherwood estimado, se determinó el coeficiente de transferencia de masa en el líquido.

5.2.3.4 Coeficiente de transferencia de masa en el sólido, $k_{s}$ : se estimó por aplicación de las relaciones entre el fenómeno microscópico de difusión dentro del sólido y el fenómeno macroscópico de transferencia de masa desde la fase sólida hacia la fase líquida según las expresiones 5.17 para lámina y 5.21 para esfera porosa empleando los valores de $D_{\text {ef }}$ estimados en el capítulo anterior.

En las tablas 5.5 a 5.8 se resumen los valores estimados para los parámetros descriptos para cada uno de los tipos de sólidos ensayados:

Tabla 5.5: Parámetros asociados al modelo de transferencia de masa para laminado sin hidrolizar.

\begin{tabular}{|l|c|l|}
\hline $\begin{array}{l}\text { Difusividad efectiva en el sólido, } \\
\mathrm{D}_{\mathrm{ef}}\end{array}$ & $0,88.10^{-11} \mathrm{~m}^{2} \mathrm{~s}^{-1}$ & Experimental \\
\hline $\begin{array}{l}\text { Difusividad molecular en el } \\
\text { solvente, } \mathrm{D}_{\mathrm{L}}\end{array}$ & $8,67.10^{-10} \mathrm{~m}^{2} \mathrm{~s}^{-1}$ & $\begin{array}{l}\text { Estimado por la correlación de } \\
\text { Wilke-Chang (ecuación 5.8) }\end{array}$ \\
\hline $\begin{array}{l}\text { Coeficiente de transferencia de } \\
\text { masa en el líquido, } \mathrm{k}_{\mathrm{L}}\end{array}$ & $3,15.10^{-6} \mathrm{~ms}^{-1}$ & $\begin{array}{l}\text { Estimado por la correlación de } \\
\text { Geankoplis (ecuación 5.10) }\end{array}$ \\
\hline $\begin{array}{l}\text { Coeficiente de transferencia de } \\
\text { masa en el sólido, } \mathrm{k}_{\mathrm{S}}\end{array}$ & $5,17.10^{-7} \mathrm{~ms}^{-1}$ & Estimado por la ecuación 5.17 \\
\hline
\end{tabular}

Tabla 5.6: Parámetros asociados al modelo de transferencia de masa para expandido sin hidrolizar.

\begin{tabular}{|l|l|l|}
\hline $\begin{array}{l}\text { Difusividad efectiva en el sólido, } \\
D_{\text {ef }}\end{array}$ & $1,67.10^{-10} \mathrm{~m}^{2} \mathrm{~s}^{-1}$ & Experimental \\
\hline $\begin{array}{l}\text { difusividad molecular en el } \\
\text { solvente, } \mathrm{D}_{\mathrm{L}}\end{array}$ & $8,67.10^{-10} \mathrm{~m}^{2} \mathrm{~s}^{-1}$ & $\begin{array}{l}\text { Estimado por la correlación de } \\
\text { Wilke-Chang (ecuación 5.8) }\end{array}$ \\
\hline
\end{tabular}




\begin{tabular}{|l|c|l|}
\hline $\begin{array}{l}\text { Coeficiente de transferencia de } \\
\text { masa en el líquido, } \mathrm{k}_{\mathrm{L}}\end{array}$ & $3,15.10^{-6} \mathrm{~ms}^{-1}$ & $\begin{array}{l}\text { Estimado por la correlación de } \\
\text { Geankoplis (ecuación 5.10) }\end{array}$ \\
\hline $\begin{array}{l}\text { Coeficiente de transferencia de } \\
\text { masa en el sólido, } \mathrm{k}_{\mathrm{S}}\end{array}$ & $2,3.10^{-7} \mathrm{~ms}^{-1}$ & Estimado por la ecuación 5.21 \\
\hline
\end{tabular}

Tabla 5.7: Parámetros asociados al modelo de transferencia de masa para laminado hidrolizado.

\begin{tabular}{|l|c|l|}
\hline $\begin{array}{l}\text { Difusividad efectiva en el sólido, } \\
D_{\text {ef }}\end{array}$ & $4,60.10^{-11} \mathrm{~m}^{2} \mathrm{~s}^{-1}$ & Experimental \\
\hline $\begin{array}{l}\text { Difusividad molecular en el } \\
\text { solvente, } \mathrm{D}_{\mathrm{L}}\end{array}$ & $8,67.10^{-10} \mathrm{~m}^{2} \mathrm{~s}^{-1}$ & $\begin{array}{l}\text { Estimado por la correlación de } \\
\text { Wilke-Chang (ecuación 5.8) }\end{array}$ \\
\hline $\begin{array}{l}\text { Coeficiente de transferencia de } \\
\text { masa en el líquido, } \mathrm{k}_{\mathrm{L}}\end{array}$ & $3,15 \cdot 10^{-6} \mathrm{~ms}^{-1}$ & $\begin{array}{l}\text { Estimado por la correlación de } \\
\text { Geankoplis (ecuación 5.10) }\end{array}$ \\
\hline $\begin{array}{l}\text { Coeficiente de transferencia de } \\
\text { masa en el sólido, } \mathrm{k}_{\mathrm{S}}\end{array}$ & $6,32.10^{-8} \mathrm{~ms}^{-1}$ & Estimado por la ecuación 5.21 \\
\hline
\end{tabular}

Tabla 5.8: Parámetros asociados al modelo de transferencia de masa para expandido hidrolizado.

\begin{tabular}{|l|c|l|}
\hline $\begin{array}{l}\text { Difusividad efectiva en el sólido, } \\
\mathrm{D}_{\text {ef }}\end{array}$ & $2,63.10^{-10} \mathrm{~m}^{2} \mathrm{~s}^{-1}$ & Experimental \\
\hline $\begin{array}{l}\text { Difusividad molecular en el } \\
\text { solvente, } \mathrm{D}_{\mathrm{L}}\end{array}$ & $8,67.10^{-10} \mathrm{~m}^{2} \mathrm{~s}^{-1}$ & $\begin{array}{l}\text { Estimado por la correlación de } \\
\text { Wilke-Chang (ecuación 5.8) }\end{array}$ \\
\hline $\begin{array}{l}\text { Coeficiente de transferencia de } \\
\text { masa en el líquido, } \mathrm{k}_{\mathrm{L}}\end{array}$ & $3,15.10^{-6} \mathrm{~ms}^{-1}$ & $\begin{array}{l}\text { Estimado por la correlación de } \\
\text { Geankoplis (ecuación 5.10) }\end{array}$ \\
\hline $\begin{array}{l}\text { Coeficiente de transferencia de } \\
\text { masa en el sólido, } \mathrm{k}_{\mathrm{S}}\end{array}$ & $1,35.10^{7} \mathrm{~ms}^{-1}$ & Estimado por la ecuación 5.21 \\
\hline
\end{tabular}

\subsubsection{Aplicación del modelo}

Para describir aproximadamente el fenómeno de extracción se empleó la simplificación del balance macroscópico descripto en la sección 5.1.2.2, utilizando los parámetros estimados en la sección anterior. Las expresiones propuestas de balance de materia que permitieron estimar la variación del contenido de aceite en la fase líquida y en la fase sólida con respecto al tiempo son:

a) en el sólido:

$$
-\frac{d \hat{c_{S}}}{d t}=\frac{k_{S} \cdot A}{V_{S}}\left(\hat{c_{S}}-K c_{L}\right)
$$


b) en el líquido:

$\frac{d c_{L}}{d t}=-\frac{Q_{L} \cdot c_{L}}{V_{L}}+\frac{k_{L} \cdot A}{V_{L}}\left(\frac{\hat{c_{S}}}{K}-c_{L}\right)$

ecuación 5.4

La solución de estas ecuaciones se obtuvo por el método de la fórmula de diferenciación numérica con la herramienta MatLab® 2008. A partir de estas soluciones, se estimó el perfil simulado de evolución del contenido de aceite en la miscela a la salida de la columna y el perfil simulado de evolución del contenido residual de aceite en el sólido (Mantell y col., 2002; Espinoza-Pérez y col, 2007; Pampraro, y col., 2002; Majumdar y col., 1995; Rivero Martinez, 2002).

En las figuras 5.10 y 5.11 se representó la concentración de aceite en la miscela a la salida de la columna de extracción en función del tiempo, para los sólidos laminado y expandido, respectivamente, sin pretratamiento enzimático. Cada figura muestra, tanto los valores obtenidos experimentalmente como los valores simulados predichos por el modelo. En las figuras 5.12 y 5.13 se grafican las evoluciones de la concentración experimental y calculada para los sólidos laminado y expandido con pretratamiento enzimático, respectivamente.

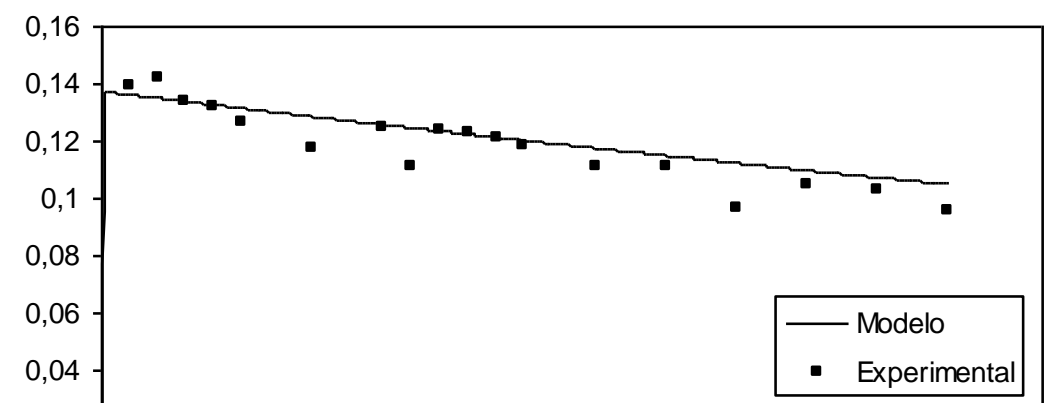


Figura 5.10: Evolución del contenido de aceite a la salida de la columna de extracción para laminado sin hidrolizar.

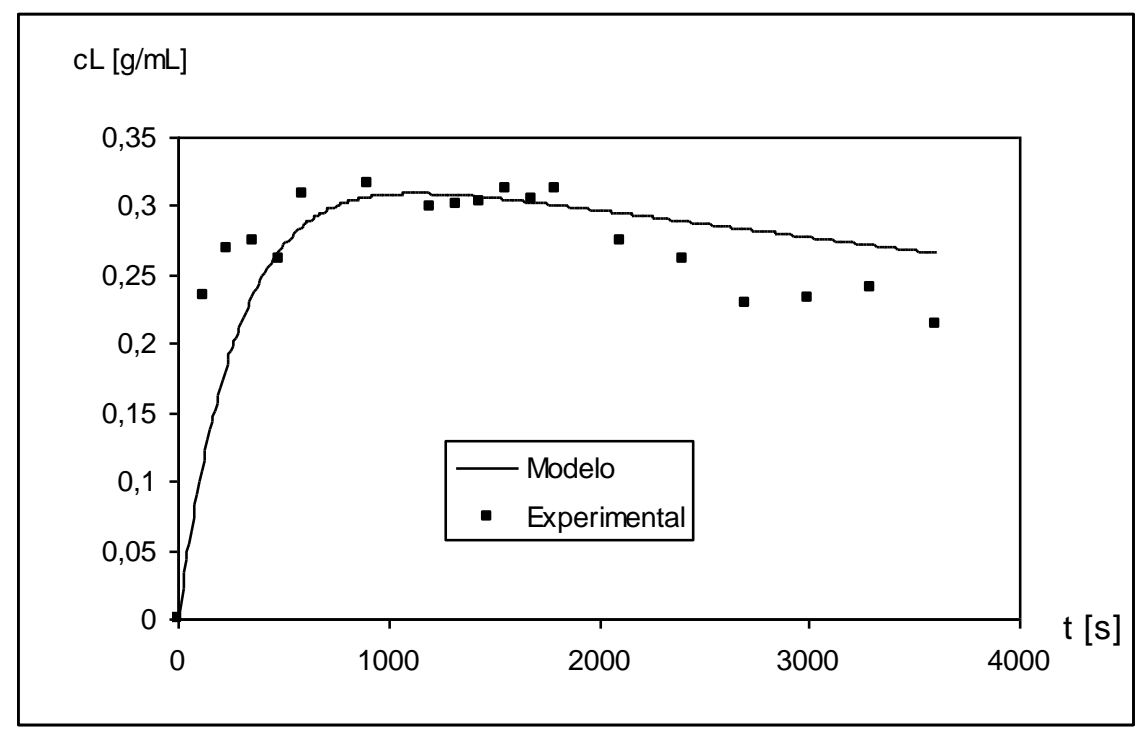

Figura 5.11: Evolución del contenido de aceite a la salida de la columna de extracción para expandido sin hidrolizar.

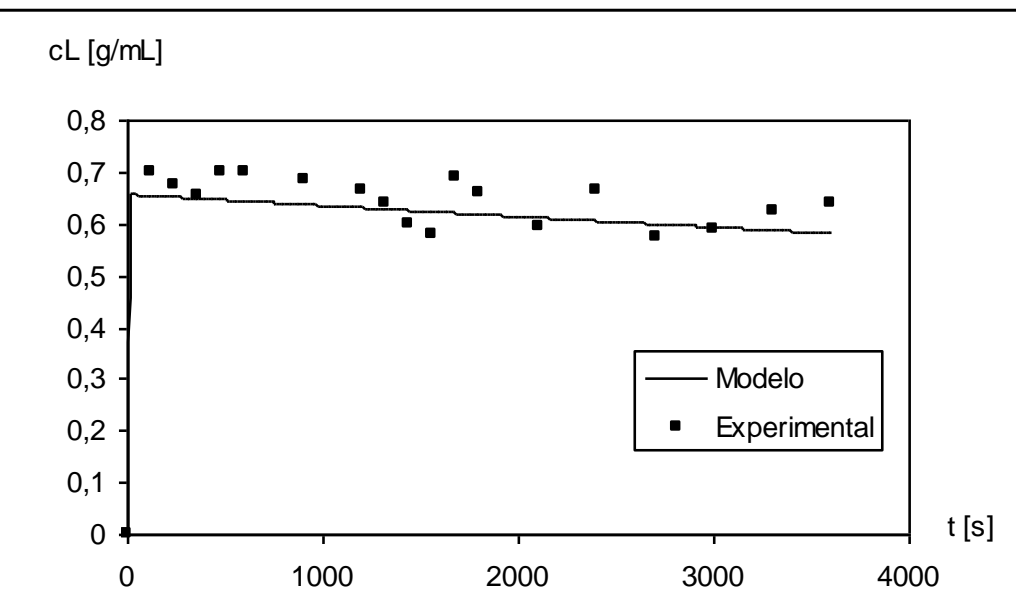


Figura 5.12: Evolución del contenido de aceite a la salida de la columna de extracción para laminado hidrolizado.

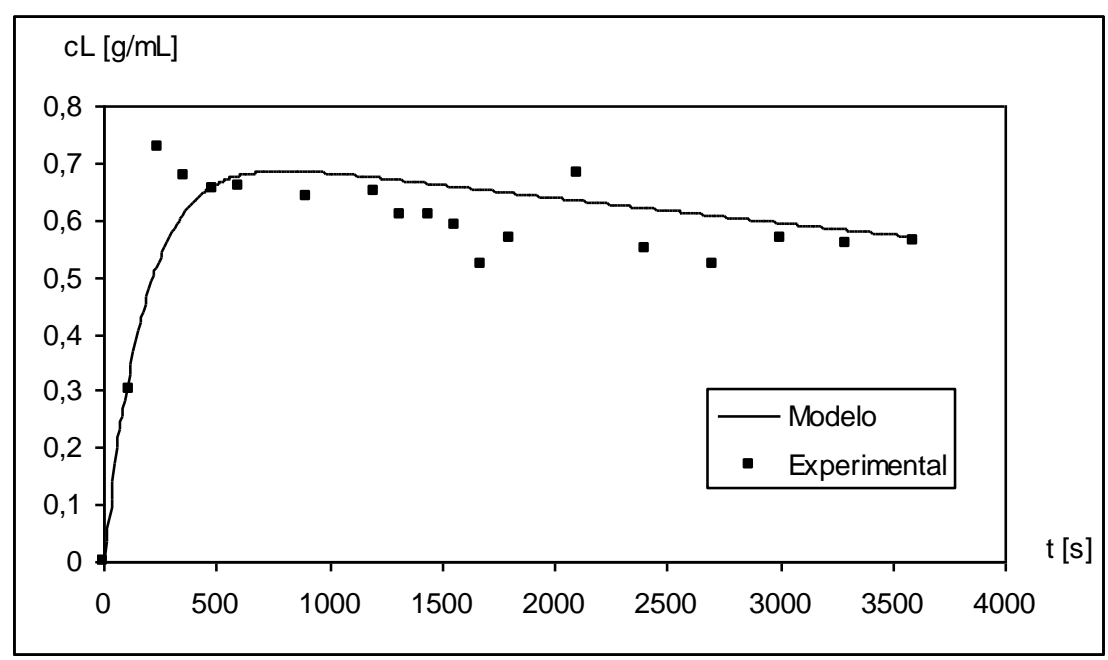

Figura 5.13: Evolución del contenido de aceite a la salida de la columna de extracción para expandido hidrolizado.

Las figuras muestran una buena correspondencia entre los datos experimentales y los valores calculados con el modelo empleado para el presente esquema experimental y el equipo de extracción utilizado. La suposición de concentración interfacial constante empleada en este modelo sólo es válida cuando el proceso global es controlado por la difusión (Espinoza-Pérez y col., 2007) como puede observarse comparando los órdenes de magnitud de los coeficientes de difusión y de transferencia de masa en el sólido y en el líquido (ver Tablas 5.5 a 5.8).

En la figura 5.14 se presentan la comparación los resultados experimentales y los calculados con el modelo para los todos los sólidos ensayados. 


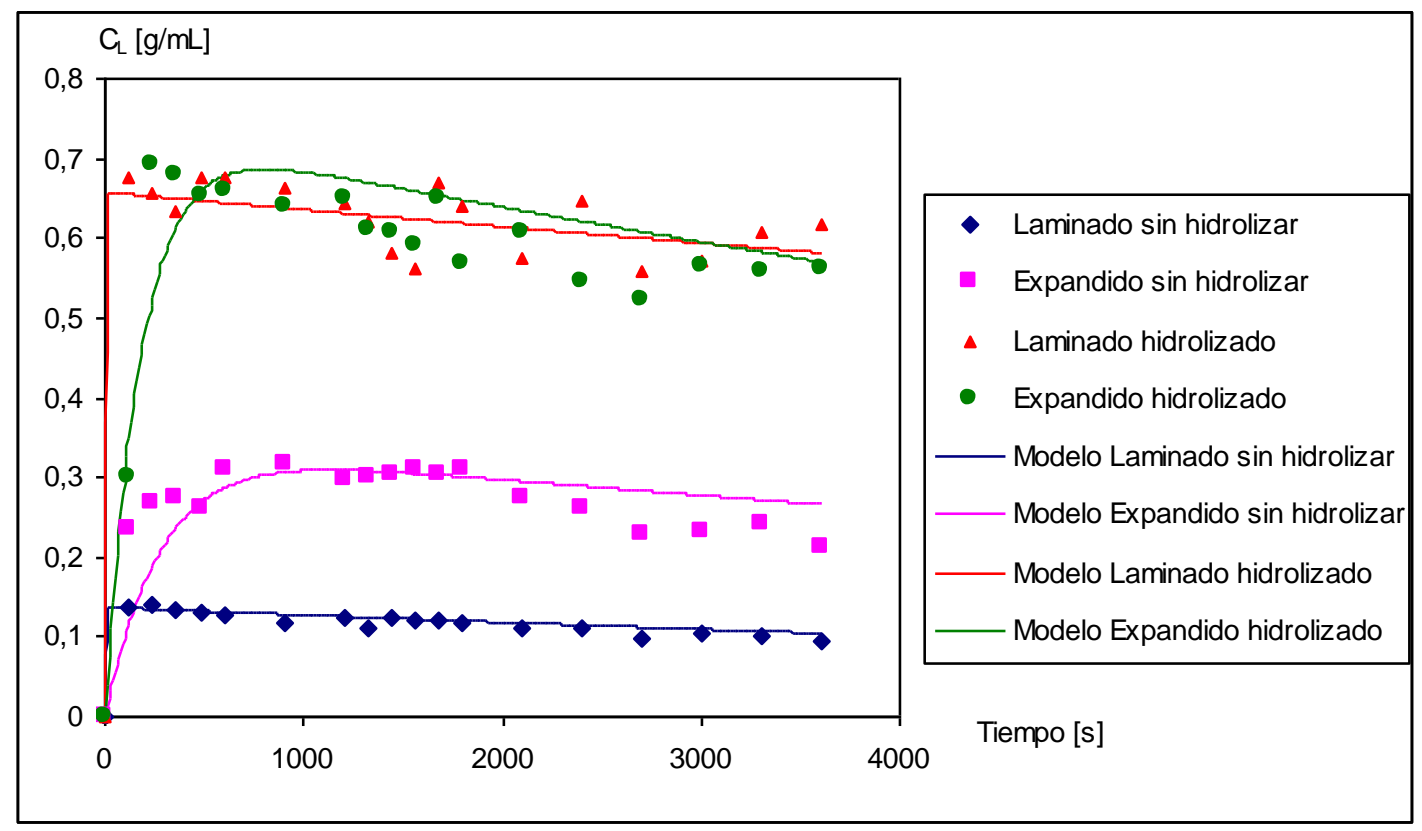

Figura 5.14: Evolución comparada del contenido de aceite en la miscela a la salida de la columna de extracción

Como puede observarse en la Fig. 5.14, la máxima cantidad de aceite se obtiene para el caso del lecho constituido por expandido de soja hidrolizado ya que transcurridos $240 \mathrm{~s}$ de contacto se obtiene $0,70 \mathrm{gmL}^{-1}$ de aceite en comparación con $0,65 \mathrm{gmL}^{-1}$ que se obtienen para el caso de laminado hidrolizado. Por otro lado, los gráficos muestran que valores menores se obtienen para el lecho constituido por laminado de soja sin hidrolizar; al cabo de aproximadamente 2 minutos de extracción se obtienen aproximadamente $0,14 \mathrm{gmL}^{-1}$ de aceite. Se observa que la máxima cantidad de aceite obtenida para expandido sin hidrolizar $\left(0,31 \mathrm{gmL}^{-1}\right)$ es más del doble en comparación con el máximo alcanzado para laminado sin hidrolizar $(0,14$ $\left.\mathrm{gmL}^{-1}\right)$. La diferencia podría deberse a la influencia que ejerce el grado de destrucción de las estructuras celulares sobre la difusión del aceite en el sólido y es significativa teniendo en cuenta la elevada solubilidad del aceite en el solvente hexano. A tiempos cortos de extracción se observan mayores contenidos de aceite en la miscela a la salida de la columna si se emplean láminas hidrolizadas en lugar de expandido hidrolizado. Estos resultados son consistentes con los rendimientos máximos obtenidos en el Capítulo 3. 
5.2.4.1 Efecto del caudal de alimentación, $Q$. En la Figura 5.15 se representan las simulaciones del contenido de aceite para diferentes caudales de alimentación del hexano al extractor. En la Fig. 5.15a) se muestra la evolución del aceite residual en el sólido y en 5.15b) la fracción en masa de aceite extraído a la salida del extractor, calculados ambos valores en función de la masa total inicial de sólido empleada para expandido hidrolizado.
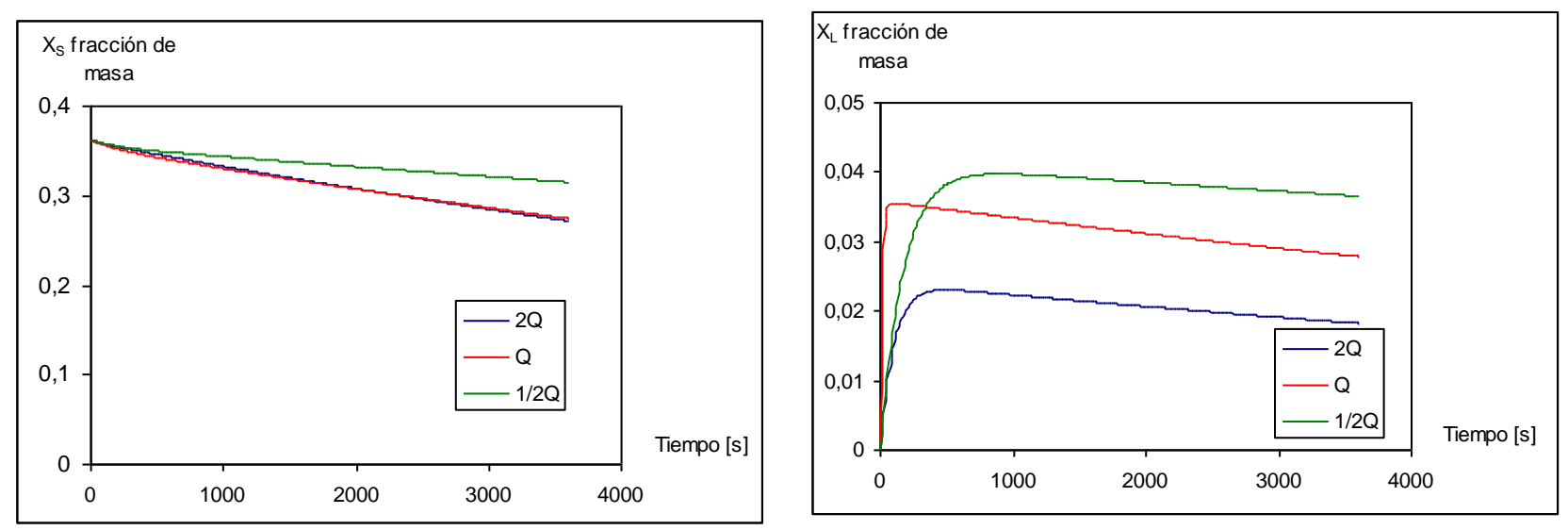

Figura 5.15: Efecto del caudal de alimentación de hexano, $\mathbf{Q}$.

a) Evolución en fracción de masa en el sólido.

b) Evolución en fracción de masa en el líquido.

Como puede observarse, si el caudal $Q$ de alimentación de hexano al extractor aumenta ocurre una disminución de la fracción de masa obtenida en la corriente de salida por efecto de una circulación más rápida del hexano dentro del extractor. Analizando las evoluciones de la fracción de masa de aceite residual en el sólido se observa que a mayores caudales se produce una disminución más pronunciada de la cantidad de aceite residual debido a que la relación sólido-líquido aumenta y por ello más aceite es transferido desde la fase sólida hacia la fase líquida.

5.2.4.2 Efecto de la relación área/volumen en el sólido, $A / V_{s}$. En la Figura 5.16 se representan las curvas simuladas del contenido de aceite para diferentes relaciones área/volumen en el sólido a extraer: en a) se muestra la evolución del aceite residual en el sólido y en b) la fracción en masa de aceite extraído a la salida del extractor, calculados ambos valores en función de la masa total inicial de sólido empleada para expandido hidrolizado. 

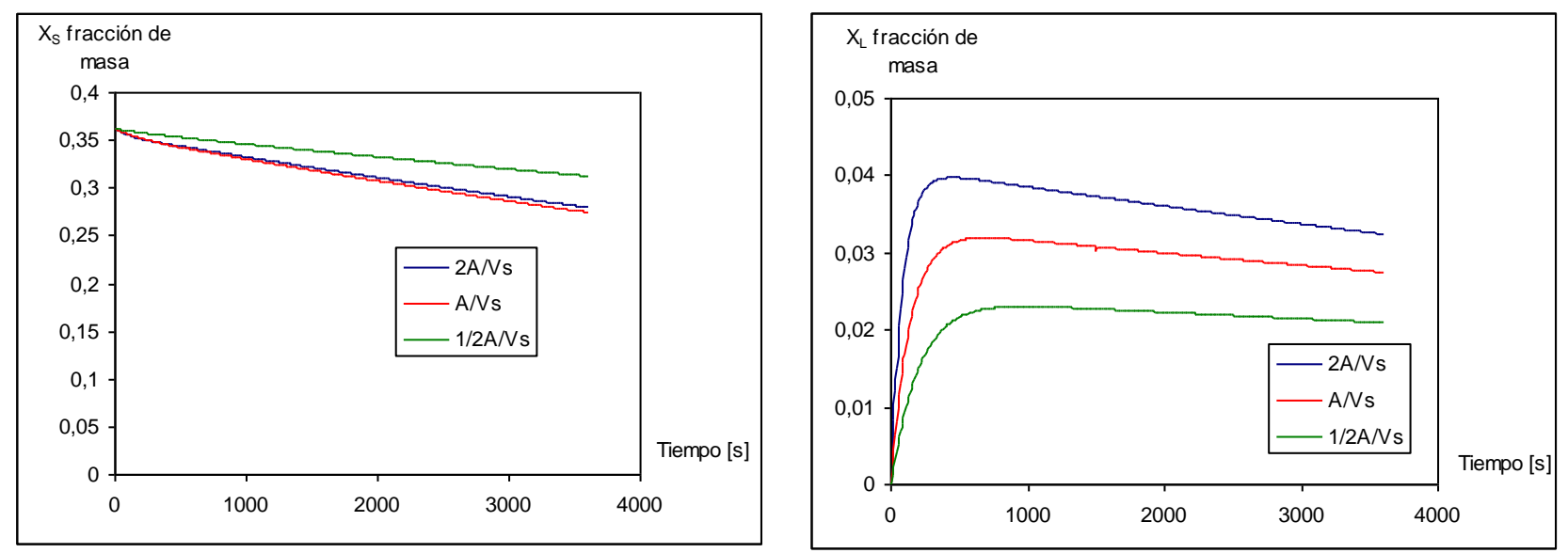

Figura 5.16: Efecto de la relación área/volumen, $A V_{S}$.

a) Evolución en fracción de masa en el sólido.

b) Evolución en fracción de masa en el líquido.

Cuando se emplean relaciones $A / V_{S}$ mayores se obtienen mayores cantidades de aceite en la miscela de salida debido a que aumenta el área disponible para la transferencia de masa desde la fase sólida hacia la fase líquida. Del mismo modo, se producen mayores decaimientos en la cantidad de aceite residual en el sólido debido a que más aceite es transferido al solvente a través de una interfase mayor. Este fenómeno se puede correlacionar con las mayores transferencias obtenidas para sólidos hidrolizados, los cuales presentaron mayores áreas específicas (ver Tabla 5.4).

5.2.4.3 Efecto del coeficiente de transferencia de masa en el líquido, $k_{L}$. En la Figura 5.17 se representan las curvas simuladas del contenido de aceite para distintos valores del coeficiente de transferencia de masa en el líquido: en a) se muestra la evolución del aceite residual en el sólido y en b) la fracción en masa de aceite extraído a la salida del extractor, calculados ambos valores en función de la masa total inicial de sólido empleada para expandido hidrolizado.
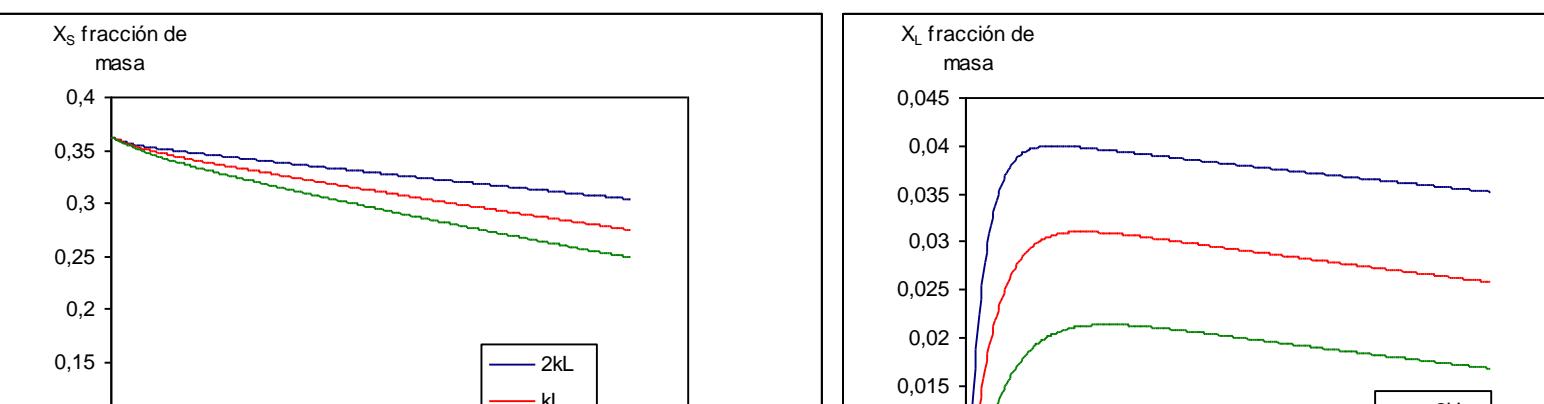
Figura 5.17: Efecto del coeficiente de transferencia de masa en el líquido, $\mathbf{k}_{\mathbf{L}}$.

a) Evolución en fracción de masa en el sólido.

b) Evolución en fracción de masa en el líquido.

Las variaciones del coeficiente de transferencia de masa en el líquido, $\mathrm{k}_{\mathrm{L}}$, si los demás parámetros son mantenidos constantes, pueden asimilarse a una modificación del solvente empleado o de la temperatura empleada en la extracción (ver ecuaciones 5.5 a 5.8). En la miscela a la salida del extractor se obtienen mayores cantidades de aceite para mayores $\mathrm{k}_{\mathrm{L}}$ debido a la transferencia rápida del soluto en la fase líquida, mientras que en la fase sólida se observa un efecto contrario debido a que la diferencia de concentraciones entre el sólido, la interfase y el líquido es menor, por la rápida transferencia que ocurre en la fase líquida.

5.2.4.4 Efecto del coeficiente de transferencia de masa en el sólido, $k_{s}$. En la Figura 5.18 se representan las curvas simuladas del contenido de aceite para distintos valores del coeficiente de transferencia de masa en el sólido: en a) se muestra la evolución del aceite residual en el sólido y en b) la fracción en masa de aceite extraído a la salida del extractor, calculados ambos valores en función de la masa total inicial de sólido empleada para expandido hidrolizado.
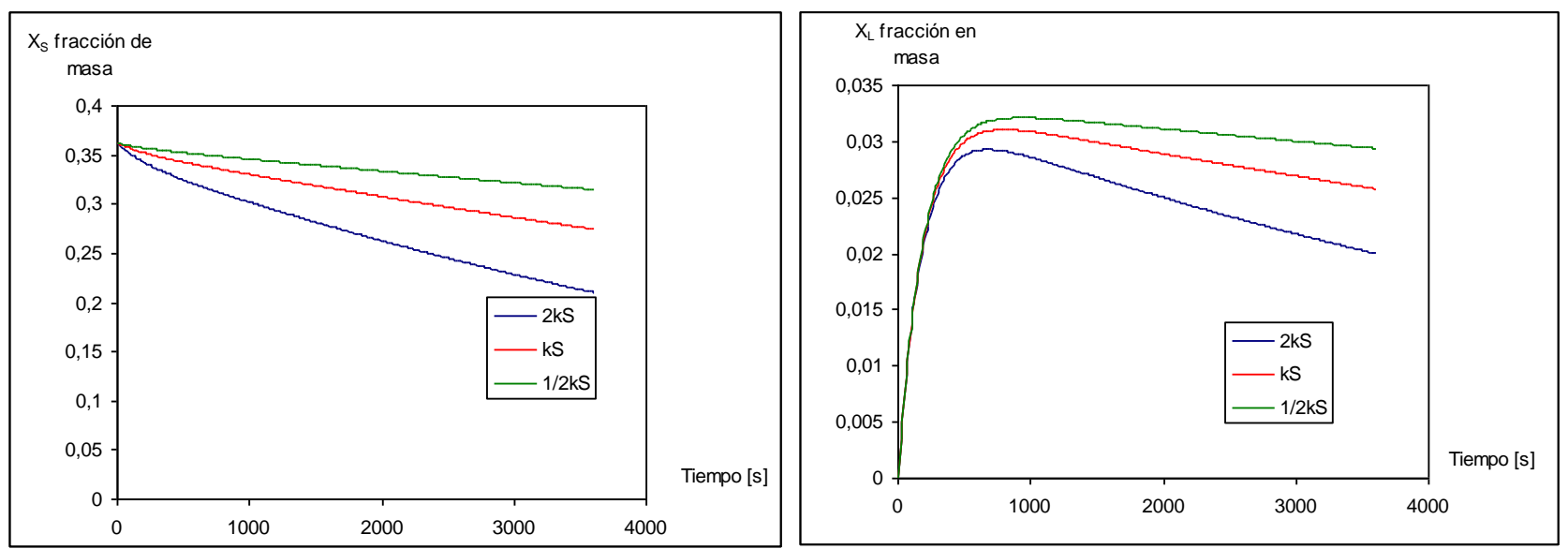
Figura 5.18: Efecto del coeficiente de transferencia de masa en el sólido, $\mathbf{k}_{\mathrm{s}}$.

a) Evolución en fracción de masa en el sólido.

b) Evolución en fracción de masa en el líquido.

Las variaciones del coeficiente de transferencia de masa en el sólido, $\mathrm{k}_{\mathrm{S}}$, si los demás parámetros son mantenidos constantes, pueden asimilarse a una modificación de las características del sólido, específicamente del coeficiente de difusión efectivo, $\mathrm{D}_{\mathrm{ef}}$ (ver ecuación 5.17). Como puede observarse, para mayores coeficientes de transferencia de masa en el sólido se produce una disminución más drástica del aceite residual contenido en el sólido debido a que el transporte difusivo en el mismo es más rápido. Ese fenómeno no se traduce en mayores contenidos de aceite en la miscela de salida porque la fase más cercana a las partículas sólidas no es fácilmente circulada a la miscela de salida. Finalmente, es evidente que el coeficiente de transferencia de masa en el sólido es el parámetro que mayor influencia ejerce sobre el contenido de aceite, tanto en la fase líquida como en la fase sólida. Este fenómeno corrobora la suposición de que la difusión es determinante de la velocidad global de extracción.

\subsection{CONCLUSIONES PARCIALES}

- El modelo matemático propuesto de balance macroscópico resultó apropiado para describir el sistema de extracción en columna de lecho fijo 
como puede observarse por comparación entre los datos experimentales y las soluciones numéricas obtenidas.

- El fenómeno de transferencia de masa que determina la velocidad de extracción fue la difusión de aceite que tiene lugar dentro del sólido, lo que puede deducirse por comparación de los coeficientes de transferencia de masa en el líquido y en cada uno de los sólidos ensayados.

- La máxima velocidad de extracción de aceite con hexano en columna de lecho fijo se obtuvo cuando el lecho estaba constituído por expandido pretratado enzimáticamente.

- El modelo propuesto predice que para obtener bajos contenidos residuales de aceite en el material de partida deben emplearse sólidos con coeficientes de difusión elevados, caudales de alimentación de solvente bajos, altas áreas específicas y solventes de extracción con altos coeficientes de transferencia de masa en el líquido.

En base a los resultados obtenidos, la mejor adaptación del pretratamiento enzimático al proceso actual de extracción industrial sería la realización de la incubación enzimática sobre expandido de soja. 
Capítulo 6

Conclusiones

\section{CONCLUSIONES}


Los resultados obtenidos en este estudio permiten corroborar totalmente la hipótesis general planteada al comienzo del trabajo. En su desarrollo se analizó la factibilidad técnica de emplear la hidrólisis enzimática como pretratamiento en la extracción con solvente de aceite de soja a fin de mejorar la eficiencia del proceso. Se emplearon como material de partida laminado y expandido de soja. Sobre estos sólidos se llevó a cabo una incubación enzimática con $\alpha$-amilasa, glucoamilasa, pectinasa, celulasa, hemicelulasa y proteasa. Se seleccionaron las condiciones óptimas de $\mathrm{pH}$, tiempo y temperatura de la incubación y la combinación de actividades enzimáticas, para maximizar el rendimiento de la extracción en términos de cantidad de aceite. Se evaluó la influencia del tratamiento enzimático sobre el transporte difusivo que ocurre durante la extracción del aceite determinando experimentalmente coeficientes de difusión para cada sólido. Por último, se caracterizó la extracción en una sección de lecho fijo constituido por las semillas tratadas y se estableció un modelo matemático para describir el comportamiento de la cinética de esta extracción.

Los resultados del capitulo 3 muestran un incremento general del aceite extraíble empleando incubación enzimática como pretratamiento. El incremento mayor se alcanzó cuando se emplearon todas las enzimas ensayadas, $\alpha$-amilasa, glucoamilasa, pectinasa, celulasa, hemicelulasa y proteasa, debido a que estas actividades hidrolasas catalizan la ruptura de enlaces presentes en macromoléculas que componen las estructuras celulares de materiales vegetales. Para todas las corridas experimentales se obtuvieron incrementos en el rendimiento debido a esta acción degradativa y en menor medida, a la liberación de aceite que se encuentra enlazado formando parte de moléculas más complejas. Por otro lado, la calidad final del aceite extraído con ayuda enzimática no es afectada significativamente por el pretratamiento. La acidez resultó más alta que lo esperado para un aceite crudo sin refinar, probablemente debido a una deficiente inactivación de las lipasas nativas o a un cierto grado de hidrólisis debido a la temperatura de incubación y al medio acuoso necesario para llevar a cabo el tratamiento enzimático.

Estos hechos indican, que sería posible, desde un primer análisis teórico, utilizar la hidrólisis enzimática como pretratamiento viable en los procesos convencionales de extracción de aceite por solvente. El empleo de este pretratamiento podría traducirse en reducción de tiempos y/o cantidad de solvente empleado en estos procesos. 
Se obtuvieron las expresiones matemáticas que permiten definir la dependencia del rendimiento de extracción respecto de las variables ensayadas $\mathrm{pH}$, temperatura y tiempo del proceso enzimático. Estas expresiones permiten, además, predecir la combinación óptima de dichas variables necesaria para obtener los rendimientos máximos de aceite para cada tipo de sólido ensayado. Para laminado de soja se obtuvieron los rendimientos de aceite más altos, en comparación con los obtenidos para expandido, identificándose menores grados de hidrólisis sobre sustratos desnaturalizados por calor, como el expandido, que en los materiales no tratados térmicamente, como el laminado.

El conocimiento de las variables que influencian la eficacia del proceso medida en términos de rendimiento en aceite y las condiciones óptimas para maximizarlo proporcionan la base teórica necesaria para el desarrollo de una metodología de tratamiento enzimático que sea adaptable a las líneas de procesado convencionales.

Los ensayos de extracción con solvente del Capítulo 4 que se realizaron sobre los sólidos pretratados enzimáticamente permitieron describir el fenómeno de difusión en estado no estacionario por aplicación de la segunda ley de Fick. A partir del ajuste al modelo difusional en una dirección, se estimaron los coeficientes de difusión en el sólido. Se ha observado que el coeficiente de difusión efectiva es mayor para los sólidos que han sufrido más número de pretratamientos, lo cual es consistente con el grado de degradación de las estructuras celulares.

También se determinó la influencia de la temperatura sobre la difusión del aceite desde los sólidos hacia el solvente hexano. El comportamiento del sistema con la temperatura se describió mediante el modelo de Arrhenius. El ajuste se puede emplear para definir la temperatura de extracción más conveniente desde el punto de vista difusional y operacional.

La estimación de los coeficientes de difusión en el sólido permitió estimar las velocidades de extracción de aceite por el solvente y determinar en forma precisa la influencia de la difusión sobre el proceso global de extracción. Esta información puede emplearse para evaluar la reducción en los tiempos de extracción o la optimización de los volúmenes de solvente empleado.

Por último, en el Capítulo, 5 partiendo de balances macroscópicos en estado no estacionario para las fases sólida y líquida de una columna de extracción, se modeló el comportamiento de la extracción sobre los sólidos hidrolizados considerando a la columna como una sección del lecho fijo de un extractor industrial. Se estimaron 
coeficientes de transferencia de masa en el solvente a partir de correlaciones empíricas y coeficientes de transferencia de masa en el sólido a partir de los balances propuestos.

La aplicación del modelo simplificado permitió encontrar una expresión matemática para describir la variación del contenido de aceite, tanto en la fase del solvente, como en la fase sólida constituida por el material de partida. Esta descripción del sistema y del fenómeno de extracción constituye la base necesaria para la evaluación del pretratamiento enzimático acoplado a la extracción industrial de aceite de soja por solvente.

Si bien la velocidad mayor de extracción se obtuvo para lechos fijos de expandido de soja hidrolizado, la diferencia entre esta velocidad y la obtenida para laminado no fue significativa. Los coeficientes de transferencia de masa en el sólido resultaron mayores en el caso de expandido debido a la estructura más porosa y más abierta de la matriz sólida por efectos del tratamiento hidrotérmico, sin embargo menos aceite es liberado por la acción específica de las enzimas, como se deduce de los rendimientos máximos del capítulo 3 , obteniéndose resultados globales de velocidad de extracción similares.

El modelo propuesto predijo que para obtener bajos contenidos residuales de aceite en el material de partida deben emplearse sólidos con coeficientes de difusión elevados, caudales de alimentación de solvente bajos, altas áreas específicas y solventes de extracción con altos coeficientes de transferencia de masa en el líquido. Los sólidos con coeficientes de difusión más altos y mayores áreas específicas para la transferencia de masa fueron los obtenidos por aplicación de mayor número de pretratamientos. El empleo de laminado hidrolizado o de expandido hidrolizado para alimentar los extractores industriales será entonces una solución de compromiso entre lograr mayor difusión o mayor ataque enzimático. Finalmente, a partir de estos datos es posible ajustar, de ser necesario, el diseño de los extractores para lixiviar estos materiales hidrolizados.

Desde un punto de vista global del proceso industrial de extracción y en función de estas conclusiones, se podría implementar este pretratamiento enzimático a continuación de la operación de laminado. Una opción posible podría ser la realización del tratamiento enzimático dentro del extrusor donde se lleva a cabo la operación de expandido. La incorporación de agua durante la incubación enzimática plantea una dificultad técnica, ya que durante la extracción con solvente el sólido 
debe presentar valores de humedad reducidos, no mayores al $10 \%$. Por ello, una perspectiva de investigación y desarrollo debería enfocarse, por un lado, a la solución de este problema, y por el otro, al diseño de un reactor adecuado para la incubación enzimática a escala industrial. 


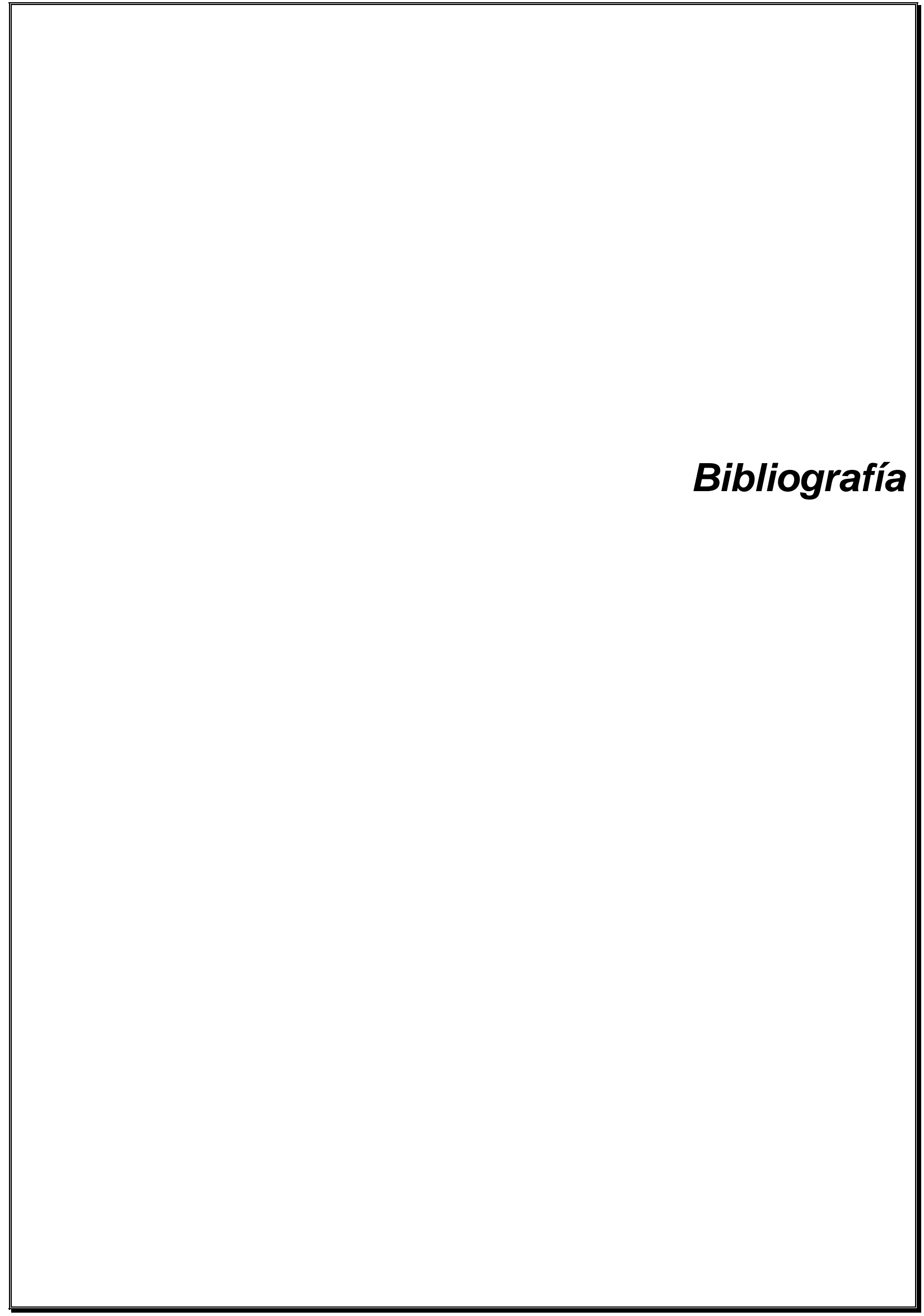




\section{BIBLIOGRAFÍA}

Abraham, G; R.J. Hron Sr. y s.P. Koltun (1988) - Modelling the solvent extraction of oilseeds. JAOCS, 65, 129.

Aceites y Grasas (2009) - China y Argentina: El crushing de soja. Las cifras de la soja: Las divisas que genera el compljo de soja argentino. Marzo de 2009.

Adler-Nissen, J.A. (1986) - A review of food protein hydrolysis-especific areas. In: Enzymatic Hydrolysis of Food Proteins (Adler-Nissen, J. Eds). Elsevier Applied Publishers, London and New York, 78.

Asociación Americana de Soja (ASA) y Universidad de Texas, Centro de Desarrollo e Investigación de Proteínas Alimentarias (1995) - Expanders: Historial - Usos y ventajas. Aceites y Grasas, 18, 34.

Baehr, H.D. y K. Stephan (2006) - Heat and Mass Transfer. $2^{\text {nd }}$ Edition. Berlin, Germany: Springer-Verlag.

Bair, C.W. y H.E. Snyder (1980) - Electron microscopy of a soybean lipid bodies. JAOCS, V, 279.

Barrios, V.A.; D.A. Olmos, R.A. Noyola y C.A. Lopez-Munguia (1990) - "Optimization of an enzymatic process for coconut oil extraction". Oleagineaux, 45, 35.

Bhatnagar, S. y B.N. Johari (1987) - Microbial enzymes in the processing of oil seds. Current Science, 56, 775.

Binkley, C.R. y R.C. Wiley (1981) - Chemical and physical treatment effects on solidliquid extraction of apple tissue. J. Food Sci., 46, 729.

Bocevska, M; D. Karlovic, J. Turkulov and D. Pericin (1993) - Quality of corn germ oil obteined by aqueous extraction. JAOCS, 70, 1273. 
Bouvier, F. y B. Entressangles (1992) - Utilization of cellulases and pectinases in the extraction of palm oil. Revue Francaise des Corps Gras, 39, 245.

Buenrostro, M. and C.A. Lopez-Munguia (1986) - Enzymatic extraction of avocado oil. Biotechnol. Lett., 8, 505.

Cacace, J.E. y G. Mazza (2003) - Mass transfer during extraction of phenolic compounds from milled berries. J. Food Eng. 59, 379.

Carrín, M.E. y G.H. Capriste (2008) - Mathematical modeling of vegetable oil-solvent extraction in a multistage horizontal extractor. Journal of Food Engineering, 85, 418.

Carslaw, H.S. y J.C. Jaeger (1959) - Conduction of heat in solids. Oxford, UK: Clarendon Press.

Cater, C.M.; K.C. Rhee; R.D. Hagenmaier and K.F. Mattil (1974) - Aqueous extraction an alternative oilseed milling. JAOCS, 51, 137.

Chalermchat, Y.; M. Fincan y P. Dejmek (2004) - Pulsed electric treatment for solidliquid extraction of red beetroot pigment: mathematical modeling of mass transfer. Journal Food Eng., 64, 229.

Chang, R. (1986) - Fisicoquímica con aplicaciones a sistemas biológicos. México: Compañía Editorial Continental S.A.

Cheah, S.C.; M.A. Augustin y L.C.L. Ooi (1990) - "Enzymatic extraction of palm oil". Palm Oil Res. Bull. Malaysia, 20, 30.

Christensen, F.M. (1989) - Enzyme technology versus engineering technology in the food industry. Biotechnol. Appl. Biochem., 11, 249.

Christensen, F.M. (1991) - Extraction by aqueous enzymatic process. INFORM, 2 , 984. 
Crank, J. (1959) - The mathematics of diffusion -. Oxford, UK: Clarendon Press.

Cussler, E.L. (1984) - Diffusion: mass transfer in fluid systems. Cambridge, UK: Cambridge University Press.

Dominguez, H; M.J. Núñez y J.M. Lema (1995a) - Procesado acuoso de soja con tecnología enzimática: extracción de aceite y producción de aislados" - Grasas y Aceites, 46, 11.

Dominguez, H.; M.J. Nuñez and J.M. Lema (1995b) - Enzyme-assisted hexane extraction of soja bean oil. Food Chem., 54, 223.

Doulia, D.; K. Tzia y V. Gemas (2000) - A knowledge base for the apparent mass difusión coefficient (Deff) of foods. International J. of Food Properties, 3, 1.

Düsterhöft, E.M.; A.W. Bonte; J.C. Venekamp y A.G.J. Voragen (1993) - The role of fungal polysaccharidases in the hydrolysis of cell wall materials from sunflower and palm-kernel meals" - World J. Microbiol. Biotechnol., 9, 544.

Espinoza-Pérez, J.D.; A. Vargas, V.J. Robles-Olvera, G.C.Rodríguez-Jimenes y M.A. García-Alvarado (2007) - Mathematical modeling of caffeine kinetic during solidliquid extraction of coffe beans. J. of Food Eng. 81, 72.

Fan, H.P., J.C. Morris y H. Wakenham (1948) - "Diffusion Phenomena in solvent extraction of peanut oil”. Industrial and Engineering Chemistry, 40, pp195-199.

Fetzer, W. (1998) - Planta de preparación de semillas combinadas. Aceites y Grasas, 32, 436.

Finlayson-Pitts, B.J. y J.N. Jr Pitts (1993) - "Volatile organic compounds: Ozone formation, alternative fuels and toxics". Chem. Ind., 20, 796. 
Fullbrook, P.D. (1983) - The use of enzymes in the processing of oilseeds. JAOCS, 60,476 .

García-Serrato, A. (1981) - Extraction of oil from soybeans. JAOCS, 58, 157.

Geankoplis, C.J. (1998) - Procesos de transporte y operaciones unitarias. 3ra Edición. México: CECSA.

Hagenmaier, R.; C.M. Cater and K.F. Mattil (1972) - Critical unit operations of the aqueous processing of fresh coconuts. JAOCS, 49, 178.

Hinnes, A.L. y R.N. Maddox (1984) - Transferencia de masa. Aplicaciones y Fundamentos. México, México DF: Editorial Prentice-Hall Hispanoamericana S.A.

Hoja Técnica Multifect GC, Genencor International, Inc. (2001).

Hoja Técnica Optidex L-400, Genencor International, Inc. (2001).

Hoja Técnica Spezyme Fred Genencor International, Inc. (2001).

Hoja Técnica Multiefect Neutral, Genenor International, Inc. (2004).

Hoja Técnica Pektozyme UltraC, Genenor International, Inc. (2004).

Hoja Técnica GC440, Genencor International, Inc. (2004).

Horwitz, W (1998) - Methods of Analysis of the Association of Official Analytical Chemist's. $16^{\text {th }}$ Edition, Wisconsin, USA.

Infobae.com (2009) - Cuantiosas pérdidas del agro en la campaña 2009. Julio de 2009.

Johnson, L.A. and E.W. Lusas (1983) - Comparision of alternative solvents for oils extraction. JAOCS, 60, 229. 
Karnofsky, R. (1987) - Design of oilseed extractors I. Oil extraction (supplement). JAOCS, 64, 1533.

Karnofsky, R. (1986) - Design of oilseed extractors. JAOCS, 63, 1011.

Karnofsky, R. (2001) - Diseño de extractores para semillas oleaginosas. Aceites y Grasas, 42, 109.

Kincal, N.S. y F. Kaymak (1990) - "Simultaneous diffusion and degradation of ascorbic acid in potato blanching", In: Spiers, W.; H.Schubert, editors. Engineering and Food, vol.l: Physical properties and process control. London: Elsevier Applied Science, pp512.

Kulkarni, B.S.; A. D'Anquin y V. Graci (1955) - Measurement of extractability of raw and cooked cottonseed flakes. JAOCS, 23, 178.

Lange, N.A. (1961) - Handbook of Chemistry. New York, USA: McGraw-Hill Inc.

Lanzani, A.; M.C. Petrini, O. Cozzoli, P.Gallavresi, C. Carola G. Jacini (1975) - "On the use of enzymes for vegetable-oil extraction. A preliminary report". Riv. Ital. Sostanze Grasse, L11, 226.

Lawhon, J.T.; L.J. Manak; K.C. Rhee and E.W.Lusas (1981a) - Production of oil and protein food products from raw peanuts by aqueous extraction and ultrafiltration. J. Food Sci., 46, 391.

Lawhon, J.T.; L.J. Manak; K.C. Rhee; K.S. Rhee and E.W.Lusas (1981b) Combining aqueous extraction and membrane isolation techniques to recovery protein and oil from soybeans. J. Food Sci., 46, 912.

Lusas, E.W. and G.M. Jividen (1987) - Glandless cottonseed: A review of the first 25 years of processing and utilization research. JAOCS, 64, 839. 
Majumdar, G.C.; A.N. Samanta and S.P. Sengupta (1995) - "Modeling solvent extraction of vegetable oil in a packed bed". JAOCS, 72, 971.

Mantell, C.; Rodriguez, M. y E. Martinez de la Ossa (2002) - Semi-batch extraction of anthocyanins from red grape pomace in packed beds: experimental results and process modelling. Chemical Engineering Science 57, 3831.

MatLab (2008). The language of technical computing. The MathWorks, Inc.

McGlone, O.C.; C.A. Lopez-Munguia and J.V. Cater (1986) - Coconut oil extraction by a new enzymatic process. J.Food Sci., 51, 695-697.

Métodos Analíticos en Alimentaria, Aceites y Grasas. Determinación del grado de acidez, pp14. Editado por Panreac Química S.A. Sevilla, 1999.

Métodos Analíticos en Alimentaria, Aceites y Grasas. Determinación del índice de peróxidos, pp15. Editado por Panreac Química S.A. Sevilla, 1999.

Métodos Analíticos en Alimentaria, Aceites y Grasas. Determinación del índice de iodo, pp54. Editado por Panreac Química S.A. Sevilla, 1999.

Milligan, E.D. (1976) - Survey of solvent extraction equipment. JAOCS, 53, 234.

Montgomery, D.C (1991) - Design and analysis of experiment. New York, USA: Wiley Inc.

Mustakas, G.C. (1980) - Recovery of oil from soybeans. In: Handbook of Soy Oil Processing and Utilization (Erikson, D.R. Ed.) St. Louis, USA: American Soybean Association and American Oil Chemist's Society.

Olsen, H.S. (1988) - "Aqueous enzymatic extraction of oil from seeds" In: Asian Food Confrence Proceedings-Bankgok, Thailand Reprinted by Novo Industry A/S, ppA06041a. 
Ong, J.T.L. (2002) - El impacto de las condiciones de preparación de las semillas de soja sobre la calidad y el rendimiento del aceite. Aceites y Grasas, 47, 237.

Pajonk, A.S.; R. Saurel y J. Andrieu (2003) - Experimental study and modelling of effective sodium chloride diffusion coefficients values during Emmental cheese brining. J. Food Eng. 36, 307.

Pramparo, M; S. Gregory and M. Mattea (2002) - Immersion vs. Percolation in the extraction of oil from oleaginous seeds". J.A.O.C.S. 79, 955.

Pearson, D. (1981) - Técnicas de Laboratorio para el Análisis de Alimentos. 2da Edición, Zaragoza, España.

Pedrotti, S. y F. Boling (1999) - Uso de los expanders en la preparación moderna de soja. Aceites y Grasas 35, 300.

Pérez-Galindo, J.A.; J.López-Miranda y I.R. Martín-Dominguez (2000) - "Geometric and Reynolds Lumber effects on oregano (Lippia Berlaudieri Schaver) essencial oil extraction" J. Food Eng. 44, 127.

Reid, R.C.; J.M. Prausnitz y T.K. Sherwood (1987) - The Properties of Gases and Liquids. $4^{\text {th }}$ Edition, New York, USA: McGraw-Hill.

Rivero Martinez, M.J. (2002) - Tesis: "Diseño del proceso de purificación de estireno mediante adsorción en alúmina" - TDR-121505-172016, ISBN: SA.132-2005/858102-408-2. Universidad de Cantabria.

Rosenthal, A.; D.L.Pyle and K. Niranjan (1996) - Aqueous and Enzymatic Extraction of Editable Oils from Oilseeds. Enzymes and Microbiol. Tech., 19, 401.

Rosenthal, A; D.L. Pyle; K. Nirvanjan; S. Gilmour y L. Trinca (2001) - "Combined effect of operational variables and enzyme activity on aqueous enzymatic extraction of oil and protein from soybean" - Enzyme and Microbial Technology, 28, 499. 
Şaşmaz, D.A. (1996) - "Evaluation of the diffusion coefficient of rapeseed oil during solvent extraction with hexane" - JAOCS, 73, 669.

Schwartzberg, H.G. y R.Y. Chao (1982) - "Solute diffusivities in leaching processes". Food Technol., 36, 73.

SAGYP, Secretaría de Agricultura, Ganadería, Pesca y Alimentación (2009) Análisis de la cadena de aceite de soya. www.alimentosargentinos.gov.ar/03/olea/a soja/aceite soja.httm, Ing. Walter F. García.

Seikova, I; E.Simenov y E. Ivanova (2004) - "Protein leaching from tomato seed experimental kinetics and prediction of effective diffusivity". J.Food Eng., 61, 165.

Shankar, D; Y.C. Agrawal, B.C. Sarkar y B.N. Singh (1997) - Enzymatic hydrolysis in conjunction with conventional pretreatment to soybean for enhaced oil availability and recovery" - JAOCS, 74, 1543.

Sherba, S.E.; R.B. Steigerwalt; W.T: Faith and C.V. Smythe Jr. (1972) - Soybean fractionation employing a protease. U.S. patent 3.640.725.

Sherwood, T.K.; R.L.Pigford y C.R. Wilke (1979) - Transferencia de masa. Buenos Aires, Argentina: Editorial Géminis.

Simeonov, E.; I. Tsibranska y A. Minchev (1999) - "Solid-liquid extraction from plants-experimental kinetics and modeling. Chemical Engineering Journal, 73, 255.

Sineiro, J. H. Dominguez, M.J. Núñez y J.M. Lema (1996) - "Ethanol extraction of polyphenols in an inmersión extractor. Effect of pulsing flow" - JAOCS, 73, 1121.

Sineiro, J.; H. Dominguez y M.J. Núñez (1998) - Influencia del tratamiento enzimático en la calidad de aceites vegetales" - Grasas y Aceites, 49, 191.

Singh, P.P.; D.E. Maier; M.R. Okos; E: Cattanach y K.P. Trumble (1999) - Effects of physical properties and operating parameters an soybean flaking. JAOCS, 76, 981. 
Smith, A.S. (1952) - Evaluation of extraction rate measurements. JAOCS, 421.

Smith, D.C.; Y.C. Agrawal, B.C. Sarkar y B.N. Singh (1993) - Enzymatic hydrolysis pretreatment for mechanical expelling of soybeans" - JAOCS 70, 885.

Sosulski, K.; F.W. Sosulski and E.Coxworth (1988) - Carbohydratase hydrolysis of canola to enhance oil extraction with hexane. JAOCS, 65, 357.

Sosulski, K. y F.W.Sosulski (1993) - Enzyme-Aided vs Two-Stage Processing of Canola: Technology Product Quality and Cost Evaluation. JAOCS, 70, 825.

Spiro, M. y R.M. Selwood (1984) - "The kinetic and mechanism of caffeine infusion from coffe: the effect of particle size". J.Food Sci.Agric., 35, 915.

Steel, R.G.D. y J.H. Torrie (1997) - Bioestadística: Principios y Procedimientos. 2da edición, México D.F: McGraw Hill S.A.

Tano-Debrah, K. and Y. Ohta (1994) - Enzyme-assited aqueous extraction of fat from kernels of shea tree Butyrospernum parkii. JAOCS, 71, 979.

Tano-Debrah, K. and Y. Ohta (1995a) - Enzyme-assisted aqueous extraction of shea fat: a rural approach. JAOCS, 72, 251.

Tano-Debrah, K y Y. Ohta (1995b) - Application of Enzyme-Assisted Aqueous Fat Extraction to Cocoa Fat. JAOCS, 72, 1409.

Thomas, G.C.; V.G. Krioukov y H.A. Vielmo (2005) - Simulation of vegetable oil extraction in counter-current crossed flows using the artificial neural network. Chem. Eng. Processing, 44, 581.

Treybal, R.E. (1980) - Operaciones de Transferencia de Masa. 2da Edición. México D.F.: McGraw Hill S.A. 
Tzen, J.T.C. y A.H.C. Huang (1992) - Surface structure and properties of plant seed oil bodies. J. Biol. Chem., 117, 327.

Varzakas, T.H.; G.C. Leach; C.J. Israilides y D. Arapaglou (2005) - Theoretical and experimental approaches towards the determination of solute effective diffusivities in foods. Enzyme and Microbiol. Technol., 37, 29.

Veloso, G.O.; V.G. Krioukov y H.A. Vielmo (2005) - Mathematical modeling of vegetable oil extraction in a counter-current crossed flow horizontal extractor. J. Food Eng., 66, 477.

Welti-Chanes, J.; F. Vergara-Balderas y D. Bernúdez-Aguirre (2005) - "Transport phenomena in food engineering basic concepts and advances". J. Food Eng., 67, 113.

Wiese, K.L. y H.E. Snyder (1987) - Analysis of the oil extraction process in soybeans: A new continuous procedure. JAOCS, 64, 402.

Yoon, S.H.; I.H. Kim; S.H. Kim and T.W. Kwon (1991) - Effects of enzyme treatments and ultrasonification on extraction yield of lipids of protein from soybean by aqueous process. Korean J. Food Sci. Technol., 23, 673.

Zweytick, D.; K. Athensteadt y G. Daum (2000) - Intracellular lipid particles of euraryotic cells. Bioquimica et Biophysica Acta, 1469, 101. 


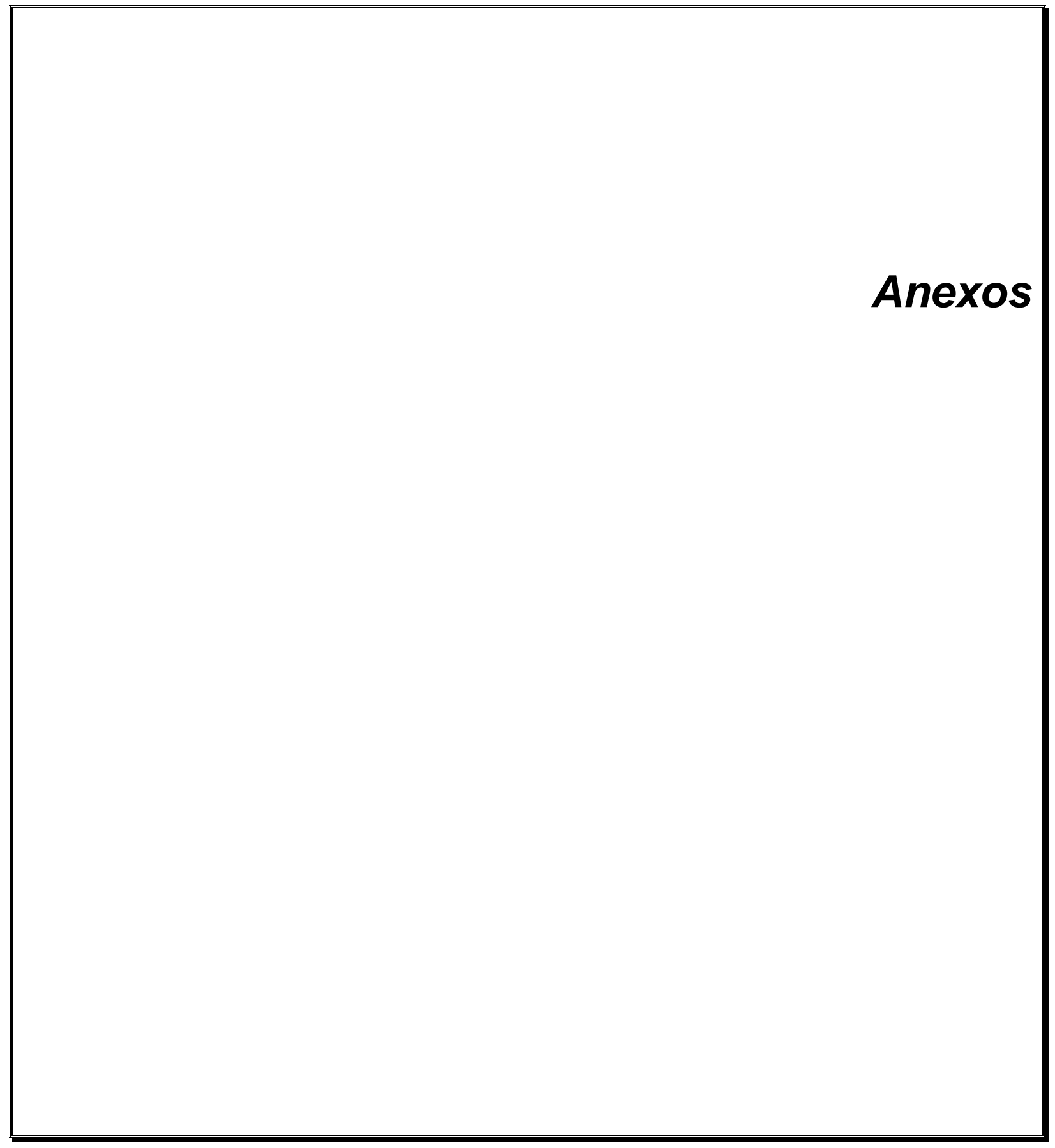




\section{PRODUCT DESCRIPTION - PD 214613-3.0EN}

\section{PEKTOZYMETM Ultra C}

Fruit Juice Enzyme

\section{Description}

PEKTOZYMETM Ultra $C$ is a pectolytic enzyme complex.

PEKTOZYMETM Ultra $C$ is produced by fermentation with a selected strain of fungus.

\section{Application areas}

All applications in citrus fruit processing where the goal is a fast viscosity reduction without negative influence on cloud stability, such as Pulp Wash, Core Wash, Viscosity Reduction in orange juice and production of a cloudifier from citrus fruit peel.

\section{Potential benefits}

- Fast reduction of viscosity

- High yield of juice and solids

- High stability of the cloud

\section{Usage levels}

Depending on the application

Temperature

Reaction time

(depending on the application)

However, as temperature and time affect the treatment, tests should be carried out to find the optimum dosage.

\section{Directions for use}

PEKTOZYMETM Ultra $C$ is added to the extraction process for pulp and core wash or directly into the juice for viscosity reduction. The Technical Memorandum on applications in citrus fruit processing gives detailed information. The enzyme is diluted with water or juice (1:10) prior to the addition.

\section{Composition}

PEKTOZYMETM Ultra $\mathrm{C}$ is composed of:

- Protein (enzymes)

- Water (enzyme carrier)

- Potassium chloride (stabilizer)

\section{Physical/chemical specifications}

Physical form

Colour*

Pectolytic activity

liquid

${ }^{*}$ Colour may vary from batch to batch.

dark brown 135 units/g

\section{Microbiological specifications}

Total viable count

Coliforms

E. coli

Salmonella species

Mycotoxins*

Antibiotic activity

* Aflatoxin B1, ochratoxin A, sterigmatocystin, T-2 toxin,

zearalenone

\section{Heavy metal specifications}

Arsenic

Lead

Heavy metals (as $\mathrm{Pb})$

less than $3 \mathrm{mg} / \mathrm{kg}$ less than $5 \mathrm{mg} / \mathrm{kg}$ less than $30 \mathrm{mg} / \mathrm{kg}$

\section{Nutritional data}

Calculated values per $100 \mathrm{~g}$
Energy

Protein

Fat

Carbohydrates

Potassium chloride

Water

Ash less than 50000 /gram less than $30 /$ gram absent in 25 grams absent in 25 grams negative by test negative by test
$40 / 168 \mathrm{Kcal} / \mathrm{kJ}$ less than 2-10 g less than $1 \mathrm{~g}$ $1-10 \mathrm{~g}$ $15-19 \mathrm{~g}$ $85-95 \mathrm{~g}$ 


\section{PRODUCT DESCRIPTION - PD 214613-3.0EN}

\section{PEKTOZYMETM Ultra C}

Fruit Juice Enzyme

\section{Storage}

PEKTOZYME ${ }^{\text {TM }}$ Ultra C should be stored dry and cool (max. $\left.10^{\circ} \mathrm{C} / 50^{\circ} \mathrm{F}\right)$.

After this period, the activity loss is $2-3 \%$ per month. The shelf life of PEKTOZYME TM Ultra C is 12 months when stored as recommended in unbroken packaging.

\section{Packaging}

Transparent containers $\mathrm{w} /$ steel pallet of $1,000 \mathrm{~kg}$ net (2,200 lbs net).

\section{Purity and legal status}

PEKTOZYMETM Ultra C meets the specifications laid down by the Joint FAO/WHO Expert Committee on Food Additives and the Food Chemicals Codex.

PEKTOZYMETM Ultra $C$ is approved by most countries for use in food. However, as legislation regarding its use in food may vary from country to country, local food regulations should always be consulted concerning the status of this product. Advice regarding the legal status of this product may be obtained on request.

\section{Safety and handling}

Avoid unnecessary contact with enzyme preparations during handling. In case of spillage, rinse with water. Additional information can be found in the Material Safety Data Sheet.

\section{GMO status}

The microorganisms used for production of PEKTOZYMETM Ultra $\mathrm{C}$ are developed by traditional non-GMM technique.

\section{Allergens}

The table below indicates the presence (as added component) of the following allergens and products thereof (according to US Food Allergen and Consumer Proctection act (FALCPA), 2004 and Directive 2000/13/EU as amended).

\begin{tabular}{|c|c|l|l|}
\hline Yes & No & Allergens & Description of components \\
\hline & $\mathbf{X}$ & $\begin{array}{l}\text { Cereals containing } \\
\text { gluten }\end{array}$ & \\
\hline & $\mathbf{X}$ & Crustaceans & \\
\hline & $\mathbf{X}$ & Eggs & \\
\hline & $\mathbf{X}$ & Fish & \\
\hline & $\mathbf{X}$ & Peanuts & \\
\hline & $\mathbf{X}$ & Soybeans & \\
\hline & $\mathbf{X}$ & Milk (incl. lactose) & \\
\hline & $\mathbf{X}$ & Nuts & \\
\hline & $\mathbf{X}$ & Celery & \\
\hline & $\mathbf{X}$ & Mustard & \\
\hline & $\mathbf{X}$ & Sesame seeds & \\
\hline $\mathbf{X}$ & & $\begin{array}{l}\text { Sulphur dioxide and } \\
\text { sulphites }(>10 \mathrm{mg} / \mathrm{kg})\end{array}$ & $\begin{array}{l}\text { Sodium metabisulphite } \\
\text { (approx. 20 ppm) }\end{array}$ \\
\hline & $\mathbf{X}$ & Lupin & \\
\hline & $\mathbf{X}$ & Molluscs & \\
\hline
\end{tabular}




\section{Multifect ${ }^{\circledR}$ XL}

\section{Genencor $^{\circledR}$ Endoxylanase}

\section{Product Information}

\section{DESCRIPTION}

Multifect ${ }^{\circledR} X L$ enzyme is an endoxylanase derived from a selected strain of Trichoderma reesei. Typical application areas for the Multifect $^{\circledR} \mathrm{XL}$ product include baking, waste treatment and agricultural silage.

\section{TYPICAL CHARACTERISTICS}

$\begin{array}{ll}\text { Activity: } & 445 \mathrm{XAU} / \mathrm{ml} \text { (minimum) } \\ \text { Appearance: } & \text { Brown liquid } \\ \text { Grade: } & \text { Food grade, Kosher } \\ \text { Specific gravity: } & 1.0-1.2 \mathrm{~g} / \mathrm{ml}\end{array}$

\section{Unit Definition}

The activity of Multifect ${ }^{\circledR} X L$ enzyme is expressed in $X A U / m l$. The XAU is based on the release of Remazol Brilliant Blue-dyed oat spelt xylan at $\mathrm{pH} 4.5,40^{\circ} \mathrm{C}\left(104^{\circ} \mathrm{F}\right)$ in 10 minutes, using an endoxylanase reference standard.

\section{pH Dependency}

The $\mathrm{pH}$ range for the activity of Genencor Multifect ${ }^{\circledR} \mathrm{XL}$ enzyme is approximately 3.0 to 7.0 , with an optimum performance at $\mathrm{pH}$ 5.0. The exact $\mathrm{pH}$ optimum will depend on process variables, including temperature, time, substrate nature and concentration.

\section{Temperature Dependency}

The activity of Multifect ${ }^{\circledR} \mathrm{XL}$ enzyme is effective in the temperature range of $40^{\circ} \mathrm{C}\left(105^{\circ} \mathrm{F}\right)$ to $65^{\circ} \mathrm{C}\left(150^{\circ} \mathrm{F}\right)$, with an optimum performance at $60^{\circ} \mathrm{C}\left(140^{\circ} \mathrm{F}\right)$. The exact temperature optimum will depend on many process variables, such as $\mathrm{pH}$, time, substrate concentration and nature.

\section{BIOCHEMICAL PARAMETERS}

Enzyme type: Cellulase enzyme complex, standardized on endoxylanase activity

Side Activities: Virtually no protease, lipase or amylase side-activities

\section{APPLICATION RECOMMENDATIONS}

Multifect ${ }^{\circledR} \mathrm{XL}$ enzyme facilitates plant extractions, such as coffee and tea, and reduces viscosity (e.g. dough). Dispersion of the enzyme is important when used in dry or highly viscous substrates.

\section{DOSAGE}

For the best fit of Multifect ${ }^{\circledR} X L$ endoxylanase in your process, an in-plant optimization of dosage is recommended.

\section{REGULATORY STATUS}

This product meets or exceeds the Joint FAO/WHO Expert Committee on Food Additives (JECFA) and the Food Chemicals Codex (FCC) specifications for enzyme preparations used in food and is GRAS (Generally Recognized As Safe) in the United States.

\section{STORAGE \& STABILITY}

Multifect ${ }^{\circledR} \mathrm{XL}$ endoxylanase will meet the declared activity of $445 \mathrm{XAU} / \mathrm{ml}$ upon arrival at the customer's plant.

Genencor ${ }^{\circledR}$ enzymes can be safely stored in unopened and sealed original containers. Enzyme containers should be stored below $20^{\circ} \mathrm{C}\left(70^{\circ} \mathrm{F}\right)$, preferentially refrigerated and sheltered against direct sunlight.

During storage Multifect ${ }^{\circledR} \mathrm{XL}$ enzyme will have an activity loss of less than $18 \%$ per year at a temperature of $25^{\circ} \mathrm{C}\left(75^{\circ} \mathrm{F}\right)$, or less than $12 \%$ per year at a temperature of $4^{\circ} \mathrm{C}\left(40^{\circ} \mathrm{F}\right)$. For more information on the storage of this product, please contact your Genencor International ${ }^{\circledR}$ representative.

\section{PACKAGING}

Multifect ${ }^{\circledR} \mathrm{XL}$ enzyme is available in various packaging sizes. Please contact Genencor International ${ }^{\circledR}$ for detailed information.

Please note that some Genencor ${ }^{\circledR}$ products are sold in full pallet loads only.

\section{SAFETY \& ENZYME HANDLING}

Inhalation of enzyme dust and mists should be avoided. In case of contact with the skin or eyes, promptly rinse with water for at least 15 minutes.

For detailed handling information, please refer to the appropriate Material Safety Data Sheet, the Enzyme Technical Association (ETA) handbook Working Safely With Enzymes, and the Association of Manufacturers of Fermentation Enzyme Products (Amfep) handbook Guide to the Safe Handling of Microbial Enzyme Preparations. All are available from Genencor International ${ }^{\circledR}$. 


\section{TECHNICAL SERVICE}

Genencor International ${ }^{\circledR}$ will work with customers to enhance processes and solve problems. Let us know what you need and we will assist you.

For more information:

USA and Canada

Genencor International, Inc.

200 Meridian Centre Blvd., Rochester, NY 14618 USA

Telephone: 1-800-847-5311 (USA)

Telephone: +1-585-256-5200

Telefax: +1-585-244-4544

Europe, Africa and Middle East

Genencor International B.V.

P.O. Box 218, 2300 AE Leiden, The Netherlands

Telephone: +31-71-5686-168

Telefax: +31-71-5686-169

\section{Latin America}

Genencor International Argentina S.R.L.

Carlos Pellegrini 1149, Piso 13

1009 Buenos Aires, Argentina

Telephone: +54-11-4129-2300

Telefax: +54-11-4326-4411

\section{Asia/Pacific}

Genencor International Asia Pacific PTE, LTD.

3 Killiney Road

\#05-02 Winsland House, Singapore 239519

Telephone: +65-6838-7410

Telefax: $+65-6737-1218$

Web Address

www.genencor.com

(c) Genencor International, Inc., 2004. MULTIFECT, GENENCOR, GENENCOR INTERNATIONAL, and INNOVATIVE BY NATURE are registered trademarks of Genencor International, Inc. or its affiliated companies.

The information contained in this product literature is, to the best of our knowledge, true and accurate and the product as sold is in conformance with the specifications set forth herein as determined by the assay methods described. Due to conditions of
use, technical errors or omissions, improper handling or storage beyond our control, Genencor International hereby DISCLAIMS ANY EXPRESS OR IMPLIED WARRANTIES, INCLUDING THE IMPLIED WARRANTIES OF
MERCHANTABILITY OR FITNESS FOR A PARTICULAR PURPOSE. Genencor MERCHANTABILITY OR FITNESS FOR A PARTICULAR PURPOSE. Genencor
International shall not be liable for any incidental, consequential, or special International shall not be liable for any incidental, consequential, or special
damages resulting in any way from the furnishing, performance, or use of this product literature or the product described herein.

Nothing contained herein shall be construed as a representation by Genencor International that the use or resale of the product or processes described herein will not violate any rules or regulations or infringe upon patents or other intellectual property rights of third parties or that the recommendations and usage suggestions

REV0704

2112

MUL32CX

03 


\title{
(3) Genencor International ${ }^{\circ}$ Innovative by Nature
}

\section{Multifect ${ }^{\circledR}$ Neutral}

\author{
Genencor $^{\circledR}$ Bacterial Neutral Protease
}

\section{Product Information}

\section{DESCRIPTION}

Multifect ${ }^{\circledR}$ Neutral enzyme is a bacterial neutral enzyme preparation derived from a controlled fermentation of a non-genetically modified strain of Bacillus amyloliquefaciens. This product is characterized by its ability to hydrolyze a broad range of substrates at neutral $\mathrm{pH}$. It is ideally suited for protein hydrolysis applications in which pH adjustment is either not feasible or not possible. Typical substrates effectively hydrolyzed by Multifect Neutral include casein, whey, meat, soy, gelatin and grains utilized in the brewing process. The hydrolyzed proteins from grains provide free amino nitrogen for improved yeast nutrition resulting in alcohol yield efficiencies. Use of Multifect ${ }^{\circledR}$ Neutral in the brewing process may also provide improved efficiency in downstream processing.

\section{TYPICAL CHARACTERISTICS}

$\begin{array}{ll}\text { Activity: } & >1600 \mathrm{AU} \text { (azo units) } / \mathrm{g} \\ \text { Appearance: } & \text { Amber to brown liquid } \\ \text { Grade: } & \text { Food grade } \\ \text { pH: } & 5.5-6.0 \\ \text { Specific gravity: } & 1.13-1.23 \mathrm{~g} / \mathrm{ml} \\ \text { Description: } & \text { Metallo neutral endopeptidase }\end{array}$

The activity of Multifect ${ }^{\circledR}$ Neutral is expressed as $\mathrm{AU} / \mathrm{g}$ based on hydrolysis of Azo-casein substrate at $\mathrm{pH} 7.5$ for 5 minutes at $30^{\circ} \mathrm{C}$ $\left(86^{\circ} \mathrm{F}\right)$.

\section{OPERATING CONDITIONS}

Multifect ${ }^{\circledR}$ Neutral is most effective at an operating $\mathrm{pH}$ of 6 - 8 (optimum of 7.0$)$ and temperature range of $40-60^{\circ} \mathrm{C}(104-$ $140^{\circ} \mathrm{F}$ ). Due to the complex nature of proteins as substrates and the hydrolysis reactions involved, the exact temperature and $\mathrm{pH}$ required to achieve the end point desired will vary from process to process, substrate to substrate and plant to plant. Additionally, process parameters such as solids level, time, enzyme concentration, etc. will also play key roles in determining the exact process conditions required. Genencor's Technical Service staff is always available to work with you to determine the exact set of conditions to achieve the most efficient and economical process for your situation.

Enzyme inactivation can be achieved by processing the solution at greater than $80^{\circ} \mathrm{C}\left(176^{\circ} \mathrm{F}\right)$ for 3-7 minutes; adjusting the $\mathrm{pH}$ below 3.0 and holding at greater than $50^{\circ} \mathrm{C}\left(122^{\circ} \mathrm{F}\right)$ for 30 minutes.

\section{APPLICATION RECOMMENDATIONS}

Multifect ${ }^{\circledR}$ Neutral demonstrates catalytic activity on the proteins found in most commercial agricultural plants and animals. However, its effectiveness is greatest on casein, soy and wheat proteins as well as being able to greatly reduce viscosity and improve processing of fish or chicken by products. Typical experiments measuring degree of hydrolysis (DH) show Multifect ${ }^{\circledR}$ Neutral to be very effective during hydrolysis of materials at biological pHs and able to function at solids levels as high as $30-35 \%$.

The following graphs show the hydrolysis capabilities of Multifect ${ }^{\circledR}$ Neutral on a variety of substrates under controlled DH reactions:
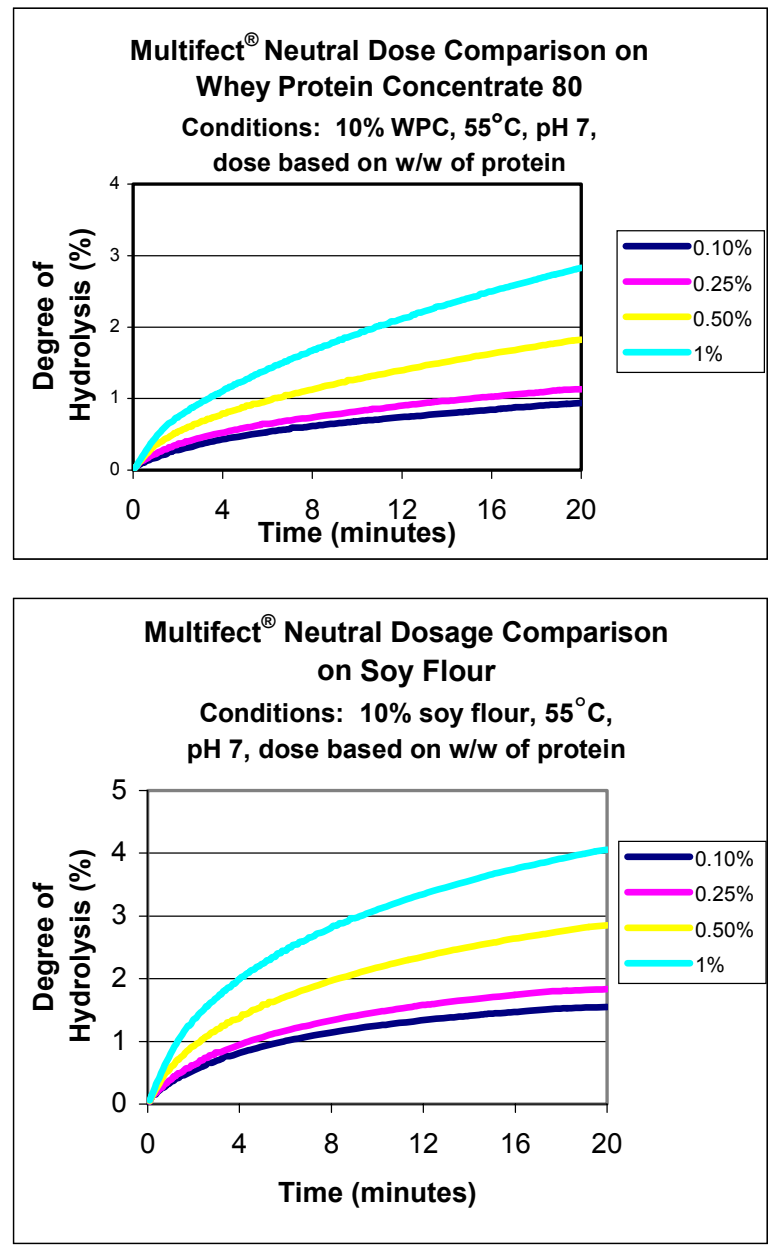


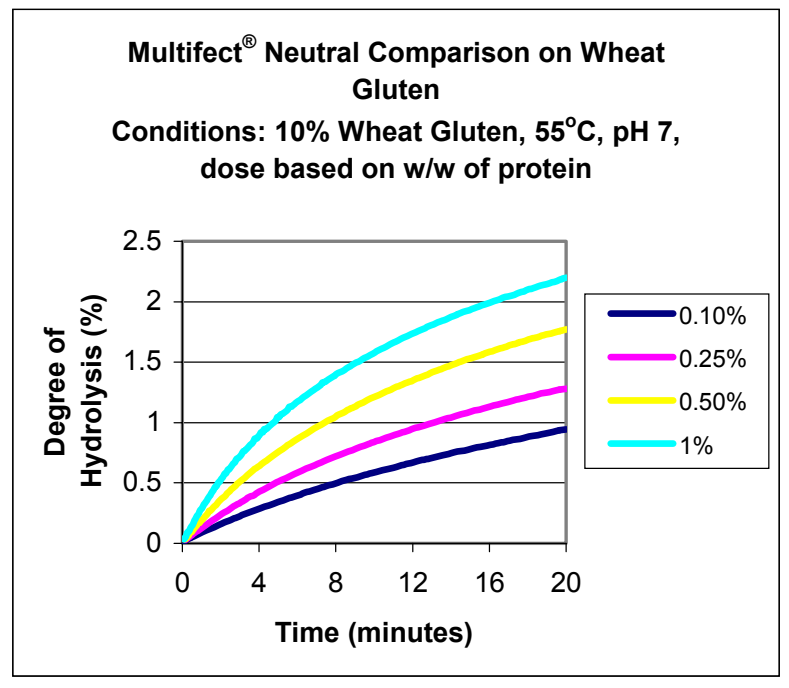

Post hydrolysis amino acid analysis indicates that the neutral protease action pattern cleaves over a range of sites on the protein backbone. Compared to alkaline endopeptidases, this action pattern could result in reduced bitterness. Multifect ${ }^{\circledR}$ Neutral is not an exopeptidase, thus some flavor profiles may still be enhanced.

Typical dosage levels for using Multifect ${ }^{\circledR}$ Neutral range from $0.1 \%$ to $1.0 \%$ depending on the application criteria, the processing parameters being utilized and the attributes desired in the hydrolysate being developed. For applications where processing time and efficiency are critical and viscosity reduction is the key element being modified, higher doses are typically recommended. Lower doses are more suitable where exact molecular weight ranges or flavor profiles are specified.

\section{PACKAGING}

Multifect ${ }^{\circledR}$ Neutral is available in $28 \mathrm{~kg}$ pails; $225 \mathrm{~kg}$ drums and $1125 \mathrm{~kg}$ totes, with bulk deliveries available upon request.

\section{STORAGE \& STABILITY}

Multifect ${ }^{\circledR}$ Neutral can be safely stored in unopened and sealed original containers. Enzyme containers should be stored below $20^{\circ} \mathrm{C}\left(70^{\circ} \mathrm{F}\right)$, preferentially refrigerated and sheltered from direct sunlight.

\section{SAFETY \& ENZYME HANDLING}

Inhalation of enzyme dust and mists should be avoided. In case of contact with the skin or eyes, promptly rinse with water for at least 15 minutes.

For detailed handling information, please refer to the appropriate Material Safety Data Sheet, the Enzyme Technical Association (ETA) handbook Working Safely With Enzymes, and the Association of Manufacturers of Fermentation Enzyme Products (Amfep) handbook Guide to the Safe Handling of Microbial Enzyme Preparations. All are available from Genencor International ${ }^{\circledR}$.

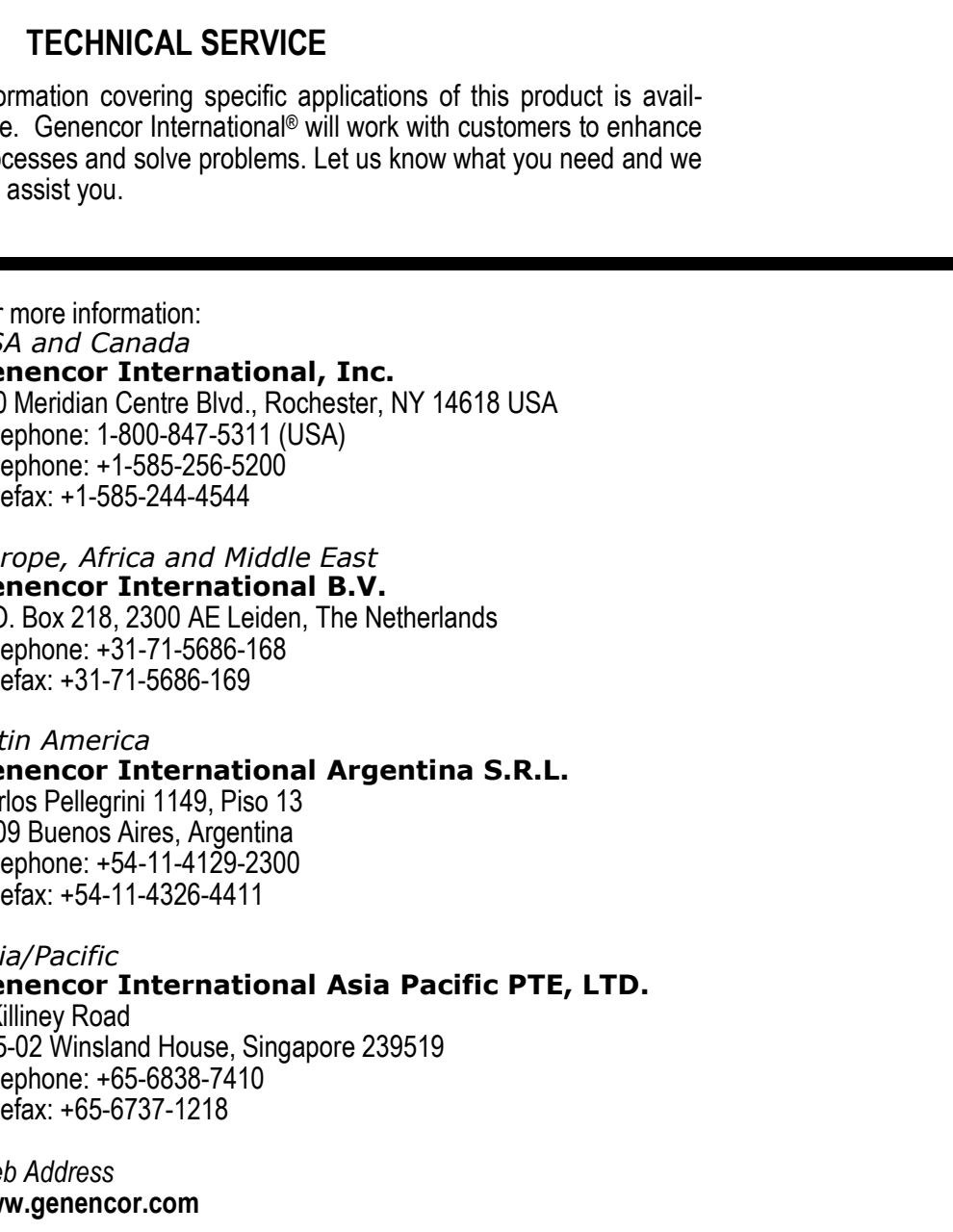

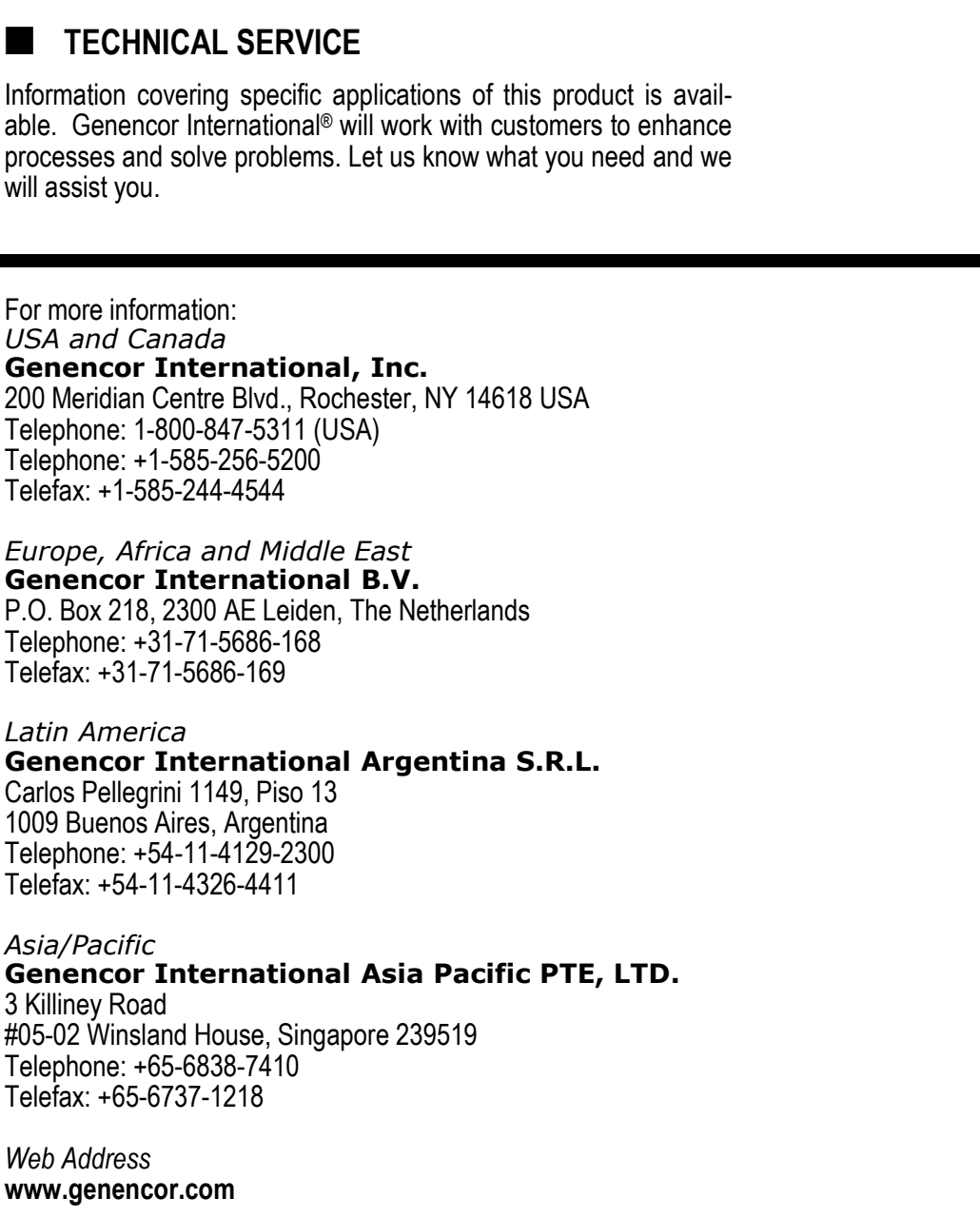

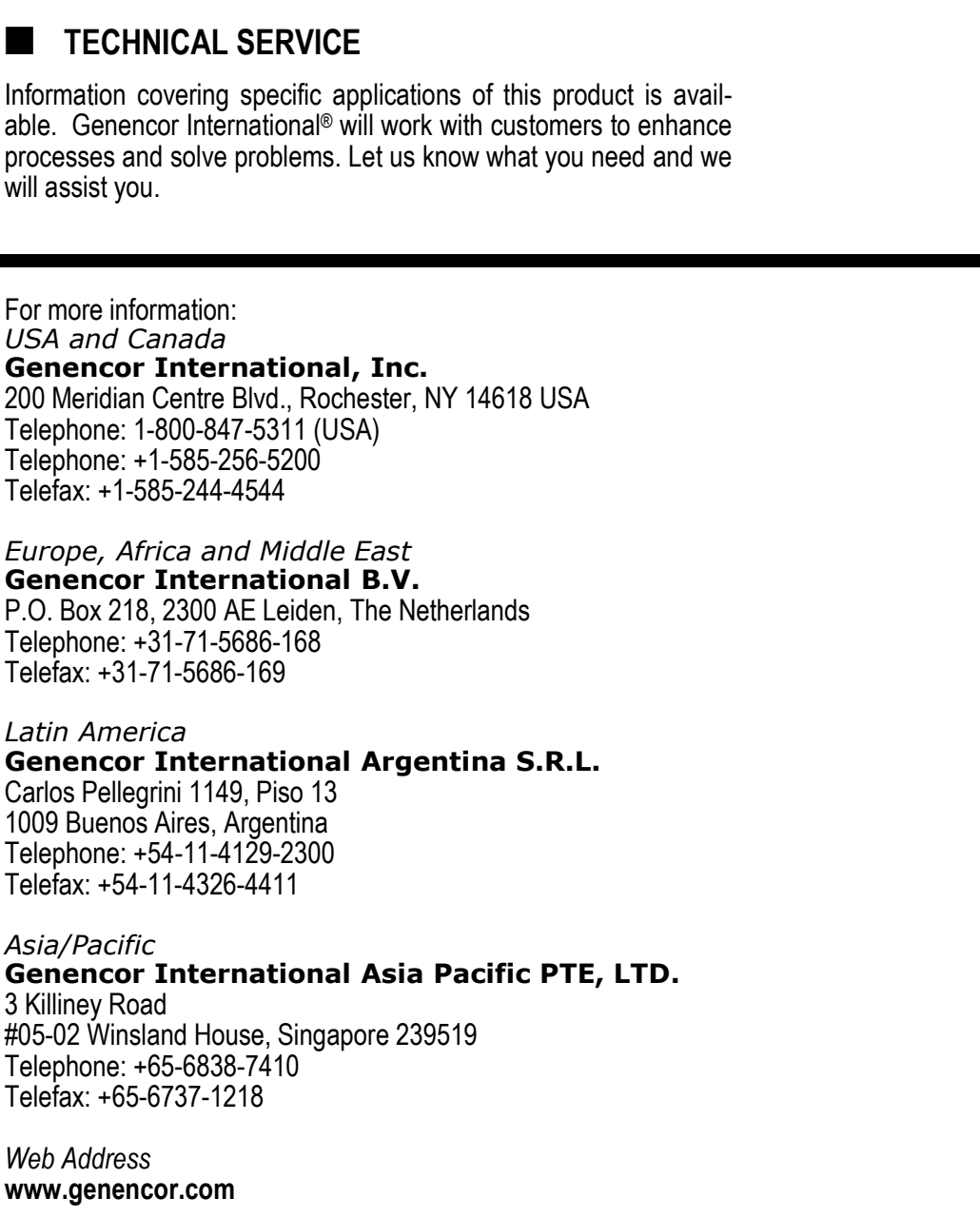

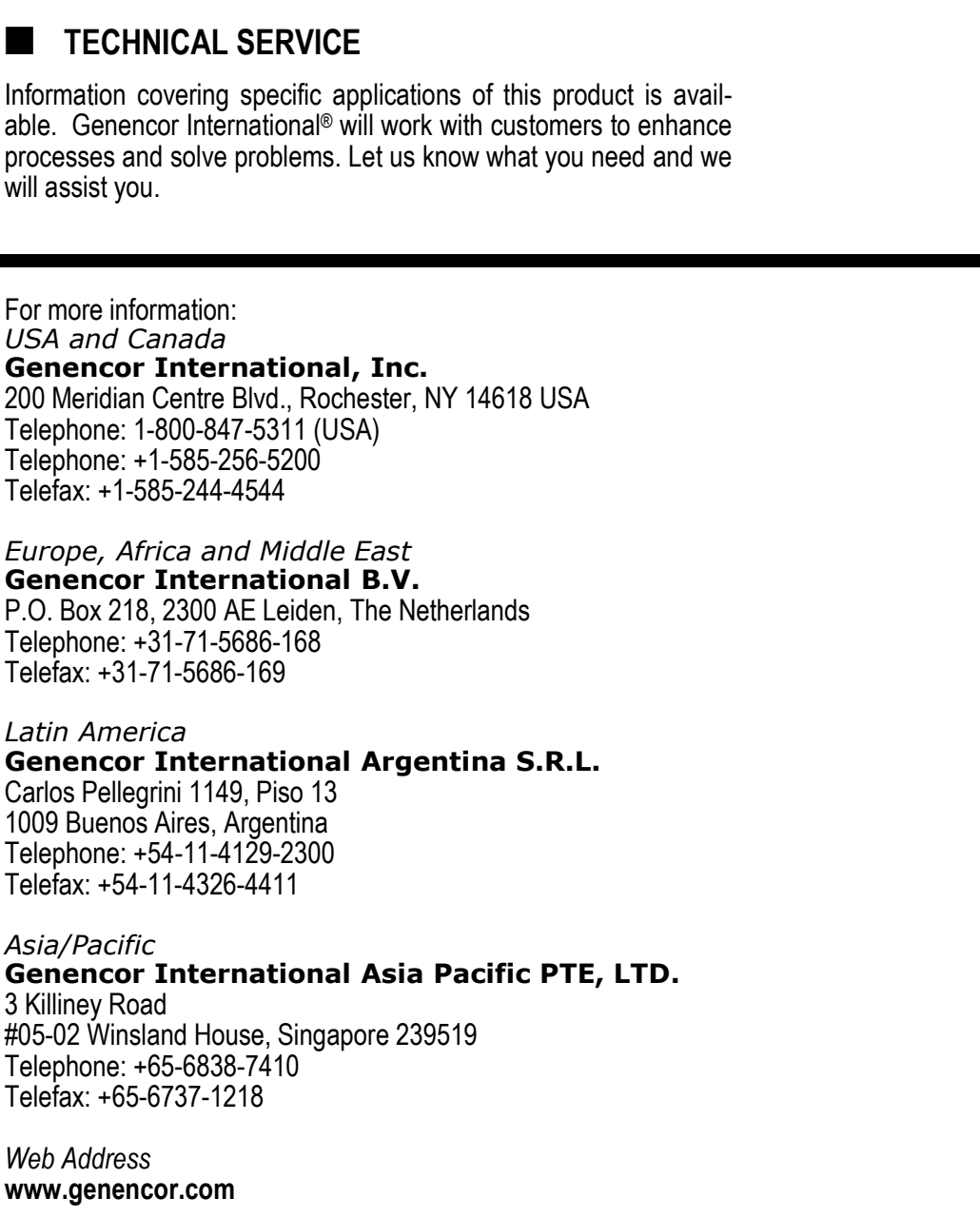

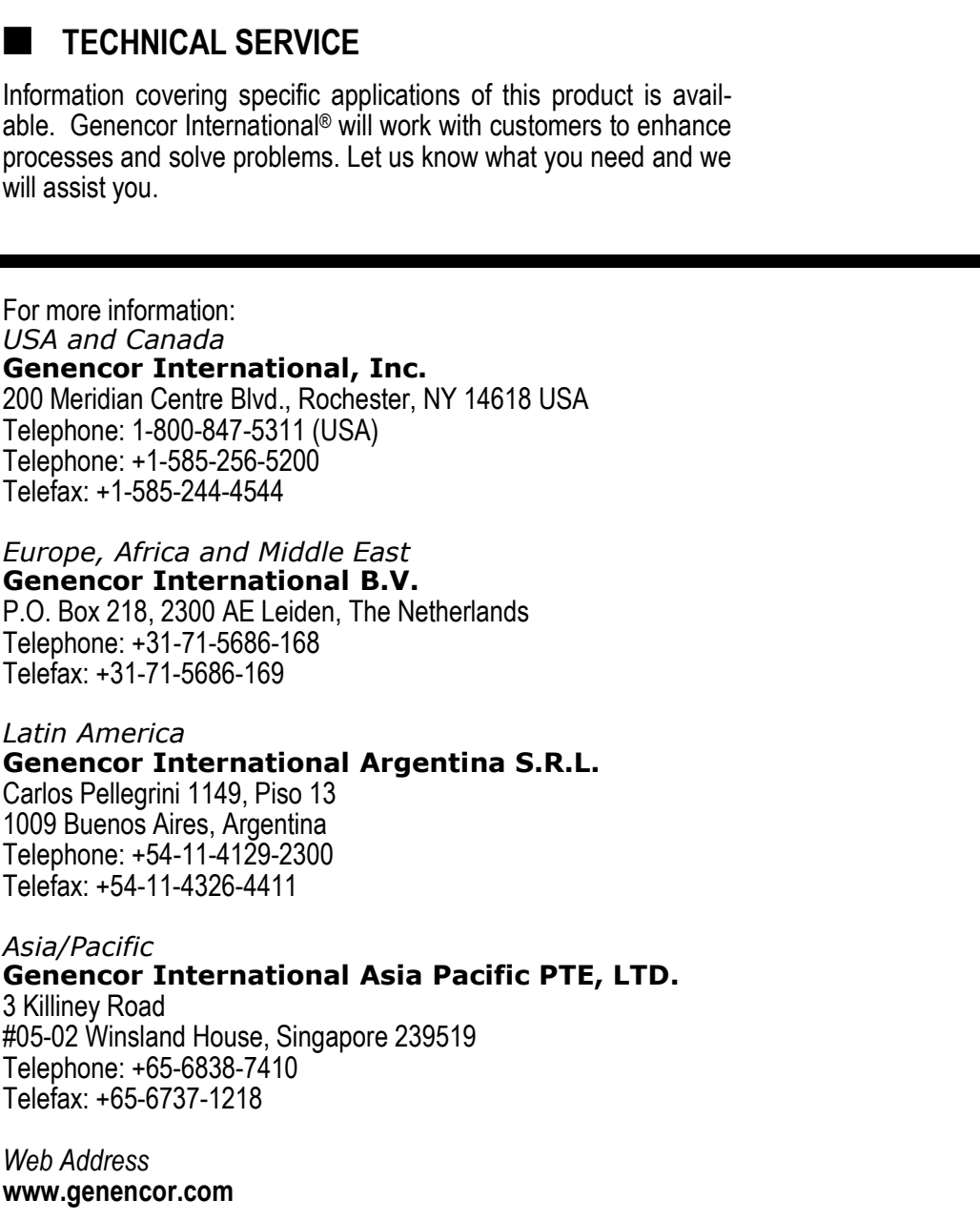

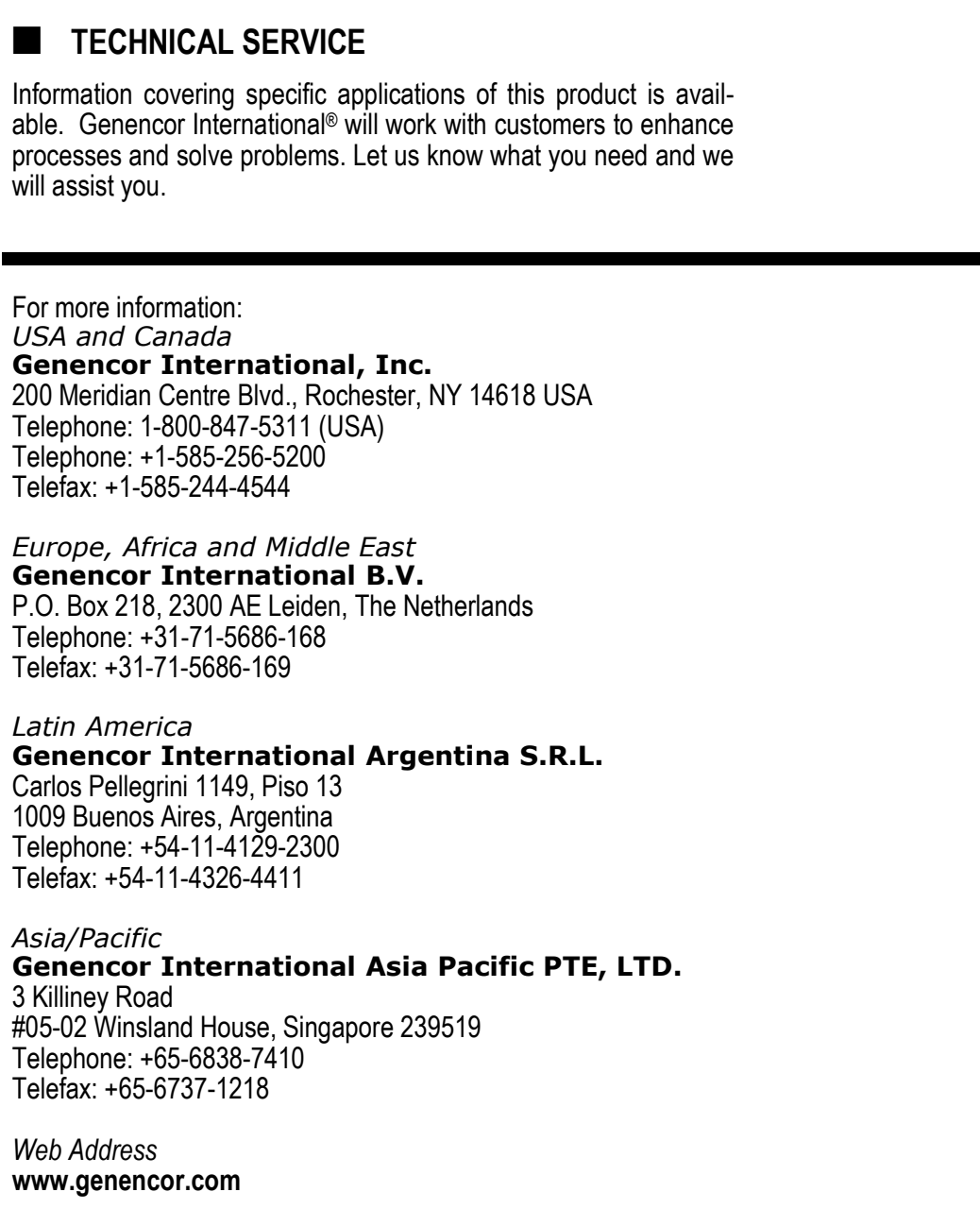

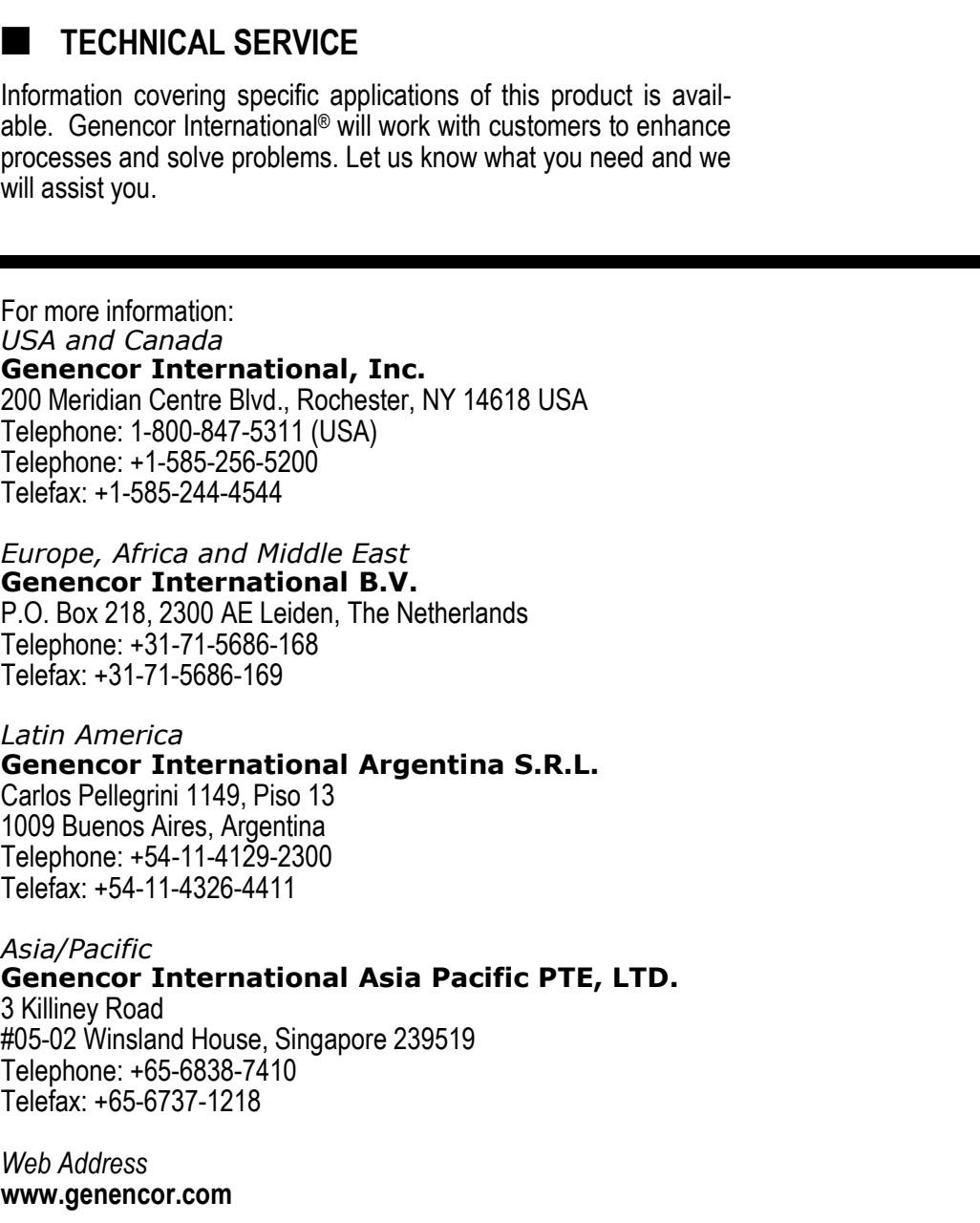

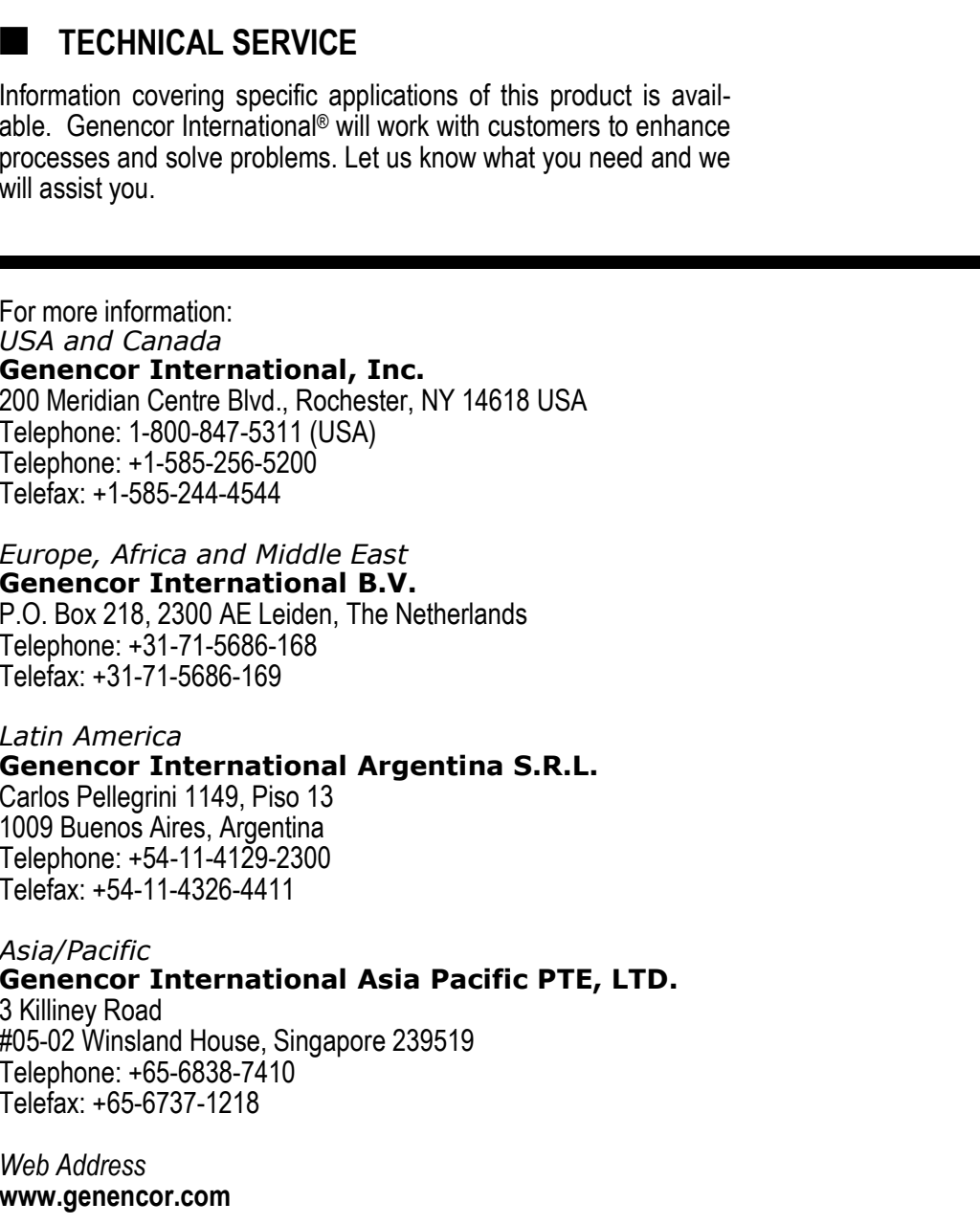

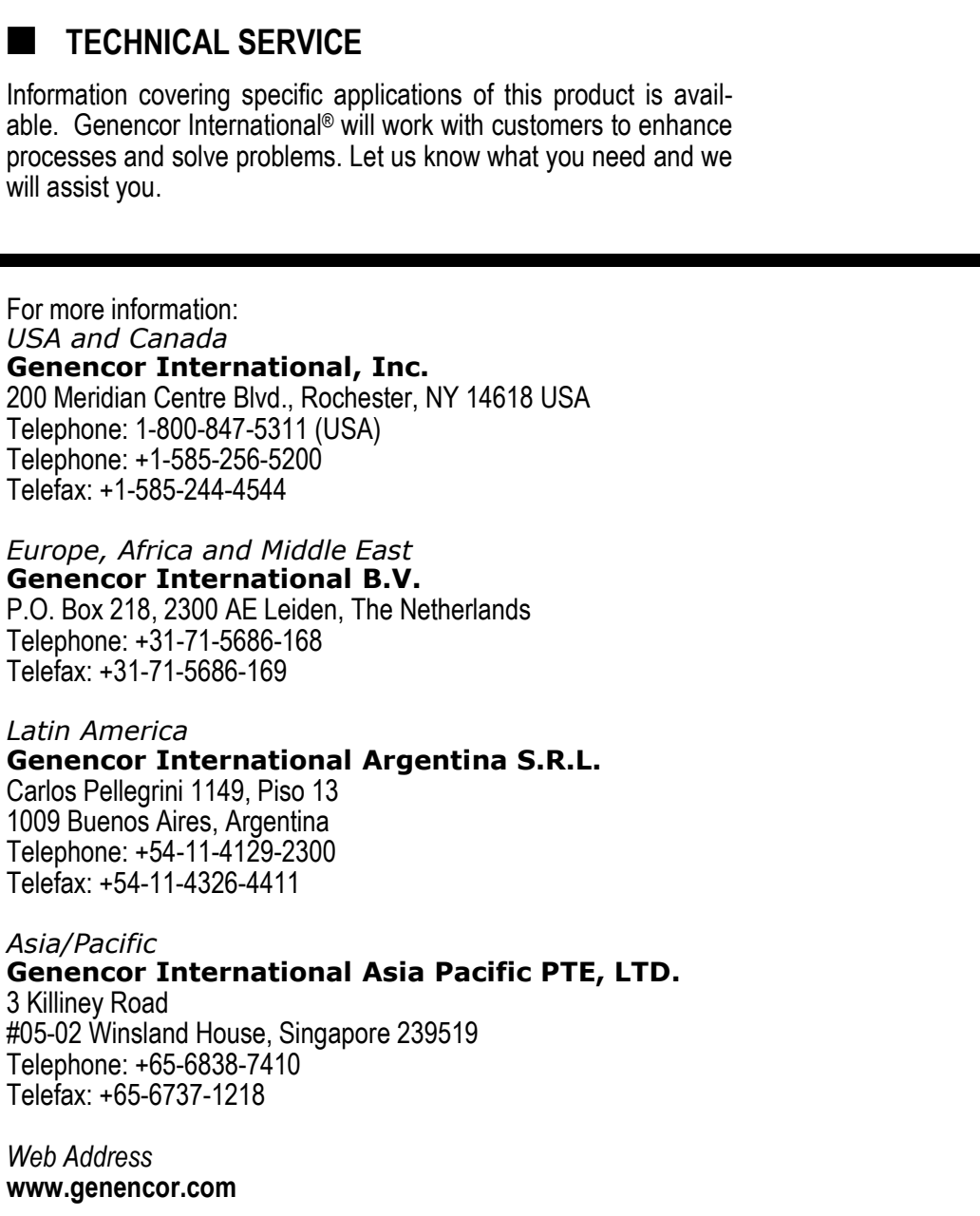

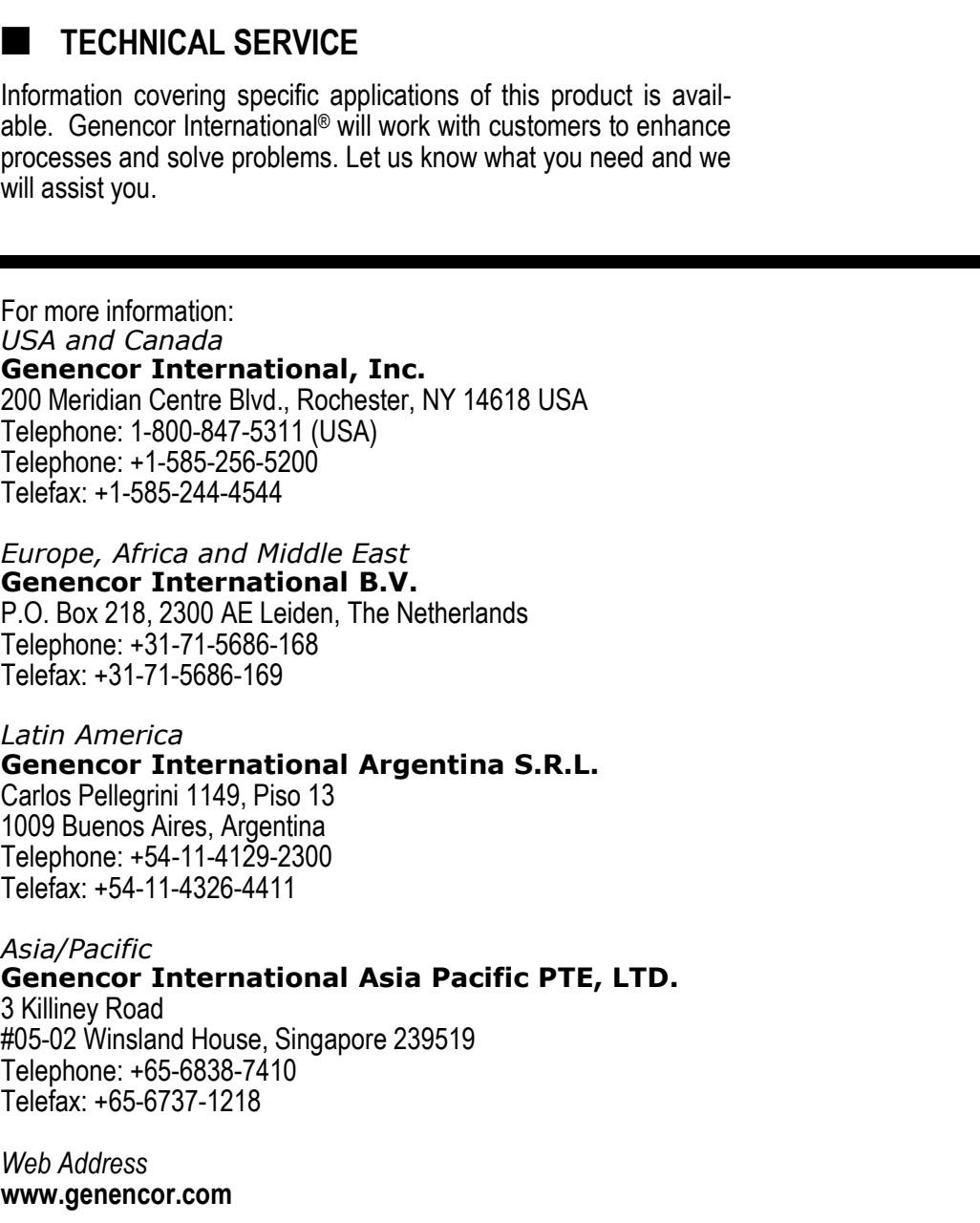

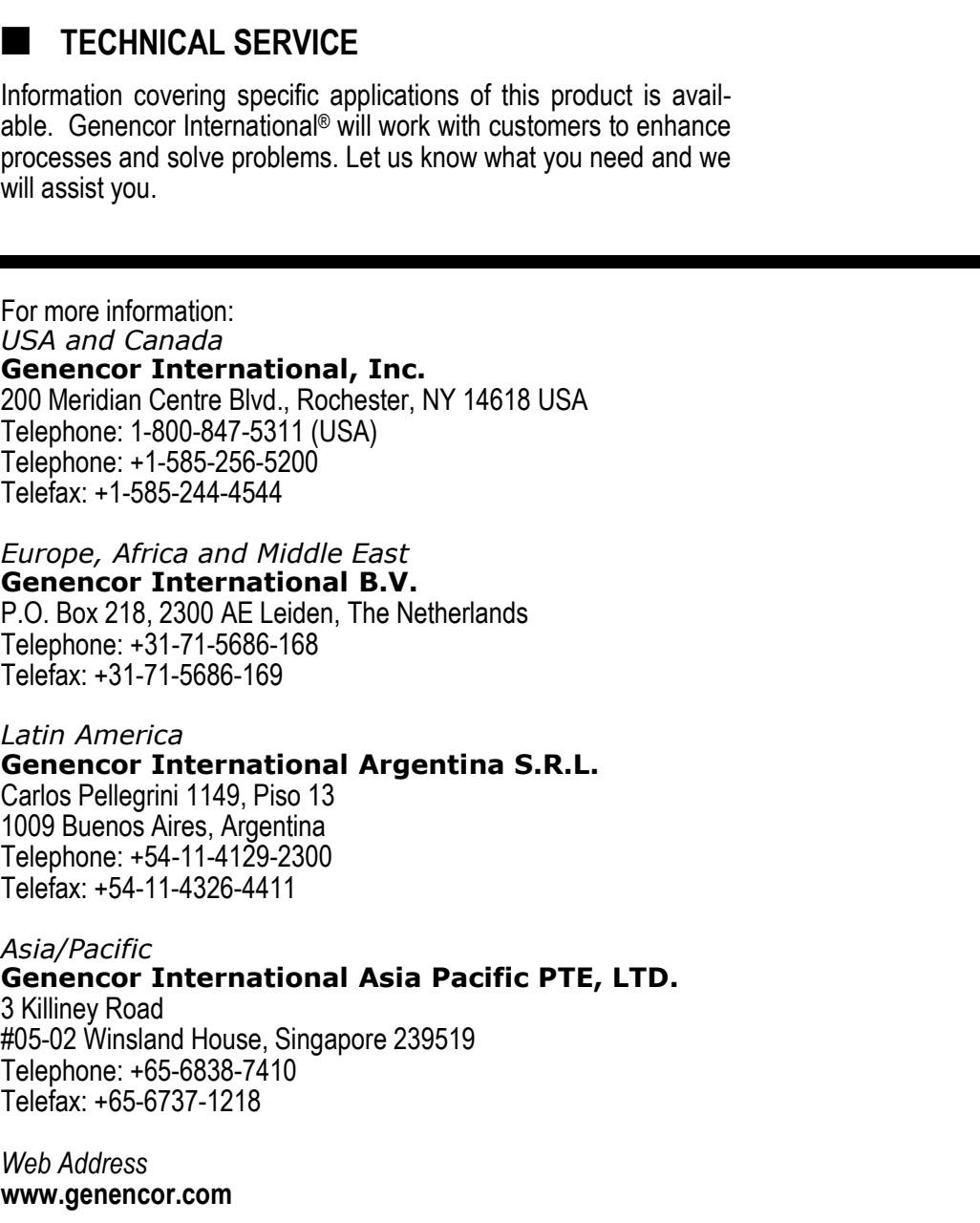

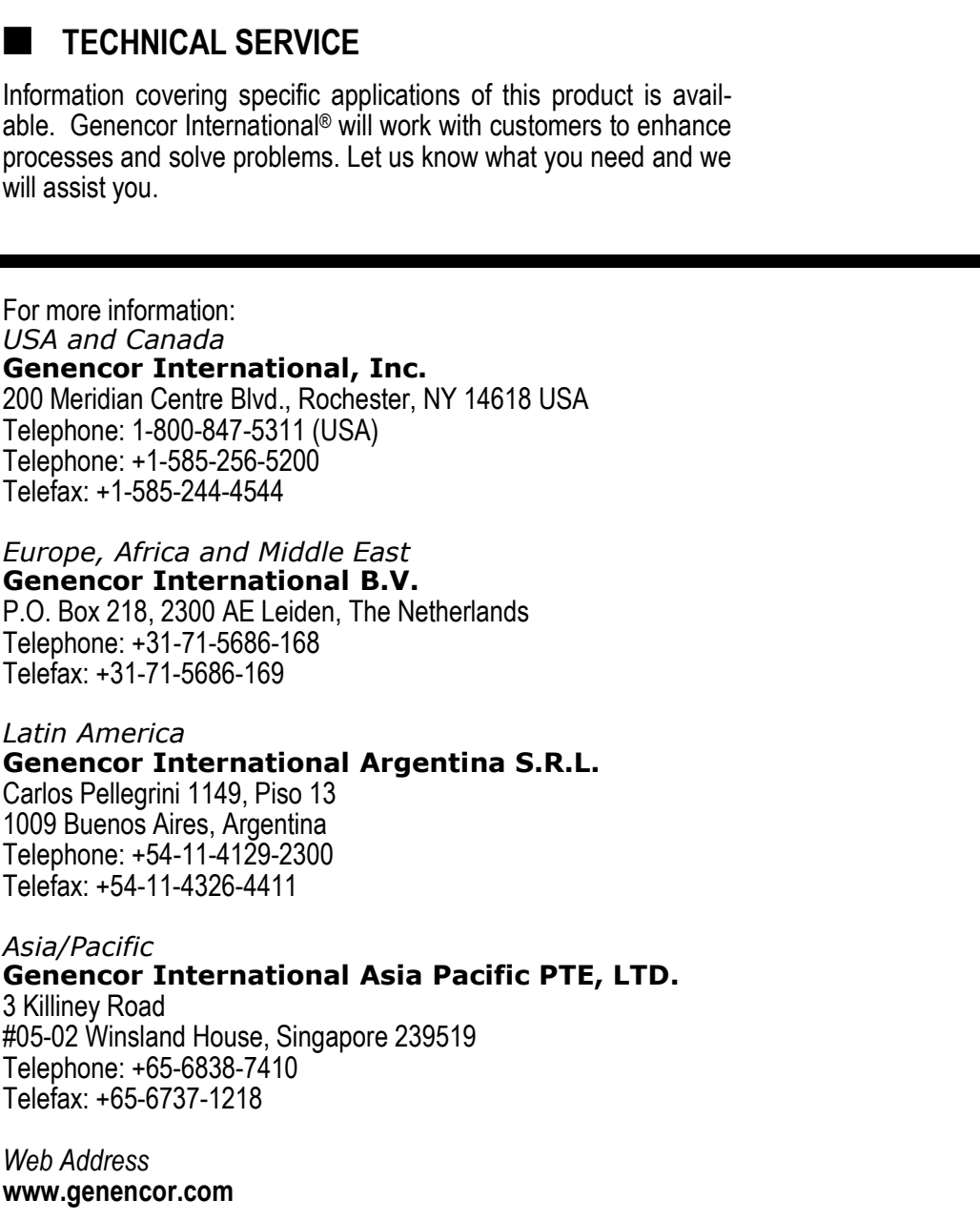

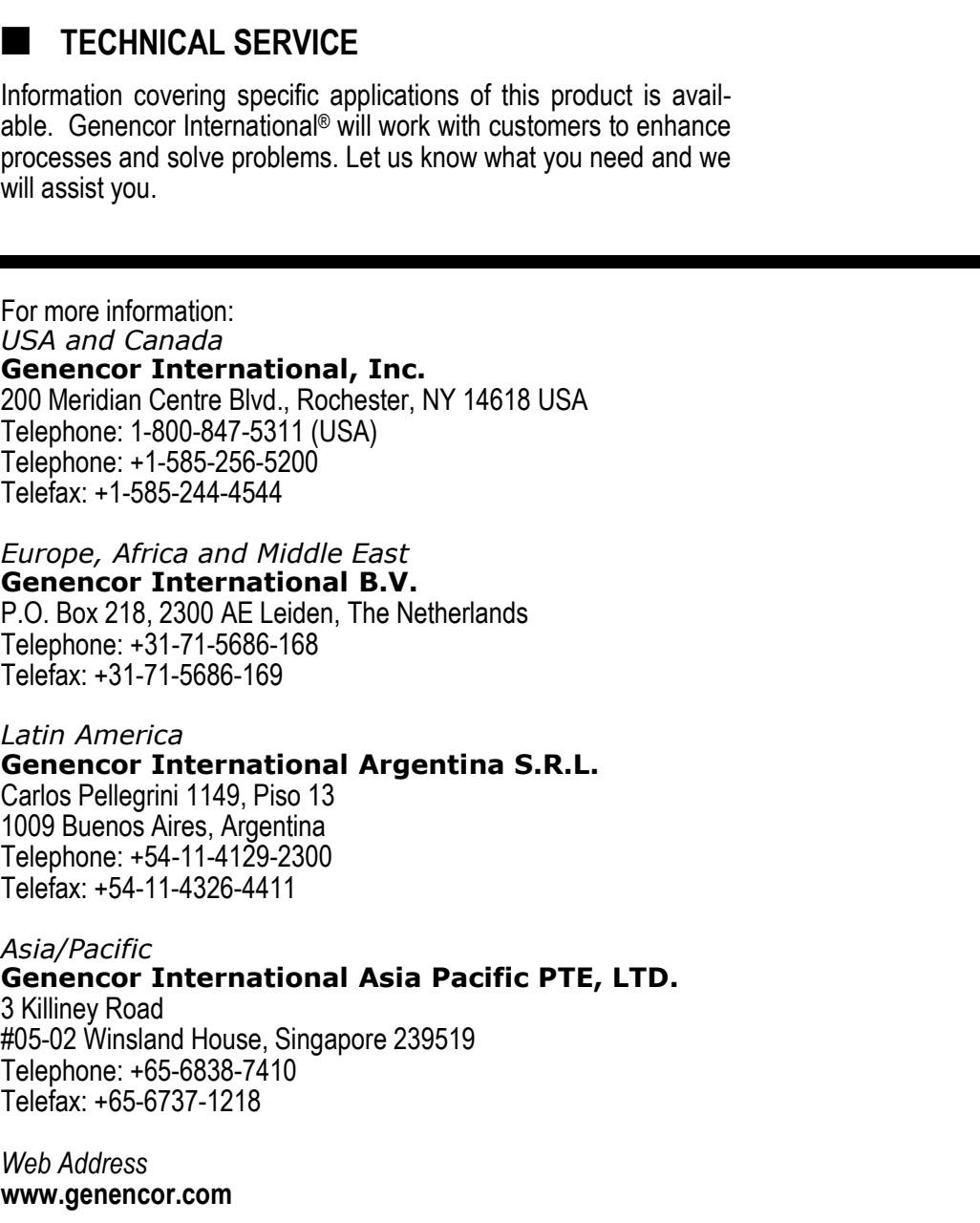

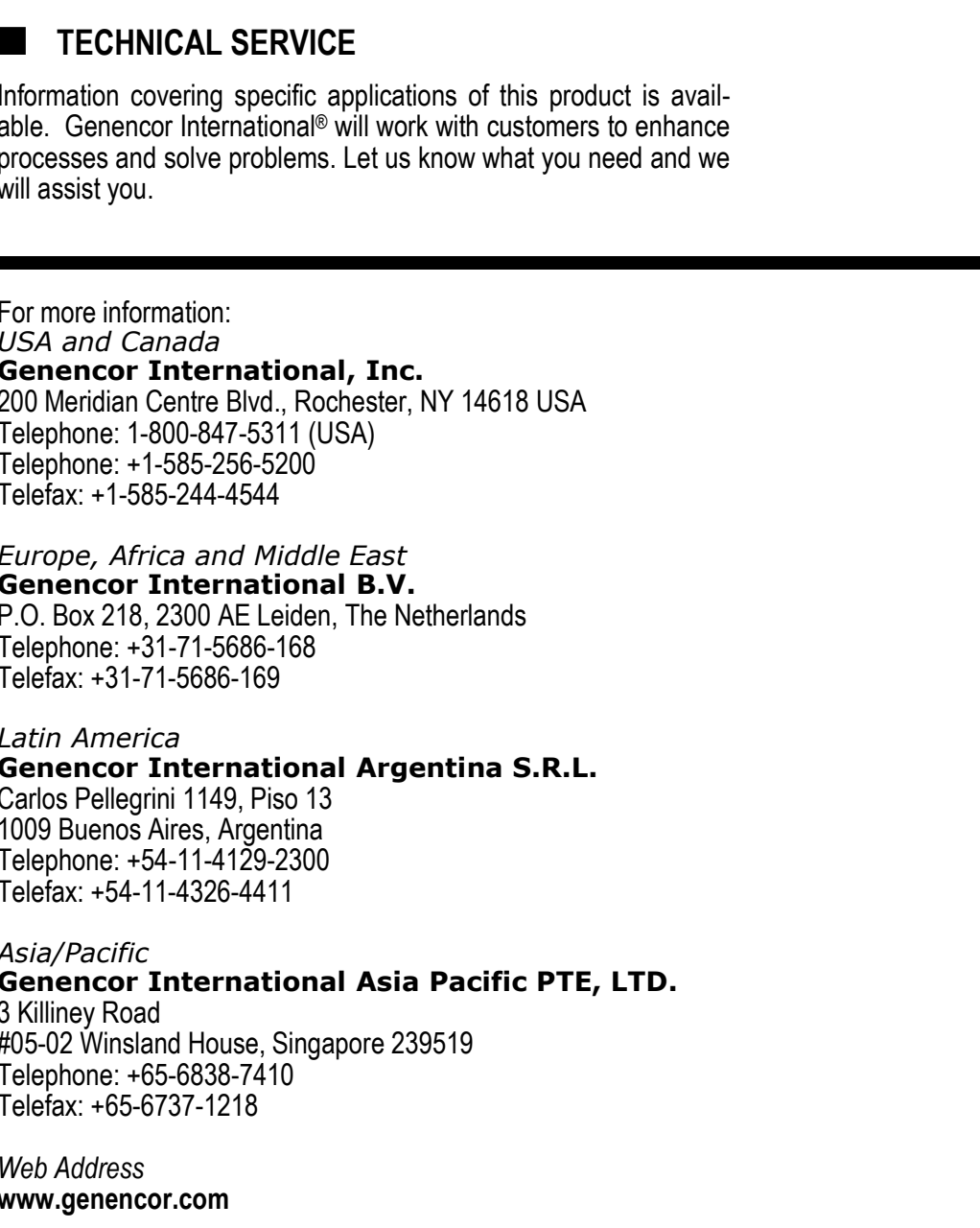

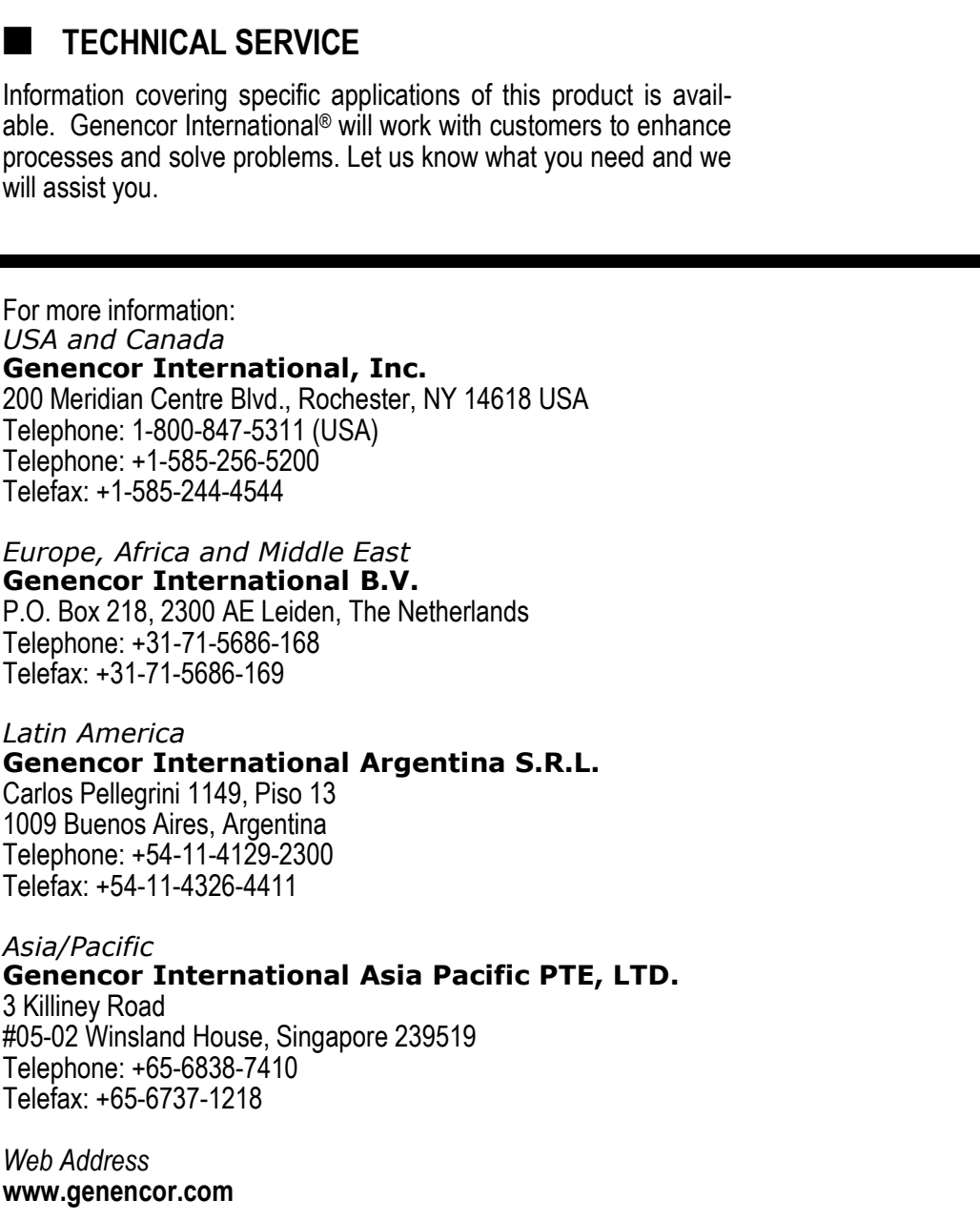

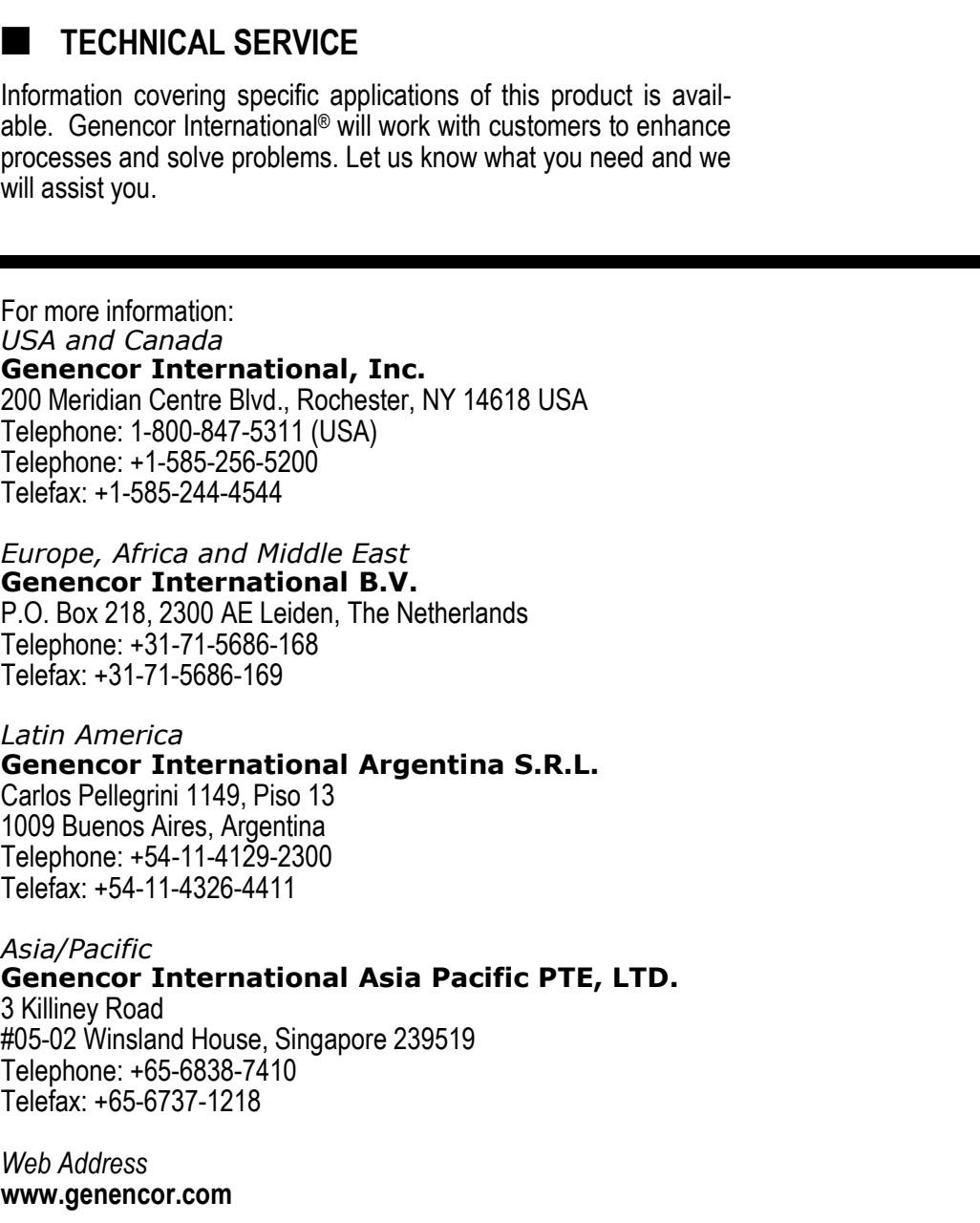

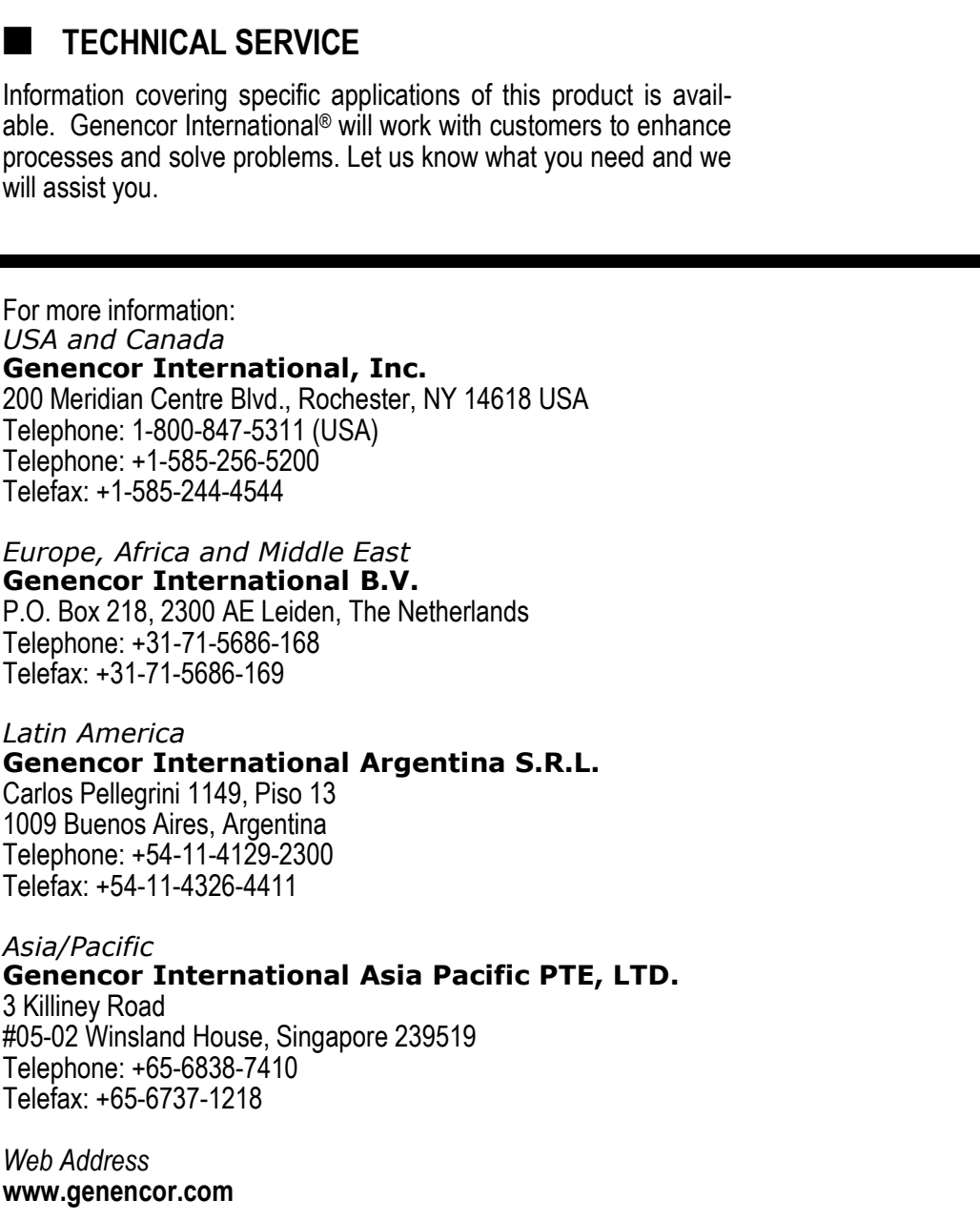

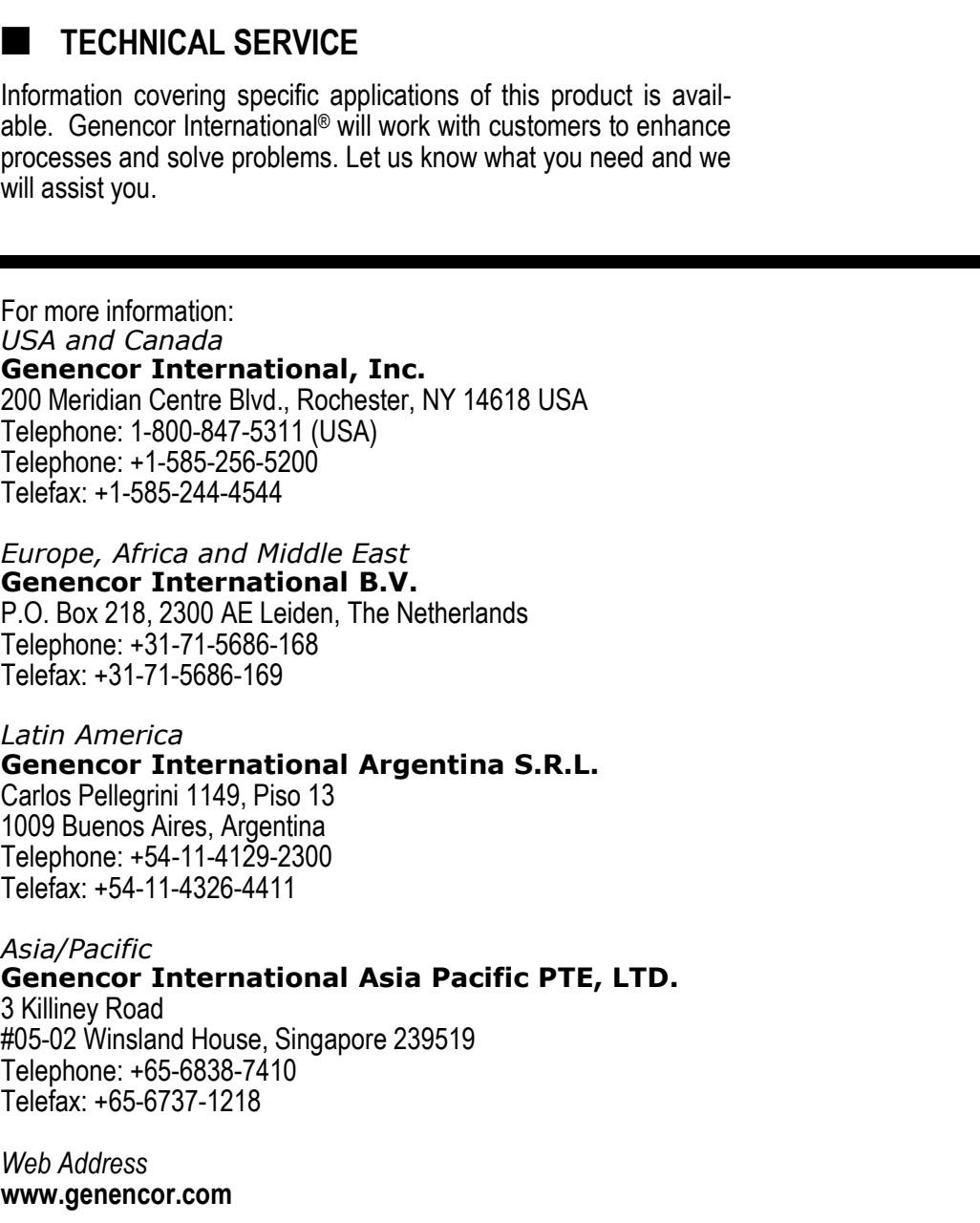

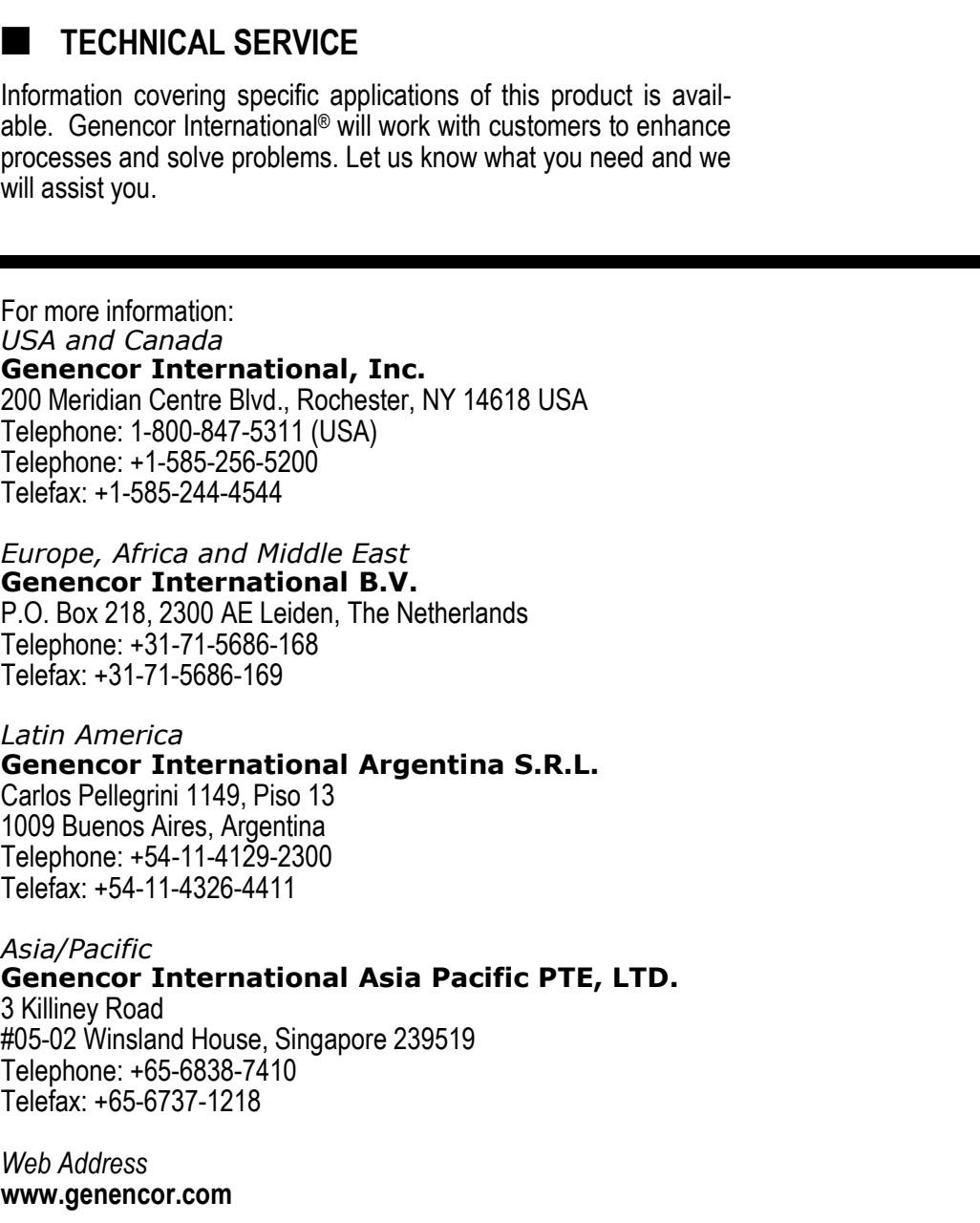

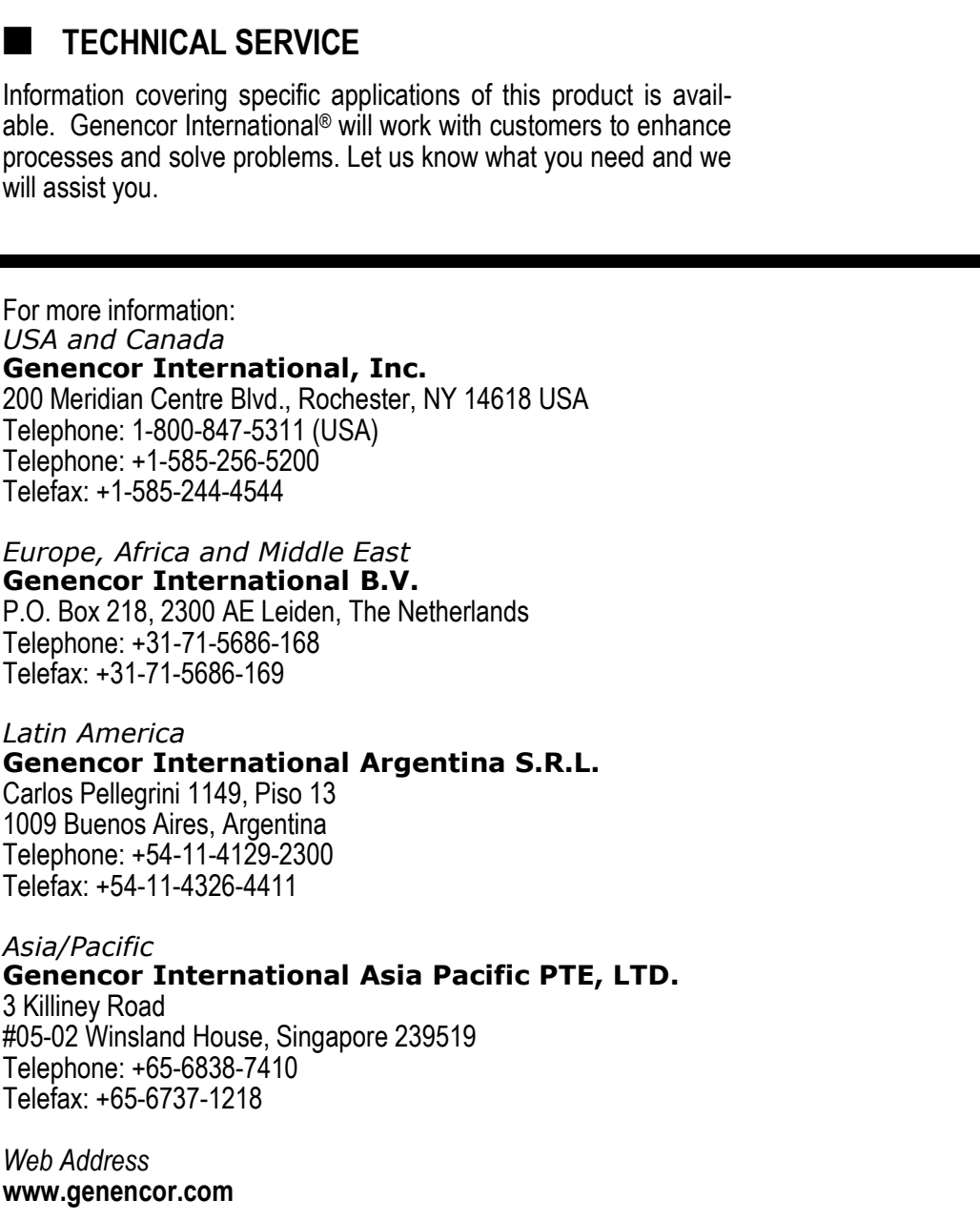

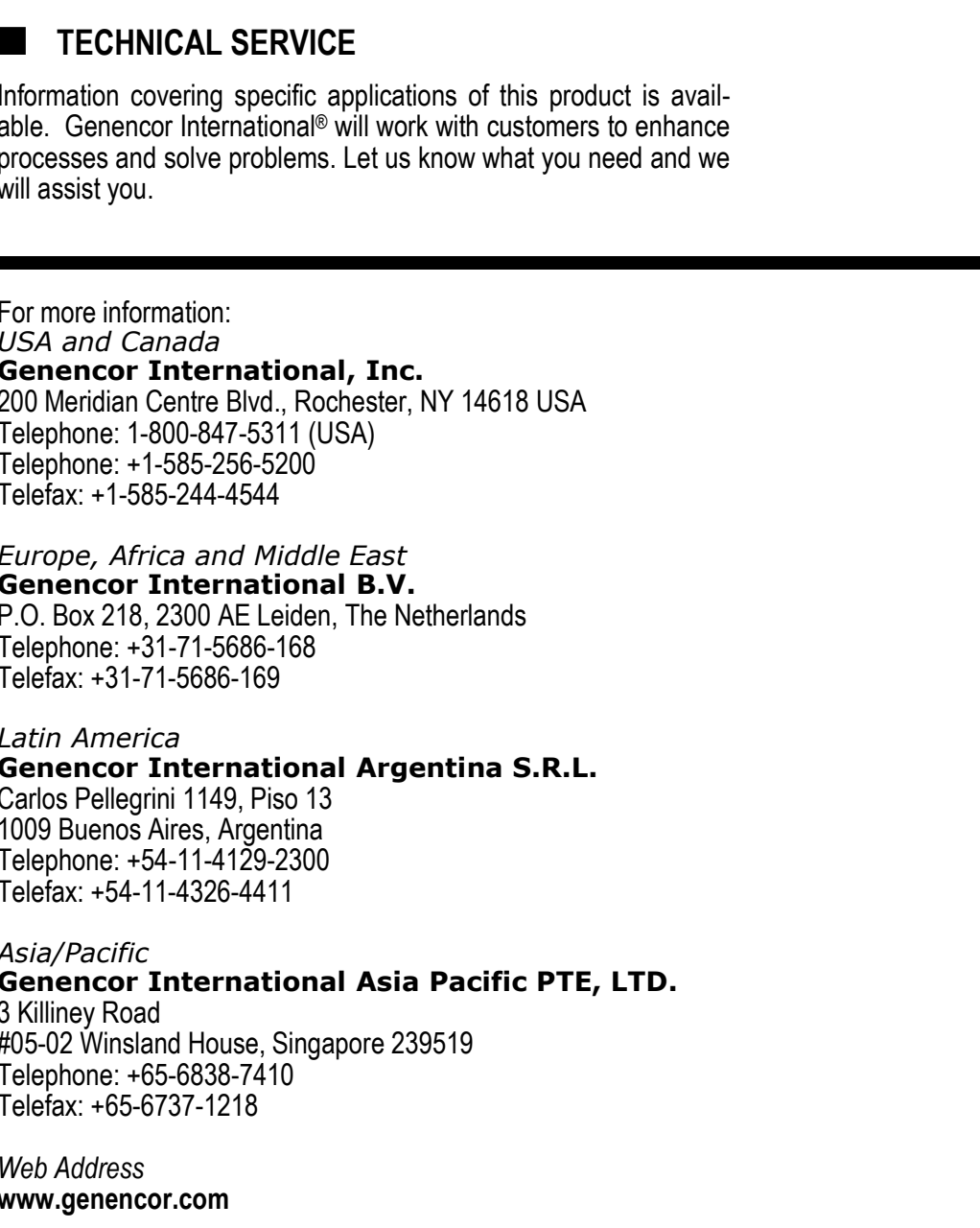

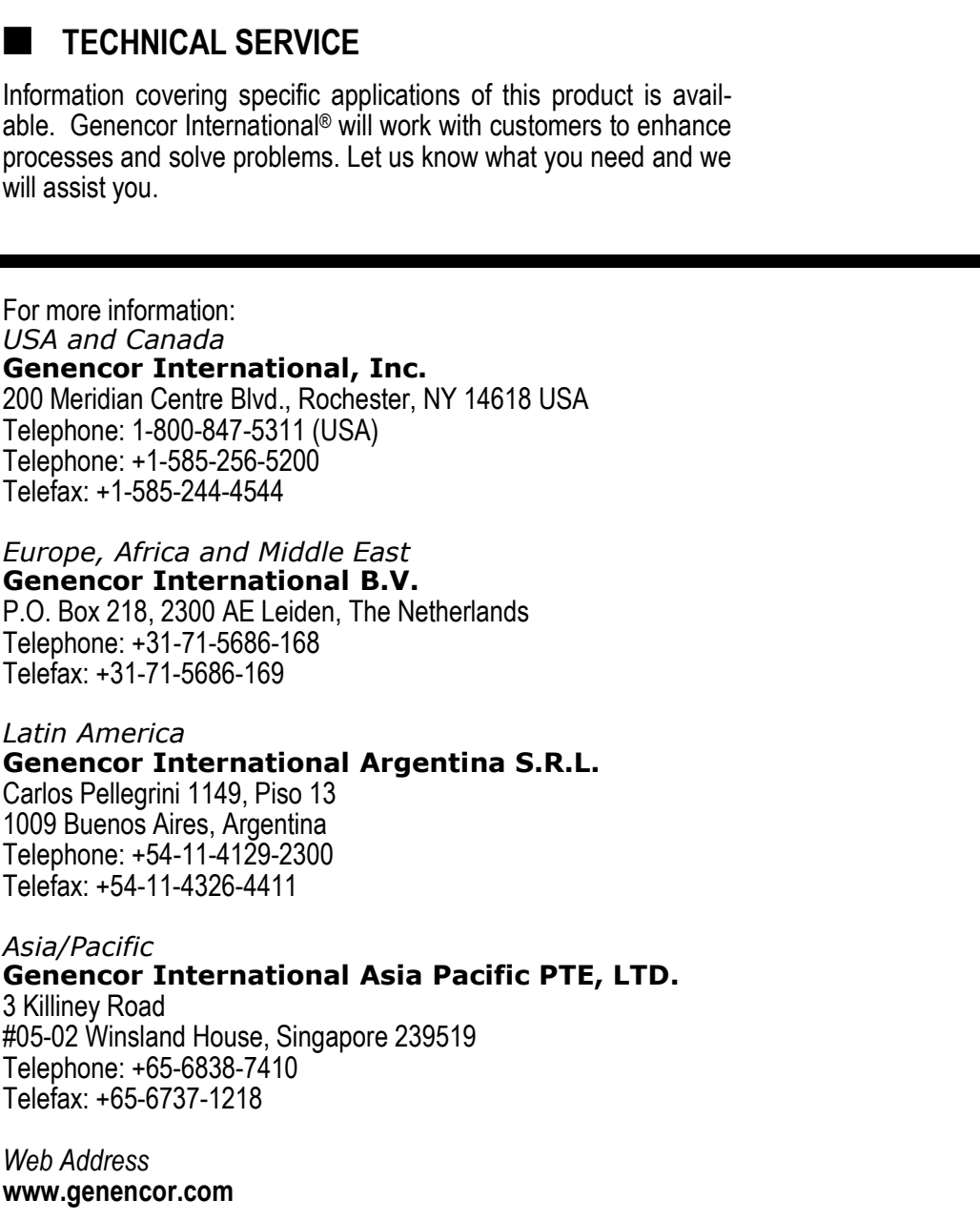

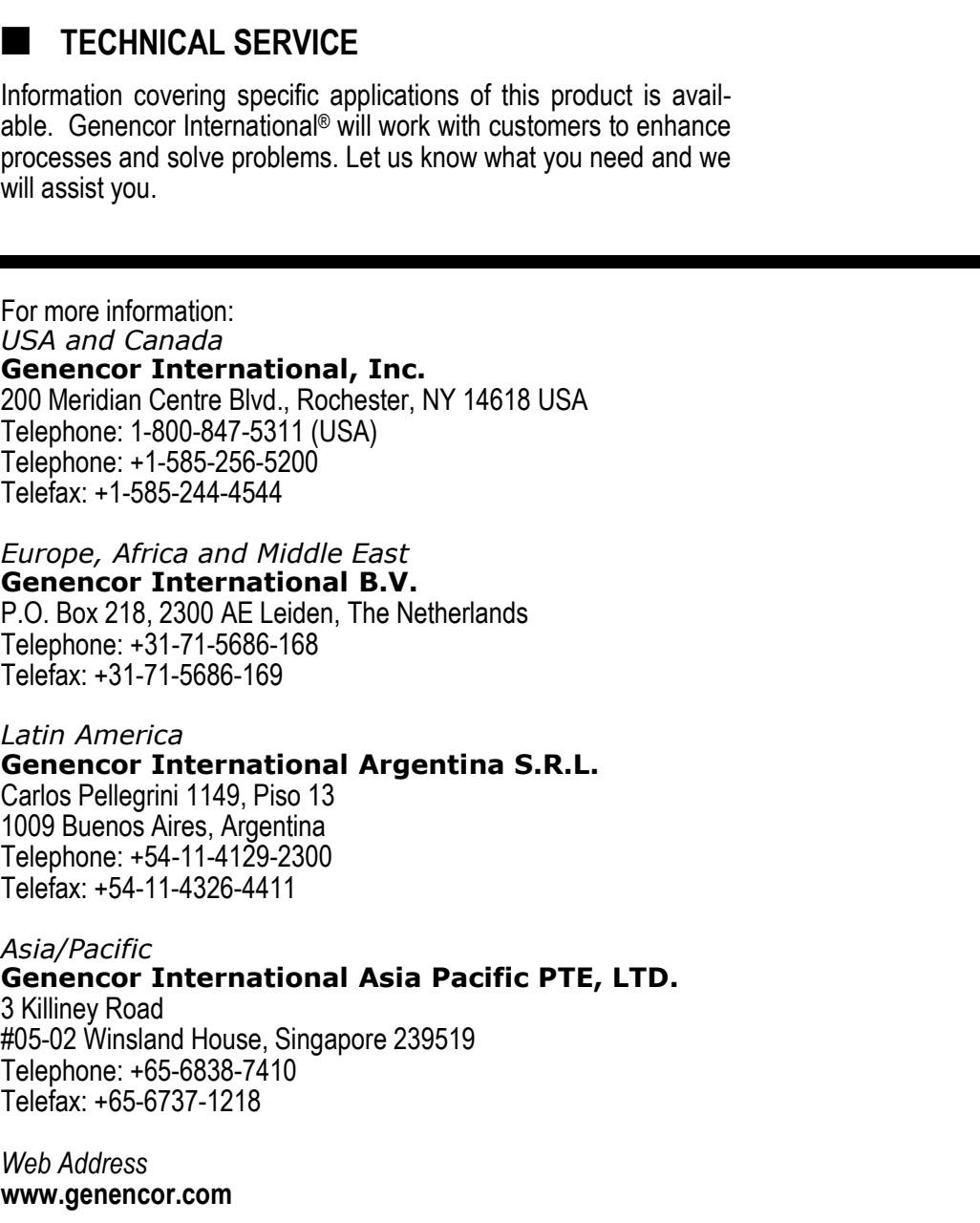

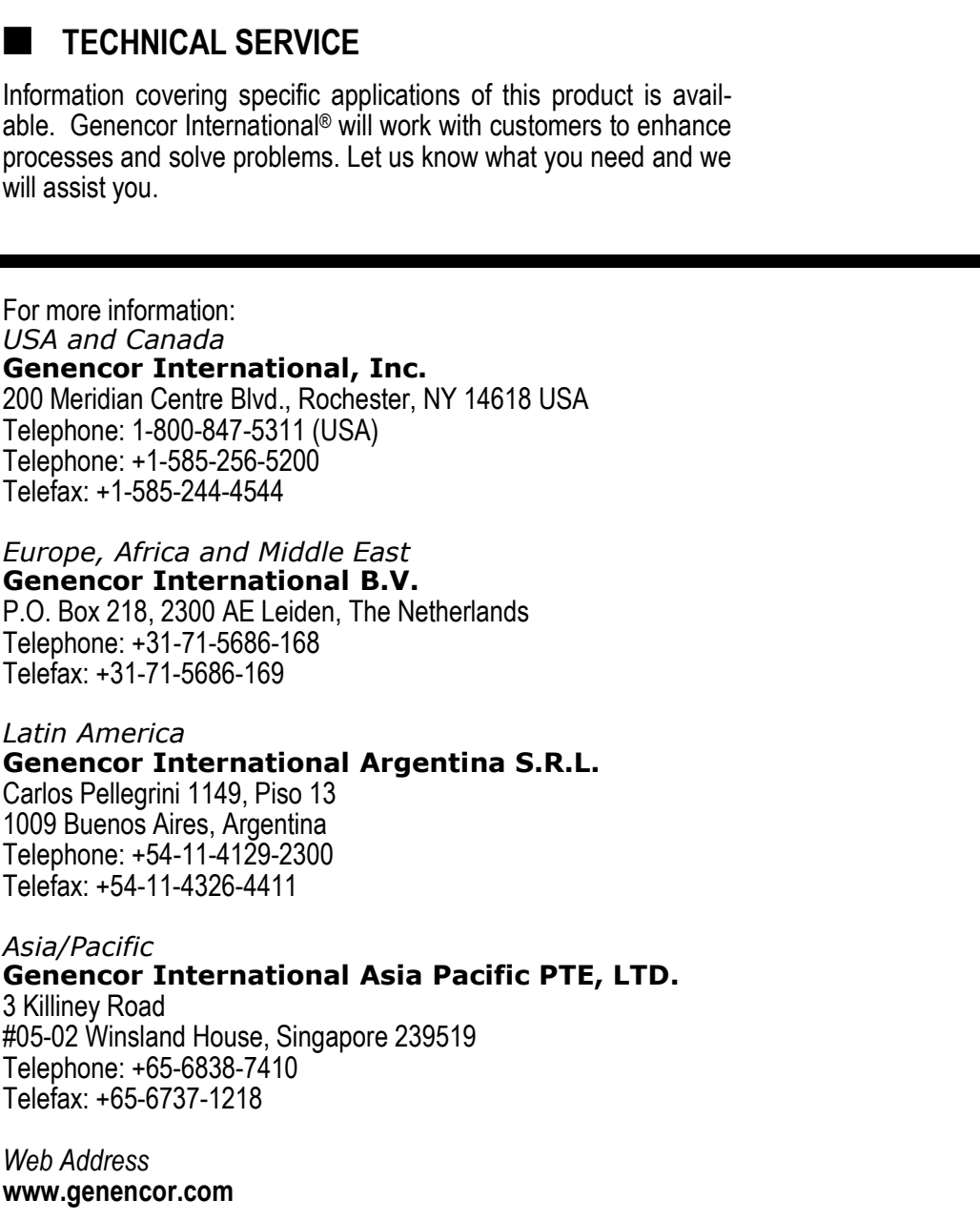

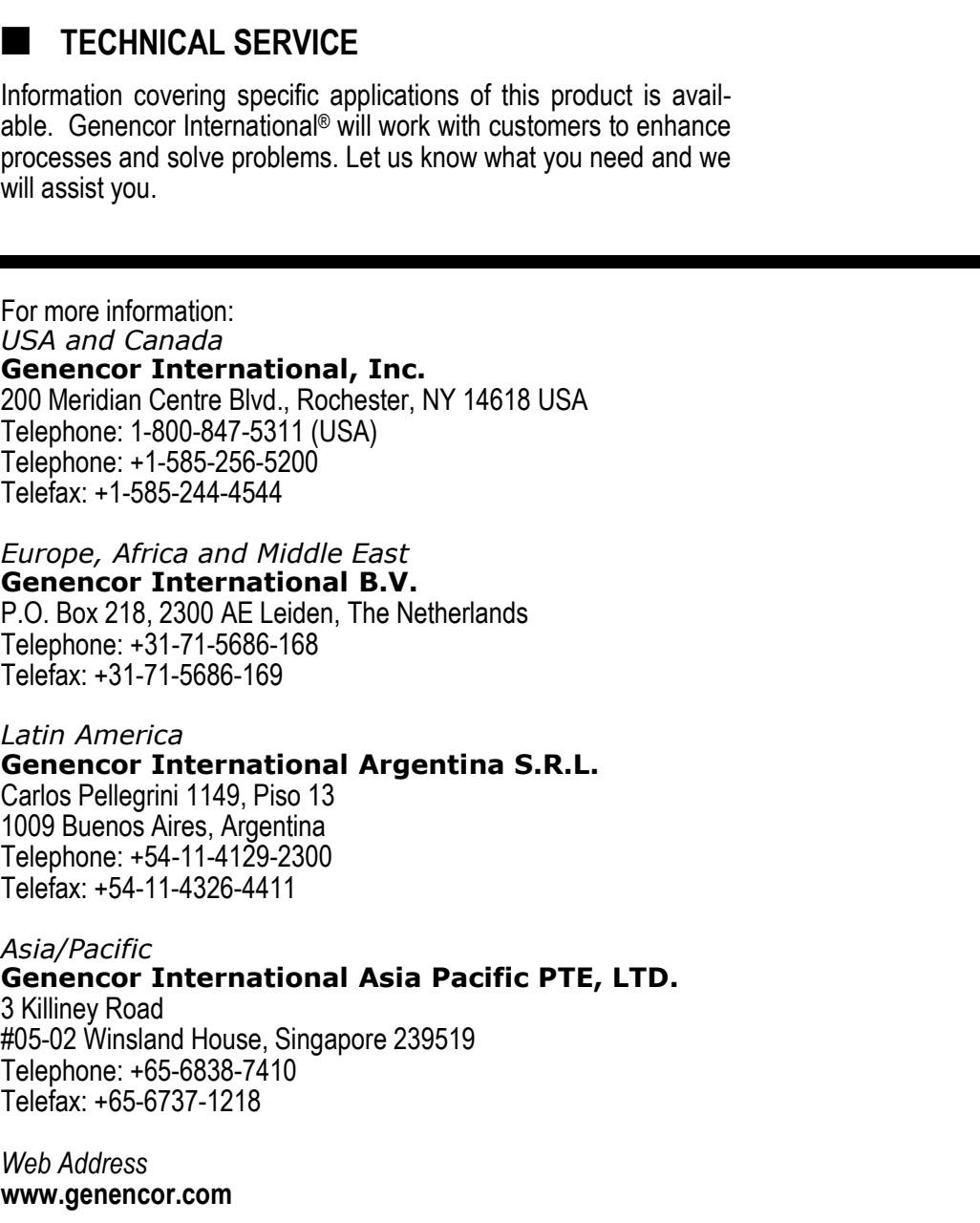

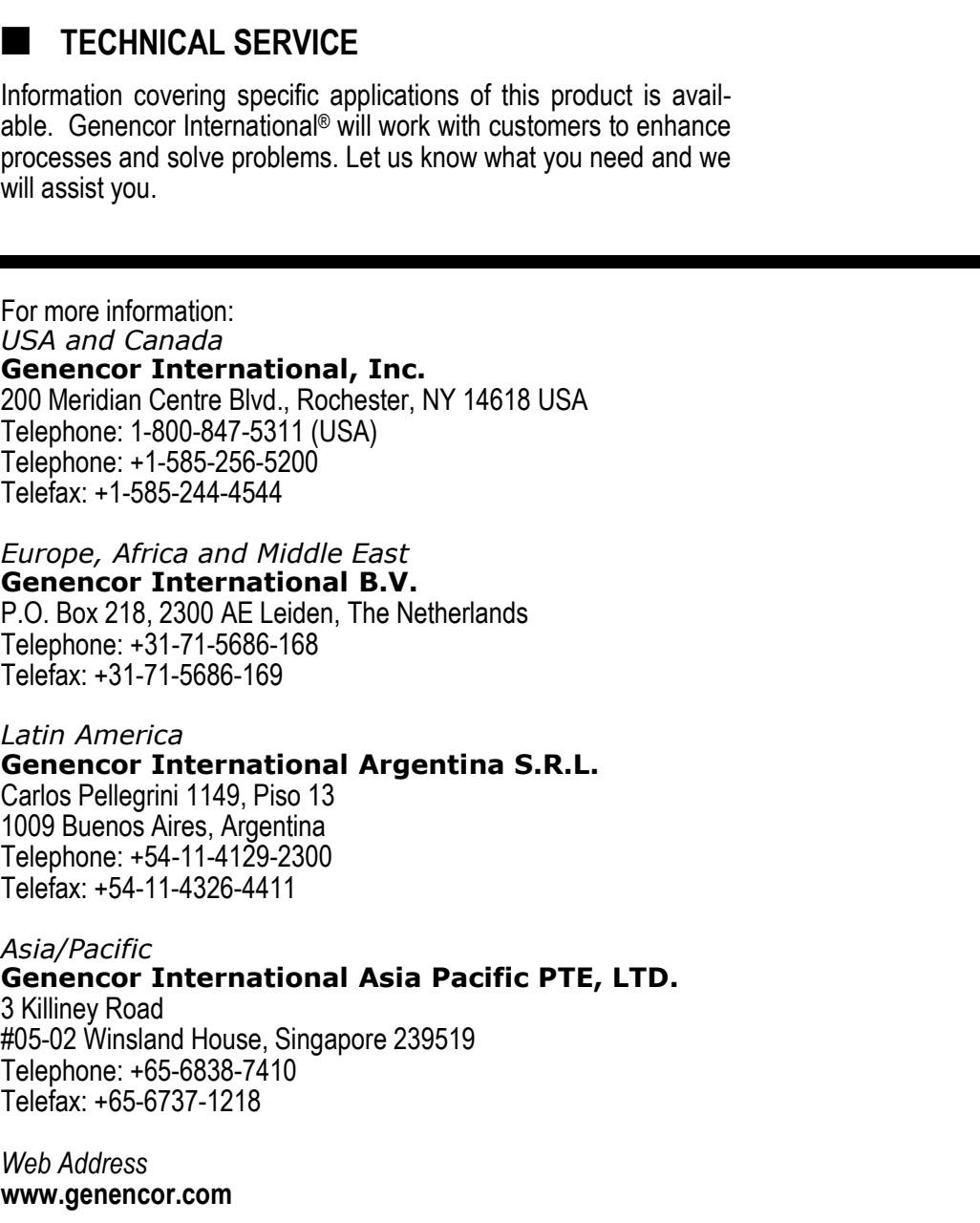

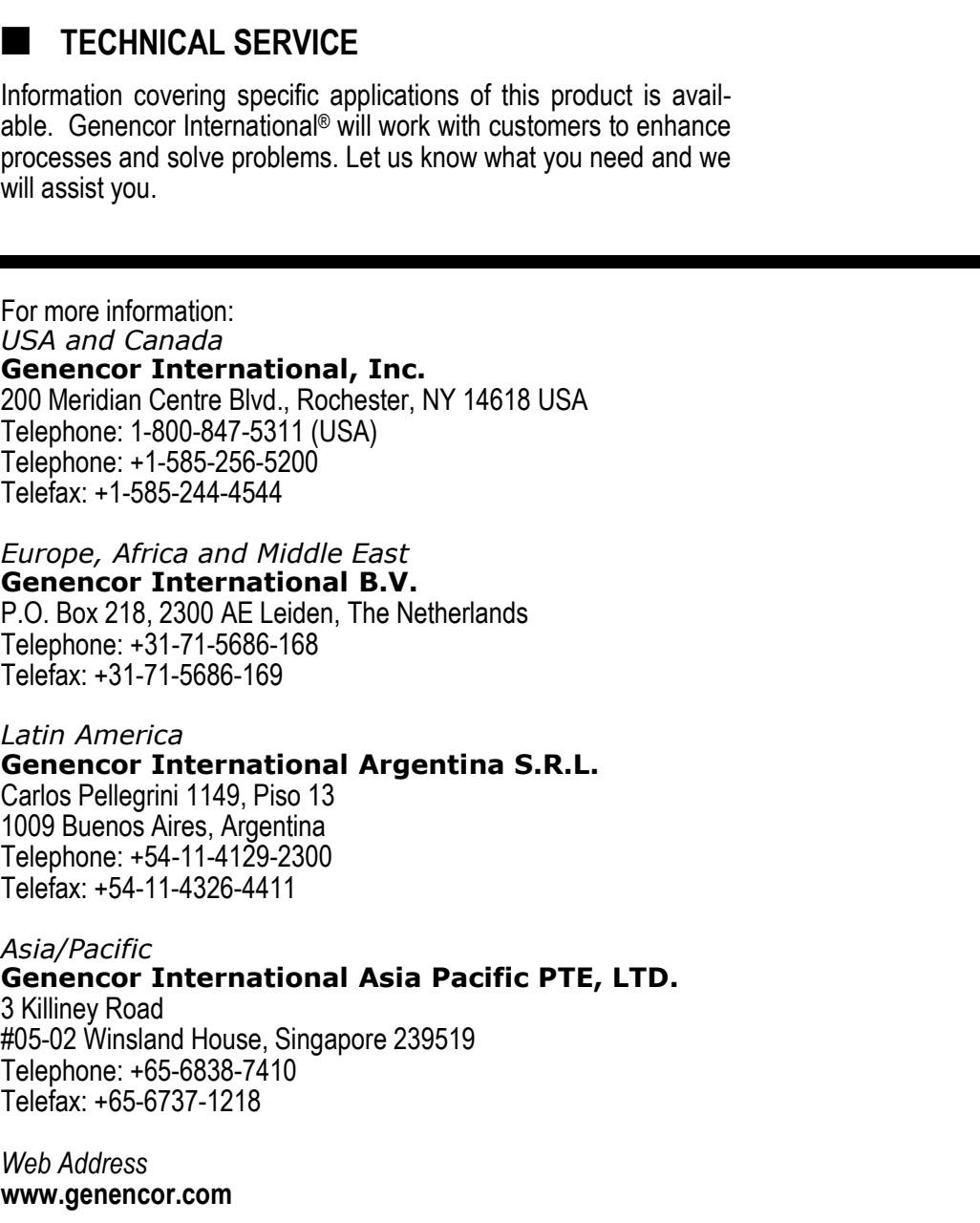

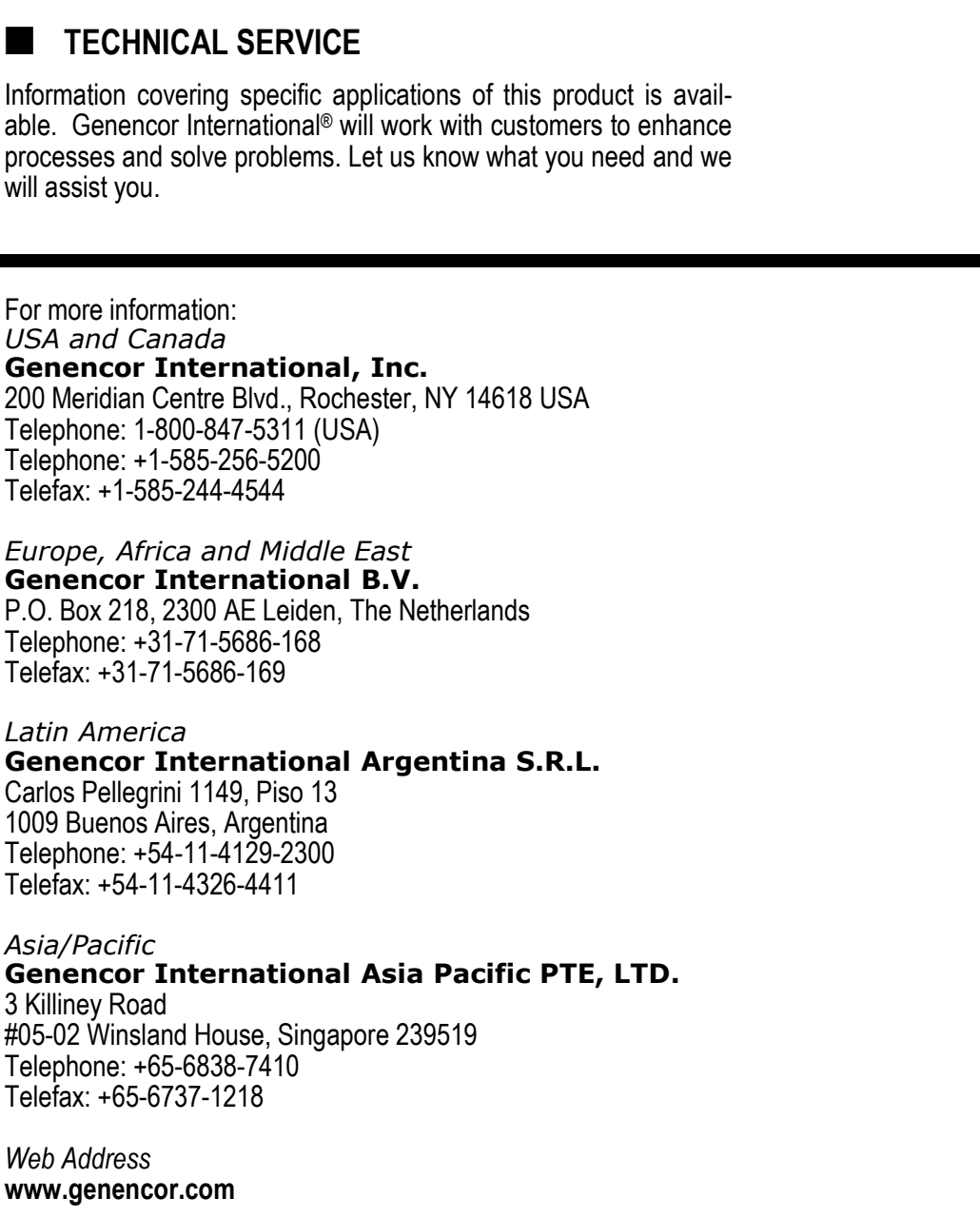

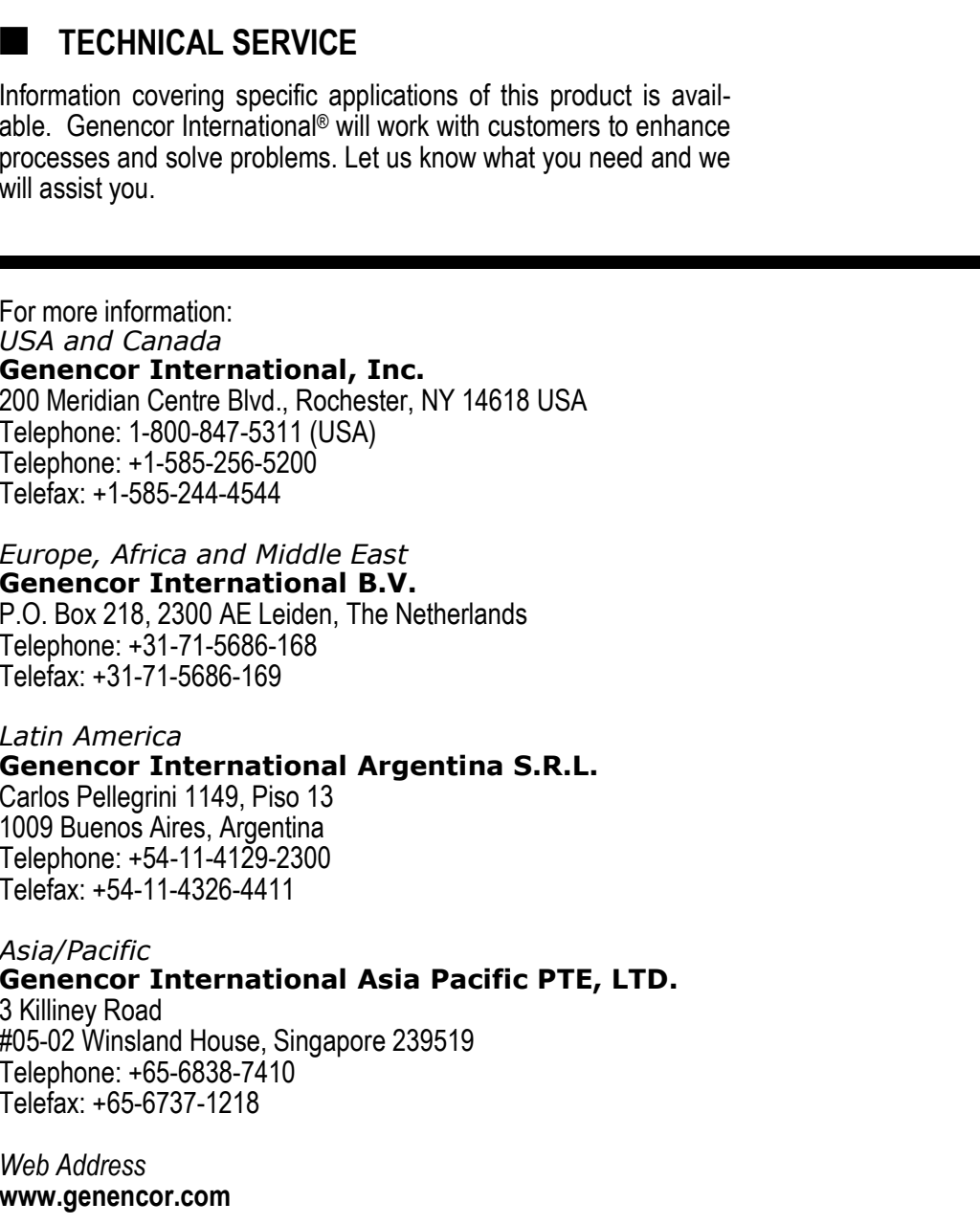

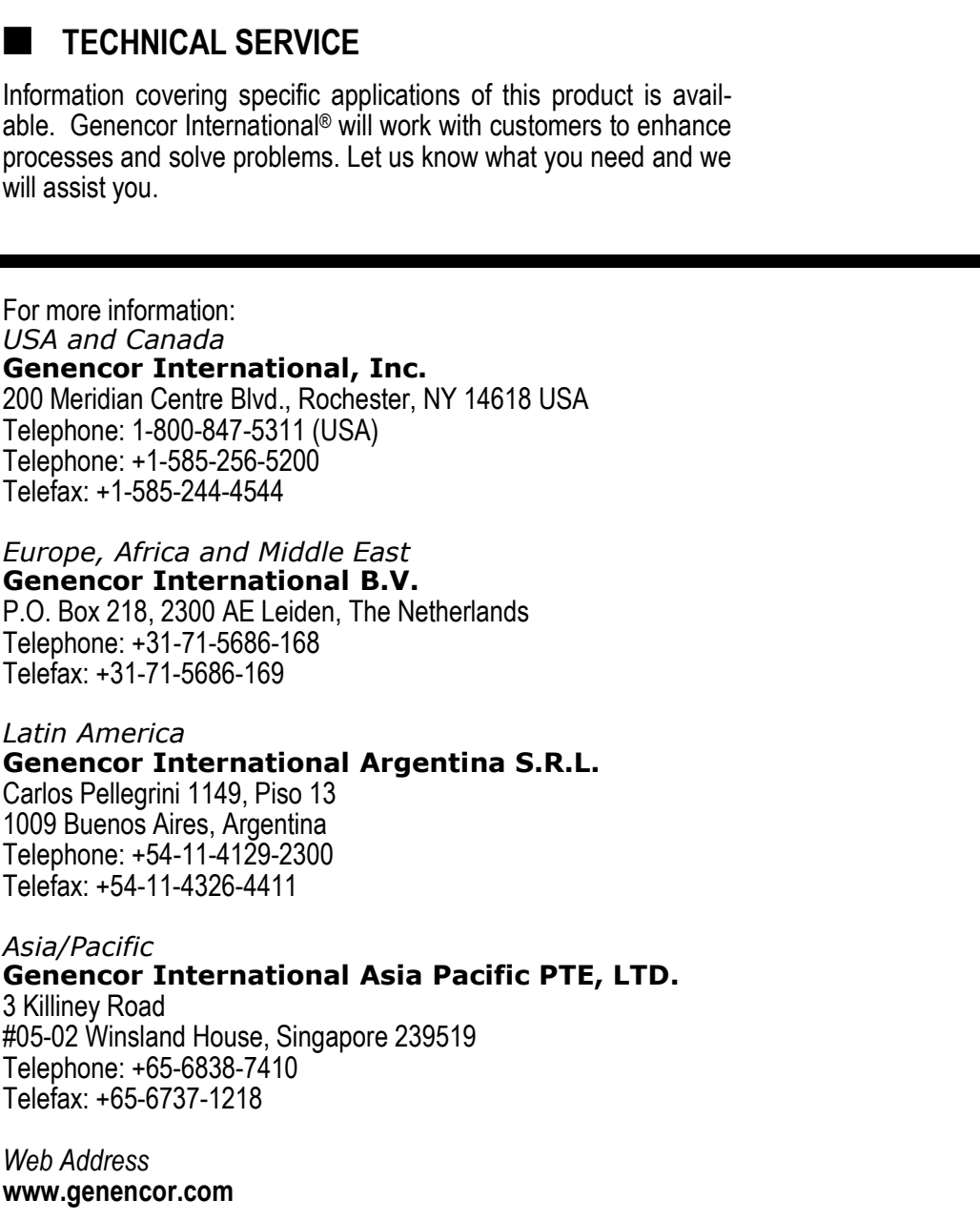

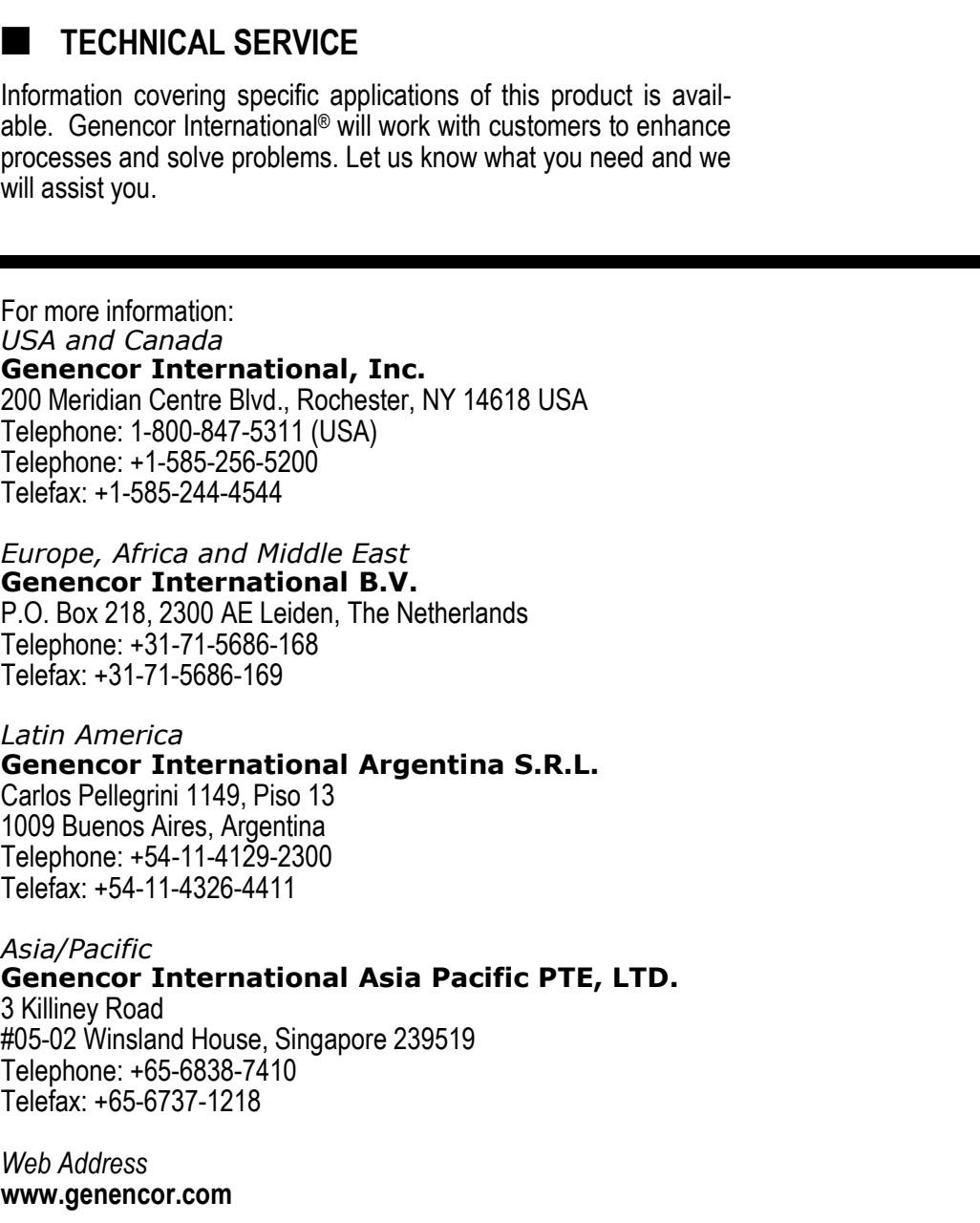

(c) Genencor International, Inc., 2004. MULTIFECT, GENENCOR, GENENCOR INTERNATIONAL, and INNOVATIVE BY NATURE are registered trademarks of Genencor International, Inc. or its affiliated companies.

The information contained in this product literature is, to the best of our knowledge, true and accurate and the product as sold is in conformance with the specifications use technical as deternised by the assay in conth USencor International WARRANTIES INCLUDING THE IMPLIED WARRANTIES OF MERCHANTABILITY OR FITNESS FOR A PARTICULAR PURPOSE. Genencor International shall not be liable for any incidental, consequential, or special damages resulting in any way from the furnishing, performance, or use of this product literature or the product described herein.

Nothing contained herein shall be construed as a representation by Genencor International that the use or resale of the product or processes described herein will property rights of third parties or that the recommendations and or other intellectual described constitute any authorization or inducement to infringe any such rights.

REV0704

2112 MFNEUTRALO1

03 


\section{Multifect ${ }^{\circledR} \mathrm{GC}$}

\section{Concentrated Cellulase Enzyme for Animal Feed Applications}

\section{Product Information}

\section{DESCRIPTION}

Multifect ${ }^{\circledR}$ GC enzyme is a cellulase derived from a selected strain of Trichoderma reesei. It contains also a high amount of beta-glucanase activity. It is applied in animal feed for hydrolysis of cellulose in plant fiber as well as hydrolysis of beta-glucans.

\section{TYPICAL CHARACTERISTICS}

$\begin{array}{ll}\text { Activity: } & 82 \mathrm{GCU} / \mathrm{g} \text { (minimum) } \\ \text { Appearance: } & \text { Amber liquid } \\ \text { pH: } & 4.8-5.2 \\ \text { Grade: } & \text { Food grade, Kosher } \\ \text { Specific gravity: } & 1.06-1.11 \mathrm{~g} / \mathrm{ml}\end{array}$

\section{Unit Definition}

The activity of Multifect ${ }^{\circledR}$ GC cellulase is expressed in GCU/g. The GCU assay measures the amount of glucose released during incubation of a specific type of filter paper with the enzyme at $50^{\circ} \mathrm{C}\left(122^{\circ} \mathrm{F}\right)$ in a 60 minute period. The assay method is available upon request.

\section{pH Dependency}

The $\mathrm{pH}$ range for the enzyme activity of Multifect ${ }^{\circledR} \mathrm{GC}$ cellulase is approximately 3.0 to 5.7 , with an optimum performance at $\mathrm{pH}$ 4.5. The exact $\mathrm{pH}$ optimum will depend on process variables, including temperature, time, substrate concentration and nature.

\section{Temperature Dependency}

The activity of Multifect ${ }^{\circledR}$ GC cellulase is effective in the temperature range of $35^{\circ} \mathrm{C}\left(95^{\circ} \mathrm{F}\right)$ to $70^{\circ} \mathrm{C}\left(160^{\circ} \mathrm{F}\right)$, with an optimum performance at $55^{\circ} \mathrm{C}\left(130^{\circ} \mathrm{F}\right)$. The exact temperature optimum will depend on many process variables, such as $\mathrm{pH}$, time, substrate concentration and nature.

\section{Inactivation}

The enzyme can be inactivated by holding for 10 minutes at a temperature above $85^{\circ} \mathrm{C}\left(185^{\circ} \mathrm{F}\right)$.

\section{BIOCHEMICAL PARAMETERS}

Enzyme type: Cellulase enzyme complex

IUB\#:

CAS \#:

9012-54-8

Side activities: (hemi)cellulase, xylanase, glucanase, virtually no protease, lipase or amylase side activities

Inhibitors:

$$
\text { High glucose, cellobiose }
$$
concentrations

\section{APPLICATIONS}

Multifect ${ }^{\circledR}$ GC cellulase enzyme is designed for hyrolysis of fibrous plant material of the Non-Starch Polysaccharide fraction, especially cellulose and beta-glucans. The enzyme has also some xylanase activity. Multifect ${ }^{\circledR}$ GC enzyme reduces viscosity in processing of fibrous feed raw materials and it will work also in the animal gut by reducing viscosity created by the soluble non-starch polysaccharides in the digesta. Typical feed ingredients benefiting from the action of Multifect ${ }^{\circledR}$ GC enzyme are barley, malt, oats, wheat bran, rice bran, corn bran, DDG, grain sorghum, sugarbeet pulp, rye, wheat, corn stovers and grass. It can also be used in the production of grass or corn silage.

\section{DOSAGE}

A dosage rate of $0.1-0.2 \mathrm{~kg}$ of Multifect ${ }^{\circledR} \mathrm{GC}$ cellulase enzyme per ton of complete feed ( $8-16 \mathrm{GCU} / \mathrm{kg}$ of complete feed) is recommended as a starting point for the optimization of enzyme dosage.

\section{REGULATORY STATUS}

Multifect ${ }^{\circledR}$ GC celluase complies with the current FAO/WHO and Food Chemical Codex recommended specifications for food-grade enzymes and is GRAS (Generally Recognized As Safe) in the United States. The enzyme and the source organism are listed in the 2002 Official Publication of AAFCO (Association of American Feed Control Officials, Incorporated).

\section{PACKAGING}

Multifect ${ }^{\circledR}$ GC cellulase enzyme is available in $25 \mathrm{~kg}$ polyethylene pails, $225 \mathrm{~kg}$ polyethylene drums and $1,100 \mathrm{~kg}$ polyethylene totes.

\section{STORAGE}

Multifect ${ }^{\circledR} \mathrm{GC}$ cellulase enzyme will meet the declared activity of $82 \mathrm{GCU} / \mathrm{g}$ upon arrival at the customer's plant.

Genencor ${ }^{\circledR}$ enzymes can be safely stored in unopened and sealed original containers. Enzyme containers should be stored below $20^{\circ} \mathrm{C}\left(70^{\circ} \mathrm{F}\right)$, preferably refrigerated and sheltered against direct sunlight.

During storage, Multifect ${ }^{\circledR}$ GC cellulase enzyme will have an activity loss at elevated temperatures and under no circumstances should the containers be stored above $35^{\circ} \mathrm{C}$. For more information on the storage of this product, please contact your Genencor International ${ }^{\circledR}$ representative. 
SAFETY \& ENZYME HANDLING

Inhalation of enzyme dust and mists should be avoided. In case of contact with the skin or eyes, promptly rinse with water for at least 15 minutes.

For detailed handling information, please refer to the appropriate Material Safety Data Sheet, the Enzyme Technical Association (ETA) handbook Working Safely With Enzymes, and the Association of Manufacturers of Fermentation Enzyme Products (Amfep) handbook Guide to the Safe Handling of Microbial Enzyme Preparations. All are available from Genencor International ${ }^{\circledR}$

\section{TECHNICAL SERVICE}

Genencor International ${ }^{\circledR}$ will work with customers to enhance processes and solve problems. Let us know what you need and we will assist you.

For more information:

USA and Canada

Genencor International, Inc.

200 Meridian Centre Blvd., Rochester, NY 14618 USA

Telephone: 1-800-847-5311 (USA)

Telephone: +1-585-256-5200

Telefax: +1-585-244-4544

Europe and Africa

Genencor International B.V.

P.O. Box 218, 2300 AE Leiden, The Netherlands

Telephone: +31-71-5686-168

Telefax: +31-71-5686-169

Latin America

Genencor International Argentina S.R.L.

Carlos Pellegrini 1149, Piso 13

1009 Buenos Aires, Argentina

Telephone: +54-11-4129-2300

Telefax: +54-11-4326-4411

Asia/Pacific

Genencor International Asia Pacific PTE, LTD.

3 Killiney Road

\#05-02 Winsland House, Singapore 239519

Telephone: +65-6838-7410

Telefax: +65-6737-1218

Web Address

www.genencor.com

(C) Genencor International, Inc., 2001. MULTIFECT, GENENCOR, GENENCOR INTERNATIONAL, and INNOVATIVE BY NATURE are registered trademarks of Genencor International, Inc. or its affiliated companies.

The information contained in this product literature is, to the best of our knowledge, true and accurate and the product as sold is in conformance with the specifications 作 WARRANTIES INCLUDING THE IMPLIED WARRANTIES OF MERCHANTABILITY OR FITNESS FOR A PARTICULAR PURPOSE. Genencor International shall not be liable for any incidental, consequential, or special product literature or the product described herein.

Nothing contained herein shall be construed as a representation by Genencor International that the use or resale of the product or processes described herein will not violate any rules or regulations or infringe upon patents or other intellectual property rights of third parties or that the recommendations and usage suggestions described constitute any authorization or inducement to infringe any such rights.

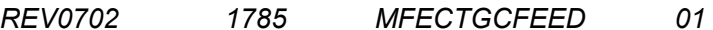

Printed on recycled paper 


\section{GC 440}

\section{Developmental Cellulase for Wheat Starch Separation}

\section{Product Information}

\section{DESCRIPTION}

GC 440 cellulase is an enzyme preparation intended for the starch and alcohol industries. The enzyme is capable of reducing viscosity and improving separation of different components of grain. GC 440 cellulase contains a combination of enzymes which effectively modify and hydrolyze non-starch carbohydrates, the structural material of plant cells. The enzyme is produced by submerged fermentation of a genetically modified strain of Trichoderma longibrachiatum.

GC 440 enzyme is effective especially on cellulose, hemicellulose and $\beta$-glucans. As a cellulase enzyme complex, the product contains multiple enzyme activities but is standardized on the basis of its activities on carboxymethylcellulose (RBB-CMC).

\section{TYPICAL CHARACTERISTICS}

$\begin{array}{ll}\text { RBB-CMC Activity: } & 1,470 \mathrm{IU} / \mathrm{g} \text { minimum } \\ \text { Appearance: } & \text { Dark amber liquid } \\ \text { Solubility: } & \text { Completely miscible in water } \\ \text { Specific gravity: } & 1.20-1.25 \mathrm{~g} / \mathrm{ml}\end{array}$

The activity of GC 440 enzyme is expressed in Remazol Brilliant Blue-carboxymethylcellulose (RBB-CMC) activity units. RBB $\mathrm{CMC}$ activity measures the release of soluble fragments that are dyed with Remazol Brilliant Blue and is determined spectrophotometrically against an internal standard. This activity is expressed in International Units (IU). A detailed assay method is available upon request.

\section{REGULATORY STATUS}

This product meets or exceeds the Joint FAO/WHO Expert Committee on Food Additives (JECFA) and the Food Chemicals Codex (FCC) specifications for enzyme preparations used in food and is GRAS (Generally Recognized As Safe) in the United States.

\section{PERFORMANCE BENEFITS}

The addition of GC 440 cellulase will provide several advantages, including:

Higher starch yield

Improved separation of gluten and starch

Increased plant capacity

Reduced water and energy consumption

Reduced viscosity of effluent streams

\section{DOSAGE GUIDELINES}

The optimum dosage of GC 440 enzyme will vary with different substrates and operating conditions, such as $\mathrm{pH}$, temperature and reaction time. A typical dosage rate of $0.25-0.4 \mathrm{~kg} /$ metric ton dry substance (DS) is recommended as a starting point for the optimization of enzyme dosage.

\section{APPLICATIONS}

In the wheat starch industry, GC 440 enzyme can be used to improve the separation of starch and gluten. It will also reduce viscosity of effluent streams.

In the fuel ethanol industry, GC 440 enzyme can be used when milled grain is used as raw material. The benefits of using GC 440 cellulase include improved starch utilization and the hydrolysis of non-starch carbohydrates which otherwise increase the mass viscosity or cause fouling in distilling equipment.

\section{EFFECT OF TEMPERATURE AND pH}

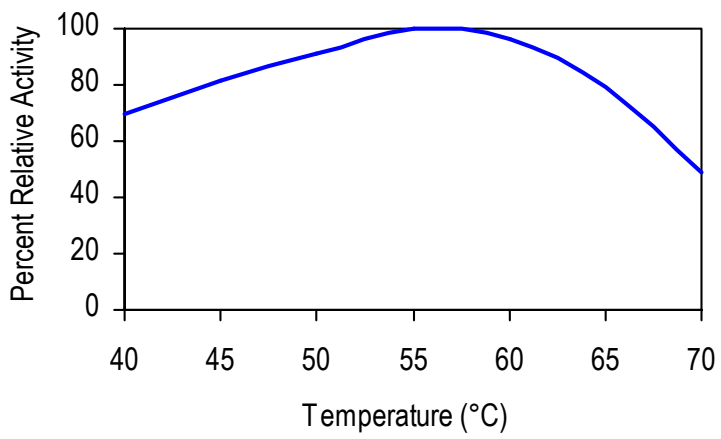

Figure 1: Temperature Activity Profile of GC 440 Resultant rate of activity on substrate for 30 minutes at $\mathrm{pH} 4.5$

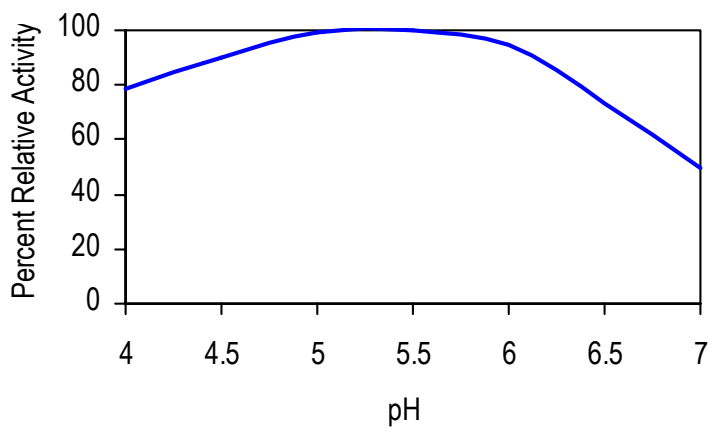

Figure 2: pH Activity Profile of GC 440 Resultant rate of activity on substrate for 30 minutes at $50^{\circ} \mathrm{C}$ 


\section{PACKAGING}

GC 440 enzyme is available in $30 \mathrm{~kg}$ polyethylene pails, $240 \mathrm{~kg}$ polyethylene drums and $1200 \mathrm{~kg}$ containers.

\section{STORAGE}

GC 440 enzyme is very stable under most storage conditions. The product maintains its stated activity for a period of at least six months when stored at $20^{\circ} \mathrm{C}\left(68^{\circ} \mathrm{F}\right)$ or below. To ensure maximum retention of activity, store the product in a cool, dry place with the container closed. Prolonged storage at higher temperatures should be avoided.

\section{SAFETY \& ENZYME HANDLING}

Inhalation of enzyme dust and mists should be avoided. In case of contact with the skin or eyes, promptly rinse with water for at least 15 minutes.

For detailed handling information, please refer to the appropriate Material Safety Data Sheet, the Enzyme Technical Association (ETA) handbook Working Safely With Enzymes, and the Association of Manufacturers of Fermentation Enzyme Products (Amfep) handbook Guide to the Safe Handling of Microbial Enzyme Preparations. All are available from Genencor International ${ }^{\circledR}$.

\section{TECHNICAL SERVICE}

TECHNICAL SERVICE
Information covering specific applications of this product is
available. Genencor International ${ }^{\circledR}$ will work with customers to
enhance processes and solve problems. Let us know what you
need and we will assist you.
For more information:
USA and Canada
Genencor International, Inc.
200 Meridian Centre Blvd., Rochester, NY 14618 USA
Telephone: 1-800-847-5311 (USA)
Telephone: +1-585-256-5200
Telefax: +1-585-244-4544

TECHNICAL SERVICE
Information covering specific applications of this product is
available. Genencor International ${ }^{\circledR}$ will work with customers to
enhance processes and solve problems. Let us know what you
need and we will assist you.
For more information:
USA and Canada
Genencor International, Inc.
200 Meridian Centre Blvd., Rochester, NY 14618 USA
Telephone: $1-800-847-5311$ (USA)
Telephone: +1-585-256-5200
Telefax: +1-585-244-4544

TECHNICAL SERVICE
Information covering specific applications of this product is
available. Genencor International ${ }^{\circledR}$ will work with customers to
enhance processes and solve problems. Let us know what you
need and we will assist you.
For more information:
USA and Canada
Genencor International, Inc.
200 Meridian Centre Blvd., Rochester, NY 14618 USA
Telephone: 1-800-847-5311 (USA)
Telephone: $+1-585-256-5200$
Telefax: +1-585-244-4544 need and we will assist you.

For more information:

USA and Canada

Genencor International, Inc.

TECHNICAL SERVICE
Information covering specific applications of this product is
available. Genencor International ${ }^{\circledR}$ will work with customers to
enhance processes and solve problems. Let us know what you
need and we will assist you.
For more information:
USA and Canada
Genencor International, Inc.
200 Meridian Centre Blvd., Rochester, NY 14618 USA
Telephone: $1-800-847-5311$ (USA)
Telephone: +1-585-256-5200
Telefax: +1-585-244-4544

Telephone: 1-800-847-5311 (USA)

Telephone: +1-585-256-5200

Telefax: +1-585-244-4544

Europe, Africa and Middle East

Genencor International B.V.

P.O. Box 218, 2300 AE Leiden, The Netherlands

Telephone: +31-71-5686-168

Telefax: +31-71-5686-169

\section{Latin America}

Genencor International Argentina S.R.L.

Carlos Pellegrini 1149, Piso 13

1009 Buenos Aires, Argentina

Telephone: +54-11-4129-2300

Telefax: +54-11-4326-4411

\section{Asia/Pacific}

Genencor International Asia Pacific PTE, LTD. 3 Killiney Road

\#05-02 Winsland House, Singapore 239519

Telephone: +65-6838-7410

Telefax: $+65-6737-1218$

Web Address

www.genencor.com

( ) Genencor International, Inc. 2004. GENENCOR, GENENCOR INTERNATIONAL, and INNOVATIVE BY NATURE are registered trademarks of Genencor International, Inc. or its affiliated companies.

The information contained in this product literature is, to the best of our knowledge, true and accurate and the product as sold is in conformance with the specifications Genencor International hereby DISCLAIMS ANY EXPRESS OR IMPLED, WARRANTIES, INCLUDING THE IMPLIED WARRANTIES OF MERCHANTABILITY OR FITNESS FOR A PARTICULAR PURPOSE. Genencor International shall not be liable for any incidental, consequential, or special , performance, or use of this product literature or the product described herein.

Nothing contained herein shall be construed as a representation by Genencor International that the use or resale of the product or processes described herein will not violate any rules or regulations or infringe upon patents or other intellectual property rights of third parties or that the recommendations and usage suggestions described constitute any authorization or inducement to infringe any such rights.

REV0704

2112

GC440A

03 